\title{
ESTUDO DE INTERAÇŌES ENTRE O ÁTOMO DE ENXOFRE E $O$ GRUPO CARBONILA, EM TIACETONAS, PELO EMPREGO DO MÉTOdO DE RESSONÁNCIA MAGNÉTICA NUCLEAR
}

CONSTANTINO TRUFEM FILHO

Tese de Doutoramento

\author{
Tese de Doutoramento \\ orientada pela
} Profa. Dra. BLANKA WLADISLAW 
A minha mãe e

à memöria de meu pai 
A Profa. Dra. Blanka Wladislaw

- meu profundo reconhecimento pela orientação segura, apoio constante e interesse dispensados à execução desta tese. 
Agradecimentos

Aos colegas de laboratörio Dr. Hans Viertler, Dr. Paulo Rober to 01 ivato e Dr. Roberto Rittner pela colaboração, pelo incen tivo e pelas doações de algumas de suas amostras.

A Srta. Bernadete Tostões Buzzi pela colaboração, pela execução dos espectros no infravermelho e pela doação de algumas de suas amostras.

Aos colegas Sr. Marino Tadeu Fabi, Srta. Liliana Marzorati, Dra. Vera L. Pardini, Sr. José E. de 0liveira, Sra. Ivani I. Mires, Srta. Isabel C. Coelho e Sr. A.G.Ayrosa pela colaboração.

Aos funcionārios do laboratōrio Sr. Antonio S.Marius, Sr. Laerte $V$. da Silva e Sr. José Neiva pela boa vontade comque nos auxiliaram.

Aos grupos dos professores Dr. Luciano F.P. do Amaral, Dr. T mothy J. Brocksom, Dr. Nicola Petragnani, Dr. Vicente G. Toscano e Dr. Yukino Miyata pelas doações de algumas matērias prị mas.

A Sandra F. Botelho Trufem pela revisão do manuscrito.

A Sra. Neyde A. Mathias pelo zelo e dedicação na datilografia.

A Fundação de Amparo à Pesquisa do Estado de São Paulo pelas bolsas concedidas. 
INDICE

Pag.

INTRODUÇAOO. . . . . . . . . . . . . . . . . . . . . 1

Capītulo 1 - INTERAÇOES INTRAMOLECULARES. . • . . . . 2

1.1. Interaçōes transanulares e homoconjugativas entre

- grupo carbonila e outros grupos. . . . . . . 2

1.2. Interações de orbitais . . . . . . . . . . . . . 7

1.2.1. Interações de orbitais no espaço. . . . . 10

1.2.2. Interaçōes de orbitais atravēs das ligaçōes. 22

1.2.3. Hipe rconjugação . . . . . . . . . . . 29

T.3. Interações entre enxofre e carbonila . . . . . . . 34

Capītulo 2 - APRESENTAÇÃO E DISCUSSÃO DE RESULTADOS : - 40

2.1. Medidas comparativas de basicidade pelo emprego do mētodo de ressonāncia magnētica nuclear. . . . . . 41

2.2. Discussão dos resultados de medidas de basicidade. 60

2.3. Apresentação de sīnteses . . . . . . . . . . . . 77

CapĩtuTo 3 - PARTE EXPERIMENTAL . . . . . . . . . . . 86

3.1. Instrumentos . . . . . . . . . . . . . . . 86

3.2. Medidas comparativas de basicidade de tiaciclanonas, alquiltiocetonas e compostos relacionados, por ressonância magnética nuclear. . . . . . . . . . 86 Notações . . . . . . . . . . . . . . 86

Preparação de amostras do sistema ternärio doadoraceptor de próton-tetracloreto de carbono. . . .

3.2.1. Descrição geral do método empregado nas iden tificações e medidas dos deslocamentos químicos dos prótons hidroxíticos do fenol e do p-clorofenol . . . . . . . . . . 
3.2.2. Anāitise estatistica dos dados experimentais Rejeição dos valores discrepantes e avaliação do erro de medida............ 90 Coeficiente de correlação e desvio padrão da reta.

3.2.3. Determinação do deslocamento quĩmico do prọ ton hidroxílico do doador em sistema ternārio: doador-aceptor de proton-tetracloreto de carbono. . . . . . . . . . . .

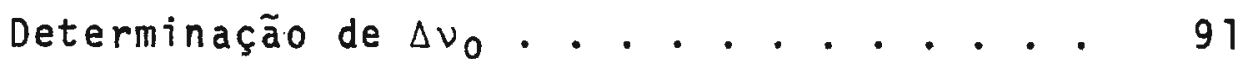

Determinação de $\Delta v^{\prime}$ o. . . . . . . . . . 92

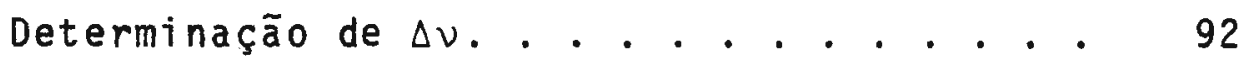

3.2.4. Determinação de constante de associação . . 93

Mētodo de Mathur e col. . . . . . . . 93

Método de Carper e col. . . . . . . . 93

3.2.5. Experiēncias realizadas . . . . . . . . 93

Experiência nọ 1

Determinação do deslocamento quĩmico do prōton hidroxîlico do fenol, à diluição infinita, em tetracloreto de carbono... . . . . . . . . . .

Experiência no 2

Determinação do desiocamento químico do pröton hidroxĩlico do p-clorofenol, à diluição infinita, em tetracloreto de carbono. . . . . . . . . . .

Experiência nọ 3

Deslocamento da ponte de hidrogenio e constante de associação do sistema: doador de prōton-ciclopenta nona (LXXXIII), em $\mathrm{CCl}_{4} \cdot$. . . . . . . . . . 
Experiência nọ 4

Deslocamento da ponte de hidrogénio e constante de associação do sistema: doador de prōton-3-tiaciclo pentanona (LXXVII), em $\mathrm{CCl}_{4} \cdot \cdot \cdot \cdot \cdot \cdot \cdot \cdot \cdot \cdot$.

Experiēncia nọ 5

Deslocamento da ponte de hidrogēnio e constante de associação do sistema: doador de prōton-ciclohexa-

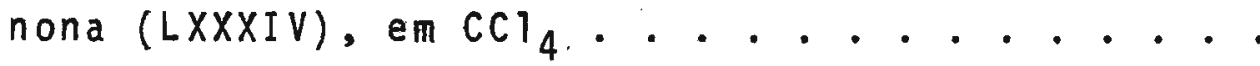

Experiência nọ 6

Deslocamento da ponte de hidrogénio e constante de associação do sistema: doador de prōton-3-tiaciclo hexanona (LXXVIII), em $\mathrm{CCl}_{4} \cdot \ldots . \cdot . \cdot \cdot \cdot \cdot$.

Experiência nọ 7

Deslocamento da ponte de hidrogênio e constante de associação do sistema: doador de prōton-cicloheptạ nona $\left(L_{X X X V}\right)$, em $\mathrm{CCl}_{4} \cdot$. . . . . . . . . .

Experiência nọ 8

Deslocamento da ponte de hidrogênio e constante de associação do sistema: doador de pröton-3-tiaciclo heptanona $(L X X I X)$, em $\mathrm{CCl}_{4}, \ldots . . . . .$. 106

Experiēncia nọ 9

Deslocamento da ponte de hidrogênio e constante de associação do sistema: doador de prōton-4-tiaciclo hexanona $(L X X X)$, em $\mathrm{CCl}_{4} \cdot \cdot \cdot \cdot \cdot \cdot \cdot \cdot \cdot \cdot \cdot \cdot$

Experiēncia nọ 10

Deslocamento da ponte de hidrogênio e constante de associação do sistema: doador de prōton-4-tiaciclo heptanona $(L X X X I)$, em $\mathrm{CCl}_{4} \cdot . \cdot . \cdot . \cdot . \cdot$. 
Experiēncia nọ 11

Desilocamento da ponte de hidrogênio; sistema: doador de próton-ciclooctanona (LXXXVI), em $\mathrm{CCl}_{4}$. .

Experiência no 12

Deslocamento da ponte de hidrogênio; sistema: doador de próton-5-tiaciclooctanona (LXXIII), em $\mathrm{CCl}_{4}$

Experiência nọ 13

Deslocamento da ponte de hidrogênio e constante de associação do sistema: doador de prōton-2-pentano-

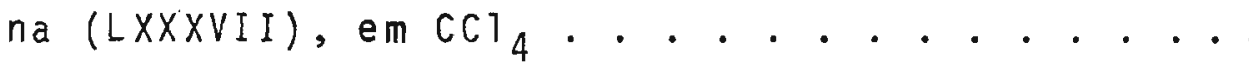

Experiência no 14

Deslocamento da ponte de hidrogénio e constante de associação do sistema: doador de pröton-2-heptanona (LXXXVIII), em $\mathrm{CCl}_{4} \cdot$. . . . . . . . . . .

Experiência nọ 15

Deslocamento da ponte de hidrogênio e constante de associação do sistema: doador de pröton-2-octanona $(L X X X I X)$, em $\mathrm{CCl}_{4} \cdot$. . . . . . . . . . . .

Experiência n! 16

Deslocamento da ponte de hidrogênio e constante de associação do sistema: doador de prōton-2-undecano

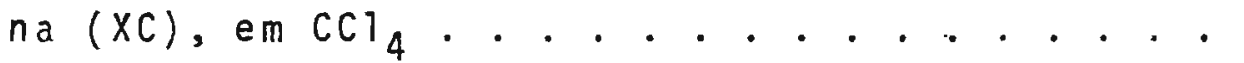

Experiência nọ 17

Deslocamento da ponte de hidrogēnio e constante de associação do sistema: doador de prōton-metiltioacetona $(X C I)$, em $\mathrm{CCl}_{4} \cdot$. . . . . . . . . . 
Experiência.nọ 18

Deslocamento da ponte de hidrogênio e constante de associação do sistema: doador de próton-etiltioace

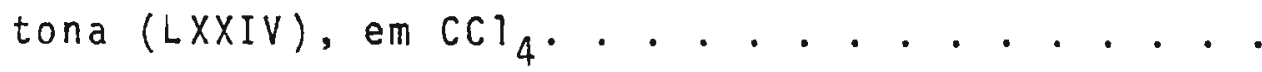

Experiēncia nọ 19

Deslocamento da ponte de hidrogēnio e constante de associação do sistema: doador de próton-4-eti1tio-2-butanona (XCII), em $\mathrm{CCl}_{4}$. . . . . . .

Experiēncia nọ 20

Deslocamento da ponte de hidrogênio e constante de associação do sistema: doador de pröton-5-etiltio-2-pentanona (XCIII), em $\mathrm{CCl}_{4} \cdot . \cdot . \cdot . \cdot$.

Experiência nọ 21

Deslocamento da ponte de hidrogénio e constante de associação do sistema: doador de prōton-6-etiltio-2-hexanona (XCIV), em $\mathrm{CCl}_{4} \cdot . \cdot . \cdot . \cdot . \cdot$

Experiência nọ 22

Deslocamento da ponte de hidrogênio e constante de associação do sistema: p-clorofenol-tetrahidrotiofeno (XCV), em $\mathrm{CCl}_{4}$. . . . . . . . . . .

Experiēncia nọ 23

Deslocamento da ponte de hidrogēnio e constante de associaçäo do sistema: p-clorofenol-tetrahidrotiofeno $(X C V)+c i c l o p e n t a n o n a(L X X X I I I)$, em $\mathrm{CCl}_{4}$.

Experiēncia n!̣ 24

Deslocamento da ponte de hidrogênio e constante de associação do sistema: doador de prōton-3-oxaciclo pentanona (XCVI), em $\mathrm{CCl}_{4}$. . . . . . . . . . 


\section{Experiēncia nọ 25}

Deslocamento da ponte de hidrogênio e constante de associação do sistema: p-clorofenol-metoxiacetona $(X C V I I)$, em $\mathrm{CCl}_{4}$. . . . . . . . . . . 130

Experiência nọ 26

Deslocamento da ponte de hidrogēnio; sistema: doador de próton-3-ciclohexenona (XV), em $\mathrm{CCl}_{4} \cdot$. .

3.3. Compostos..................... 132

3.3.1. Reagentes não purificados... . . . . 132

3.3.2. Reagentes comerciais por nós purificados. . 132

3.3.3. Compostos disponíveis em nossos laboratōrios e por nōs purificados......... 133

3.3.4. Sinteses. . . . . . . . . . . . . 134

3.3.4.1. Cicloheptanona $(L X X X V)$. . . . 134

3.3.4.2. 3-Tiaciclohexanona (LXXVIII) . . 135

3.3.4.3. 3-Tiacicloheptanona $(\operatorname{LXXIX)...~} 137$

3.3.4.4. 4-Tiacicloheptanona (LXXXI). . . 139

3.3.4.5. Ciclooctanona (LXXXVI) . . . . 139

3.3.4.6: 5-Tiaciclooctanona (LXXIII). . . 140

3.3.4.7. 4-Etiltio-2-butanona (XCII). . . 141

3.3.4.8.5-Etiltio-2-pentanona (XCIII). . 142

3.3.4.9.6-Etiltio-2-hexanona (XCIV). . . 143

3.3.4.10. 9-Tiabiciclo(3,3,1)-2-nonanona (C) 144

3.3.4.11. 3-0xaciclopentanona (XCVI). . . 147

3.3.4.12. 3-Ciclohexenona (XV)...... 148

3.4. Espectros................ 149

RESUMO..................... 152

ABSTRACT. . . . . . . . . . . . . . 156

REFERENCIAS BIBLIOGRAFICAS. . . . . . . . . . . 160 
INTRODUÇAOO

O presente trabalho faz parte de uma das linhas de pesquisa em desenvolvimento do grupo dirigido pela profa. Wladislaw. As interaçôes eletrônicas nos compostos aciclicos con tendo o sistema $-\mathrm{S}-\mathrm{CH}_{2}-\mathrm{CO}$ - tem sido objeto de investigaçōes hā algum tempo. $165,167,168$ Mais recentemente, este estudo foi extendido aos compostos contendo o sistema $-\mathrm{S}-\mathrm{CH}_{2}-\mathrm{CN} .{ }^{51,164}$

A presente tese traz uma contribuição para a referi da linha de pesquisa comas investigações do sistema $-\mathrm{S}-\mathrm{CH}_{2}-\mathrm{CO}-$, em cetonas cīclicas, além do estudo de cetonas cíclicas e acĩ clicas contendo o átomo de enxofre em posições mais afastadas. Pela primeira vez são apresentadas medidas de constantes de ba sicidades relativas para tais sistemas.

Esta tese compōe-se de três capĩtulos. O primeiro traz uma revisão bibliogrăfica de interações intramoleculares, - segundo contēm a apresentação e discussão de resultados e o terceiro capitulo encerra a parte experimental. 


\section{CAPITULO 1}

\section{INTERAÇOES INTRAMOLECULARES}

1.1: INTERAÇOES TRANSANULARES E HOMOCONJUGATIVAS ENTRE O GRUPO CARBONILA E OUTROS GRUPOS

Em 1950, Alpen e col. 3 notaram que compostos carbonílicos acíclicos substituídos em a por grupos fenila (I) apre sentavam intensificação da transição $n \rightarrow \pi$ * em relação aos anālogos não substituídos, apesar da não ocorrência de conjugação direta entre os anēis aromāticos e o grupo carbonila. Os autores sugeriram que esta intensificação seria devida ā ressonāncia não ligante entre os grupos fenila e carbonila. 0 mes mo efeito foi observado por Bennet e Burger, ${ }^{13}$ em 1953 , na ci clohexanona substituída em $\alpha$ por grupos fenila (II).<smiles>[R]C(=O)C([R])(O)O</smiles>

(I)<smiles>O=C1CCCCC1(O)O</smiles>

(I I)

Neste mesmo ano (1953), dois grupos de pesquisadores 1 iderados, respectivamente, porMarion ${ }^{109}$ e por Robinson, 5 relataram a existência de interação intramolecular entre o āto mo de nitrogênio terciārio e o grupo carbonila em molẻculas de alcalōides contendo a estrutura (IIIa). Para a explicaçāo des ta interação, denominada por Robinson e col. 5 "neutralizaçäo transanular do tipo amidico", foi sugerida a estrutura(I Ib). 


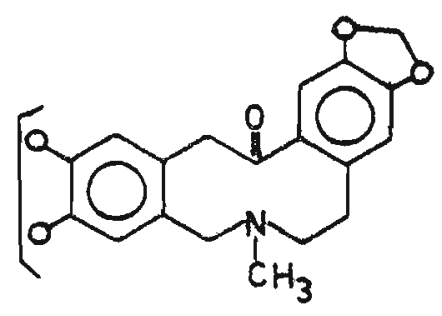

(a)

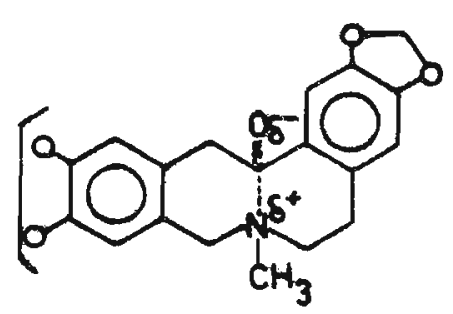

(b)

Em continuação ao trabalho iniciado por Marion e por Robinson, Leonard e col.93,94,96-102 efetuaram estudos em sistemas anālogos mais simples, verificando que nestes a inte ração transanular contribuia, não somente para o estado excitado, mas tambēm para o fundamental.

Assim, em 1954, os referidos autores, 93,94 estudando aminoaciloinas cíclicas (IV), observaram que no anel de 9 mem bros (IVb), a frequência de estiramento da carbonila era anor malmente baixa, enquanto que nos outros anēis era normal. Leo nard e col. 93,94 explicaram tal fato como sendo devido ả inte ração transanular que ocorria apenas na aminoaciloina de 9 mem bros (IVb). Essa evidência experimental, apoiada pelas medidas de pka em diferentes solventes e pela protonação no oxigê nio quando se adicionava $\mathrm{HClO}_{4}$, levou os autores a sugerirem que a interação se dava de acordo com a estrutura (V).
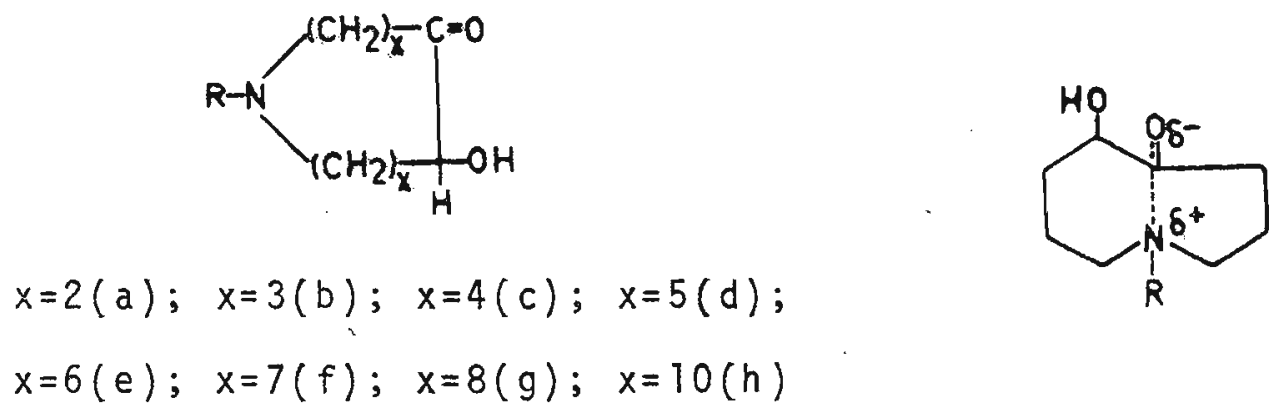
Leonard e col., 97,101 estudando a dependência de efeitos estēricos em tais interaçōes, verificaram, posteriormente, que a introdução de grupos volumosos no nitrogēnio da aminoaciloina (IVb), impedia a interação transanular. o fenōmeno foi atribuĩdo à interação estērica ("F strain") entre os grupos volumosos alquila e o grupo $\mathrm{CHOH}$ em a da carbonita.

Em 1955, Leonard e col. 102 relataram a existência de interação transanular entre nitrogênio e carbonila em aminocetonas ciclicas (VIa,b), verificando que este efeito desaparecia modificando-se as posições relativas do nitrogênio. e da carbonila (VIC), atribuindo este fato ao impedimento estērico. Posteriormente, observaram ${ }^{99,100}$ que fatores eletrônicos tambēm impediam a interação transanular. Provas adicionais para tal tipo de interação no estado fundamental, foram fornecidas pelos autores ${ }^{96}$ atravēs de medidas do momento dipo lar.

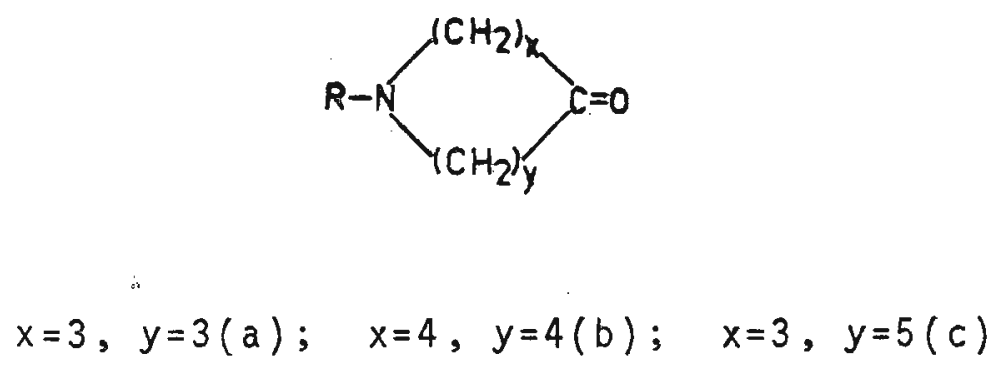

(VI)

Leonard e $0 k i, 98$ em 1955, estudando os espectros no ultravioleta de aminoaciloinas (IVb) e aminocetonas (VIa,b), observaram uma nova banda de absorção de grande intensidade na região de 220-230 nm, ausente na aminoaciloina (IVf). 0 aparẹ cimento desta banda foi atribuĩdo a uma interação entre o nitrogēnio e o grupo carbonila no estado excitado.

Em 1956, Cookson e Wariyar, ${ }^{39}$ em continuação ao 
trabalho iniciado por Alpen e col. ${ }^{3}$ estudaram cetonas $\beta, \gamma-i \underline{n}$ saturadas e notaram que a intensificação da banda de absorção da transição $n \rightarrow \pi$ * dependia da conformação da molécula. De duas conformações da ciclohexanona $\beta, \gamma$-insaturada (VIIa,b), somente na de barco distorcida (VIIb) è que ocorreria interação, uma vez que nesta os orbitais "p" dos carbonos 1 e 3 apontavam um para o outro. Confirmação desta idẻia foi fornecida pe 10 estudo de cetonas biciclicas de conformação barco fixa(VIII e IX), nas quais verificou-se grande intensificação da trans ção $n \rightarrow \pi^{*}$.

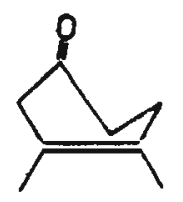

(a)

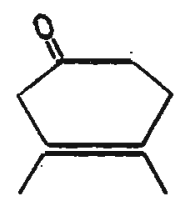

(b)

$(V I I)$

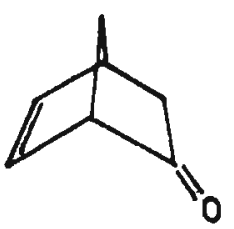

(VIII)

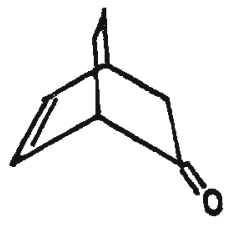

(IX)

Labhart e Wagniēre ${ }^{89}$ verificaram, posteriormente, que a intensificação da transição $n \rightarrow \pi$ * não era a ünica caracteristica de cetonas cỉclicas $\beta, \gamma$-insaturadas (VIII, IX). Os es pectros no ultravioleta destes compostos mostravam tambēm uma outra banda em aproximadamente $220 \mathrm{~nm}$. Foi sugerido que esta banda correspondia a um estado de transferência de carga, que seria tambëm responsāvel pela intensificação da transição $n \rightarrow \pi *$. Em 1958, Leonard e owens ${ }^{103}$ relataram que a cetona cĩclica (X)apresentava no ultravioleta uma banda de absorção bastante intensa a $260 \mathrm{~nm}$, ausente em compostos anālogos não substituidos, atribuindo a nova banda a uma interação transanular entre as duplas olefinica e carbonílica, no estado exci tado. Tal banda foi denominada por kosower e col.88 de "foto- 
desmōtica". Este composto (X) não demonstrou no infravermelho qualquer modificação da frequência de estiramento da carbonila que indicasse a existência desta interação no estado funda mental.

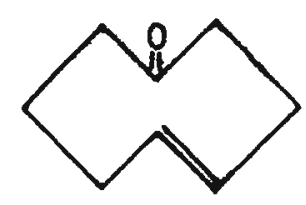

(X)

A dependência da banda de transferência de carga na intensificação da transição $n \rightarrow \pi^{*}$ de cetonas $\beta, \gamma$-insaturadas, sugerida por Labhart e Wagniēre, 89 foi ilustrada por Murre 11,11 em 1963, através do esquema 1.

\section{ESQUEMA 1}

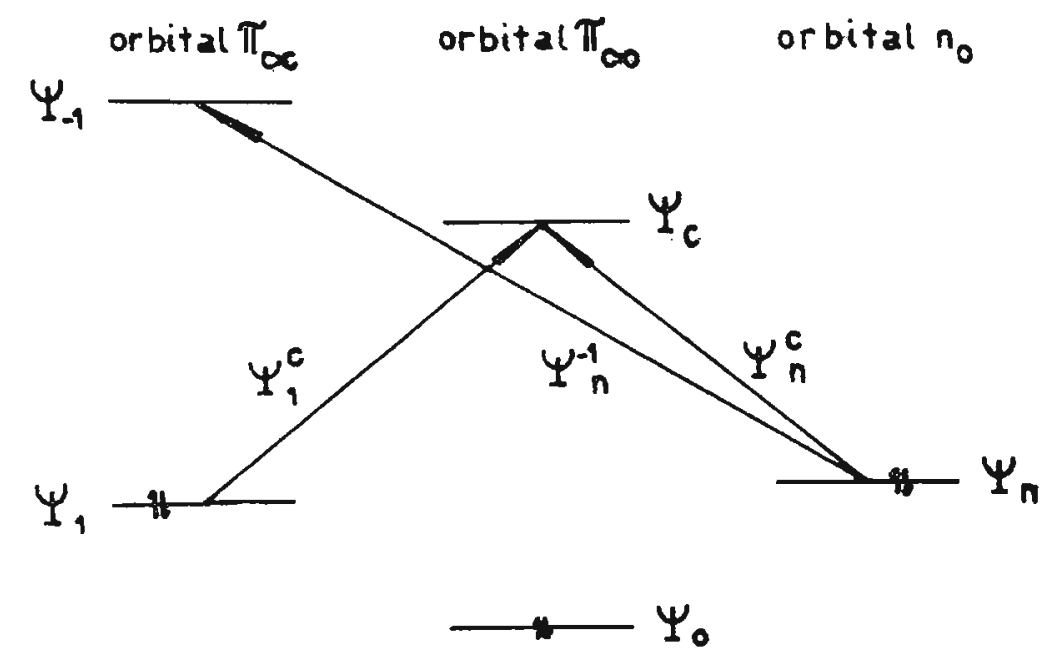

Partindo do ponto de vista que dois estados interagem apenas quando hà participação ou do mesmo orbital doador ou do mesmo orbital aceptor, o autor examinou a possibilidade de dois estados de transferência de carga interagirem com 0 estado $n \rightarrow \pi^{*}\left(\Psi_{n}^{c}\right)$. No caso em questão, seriam $\Psi_{1}^{c}$ e $\Psi_{n}^{-1}$. As suas interaçōes com o estado $\Psi_{n}^{C}$ dependeriam de dois fatores: 
1. Entrosamento ou dos orbitais $\Psi_{1}$ e $\Psi_{n}$ ou dos orbitais $\Psi_{-1}$ e $\Psi_{C}$.

2. Intensidade das bandas correspondentes a estes dois possĩveis estados de transferência de carga.

os cālculos mostraram que o entrosamento entre $\Psi_{-1}$ e $\Psi_{C}$ era maior do que entre $\Psi_{1}$ e $\Psi_{n}$, portanto, a banda correspondente ao estado $\Psi_{1}^{c}$, deveria ser mais intensa do que a correspondente ao estado $\Psi_{n}^{-1}$. Em consequéncia, o autor achou mais provāvel ser o estado de transferēncia de carga $\Psi_{1}^{C}$ o cau sador do aumento da intensidade da transição $n \rightarrow \pi *\left(\Psi_{n}^{c}\right)$. Este mesmo estado de transferéncia de carga seria responsāvel pela banda em $220 \mathrm{~nm}$.

Em 1965 , Ferguson e Nnadi 55 efetuaram uma revisão de interações eletrōnicas entre grupos não conjugados, dividindo-os em dois tipos:

1 - A interação que ocorreria quando o entrosamento entre os orbitais interagentes possuisse carāter $\pi$. A esta de nominaram "conjugaçäo transanular"e como exemplo citaram as ce tonas (VIb) e (X).

2 - A interação que ocorreria quando o entrosamento possuisse carāter o e a esta denominaram"homoconjugação". Entre os exemplos fornecidos pelos autores, encontram-se os com postos (VIII) e (IX). Como critērio para a homoconjugação,Fer guson e Nnadi ${ }^{55}$ sugeriram a intensificação da transição $n \rightarrow \pi^{*}$.

\subsection{INTERAÇOES DE ORBITAIS}

Serão relatados neste subcapĩtulo trabalhos modernos sobre interações de orbitais. Este assunto tem sido obje- 
to de grande interesse nos ültimos oito anos, sendo estimulado, principalmente, pelos cālculos teōricos de Hoffmann e col. 81 e pela introdução da espectroscopia fotoeletrônica de alta resolução por Turner e col., ${ }^{151}$ constando na literatura vārias monografias sobre o assunto. 16,21,22,57,73,79,104

$$
\text { Hoffmann e col., } 104 \text { baseados em câlculos EH e STO-3G, }
$$
distinguem trēs tipos de interações de orbitais em a-aminocetonas (XI), que serão definidos para maior clareza de exposição.

$$
\mathrm{RCL}_{\mathrm{C}} \mathrm{CH}_{2} \mathrm{NH}_{2}
$$

1 - INTERAÇAO dE ORBITAIS nO ESPAÇO - Ocorre quando hä entrosamento direto de dois orbitais, como por exemplo entre os orbitais $n$ do nitrogênio e $n$ do oxigênio. Esta intera ção, que desdobra os niveis de energia, sempre estabiliza a combinação simētrica (S) e desestabiliza a assimétrica (A) (esquema 2).

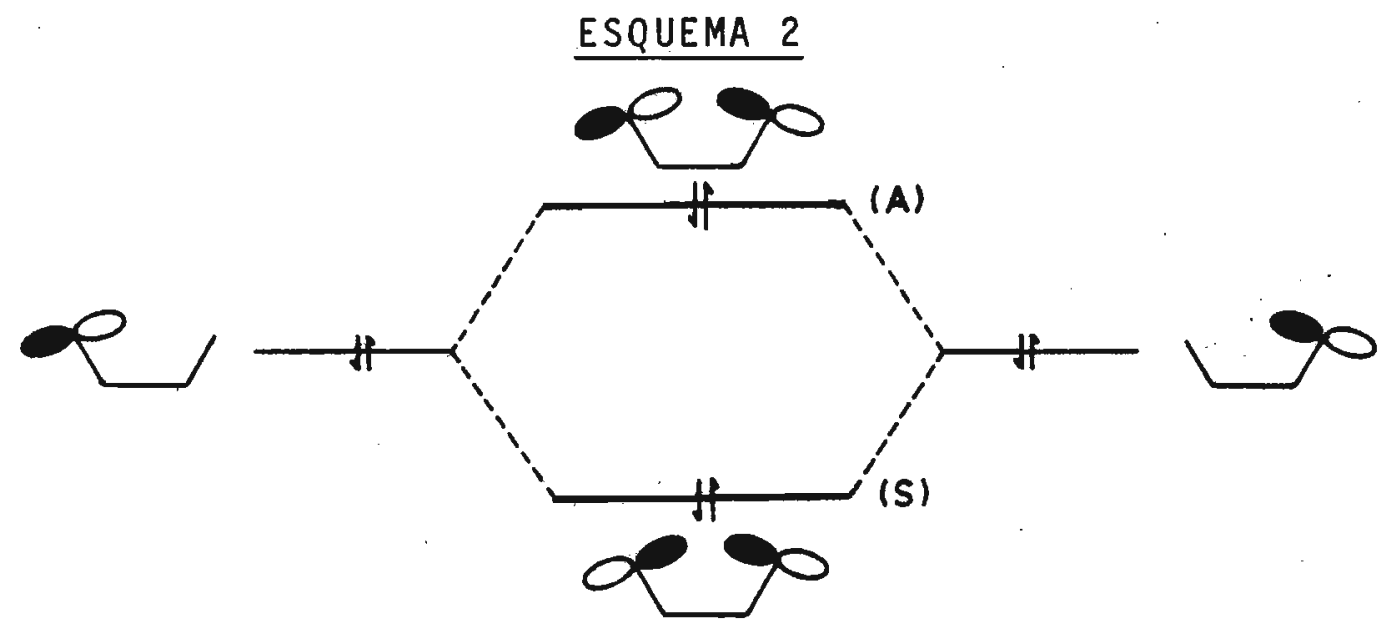

2 - INTERAÇAO de orbitAIS ATRAVES dAS LigAçoes - Dā-se quando o entrosamento entre os orbitais é atravês de uma ligação de simetria apropriada, como por exemplo entre os orbitais $n$ do oxigênio e $n$ do nitrogênio atravēs da liga- 
ção o central. Esta interação estabiliza a combinação assimétrica (A) e desestabiliza a simētrica (S) (esquema 3 ).

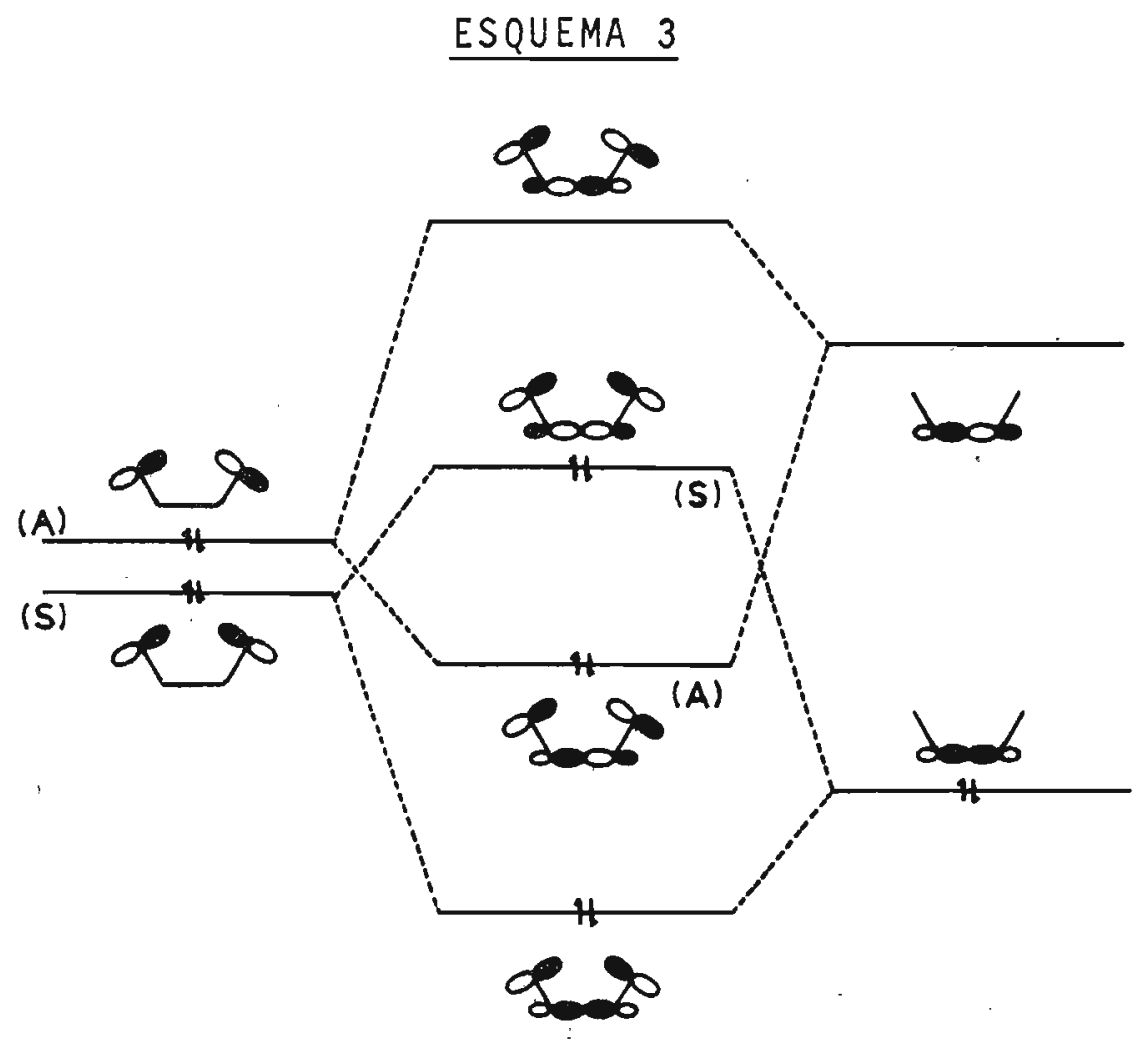

3 - HIPERCONJUGAÇAO - Ocorre quando um orbital $\pi$ interage com um orbital o apropriado. Apōs o entrosamento, o nível de menor energia è estabilizado e o de maior energia ē deses tabilizado. Como exemplo, tem-se a hiperconjugação no estado excitado entre os orbitais $\sigma_{C N}^{*}$ e $\pi_{C O}^{*}$ (esquema 4 ).

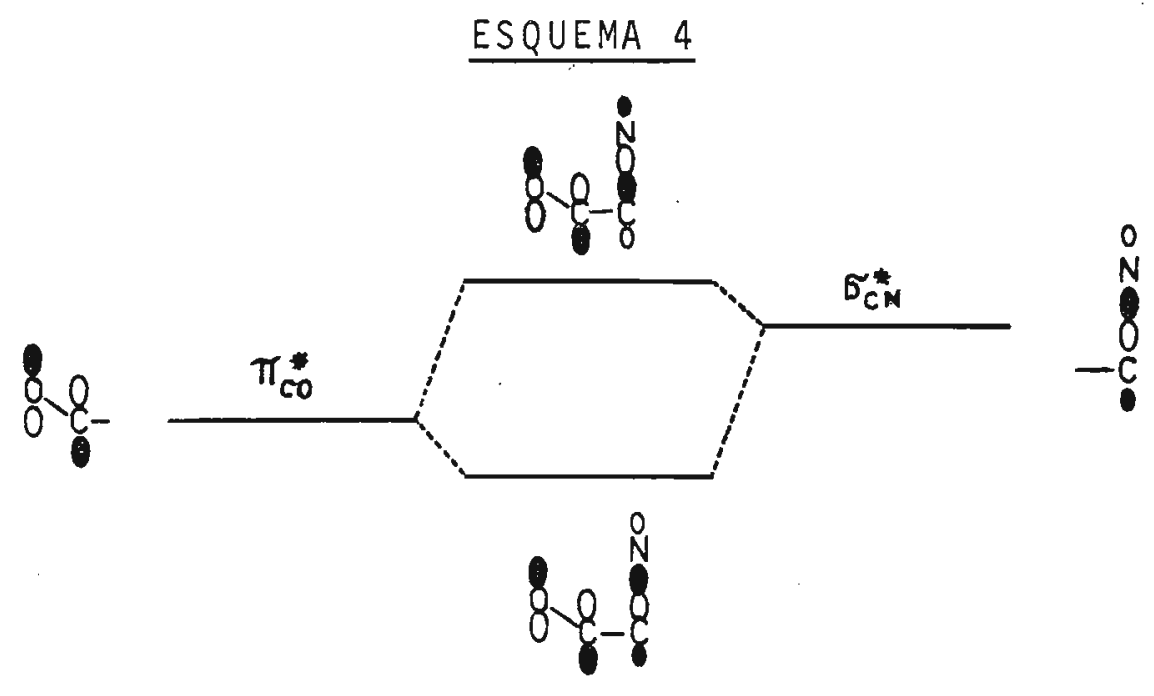


Os autores ${ }^{104}$ ressaltaram a importāncia das proximi dades e das diferenças de energia entre os orbitais interagen tes, na predomināncia de um tipo de interação sobre outro, a qual serā discutida.

Convëm ressaltar que numerosos mētodos tem sido usa dos para a detecção de interações de orbitais, entre os quais podem ser destacados: medidas de basicidade 57 e espectroscopias ultravioleta, ${ }^{57}$ fotoeletrōnica ${ }^{57}$ e ressonância magnētica nuclear do carbono 13.65

\subsubsection{Interações de orbitais no espaço}

Em 1968, Hoffmann e col.81 efetuaram cālculos de or bitais em diaminas bicĩclicas (XII, XIII) e constataram um desdobramento de 2,87 eV entre os niveis de energia dos orbitais $n$ do nitrogēnio no composto (XII). Segundo os autores, esta separação seria causada pela interação no espaço entre os referidos orbitais. Os cālculos tambëm mostrarami que o entrosamento direto seria desprezīvel para distāncias acima de $2,5 \AA$, portanto, no composto (XIII), cuja distância entre os orbitais $n$ era de $2,5 \AA$, a interação no espaço seria pequena.

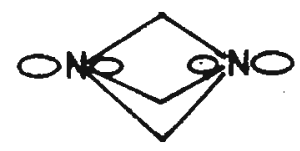

(XI I)

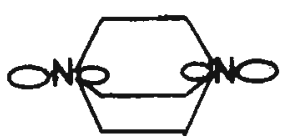

(XIII)

Foi sugerido o esquema 5 para explicar a interação entre os orbitais $n$ do nitrogênio. Este entrosamento levava a uma estabilização da combinaçāo simểtrica (S) e desestabili zação da assimétrica (A). 


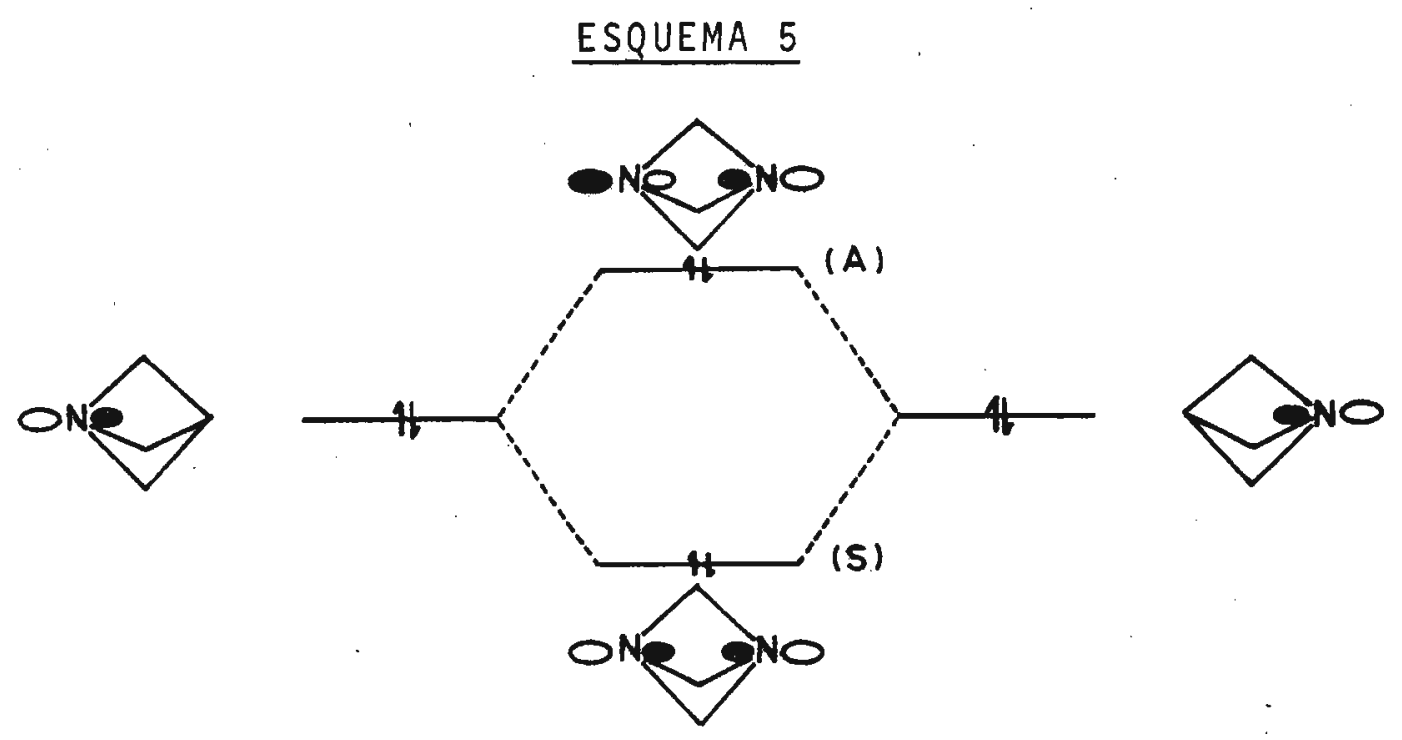

Em 1969, Stothers e Gurutada, ${ }^{65}$ usando a técnica da ressonāncia magnētica nuclear do carbono 13, observaram blindagens dos carbonos carbonîicos de cetonas $\beta, \gamma$-insaturadas, quan do comparadas com as anālogas não substituĩdas. Assim, nas ce tonas (XIV) e (XV), as blindagens eram de 1,3 e 1,0 ppm, enquanto que nas cetonas bicíclicas (VIII) e (XVI), as blindagens eram de 1,4 e 10,6 ppm, respectivamente. Os autores suge riram interação no espaço entre os orbitais $\pi_{C C}$ e ${ }^{\pi}$ co para ex plicar estas blindagens. Alëm disso, os resultados mostraram que havia dependēncia conformacional nestas interações.

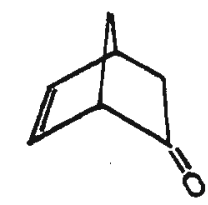

(VIII)

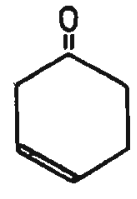

(XV)

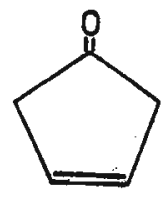

( $x \mid v$ )

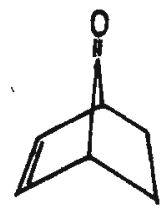

(XVI)

No perīodo de 1969-1970, Héilbronner e col., 17,19 es tudando dienos bicíclicos pelo mëtodo da espectroscopia fotoeletrōnica, relataram desdobramentos dos niveis de energiados orbitais $\pi$ no estado fundamental das molēculas (XVII) e (XVIII). Estes desdobramentos eram de $0,86 \mathrm{eV}$ para o composto (XVII) e de 0,58 eV para (XVIII). 

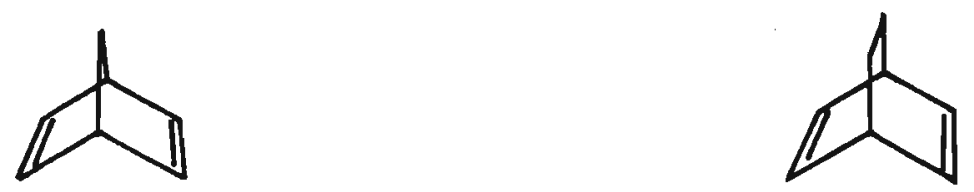

(XVII)

(XVIII)

Hoffmann e col. ${ }^{80}$ sugeriram o esquema 6 para explicar estas separações de níveis de energia causadas pela interação no espaço entre os orbitais $\pi$, no estado fundamental.

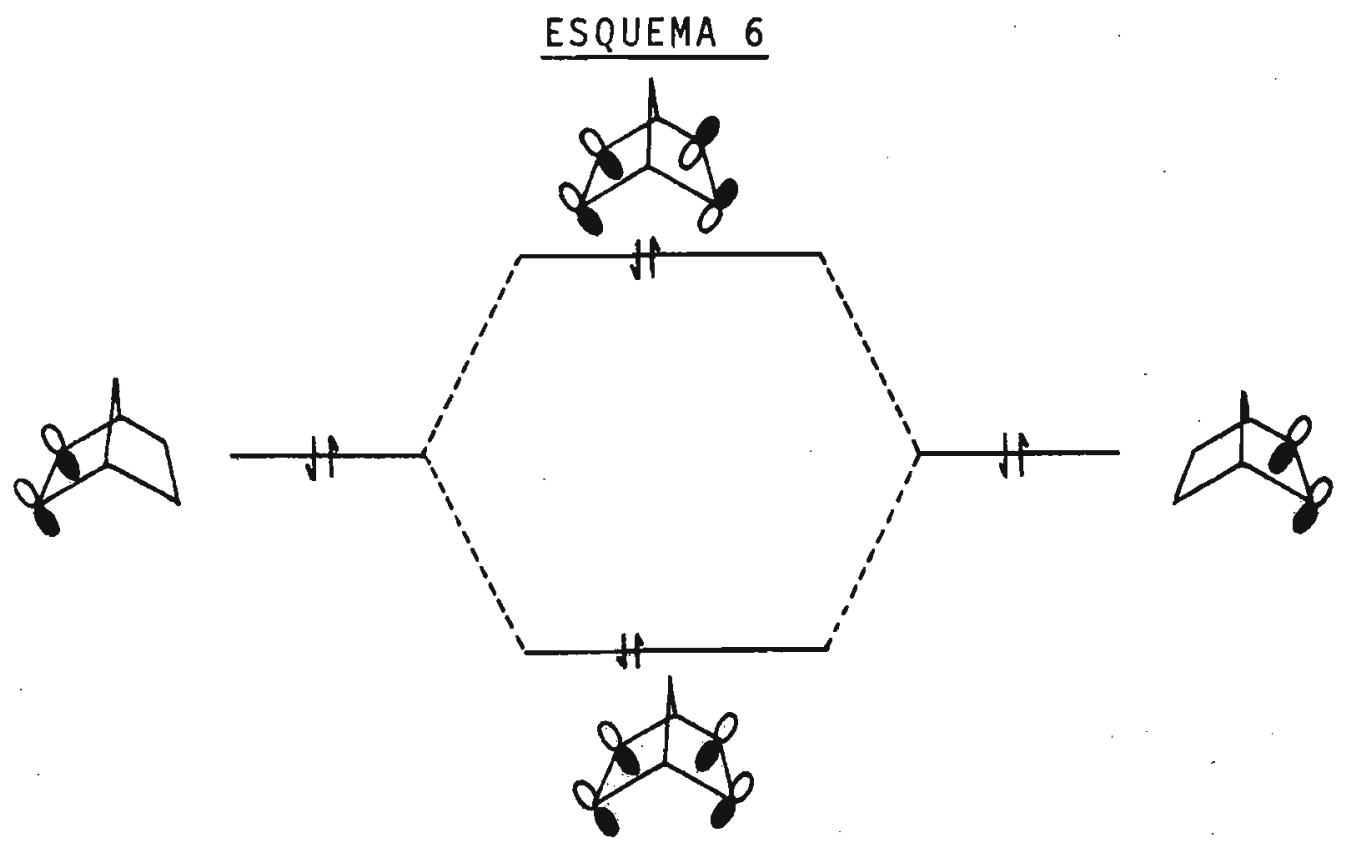

Em 1971, Weiler e col.,34,35 com o emprego da espectroscopia fotoeletrōnica em cetonas $\beta, \gamma$-insaturadas, observaram estabilizações do orbital $\pi$ olefínico de $0,80,0,65$ e 1,13 eV para os compostos (XIV), (XVI) e (VIII), respectivamente, em relação aos anālogos não substituídos. Como o efeito indutivo causava um abaixamento de energia no orbital ${ }^{\pi} C C$ no máxi mo de $0,25 \mathrm{eV}$, os autores propuseram que tais estabilizações seriam causadas, principalmente, por interaçōes de orbitais. Nos compostos simētricos (XIV) e (XVI), foi sugerida apenas in teração entre $\pi_{C C}$ e $\pi_{C O}^{*}$, que estabilizava $\pi_{C C}$ e desestabiliza va ${ }^{\star}{ }^{*} \mathrm{O}$. No composto assimētrico (VIII), a.tēm desta, foi pro- 
posta interação entre os orbitais $\pi_{C C}$ e $\eta_{0}$, que causava uma estabilização extra em ${ }_{C C}$ e desestabilizava $\eta_{0}$. Esta interação seria a responsāvel pela intensificação da transição $n \rightarrow \pi$ *, neste $\bar{u} 1$ timo composto.

Em 1972, Turner e Sweigart ${ }^{146}$ relataram a existência de interação no espaço entre os orbitais $n$ dos heteroàtomos nos compostos $(X I X)$ e $(X X)$. Os desdobramentos dos $n \bar{i}$ veis de energia de 0,25 eV para $(X I X)$ e de 0,41 eV para $(X X)$, mostraram que o entrosamento no espaço era mais importante no ditiaderivado $(X X)$.

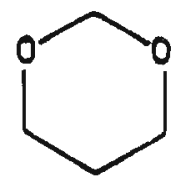

$(X I X)$

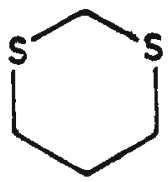

$(X X)$

Neste mesmo ano, Bock e Wagner ${ }^{23}$ notaram separações dos niveis de energia causadas por interações dos orbitais $n$ do enxofre, em dissulfetos (XXI). Os autores verificaram que a interação no espaço, no composto (XXIa), dependia do ânguloen tre os orbitais $n$ do enxofre e era máxima para $0^{0}$, além do que a introdução de grupos metilênicos (XXIb,c) entre os ätomos de enxofre, diminuia o entrosamento no espaço e favorecia interação atravēs das ligações.

$$
\begin{gathered}
\mathrm{RS}\left(\mathrm{CH}_{2}\right) \mathrm{X} S \\
\mathrm{x}=0(\mathrm{a}) ; \mathrm{x}=1(\mathrm{~b}) ; \mathrm{x}=2(\mathrm{c})
\end{gathered}
$$

Contemporaneamente, Heilbronner e co1., 27,71 estudando o isopropilidenonorbornadieno (XXII), observaram um des 
dobramento de 1,08 eV entre os níveis de energia do orbital $\pi$ do isopropilideno e da combinação assimétrica dos orbitais $\pi$ do norbornadieno. Esta separação era causada pela interação atravēs do espaço entre os referidos orbitais. Schweige col. 82 relataram o mesmo tipo de interação no metilenonorbornadieno (XXIII).

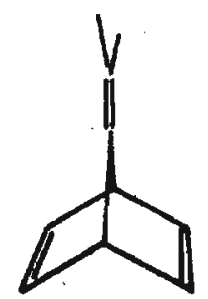

(XXII)

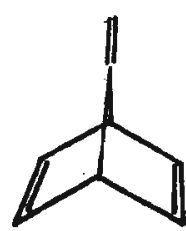

$(X X I I I)$

Heilbronner e col. 27,71 sugeriram o esquema 7 para explicar tal interação.

\section{ESQUEMA 7}

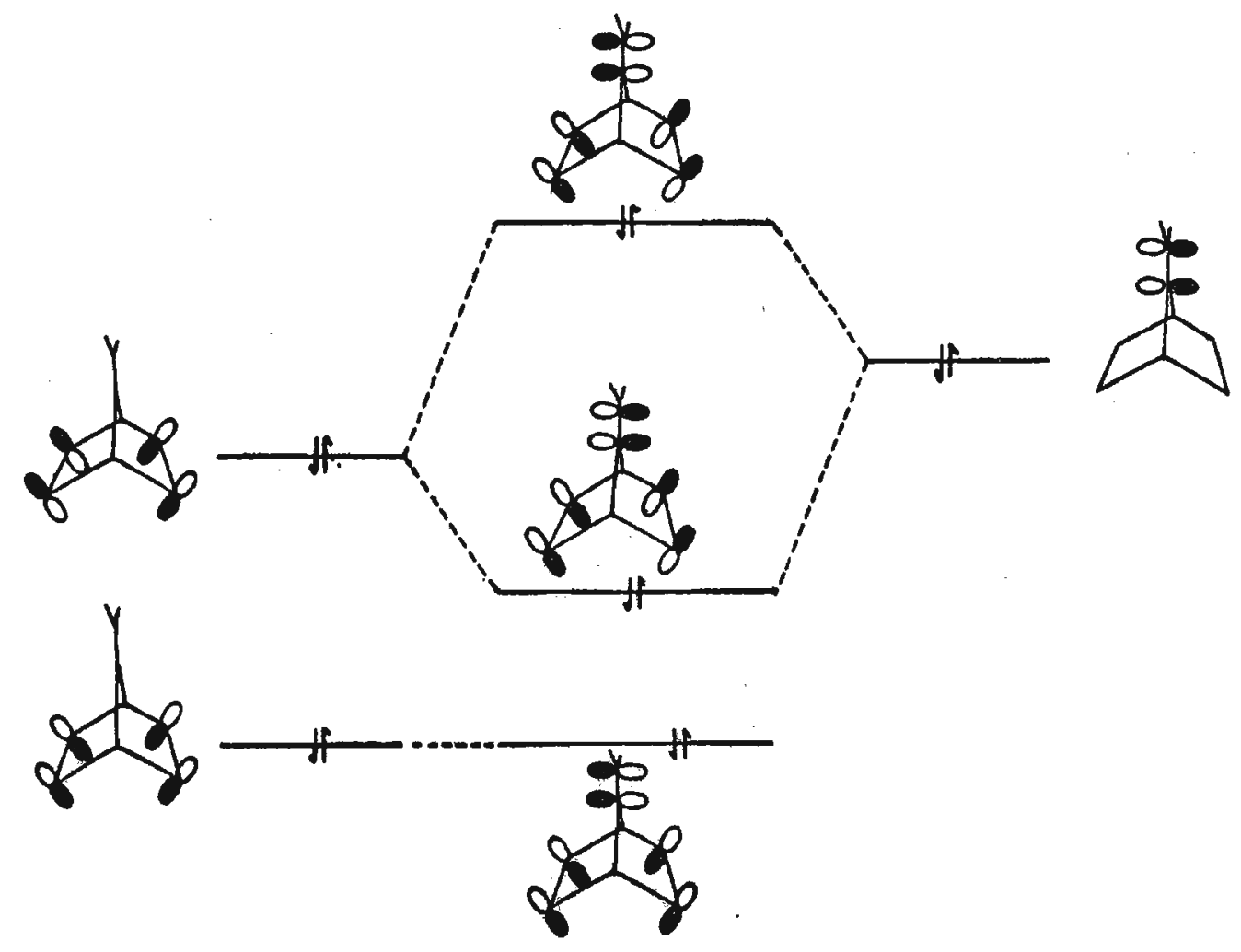


A tentativa de se detectar este tipo de interação no isopropilidenonorborneno (XXIVa) não teve êxito, devidoa uma distorção na molécula (XXIVb) que, segundo Heilbronner e col., ${ }^{71}$ causaria uma diminuição da interação atravēs do espaço. Estes pesquisadores sugeriram que a mesma distorção estaria presente na cetona $\beta, \gamma$-insaturada (XVI) e, portanto, a es tabilização observada de ${ }^{\pi} c c$ nesta cetona, seria causada,principalmente, por efeito indutivo do grupo carbonila e não inte ração entre $\pi_{C C}$ e $\pi_{C O}^{*}$, originalmente proposta por weiler e col. 34,35

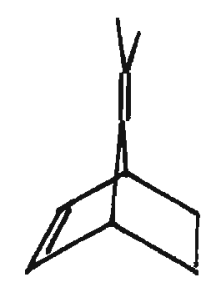

(a)

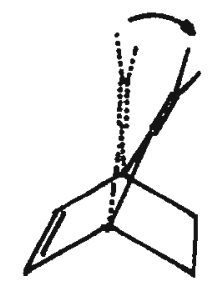

(b)

(XXIV)

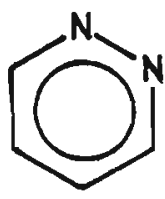

$(X X V)$

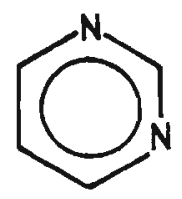

$(X X V I)$

Heilbronner e col. ${ }^{58,59}$ relataram, posteriormente, interação de orbitais $n$ do nitrogênio no espaço em diazaben zenos (XXV, XXVI). Os desdobramentos dos niveis de energia cau sados por este tipo de interação eram de $2.0 \mathrm{eV}(X X V)$ e de $1,5 \mathrm{eV}$ (XXVI). Heilbronner e col. ${ }^{58,59}$ sugeriram o esquema 8 para explicar estas separações. 0 mesmo tipo de interação foi observado pelo mesmo grupo de pesquisadores 26 em diazanaftale nos. 


\section{ESQUEMA 8}

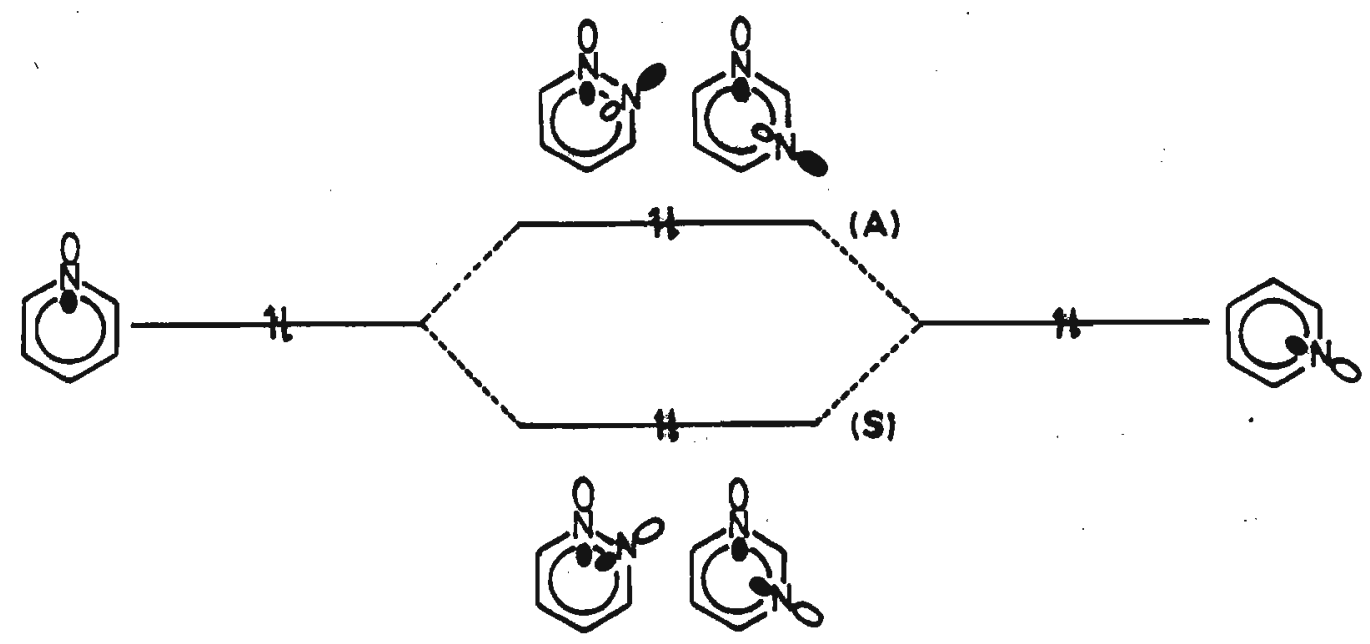

Em 1973, Hoffmann e col. 104 estudaram as interaçōes existentes na aminocetona (XI) em função de três graus de liberdade:

1 - Torção descrita pelo ângulo $\phi$ (XXVIIa), que corresponde à rotação em torno da ligação $C(1)-C(2)$ e é igual a zero quando a ligação $C(2)-N$ eclipsa com $C(1)-0$.

2 - Rotação em torno da ligação $C(2)-N$, descrita pelo ãngulo $\vartheta$ (XXVIIb), que é igual a zero quando o orbital $n$ do nitrogênio eclipsa com a ligação $c(1)-C(2)$.

3 - Angulo da ligação C-C-N.<smiles>[R]C(=O)[14CH2]N</smiles>

$\phi$ (a)<smiles></smiles>

$\theta$

(b)

$(X X V I I)$

Os cālculos mostraram uma interação no espaço entre os orbitais $n$ do oxigênio e $n$ do nitrogênia, que era māxí 
ma para $\phi=0$ e $\theta=0$ (XXVIIIa). Um razoāvel entrosamento entre os mesmos orbitais foi observado, entretanto, para $\theta=180^{\circ}$ (XXVIIIb). Este fato foi atribuĩdo a uma orientaçãomais favorāvel do que a de $\theta=0$ para a interação entre os orbitais, se bem que a pequena amplitude do orbital $n$ do nitrogênio tornava a interação menor do que em (XXVIIIa).

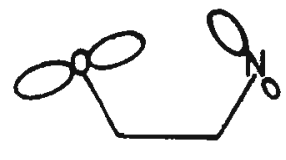

(a)

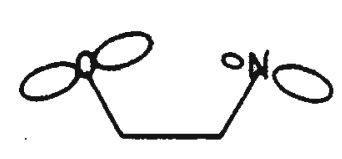

(b)

$(X X V I$ I I )

Neste mesmo ano, Johnstone e col. ${ }^{42}$ detectaram inte ração dos orbitais $\pi$ atravēs do espaço, no 5-metilenonorborne no $(X X I X)$. Assim, enquanto o orbital $\pi$ do norborneno (XXX) possuia nivel de energia de $-8,97$ eV e 0 2-metilenonorbornano (XXXI) de $-9,02$ eV, o referido composto (XXIX) possuia os orbitais $\pi$ em $-8,93$ eV e $-9,31$ eV. Houve, portanto, um desdobra mento de $0,33 \mathrm{eV}$ em relação às monoolefinas, causado pela interação dos orbitais $\pi$ no espaço.

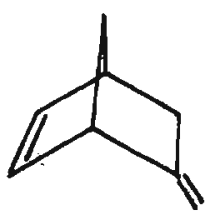

(XXIX)

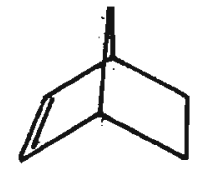

$(x x x)$

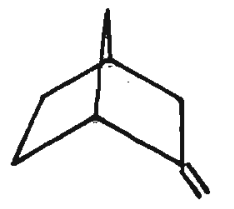

(XXXI)

Ogata e col., 66 em continuação ao trabalho de Hoffmann e col., 81 estudaram a diamina bicíclica (XXXII) e observaram um desdobramento de $0,71 \mathrm{eV}$ entre os níveis de energia dos orbitais $n$ do nitrogēnio, sugerindo que este desdobra- 
mento seria causado pela interação no espaço entre os referi dos orbitais.

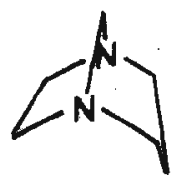

$(X X X I I)$

Rademacker e col.$^{126-129}$ e Nelsen e col. 113,114 verificaram separações entre os níveis de energia dos orbitais $n$ do nitrogēnio em hidrazinas (XXXIII). Estes desdobramentos, causados pelas interaçôes entre os referidos orbitais, eram de pendentes do ângulo $\phi(X X X I I I b)$. Os autores chegaram a esta conclusão estudando hidrazinas de conformações conhecidas. 0 emprego deste método possibilitou a obtenção de estruturas de värias hidrazinas desconhecidas. Aos mesmos resultados chega ram Batich e Adam, ${ }^{11}$ em peröxidos, e Bock e Wagner ${ }^{155}$ e Gui mon e col. 64 em dissulfetos.

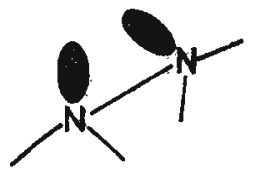

(a)

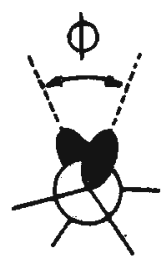

(b)

$(X X X I I I)$

Em 1973 , Rabalais e Katrib ${ }^{85}$ relataram interação en tre os orbitais $n$ e $\pi$ de alilamina (XXXIVa) e de alilmercaptana (XXXIVb). Como $\pi$ possuia nīvel de energia menor do que $n$ em ambos os compostos, o desdobramento causado por esta in teração estabilizava $\pi$ e desestabilizava $n$ em relação aos 
anālogos não substituĩdos.

$$
\begin{gathered}
\mathrm{CH}_{2}=\mathrm{CHCH}_{2} \mathrm{R} \\
R=\mathrm{NH}_{2}(\mathrm{a}) ; \mathrm{R}=\mathrm{SH}(b)
\end{gathered}
$$

(XXXIV)

Bock e col., 24 em 1974, observaram estabilização do orbital $\pi$ olefinico e desestabilização do orbital $n$ do enxo fre no etileno mono, di e tetrasubstituído pelo grupo metiltio, em relação aos não substituĩdos, sugerindo o esquema 9 para explicar o observado.

\section{ESQUEMA 9}

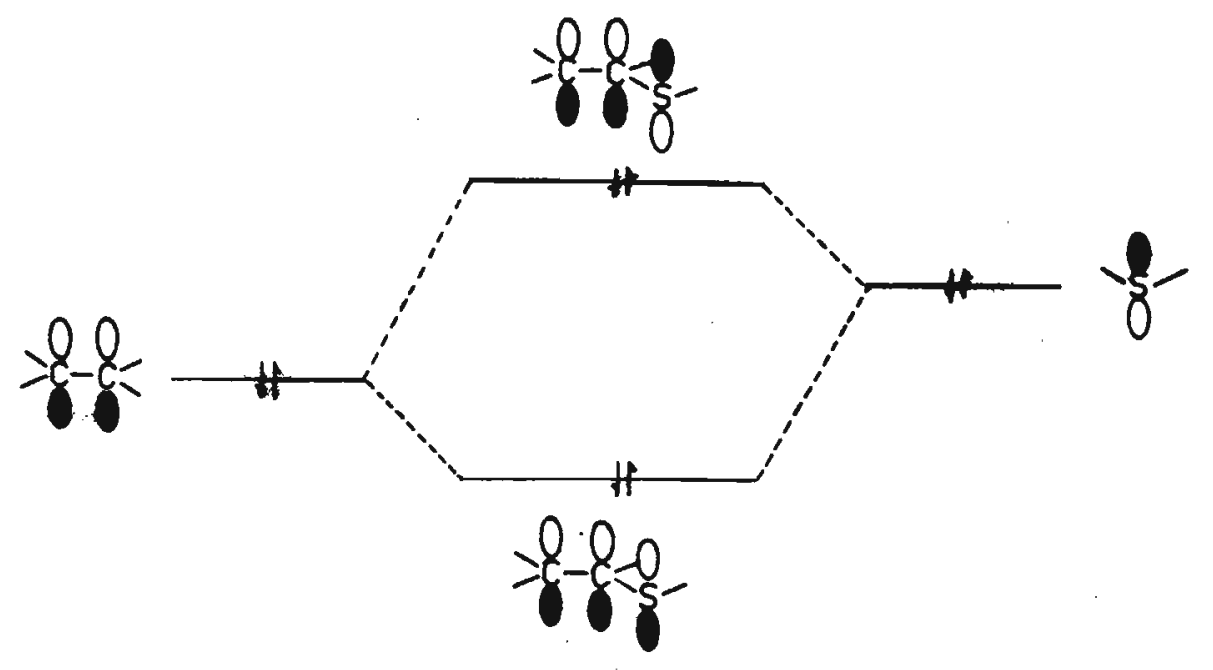

Schweig e col., 110,138 ainda em 1974, relataram inte ração no espaço entre o orbital $n$ do nitrogênio e a combina ção assimētrica dos orbitais $\pi(4 \pi a)$ da parte diolefinica do composto (XXXVa). No derivado sulfurado análogo ( $X X X V b)$, entretanto, a interação entre ${ }^{n_{S}}$ e $4 \pi a$ não foi detectada. Os autores atribuīram este fato à menor diferença de energia entre os referidos orbitais no composto nitrogenado ( $X X X V a)$ do que no sulfurado ( $X X X \vee b) .110$ 


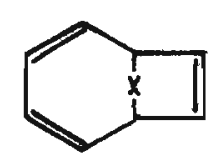

$x=N H(a) ; \quad x=S(b) ; \quad x=C O(c)$

$(X X X Y)$

Ao estudarem 0 anālogo carbonīlico $(X X X V C)$, Schweig e co1. ${ }^{134}$ notaram interação entre o orbital $n$ do oxigênio carbonílico e a combinação assimétrica dos orbitais $\pi$ da parte diolefinica, sugerindo o esquema 10 para explicar esta interação.

\section{ESQUEMA 10}

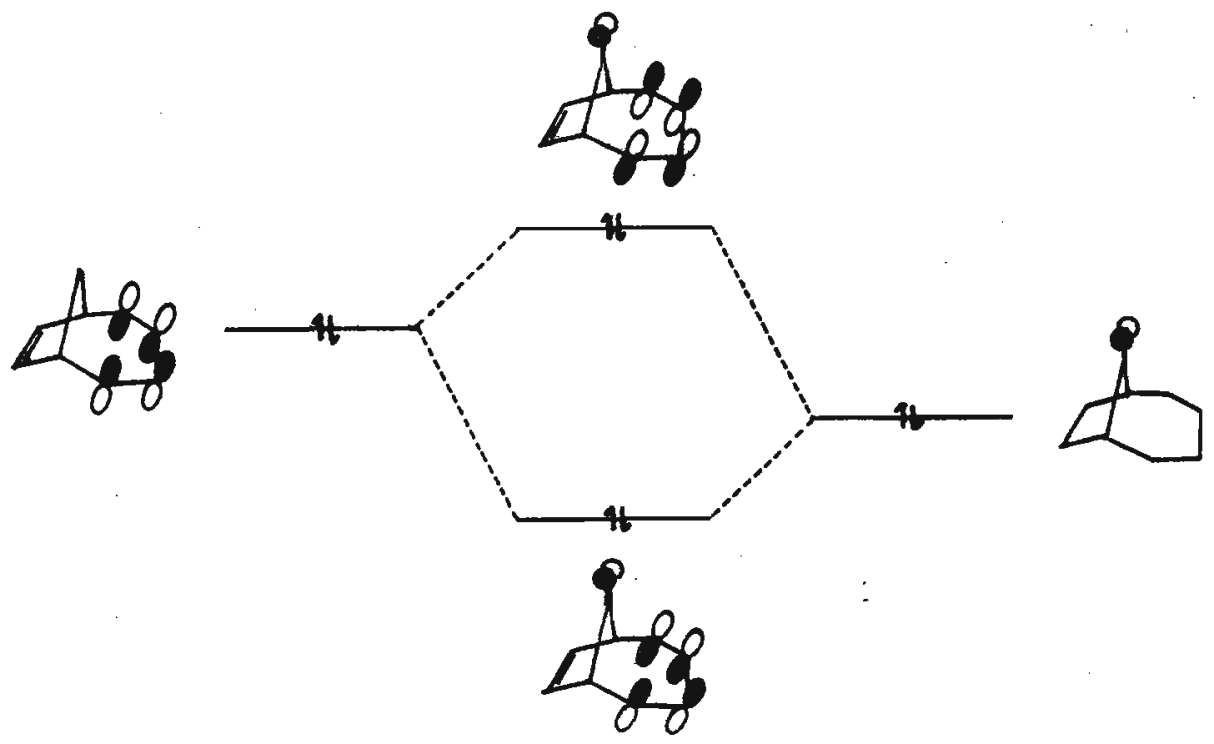

Klessinger e col..$^{74}$ estudaram um grande nümero de ce tonas $\alpha, \beta-e \beta, \gamma$-insaturadas e verificaram que os niveis de energia dos orbitais $\pi_{C C}$ eram estabilizados de 1,0 e 0,75 eV, respectivamente. Os autores confirmaram aquela sugestão feita por Weiler e co1.34,35 de que tais estabilizações seriam causadas por interações entre $\pi_{C C} e \pi^{*}$. 
Klessinger e Asmus ${ }^{7}$ relataram interações de orbitais no espaço entre as duplas exo e endocíclicas nos compostos (XXXVI) e (XXXVII), confirmando, portanto, os resultados obtidos por Johnstone e col. ${ }^{42}$ no composto (XXIX) (pag. 17 ).

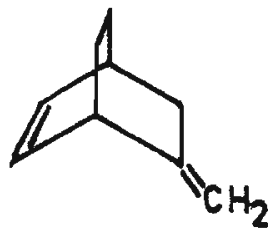

$(X X X V I)$<smiles>C=C1CC=CCC1</smiles>

$(X X X V I I)$

Ramsay e col., 130 em estudos no acilsilano (XXXVIIIa) e no acilgermānio (XXXVIIIb), pelo mētodo de espectroscopia fo toeletrônica, notaram que os niveis de energia do orbital $n$ do oxigênio eram desestabilizados de 1,1 eV (XXXVIIIa) e 1,2 eV (XXXVIIIb), quando comparados com o do composto carbonilico anālogo não substituĩdo. Este fato foi explicado como sendo devido a uma interação entre os orbitais $n_{0}$ e $\sigma_{C-X}$, que estabilizava $\sigma_{C-X}$ e desestabilizava $n_{0}$.

\section{$\mathrm{CH}_{3} \stackrel{\mathrm{O}}{\mathrm{C}} \times\left(\mathrm{CH}_{3}\right)_{3}$ \\ $X=\mathrm{Si}(a) ; \quad X=\mathrm{Ge}(b) \quad \mathrm{HSCH}_{2} \mathrm{SH}$ \\ $(X X X V I I I) \quad(X X X I X)$}

Em 1975, Guimon e col..$^{63}$ observaram um desdobramento de 1,07 eV entre os orbitais $n$ do enxofre no ditiaderiva do $(X X X I X)$, propondo uma interação atravēs do espaço entre os referidos orbitais para explicar tal separação.

Finalmente, neste mesmo ano, Neijzen e col. 112 rela taram uma interação no espaço entre os orbitaiṣ n. do oxige-- 
nio e $\pi$ olefínico em ëteres metilalilicos. Este tipo de interação causava uma pequena desestabilização em $\pi$ CC e uma pequena estabilização em $\eta_{0}$ :

\subsubsection{Interações de orbitais atravēs das ligações}

Em 1966, Cookson e co1. 38 estudaram cetonas $\gamma, \delta-i n-$ saturadas e B-aminocetonas, nas quais havia dois orbitais "p" separados por três ligações $\sigma(X L a)$, verificando que estas substāncias apresentavam uma banda de transferência de carga na região do ultravioleta. A transição responsävel por esta banda foi denominada "sigma acoplada". A razão desta nomencla tura prendia-se ao fato de que a interação entre os dois orb 1 tais "p", que tornava permissîvel tal transição, era aṭravēs da ligação o central (XLb).

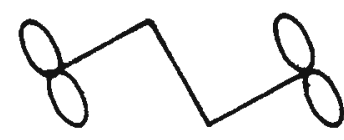

(a)

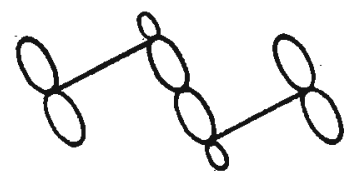

(b)

\section{$(X L)$}

Em 1968, Hoffmann e co1.81 efetuaram cālculos de or bitais no diazabiciclooctano (XIII), constatando um desdobramento dos niveis de energia dos orbitais $n$ donitrogênio $\left(n_{N}\right)$ de $1,57 \mathrm{eV}$. Neste composto (XIII), a distância entre os orbitais $n_{N}$ era de $2,5 \AA$. Os cảlculos mostraram que, nesta distân cia, a interação direta no espaço era desprezível. Baseados neste fato, Hoffmann e seu grupo sugeriram que a interaçãoentre os referidos orbitais se efetuava atravēs de uma ligação $\sigma$ apropriada, de acordo com o esquema 3 (pag. 9 ). Verificou-se, neste caso, que a combinação simétrica,(S) foi deses- 
tabilizada e a combinação assimêtrica (A), estabilizada.

No período de 1969-1970, Heilbronnere co1.18,72 efe tuaram medidas dos potenciais de ionização do diazabicicloọ tano (XIII) pelo método da espectroscopia fotoeletrônica, observando um desdobramento de $2,13 \mathrm{eV}$ entre os níveis de energia dos orbitais $n$ do nitrogênio. A anāise detalhada do es pectro fotoeletrónico desta diamina (XIII), mostrou que o seu nível de menor energia era o de uma combinação assimétrica(A) e o de maior energia, o de uma combinação simētrica (S) dos re feridos orbitais. Estes resultados confirmavam aquelas previsões feitas por Hoffmann e col.81

Hudec, 83 em 1970 , em continuação ao trabalho inicia do por cookson e col., 38 observou no ultravioleta que $\beta$-aming cetonas de conformações fixas possuiam a banda de absorção da transição sigma acoplada apenas quando as orientações de ${ }^{\pi} \mathrm{co}$ e $n_{N}$ permitiam um entrosamento atravēs da ligação o central. Assim, na aminocetona (XLI), a banda estava presente $(221 \mathrm{~nm})$, ao passo que na aminocetona (XLII), estava ausente. Na aminocetona (XLI) a conformação transdiaxial favorecia o entrosamento atravēs das ligações.

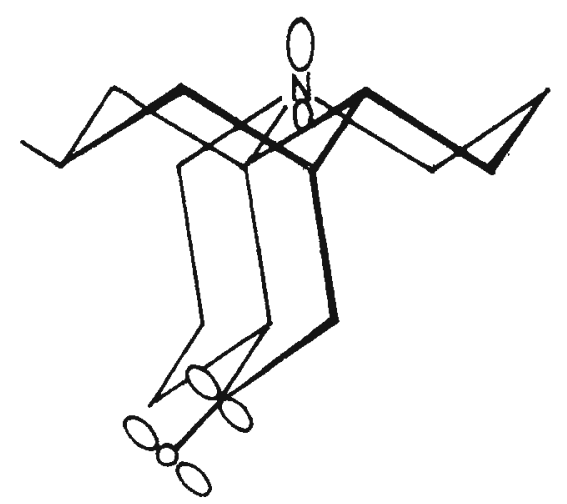

$(X L I)$

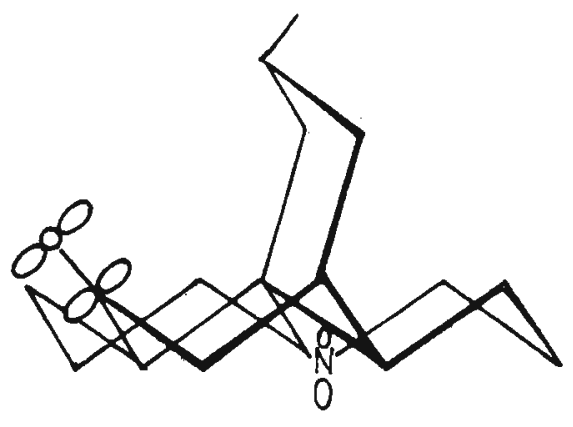

$(X L I I)$ 
Hoffmann e Swenson, ${ }^{147}$ ainda em 1970, em cālculos de orbitais de compostos $\alpha$-dicarbonilicos (XLIII), constataram um desdobramento de 1,46 eV entre os nỉveis de energia dos orbitais $n$ do oxigênio. Este desdobramento foi interpretado como sendo devido à interação destes orbitais através da liga ção $\sigma$ central, de acordo com o esquema 3 (pag. 9).

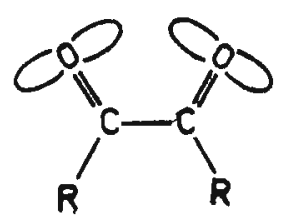

$(X L I I I)$

Em 1971, Heilbronner e col.41 efetuaram medidas dos potenciais de ionização dos compostos $\alpha$-dicarbonilicos trans (XLIV), pelo mëtodo da espectroscopia fotoeletrônica, observando separações dos níveis de energia dos orbitais $n$ do oxi gênio, de 1,6 e 1,9 eV, para (XLIVa) e (XLIVb), respectivamente. Tais desdobramentos, segundo os autores, seriam causados pelas interaçōes entre os referidos orbitais atravês da ligação o central, confirmando as previsões de Hoffmann e Swenson. 147

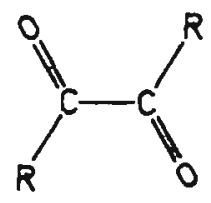

$\mathrm{R}=\mathrm{H}(\mathrm{a}) ; \quad \mathrm{R}=\mathrm{CH}_{3}(\mathrm{~b})$

(XLIV)

Cerfontain e col. 86 notaram, posteriormente, que 0 espectro na região do ultravioleta da dicetona (XLIVb), apresentava duas bandas de absorção, a 425 e $282 \mathrm{~nm}$, de mesma intensidade, atribuindo-as às transições eletrōnicas das combinações simētrica (S) e assimētrica (A) do orbital $\eta_{0}$ para ${ }^{\star}{ }^{*}$. 
Em 1972 , Turner e Sweigart ${ }^{146}$ relataram a existência de interações através das ligações entre os orbitais n dos àtomos de oxigēnio e enxofre, nos compostos cíclicos (XLV) e (XLVI). Os desdobramentos dos niveis de energia de 1,22 eV para $(X L V)$, e de 0,45 eV para (XLVI), mostraram que o entrosamento atravēs das 1 igações era mais importante no dioxader $\underline{j}$ vado $(X L V)$. 0 mesmo tipo de interação foi sugerido, contemporaneamente, por Bock e Wagner, ${ }^{23}$ para os dissulfetos (XLVII) e $(X L V I I I)$.<smiles>C1COCCO1</smiles>

$(X L V)$<smiles>C1CSCCS1</smiles>

(XLVI)

$$
\mathrm{CH}_{3} \mathrm{SCH}_{2} \mathrm{SCH}_{3}
$$

$(X L V I I)$
$\mathrm{CH}_{3} \mathrm{SCH}_{2} \mathrm{CH}_{2} \mathrm{SCH}_{3}$

$(X L V I I I)$

Guimon e col., 63 em estudos mais detalhados do mercaptal (XLVII), verificaram, posteriormente, que o desdobramento observado de 0,25 eV entre os níveis de energia dos orb $\underline{i}$ tais $n$ do enxofre, em (XLVII), era causado pela interação en tre os referidos orbitais, atravēs da ligação o do grupo met $\underline{j}$ lena central, confirmando, portanto, as sugestões de Bock e Wagner. 23

Heillbronner e col. 58,59 observaram uma separação de 1,72 ev entre os níveis de energia dos orbitais $n$ do nitrogênio no diazabenzeno (XLIX). Os autores propuseram como causa deste desdobramento, a interação entre os referidos orbitais, atravēs da ligação o central, de acordo com o esquema 11 e semelhante ao esquema 3 (pag.9).

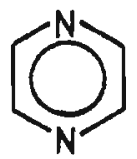

$(X L I X)$

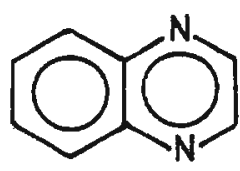

(L). 


\section{ESQUEMA 11}
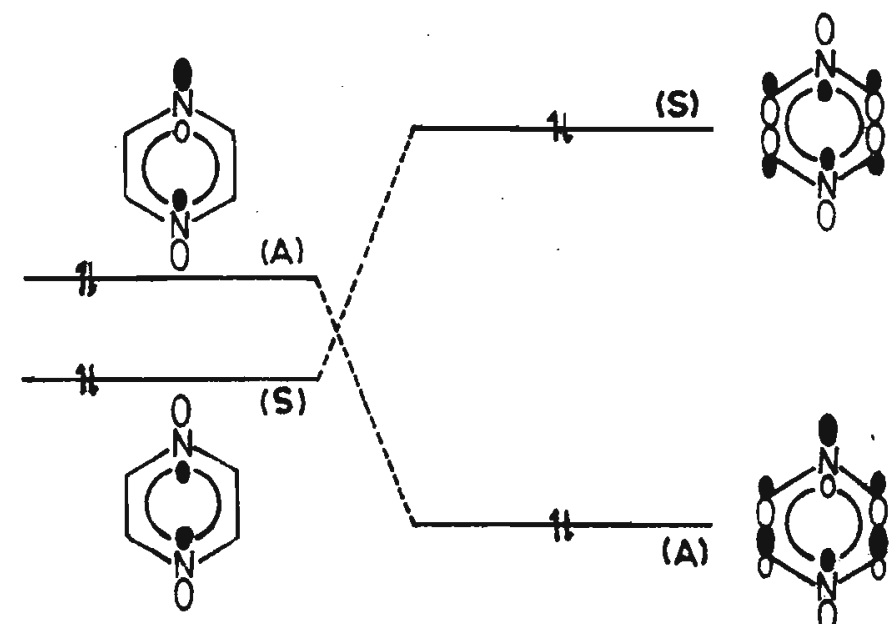

Ao estudarem o diazanaftaleno anālogo (L), Heilbron ner e col. ${ }^{26}$ verificaram um desdobramento de $1,5 \mathrm{eV}$ entre os niveis de energia dos orbitais $n$ do nitrogênio, causado pe10 mesmo tipo de interação.

No periodo de 1972-1973, Heilbronner e col. ${ }^{61,70}$ re lataram separações de $0,18 \mathrm{eV}$ e $0,35 \mathrm{eV}$ entre os niveis de energia dos orbitais $\pi$, nos dienos biciclicos (LI) e (LII), respectivamente, utilizando o mëtodo da espectroscopia fotoeletrōnica. Os cálculos e as anảlises dos espectros destes com postos (LI, LII), mostraram que a combinação assimētrica (A) era mais estabilizada do que a simétrica $(S)$. Estes fatos evi denciaram que nestes dienos (LI, LII), as interações entre os orbitais $\pi$ atravēs das ligações, eram mais importantes do que atravēs do espaço. Convém ressaltar que estes resultados confirmavam sugestöes feitas por Heilbronner, ${ }^{70}$ de que o aumento de "n" (LIII) tornava o anel hexadiēnico mais planar, o que diminuia a interação no espaço e favorecia a interação atravēs das ligações. 


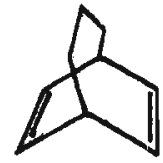

$(L I)$

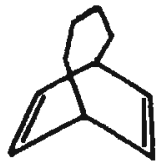

(LII)

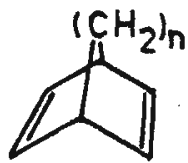

(LIII)

Em 1973, Hoffmann e col. 104 estudaram as interaçōes existentes na aminocetona (XI) em função do àngulo $\phi$ (XXVIIa, pag. 16) e do ângulo $\theta$ (XXVIIb, pag. 16). Os câlcutos mostraram que havia uma interação entre os orbitais $n$ do nitrogênio e $n$ do oxigēnio atravēs da ligação o central, sendo ain da que o entrosamento era independente do ângulo $\phi$, variando, entretanto, com 0 àngulo $\theta$, que era mäximo para $\theta=180^{\circ}$ e mínimo para $\theta=90^{\circ}$.

Neste mesmo ano (1973), Heilbronner e co1. ${ }^{60}$ efetua ram um estudo empregando a espectroscopia fotoeletrōnica, com a finalidade de obter alguma informação acerca das possiveis interações entre os orbitais $\pi$ nos dienos (LIV) e (LV), observando separações dos niveis de energia dos referidos orbitais de $0,97 \mathrm{eV}$ para (LIV) e de $0,36 \mathrm{eV}$ para (LV). Em ambos os ca sos predominava a interação atravēs das ligações. 0 menor des dobramento verificado no dieno (LV), devia-se ao fato de, tam bém neste, haver interação no espaço.
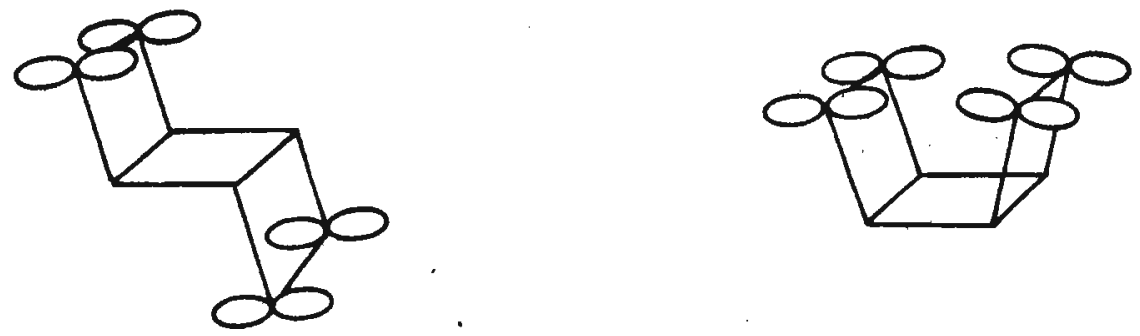
Com o objetivo de obter maiores esclarecimentos acer ca da transição sigma acoplada, no período de 1973-1974, Verho even e col. 47,157 verificaram que os espectros da aminoolefina (LVIa) e da aminocetona (LVIb) de conformações fixas, apre sentavam bandas de absorção em $220 \mathrm{~nm}$ e $243 \mathrm{~nm}$, respectivamen te, inexistentes nos anālogos não substituĩdos. Estas bandas foram atribuĩdas às transições sigma acopladas. Alēm disso, uti lizando o método da ressonáncia magnētica nuclear do carbono 13, observaram que os carbonos carbonilico e olefínico apresentavam blindagens em relação aos não substituĩdos. Estes resultados eram indicativos de um aumento da densidade eletrón ca da dupla. Com base nestes fatos, Verhoeven e col.157 propu seram que a transição sigma acoplada possuia natureza de trans ferência de carga e que esta transição envolvia a passagem de um elētron do orbital $n$ do nitrogênio para o orbital ${ }^{\mathrm{C}} \mathrm{Cx}$ va zio.

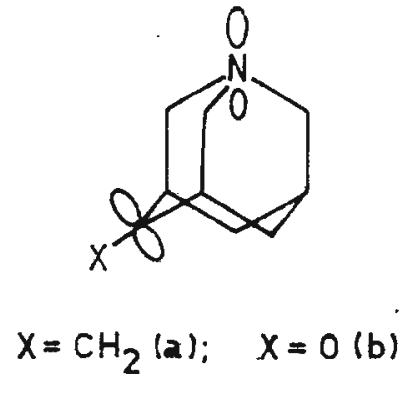

(LVI)

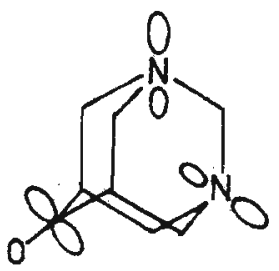

$(L V I I)$

Finalmente, em 1974 , Sasaki e col. 133 relataram interação através da ligação o central entre os orbitais $\pi$ carbonilico e $n$ do nitrogēnio, na aminocetona (LVII). Este tipo de interação causava uma estabilização de 0,18 eV no nĩvel de energia do orbital $n$ do nitrogênio. 


\subsubsection{Hiperconjugação}

Em 1966, Allinger e col. ${ }^{2}$ calcularam os orbitais da ciclohexanona substituída em a por halogénio (LVIII) com a fi nalidade de explicar a menor energia da transição $n \rightarrow \pi^{*}$ da con formação axial (LVIIIa), quando comparada com a da equato rial (LVIIIb). Os resultados obtidos indicaram que havia, na conformação axíal, uma interação hiperconjugativa entre os or bitais $\pi^{*}{ }_{C O}$ e $\sigma_{C-X}^{*}$. Como este tipo de interação estabilizava ${ }^{*}{ }_{C O}$ (esquema 12), era, portanto, responsável pela diminuição da energia da transiçãa $n \rightarrow \pi *$.

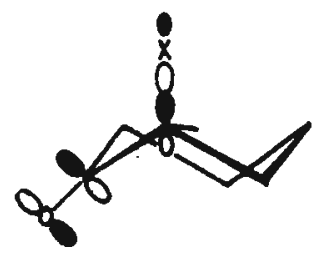

axial (a)

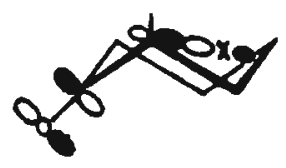

equatorial (b)

( LVIII)

ESQUEMA 12

$6 * x$

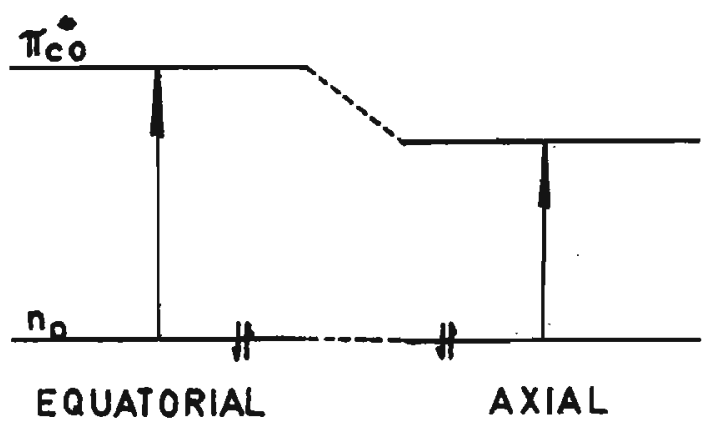

Em 1972, Schweig e Weidner, ${ }^{158,159}$ estudando etileno e derivados e utilizando-se do método da espectroscopia fo 
gia do orbital $\pi$ do propeno $(E=-9,9$ eV), quando comparado com o do etileno $(E=-10,5 \mathrm{eV})$. Os autores atribuiram esta desestabilização à interação hiperconjugativa entre os orbitais $\pi$ e o metílico, que desestabilizava o primeiro. Além disso, notaram que os orbitais $\pi$ de derivados vinilico (LIX) e alílico ( LXb) do silî́cio, tambêm e ram desestabilizados em relação aos do etileno. 0 orbital $\pi$ de $(L X b)$ ( $E=-9,0$ eV), entretanto, era mais desestabilizado do que o de ( $L I X)(E=-9,8 \mathrm{eV})$. Schweig e Weidner propuseram a existência de interações hiperconjugativas entre $\pi$ e $\sigma$ em ambos os compostos ( $L I X, L X b)$, que desesta bilizavam o nivel de energia do orbital $\pi$. No derivado vinïlico, a $\bar{e}$ m desta interação, havia tambēm um forte entrosamento entre os orbitais $\pi$ e $d_{s i}$ que estabilizava $\pi$ (esquema 13) diminuindo, portanto, o efeito da interação hiperconjugativa.
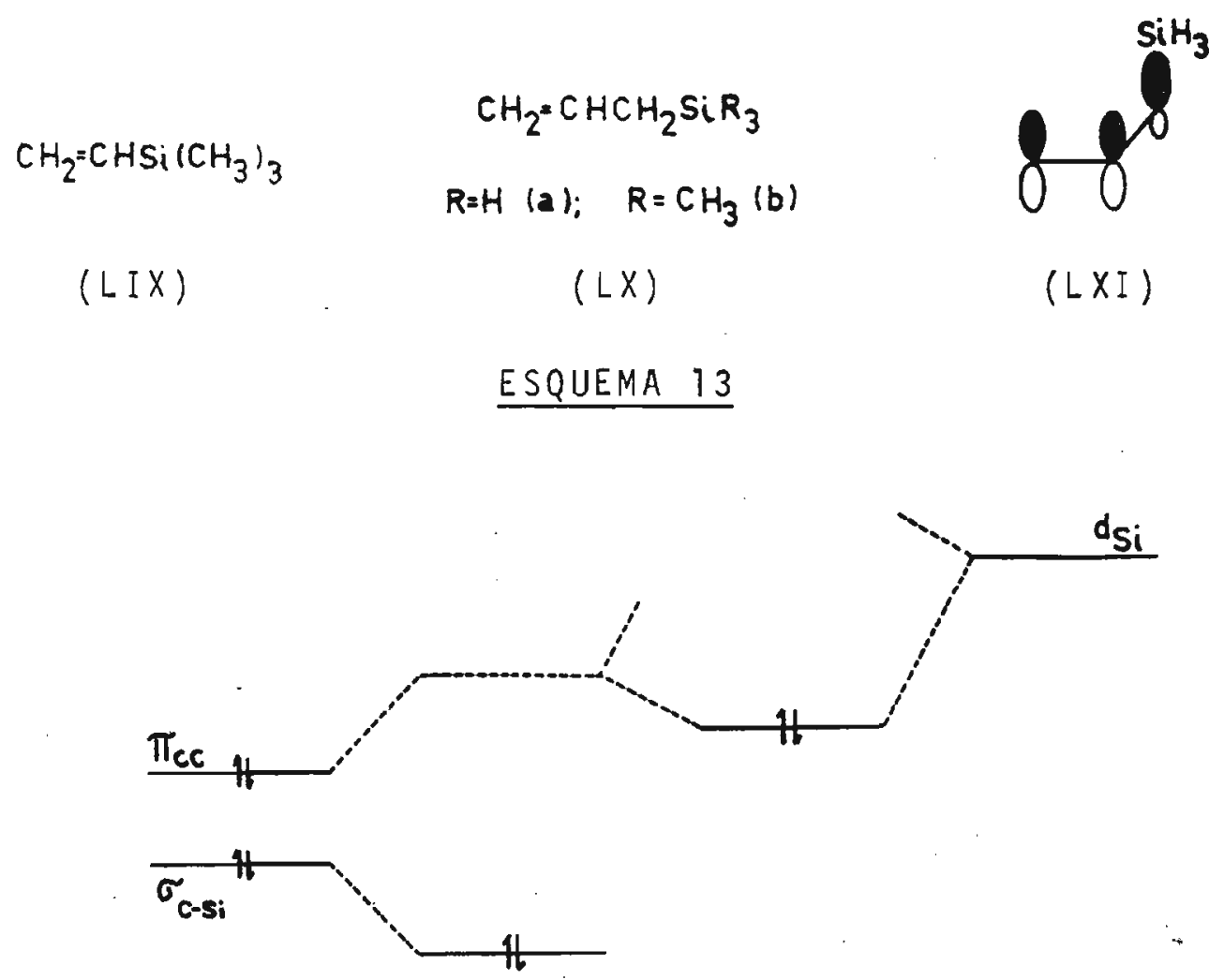
Paralelamente, Bock e col. ${ }^{108}$ relataram interação hiperconjugativa entre os orbitais $\pi$ e $\sigma_{C-S i}$ noalilsilano(LXa), semelhante àquela descrita por Schweig e Weidner 158,159 no aliltrimetilsilano (LXb). Bock e col. 108 sugeriram que a configuração (LXI) seria a responsāvel pela interação.

Neste mesmo ano (1972), Schweig e Schafer, 135,136 em estudos de conformações, atravēs da espectroscopia fotoeletrō nica, observaram que no sulfeto alilmetilico (LXIIb) e na alil mercaptana (LXIIa), havia interações hiperconjugativas entre os orbitais $\pi$ e $\sigma_{C-S}$, que seriam responsáveis pelas conformações gauche em ambos os compostos (LXIIa,b).

\section{$\mathrm{CH}_{2}=\mathrm{CHCH}_{2} \mathrm{SR}$}

$R=H(a): R=\mathrm{CH}_{3}(b)$

(LXII)

Em 1973, utilizando-se do mesmo mëtodo, Schweig e Schmidt ${ }^{137}$ relataram a existência de interação hiperconjugativa entre os orbitais $\pi$ e $\sigma_{C-X}$ em haletos de alila (LXIII). Os autores propuseram que, tambëm nestes compostos (LXIII), es te tipo de interação era importante na determinação da confor mação, nos quais a gauche era a mais estāvel.

\section{$\mathrm{CH}_{2} \mathrm{CHCH}_{2} \mathrm{X}$}

$X=F(a) ; \quad x=C(b) ; \quad x=B r(c) ; \quad x=1(d)$

\section{( LXI I I)}

Schweig e col., ${ }^{139}$ paralelamente, notaram um grande desdobramento entre os niveis de nergia dos orbitais $\pi$ e $\sigma_{\mathrm{C}-\mathrm{Hg}}$ no cloreto de alilmercúrio (LXIV), quando comparado comos an 
logos não substituĩdos, atribuindo este desdobramento à interação hiperconjugativa entre os referidos orbitais (esquema 14).

\section{ESQUEMA 14}

\section{$\mathrm{CH}_{2}=\mathrm{CHCH}_{2} \mathrm{HgCl}$}

(LXIV)

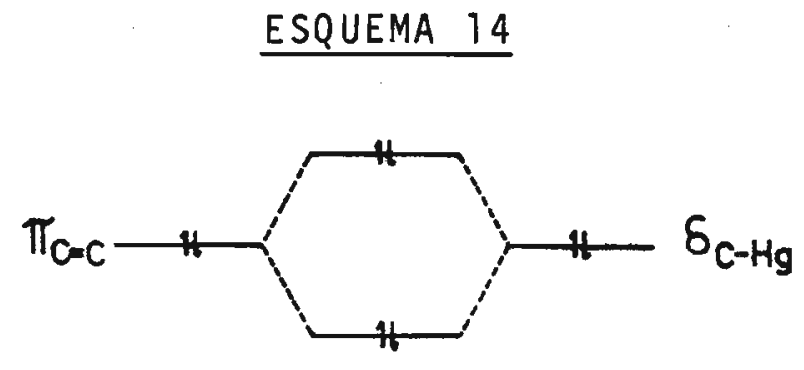

Neste mesmo ano (1973), Schweig e col. 141 estudaram alilgermânio ( $L X V a$ ) e alilestanho ( $L X V b$ ) pelo mētodo da espec troscopia fotoeletrônica e, analisando os espectros destes compostos ( $L X V a, b)$, concluiram que as conformações mais estáveis dos mesmos ( $L X V I$ ) eram determinadas por hiperconjugação.

\section{$\mathrm{CH}_{2} \mathrm{CHCH}_{2} \mathrm{MR}_{3}$ \\ $M=G e(a) ; \quad M=S n(b)$}

$(L X V)$

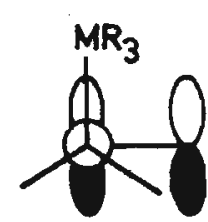

( LXVI)

0 mesmo tipo de interação foi proposto, posteriormente, por schweig e col. ${ }^{140}$ para derivados alîlico (LXVII) e vinīico (LXVIII) do fósforo. A interação entre os orbitais $\pi$ e $\sigma_{C-p}$ seria, tambēm neste caso, responsāvel pela conformação gauche destes compostos.

$$
\mathrm{CH}_{2}=\mathrm{CHCH}_{2} \mathrm{PR}_{2}
$$

(LXVII)

\section{$\mathrm{CH}_{2}=\mathrm{CHPR}_{2}$}

(LXVIII)

Em 1973, Hoffmann e col. 104 efetuaram cälculos de or bitais em aminocetonas (XI), que indicaram a existência de in- 
teração hiperconjugativa entre os orbitais $\pi *$ e $\sigma_{C-N}^{\star}$, que independia do āngulo $\theta$ (XXVIIb, pag. 16), mas variava com $\phi$ (XXVIIa, pag. 16), séndo o entrosamento mäximo para $\phi=90^{\circ}$.

Em 1974, Bock e col. 50 examinaram os niveis de ener gia dos orbitais $\sigma$ e $\pi$ no estado fundamental do acetileno (LXIXa) e seus derivados (LXIXb-e), obtidos de seus espectros fotoletrônicos. Em todos os derivados, observaram-se desestabilizações dos orbitais $\pi$ quando comparados com os do acetile no. Os referidos autores sugeriram que estas desestabilizaçōes seriam causadas por interações hiperconjugativas entre os orbitais $\sigma$ e $\pi$ (esquema 15).

\section{$R C=C^{\prime}$}

$R=R^{\prime}=H(a) ; \quad R=H, R=C H_{3}(b) ; \quad R=H_{1} R^{\prime}=\operatorname{SiH}_{3}(c) ; R=R^{\prime}=C_{3}(d) ; R=R^{\prime}=S_{i H}(e)$ (LXIX)

\section{ESQUEMA 15}

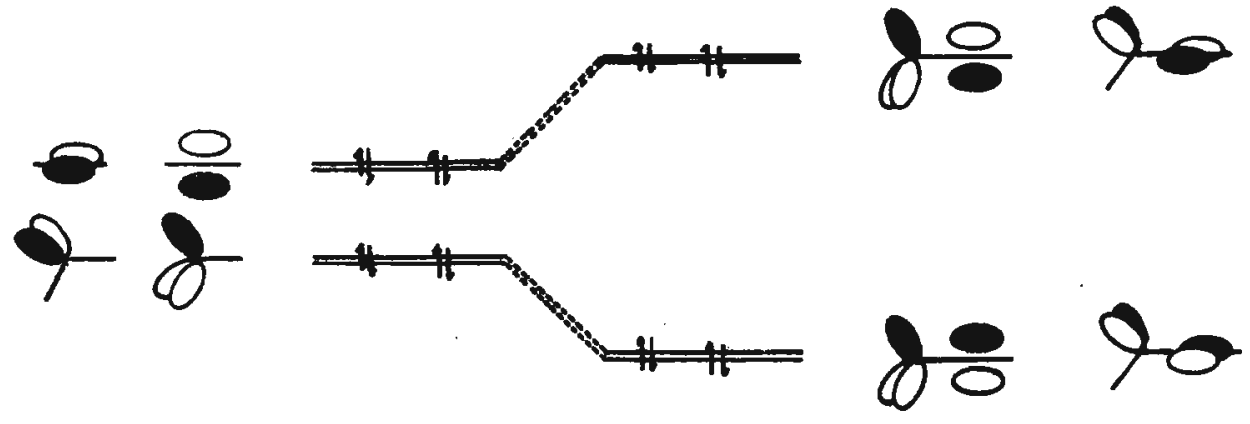

Este mesmo tipo de interação foi observado, paralelamente, na acetonitrila, por Bock e Stafast. 144

Finalmente, em 1975 , Nesmeyanov e col. 115 relataram 
a existēncia de interação hiperconjugativa entre os orbitais ${ }^{\pi} \mathrm{CO}$ e $\sigma_{\mathrm{C}-\mathrm{Hg}}$ no composto $(L X X)$, usando o mētodo da ressonāncia magnética nuclear do carbono 13. Entretanto, tal tipo de inte ração não foi detectado no composto (LXXI) sendo o fato atri buĩdo à conformação fixa, desfavorāvel ao entrosamento hiperconjugativo.<smiles>O=C1CCCCC1[Hg]Cl</smiles>

$(L X X)$

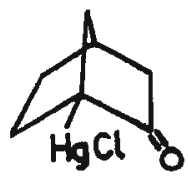

(LXXI)

\subsection{INTERAÇOES ENTRE ENXOFRE E CARBONILA}

Em 1949, Fehnel e Carmack ${ }^{54}$ observaram que cetonas contendo um grupo alquiltio ligado ao carbono $a$, apresentavam espectros no ultravioleta diferentes de compostos anālogos não substituidos. Assim, enquanto os sulfetos absorviam em $210 \mathrm{~nm}$ $(\log \varepsilon-3,00-3,25)$ e cetonas na região de $275-295 \mathrm{~nm}$ $(\log \varepsilon=1,7)$, estes $\alpha$-cetosulfetos absorviam nas regiões de $295-300 \mathrm{~nm}(\log \varepsilon=2,50)$ e $240-245 \mathrm{~nm}(\log \varepsilon=2,60)$. Para a explicação dos espectros anōmalos destes $\alpha$-cetosulfetos, fo ram sugeridas as existências de interaçōes entre carbonila, en xofre e hidrogênio em $\alpha$, propondo-se as estruturas (LXXIIa-d) como responsāveis por estes espectros característicos.

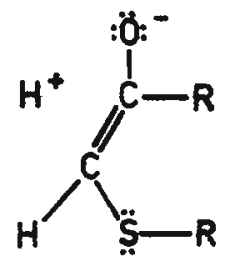

(a)

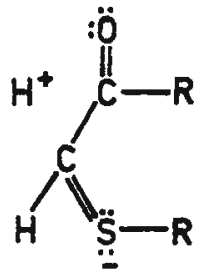

(b)

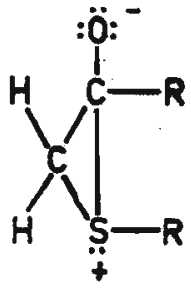

(c)

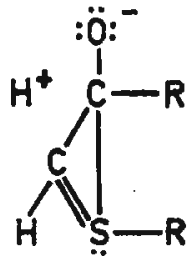

(d) 
No período de 1959-1960, Leonard e col. 91,95 estudạ ram compostos cíclicos contendo enxofre e carbonila, com a fi nalidade de obter informações sobre uma possĩvel interação transanular entre estes dois grupos. Os autores verificaram que a tiacetona (LXXIII) apresentava, no espectro de infraver melho, alēm da banda normal da carbonila $\left(1703 \mathrm{~cm}^{-1}\right)$, uma inflexão em frequência menor $\left(1684 \mathrm{~cm}^{-1}\right)$. Esta evidência experi mental, apoiada pela medida do momento dipolar, levou os auto res a sugerirem que esta cetona (LXXIII) existe como uma mistura de duas conformações: de não interação e de interação (LXXIIIa, b).

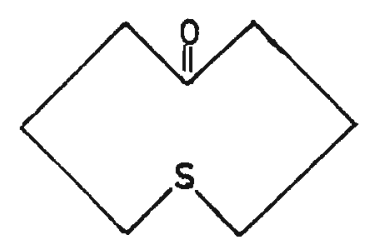

(a)

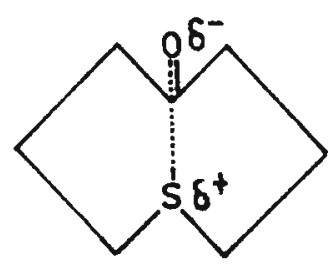

(b)

( LXXIII)

Leonarde col..$^{95}$ tambēm observaram que o espectro no ultravioleta desta tiacetona (LXXIII) apresentava umabandade absorção em $237 \mathrm{~nm}$, ausente nos anälogos não substituĩdos. 0 estudo da influência de solvente nesta banda, mostrou um deslocamento para o visível ao se passar de solventes não polares para polares. Baseando-se neste fato e levando-se em consideração a alta intensidade desta absorção $(\log \varepsilon=3,5)$, Le o nard e col. concluiram ser o estado excitado mais polarizado que 0 fundamental.

Em 1962, Bergson e De 1 in ${ }^{15}$ efetuaram um estudo das interações nos estados fundamental e excitado da etiltioaceto na (LXXIV). A diminuição da frequência de estiramento da carbonila neste composto (LXXIV) em comparação com o não subst 
tuijdo correspondente, foi por eles atribuída, na base do estú do da influência de solventes, a uma diminuição da constante de força da carbonila. Um estudo semelhante em relação à tran sição $n \rightarrow \pi^{*}$, em aproximadamente $300 \mathrm{~nm}$, levou-os a sugerirem que o estado fundamental desta molécula (LXXIV) era mais polar do que o estado excitado. Esta conclusão era contrāria à de Leonard e col. ${ }^{95}$ com respeito à tiacetona (LXXIII), na qual o es tado excitado mostrou-se mais polar do que o fundamental.

$$
\mathrm{CH}_{3} \mathrm{CH}_{2} \mathrm{SCH}_{2} \stackrel{\mathrm{C}}{\mathrm{C}} \mathrm{CH}_{3}
$$

$(L X X I V)$

Paquette e Wise, 124 em 1967, sugeriram que a tiacetona (LXXIII) estudada por Leonard e col.9, 91,95 devido à sua mo bilidade conformacional, não permitia estabelecer uma relação entre a interação enxofre-carbonila e a distáncia interatómica entre os dois centros envolvidos e, dessa forma, obter uma compreensão melhor de tal interação eletrōnica.

Com o objetivo de obter maiores informaçöes das ex gências estruturais para tais interações transanulares $\mathrm{S}-\mathrm{C}_{\mathrm{CO}}$, Paquette e wise 124 sintetizaram duas tetrahidro-1,4-tiapironas ( LXXVa,b), de tal maneira que a tiacetona de seis membros possuia conformaçāo barco rīgida. Se bem que os momentos dipo lares observados para estes compostos mostraram-se mais eleva dos do que os de molēculas semelhantes, as medidas no infravermelho não eram conclusivas quanto à existência de intera ção transanular no estado fundamental. A anälise do espectro no ultravioleta destas cetonas ( $L X X V a, b)$ mostrou, entretanto, a existência de banda de transferência de carga em aproximada mente $240 \mathrm{~nm}$. Com base no estudo do deslocamento do mäximo de 
absorção desta banda com a polaridade do solvente, os autores atribuiram esta banda de absorção a uma transferência de carga do enxofre divalente para o grupo carbonila. Posteriormente, Paquette e col. 123 mostraram que a interação era mais efe tiva em ( $L X X V b)$ do que em ( LXXVa), devido à menor distância en tre os centros envolvidos no primeiro composto, propondo a es trutura ( $L X X V I)$ para explicar tal tipo de interação.

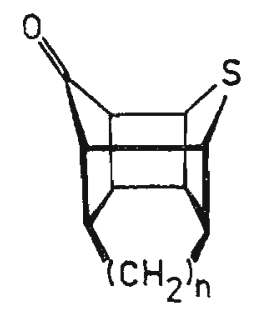

$n=1(a) ; n=2(b)$

$(L X X V)$

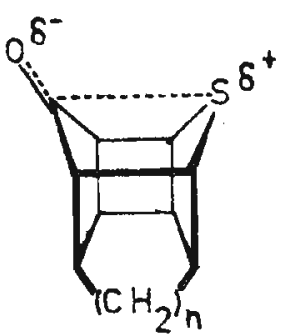

$(L X X V I)$

Herzschuh e Borsdorf, ${ }^{75}$ em 1969, efetuaram um estudo polarogräfico em 3,4 e 5-tiaciclanonas (LXXVII-LXXXI,LXXIII) e observaram que suas reduções eram consideravelmente mais fáceis do que as de cetonas anālogas não substituĩdas. Alēm dís so, notaram que as $3-t i a c i c l a n o n a s ~(L X X V I I-L X X I X)$ eram reduzi das mais facilmente do que as 4-tiaciclanonas ( $X X X X, L X X X I$ ) e estas mais facilmente do que a 5-tiaciclanona (LXXIII). A com paração de seus potenciais de meia-onda com os respectivos es pectros no ultravioleta, levou os autores a sugeriremque a fạ cilidade da redução polarográfica destas tiaciclanonas (LXXVIILXXXI, LXXIII) devia-se à interação entre enxofre e carbonila.

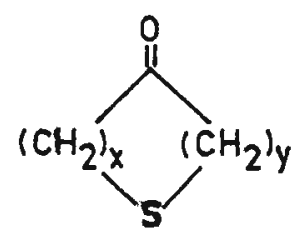

$x=1, y=2$ (LXXVII); $x=1, y=3$ (LXXVIII); $x=1, y=4$ (LXXIX); $x=2, y=2 \quad(L X X X) ; x=2, y=3$ (LXXXI); $x=3, y=3^{3}$ (LXXIII) 
Herzschuh e col. 76 observaram, posteriormente, que a 4-oxaciciohexanona (LXXXII) tambēm era reduzida mais facilmente do que a anāloga não substituĩda, atribuindo este fato $\bar{a}$ interação entre oxigênio e carbonila.

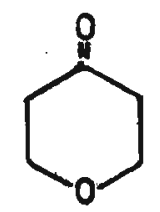

(LXXXII)

No período de 1970-1971, Wladislaw e col.165,168 re lataram que cetonas substituídas em a por um grupo alquiltio, apresentavam diminuições de basicidade quando comparadas com as anālogas não substituĩdas. Estas diminuiçōes de basicidade eram ainda acompanhadas por diminuições das frequências de es tiramento da carbonila. Para explicar estes fatos experimentais, os autores propuseram a existência de transferēncia de carga do grupo carbonila para um orbital vazio doenxofre. Não foi eliminada, entretanto, a possibilidade de estarem operando efeitos não eletrónicos, tais como impedimento estérico do grupo alquiltio e perturbações mecânicas originärias da substituição do hidrogênio em a por um ätomo de enxofre. 0 impedi mento estērico dificultaria a formação da ponte de hidrogênio, causando, consequentemente, a diminuição da basicidade. As per tubações mecānicas causariam a diminuição da frequēncia de es tiramento da carbonila.

Wladislaw e col.51,164 observaram, posteriormente, diminuiçōes de basicidade acompanhadas das diminuiçöes das frequências de estiramento do grupo ciano, em nitrilas substị tuídas em a pelo grupo alquiltio, nas quais o impedimento estérico estava ausente. Com base nestes resultados, os autores 
propuseram que os efeitos eletrōnicos seriam os responsáveis por estas diminuições da basicidade.

Convëm ressaltar que a mesma diminuição de basicida de, seguida por diminuição da frequéncia de estiramento da car bonila, foi observada pelos mesmo autores em ( $\alpha$-alquiltio)-és teres, ${ }^{165}$-tioēsteres ${ }^{165,167}$ e -amidas. 165

Wladis law e col. $161,166,167,168$ analisaram tambëm os espectros no ultravioleta dos mesmos compostos e verificaram que eram diferentes dos anālogos näo substituĩdos, sugerindo interação entre enxofre e carbonila no estado excitado. 
APRESENTAÇAO E DISCUSSAO DE RESULTADOS $29,30,162,163$

0 presente capĩtulo compõe-se de três partes. Naprị meira e na segunda, apresentam-se e discutem-se os resultados das medidas relativas de basicidade pelo método de ressonância magnética nuclear de ciclopentanona (LXXXIII), 3-tiaciclo pentanona (LXXVII), ciclohexanona (LXXXIV), 3-tiaciclohexanona (LXXVIII), cicloheptanona (LXXXV), 3-tiacicloheptanona (LXXIX), 4-tiaciclohexanona ( $L X X X)$, 4-tiacicloheptanona ( $L X X X I)$, ciclooctanona (LXXXVI), 5-tiaciclooctanona (LXXIII), 2-pentanona (LXXXVII), 2-heptanona (LXXXVIII), 2-octanona (LXXXIX), 2-undecanona $(X C)$, metiltioacetona (XCI), etiltioacetona (LXXIV), 4-etiltio-2-butanona (XCII), 5-etiltio-2-pentanona (XCIII), 6-eti1tio-2-hexanona (XCIV), tetrahidrotiofeno (XCV), 3-oxaci clopentanona (XCVI), metoxiacetona (XCVII) e 3-ciclohexenona $(X V)$. Na terceira parte, relatam-se as sinteses de alguns des tes compostos por nós efetuadas.

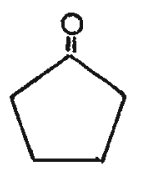

(LXXXIII)

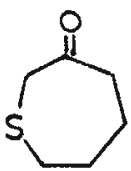

$(L X X \mid X)$

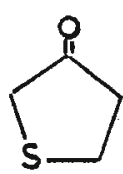

(LXXVII)<smiles>O=C1CCSCC1</smiles>

$(L X X X)$<smiles>O=C1CCCCC1</smiles>

(LXXXIV)

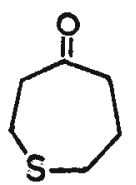

$(L \times X X)$<smiles>O=C1CCCSC1</smiles>

(LXXVIII)

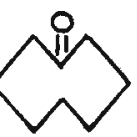

(LXXXVI)

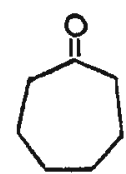

(LXXXV)

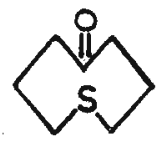

(LXXIII)

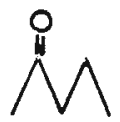

(LXXXVII)

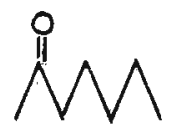

(LXXXVIII)

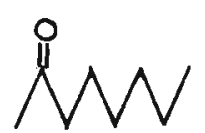

(LXXXIX)

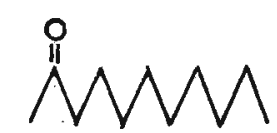

(XC)

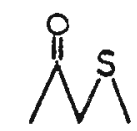

(XC) 


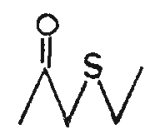

(LXXIV)

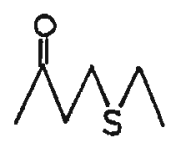

(XCII)

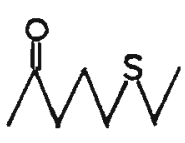

(XCIII)

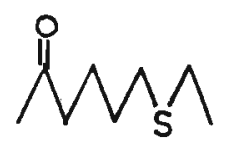

(XCIV)

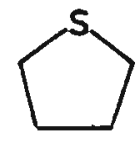

(XCV)<smiles>O=C1CCOC1</smiles>

(XCVI)

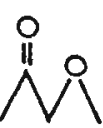

(XCVII)<smiles>O=C1CC=CCC1</smiles>

(XV)

2. 1. MEDIDAS COMPARATIVAS DE BASICIDADE PELO EMPREGO DO METODO DE RESSONANCIA MAGNETICA NUCLEAR

Conforme exposto no capitulo anterior, Wladislaw e col. 165,168 observaram que as a-alquiltiocetonas alifäticas acíclicas possuiam uma diminuição da habilidade para a formação de pontes de hidrogênio, quando comparadas com as cetonas anālogas não substituĩdas. Era de interesse verificar se a mesma diminuição ocorria em tiaciclanonas contendo o àtomo de enxofre ligado ao carbono $\alpha$, jā que a inspeção de modelos moleculares mostrava que nestes compostos, devido à rotação res trita, ficava eliminada a possibilidade de impedimento estēri co. Convém frisar que Herzschuh e Borsdorf ${ }^{75}$ jä haviam suger do interação entre enxofre e carbonila nestas tiaciclanonas, na base de absorção anormal no ultravioleta e ao verificarem que suas reduções polarogrāficas eram bem mais fāceis do que as de cetonas anālogas não substituĩdas.

As medidas comparativas de basicidade pelo mētodo de 
ressonāncia magnētica nuclear 46,125 atē então realizadas em nossos laboratörios, $132,165,168$ foram efetuadas com a utiliza ção do sistema binärio doador-aceptor de pröton. Achou-se de interesse passar-se para o estudo em sistema ternārio doador-aceptor de próton-solvente inerte. Este sistema apresentava diversas vantagens em relação ao anterior, pois, alēm de diminuir a autoassociação do doador de prōton e possibilitar uma melhor comparação com as medidas pelo mëtodo no infravermelho, desenvolvido paralelamente em nossos laboratōrios, fornecia da dos para o cálculo da constante de equilíbrio do complexo doa dor-aceptor de pröton.

o problema inicial a ser solucionado foi a escolha de um doador de prōton apropriado. Estudos anteriores deste $1 \underline{a}$ boratōrio $132,165,168$ utilizaram o fenilacetileno e o fenol co mo doadores de prötons. O fenilacetileno seria o indicado, não só pela sua pouca tendência à autoassociação, como tambẻm pela linearidade de sua molécula e pela facilidade de manipulação. Rittne ${ }^{132 b}$ verificara, entretanto, que usando-setalāci do, as diferenças de basicidades não eram significativas na presença de solvente. Em vista disso, foram escolhidos dois doadores de prótons poderosos: o fenol 44,62 e o p-clorofenol, empregando-se como solvente o tetracloreto de carbono.

Foram primeiramente efetuadas as medidas dos deslocamentos químicos dos prōtons hidroxílicos do fenol (exp. nọ 1 , pag. 93) e do p-clorofenol (exp. no.2, pag.95), a diferentes concentrações, em tetracloreto de carbono, com a finalidadede se determinar os valores de seus deslocamentos à diluição infinita $\left(\Delta \nu_{0}\right)$

A seguir passou-se às medidas em sistemas ternärios doador-aceptor de prōton-tetracloreto de carbono. os acepto- 
res de prótons inicialmente estudados foram as cetonas cīclicas não substituĩdas ( $L X X X I I I-L X X X V)$ e as tiaciclanonas contendo o ātomo de enxofre ligado ao carbono $\alpha$ (LXXVII-LXXIX). Em todas as medidas, a concentração molar do doador de prōton foi mantida constante e tão baixa quanto possĩvel, para preve nir autoassociações, dentro do limite de detectabilidade do aparelho de ressonāncia magnētica nuclear. As concentrações dos aceptores de prótons eram variāveis dentro de tal faixa, que um excesso destes era sempre presente com a finalidade de se garantir a associação 1:1.

Os valores de deslocamentos do sinal do pröton devi dos à associação ( $\Delta \nu^{\prime}{ }_{0}$ ) obtidos experimentalmente (exps. nọ 3-8, pags. 96-106) e correlacionados com os valores correspondentes de quocientes molares $n_{\mathrm{OH}} / n_{\mathrm{CO}}$, pelo emprego de fenol e p-clorofenol, acham-se nas figuras 1 e 2 , respectivamente.

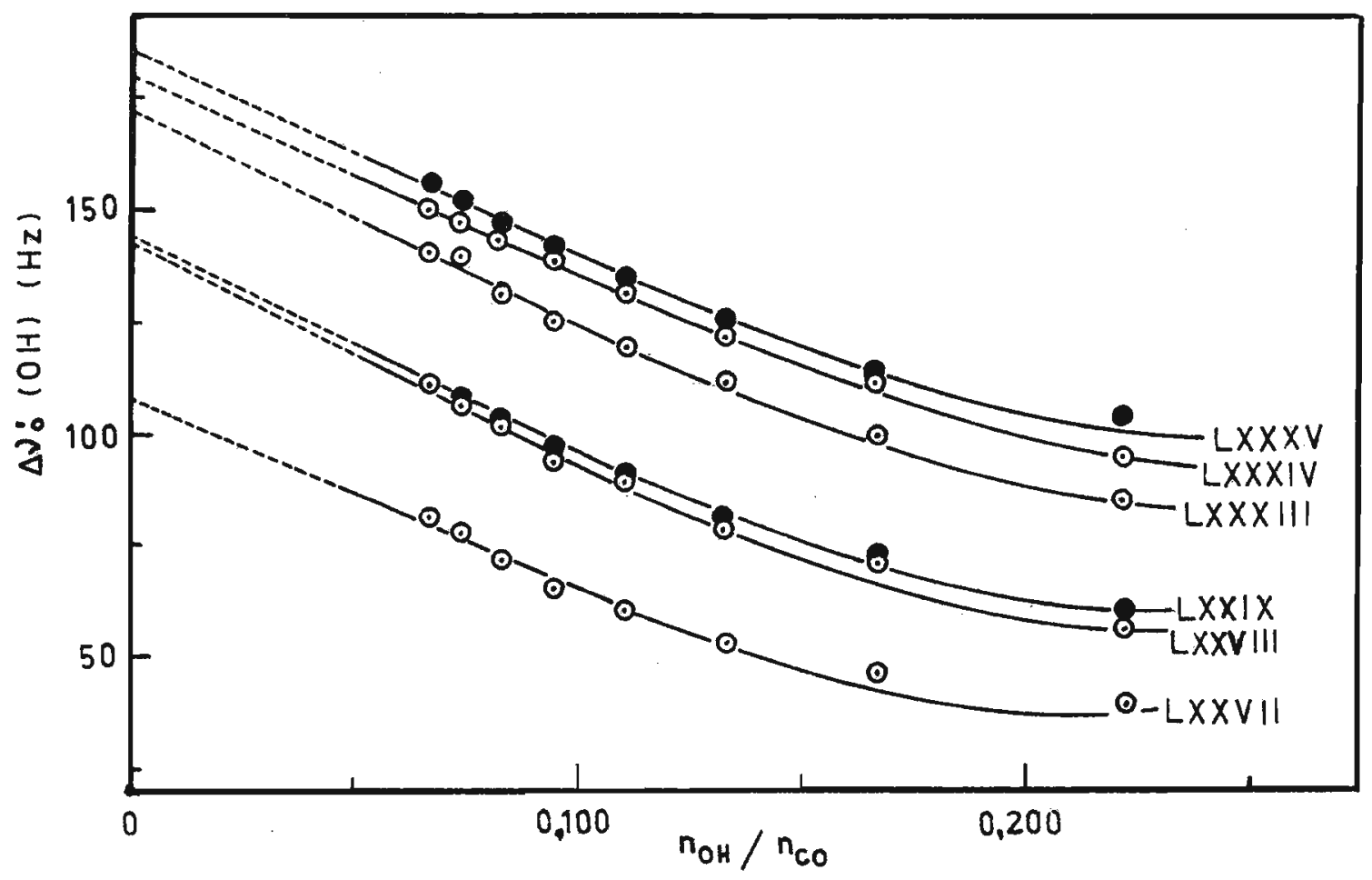

Figura 1 - Deslocamentos da ponte de hidrogēnio vs. quocien tes molares; sistema: fenol-aceptor de pröton,em $\mathrm{CCl}_{4}$. 


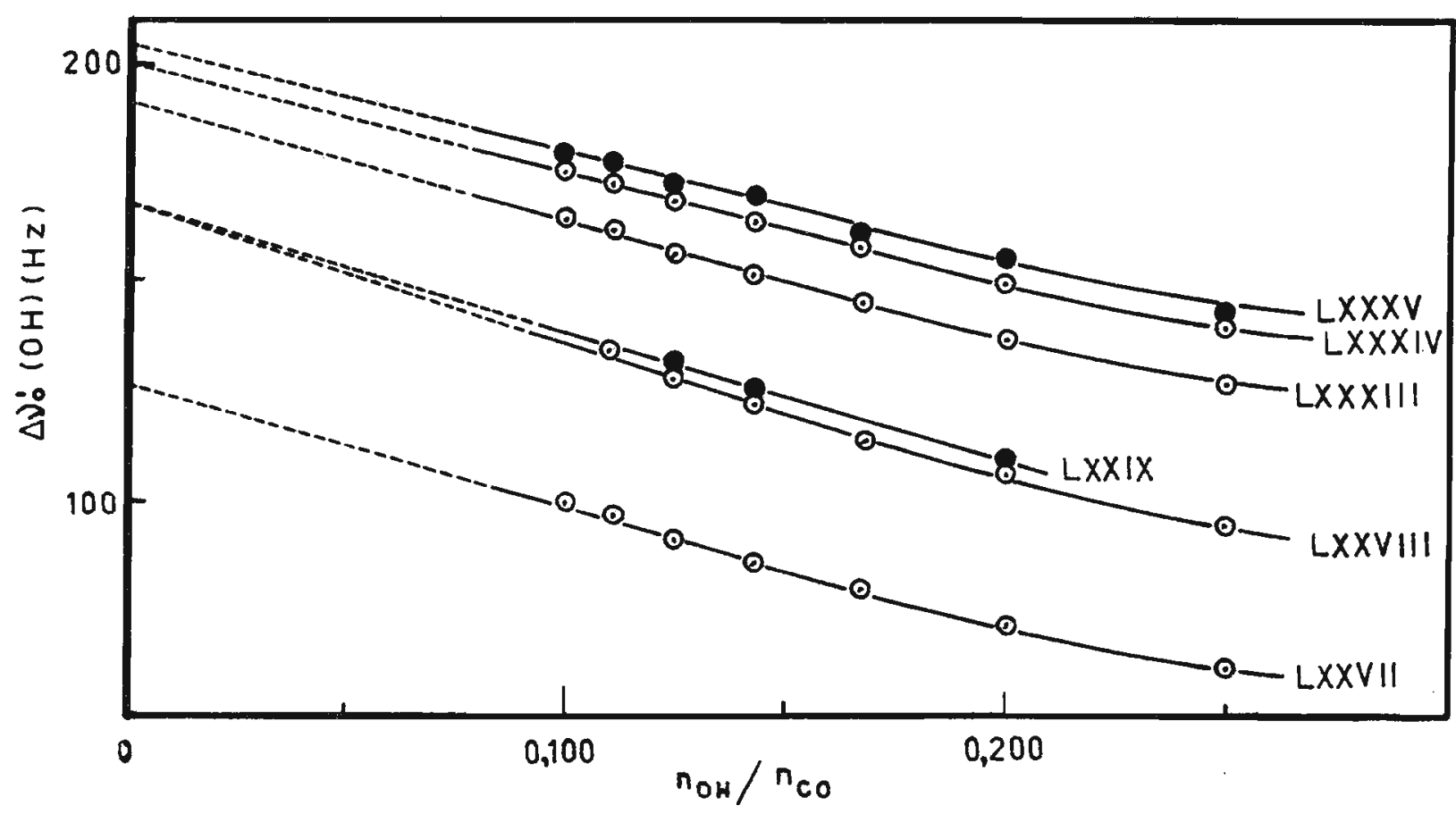

Figura 2 - Deslocamentos da ponte de hidrogênio vs. quocientes molares; sistema: p-clorofenol-aceptor de prōton, em $\mathrm{CCl}_{4}$.

Observa-se nas figuras 1 e 2 que, para cada sistema doador-aceptor, os valores de $\Delta v^{\prime} o$ aumentam à medida que aumenta a concentração de cetona (com a diminuição de $n_{O H} / n_{C O}$ ). Esta dependência entre valores de $\Delta v^{\prime} o$ e concentração de ceto na ē indicativa da existência de um equilíbrioemsolução equi 1 íbrio 1) que com aumento da concentração de cetona é desloca do para a direita.

$$
\begin{aligned}
& \text { doador }+ \text { aceptor complexo } \\
& \begin{array}{lll}
(H-X) & (Y) & (Y \cdots \cdots \cdots \cdot H-X)
\end{array}
\end{aligned}
$$

Assim, os valores limites de deslocamentos são obviamente alcançados em concentrações mais altas à medida que se aproxima da solução de doador de prōton em cetona lĩquida. Com os pontos em que as relações entre $\Delta v^{\prime} 0$ e $n_{0 H} / n_{C O}$ pareciam ser 1 ineares, foram calculadas as retas que melhor se ajustaram aos conjuntos de pontos apresentados. As 
extrapolaçöes das retas obtidas para $n_{O H} / n_{C O}=0$ forneceramos valores de $\Delta v$ agrupados na tabe 1 a 1 .

\section{$\underline{T A B E L A \quad 1}$}

Valores de $\Delta v$ para fenol e p-clorofenol associados com 3-tiaciclanonas e cetonas não substituĩdas correspondentes, em $\mathrm{CCl}_{4}$

\begin{tabular}{|c|c|c|c|}
\hline \multirow{2}{*}{ NO } & \multirow{2}{*}{ COMPOSTO } & \multicolumn{2}{|c|}{$\Delta v(H z)$} \\
\hline & & fenol & $p$-clorofenol \\
\hline LXXXIII & & 171 & 190 \\
\hline LXXVI I & & 107 & 126 \\
\hline LXXXIV & & 179 & 199 \\
\hline LXXVI I I & & 142 & 167 \\
\hline$L X X X V$ & & 185 & 203 \\
\hline$L X X I X$ & & 141 & 166 \\
\hline
\end{tabular}

A inspeção dos resultados da tabela 1 sugere que as tiaciclanonas contendo o atomo de enxofre ligado ao carbono $\alpha$, são menos bäsicas do que as anälogas não substituĩdas. Pode-se observar na figura 3 que hà concordāncia entre os resultados obtidos usando-se como doadores de prótons o fenol e o p-c1orofenol. 


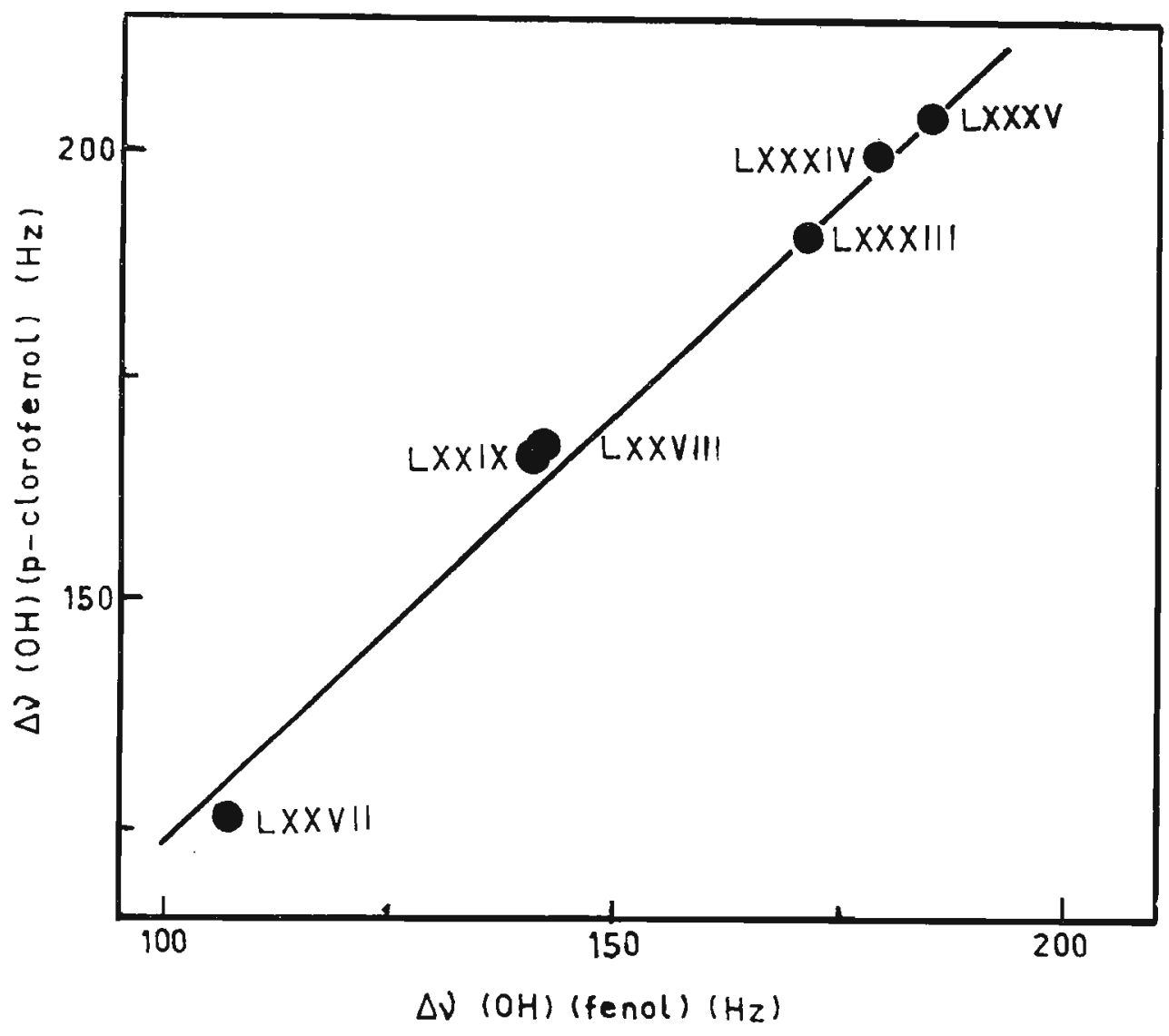

Figura $3-\Delta v$ do p-clorofenol vs. $\Delta v$ do fenol; sistema: doador-aceptor de próton, em $\mathrm{CCl}_{4}(r=0,995)$.

Considerou-se de interesse passar-se ao cälculo da constante de associação do sistema doador-aceptor de próton em tetracloreto de carbono, por dois mëtodos descritos na 1 iteratura, 33,106 já que os valores de k ass tambēm são usados pạ ra se estimar basicidade. 105 utilizando-se o primeiro mētodo, desenvolvido por Mathur e col., 106 correlacionaram-se os valo res de $1 / \Delta v^{\prime} 0$ com os de $1 /[C O]$. Foram calculadas as retas que melhor se ajustaram aos conjuntos de pontos detectados e os valores de kass, obtidos pelas relações entre seus coeficientes lineares e angulares (v. pag. 93), acham-se na tabela 2 . Empregando-se o segundo método, desenvolvido por carper $\varepsilon$ col., 33 foram correlacionados os valores de $\Delta v^{\prime} o /[c o]$ com os 
de $\Delta v^{\prime} O$. Calcularam-se as retas que se ajustaram aos conjuntos de pontos apresentados e os valores de kass, extraídos d $\underline{j}$ retamente de seus coeficientes angulares (v.pag. 93), encontram -se na tabe $1 a 2$.

\section{TABELA 2}

Valores de kass para fenol e p-clorofenol associados com 3-tia ciclanonas e cetonas não substituĩdas correspondentes, em $\mathrm{CCl}_{4}$

\begin{tabular}{|c|c|c|c|c|c|}
\hline \multirow{3}{*}{ No } & \multirow{3}{*}{ Compos to } & \multicolumn{4}{|c|}{$k_{\text {ass }}\left(M^{-1}\right)$} \\
\hline & & Métoc & o de Mathur & Mëto & o de Carper \\
\hline & & fenol & $p-c 10$ rofenol & fenol & $p$-clorofenol \\
\hline LXXX I I I & & 8,6 & 14,4 & 8,7 & 14,3 \\
\hline LXXVII & & 3,2 & 4,6 & 3,7 & 5,0 \\
\hline LXXXIV & & 10,6 & 17,3 & 10,6 & 17,3 \\
\hline LXXVI I I & & 4,6 & 7,3 & 4,7 & 7,3 \\
\hline LXXXV & & 10,7 & 17,4 & 11,1 & 17,7 \\
\hline LXXIX & & 5,5 & - & 5,6 & - \\
\hline
\end{tabular}

Deixou-se de calcular a constante de associaçäo do sistema p-clorofenol-3-tiacicloheptanona devido aos poucos pon tos disponĩveis.

Pode-se observar na figura 4 que hä concordāncia en tre os valores de $k_{\text {ass }}$ usando-se fenol e p-clorofenol comodoa dores de prötons. 
48.

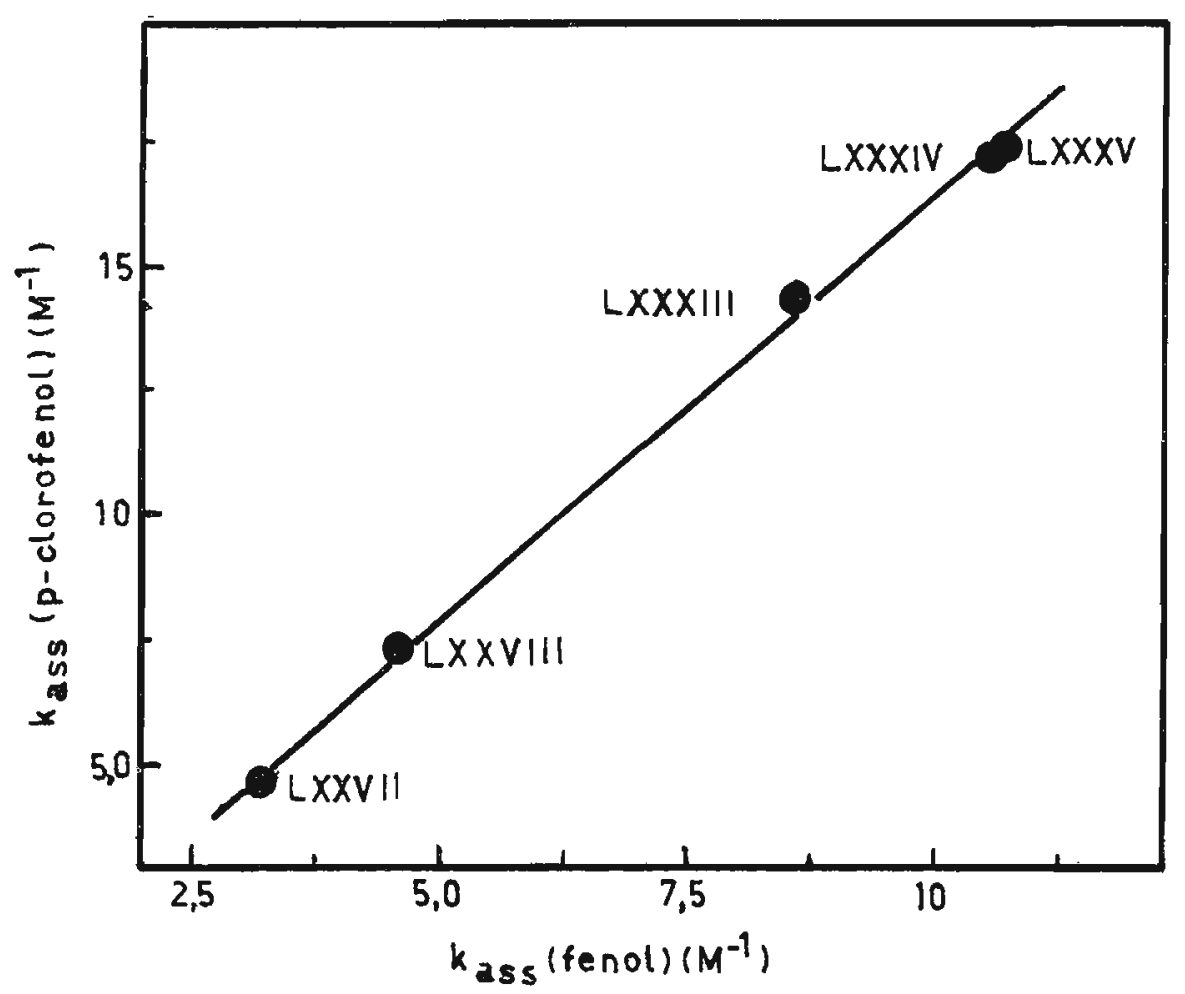

Figura 4 - kass de p-clorofenol-ciclanonas vs. kass de fenol-ciclanonas (método de Mathur); solvente: $\mathrm{CCl}_{4}(r=0,999)$.

Os valores de kass (tabela 2) confirmam os de $\Delta v$ (tabela 1), indicando que as ciclanonas tiasubstituĩdas são me nos bāsicas do que as não substituĩdas.

os estudos de espectros no ultravioleta ${ }^{54}$ e de redu ções polarogräficas ${ }^{75}$ sugeriram a possibilidade de tiaciclano nas contendo o ätomo de enxofre ligado ao carbono $\beta$, apresentarem tambēm interaçöes entre enxofre e carbonila. Em vista disso, julgou-se interessante efetuarem-se as medidas de bas $\underline{i}$ cidade de tais cetonas. Escolheram-se para este fim dois com postos: 4-tiaciclohexanona $(L X X X)$ (exp. no 9, pag.108) e 4-tia cicloheptanona (LXXXI) (exp. no 10, pag.109) jä que estes poderiam ser comparados com as cetonas não substituĩdas jä estụ 
dadas: ciclohexanona (LXXXIV) e cicloheptanona ( $X X X X V$ ). As cor relações entre $\Delta \nu^{\prime} O$ e $n_{O H} / n_{C O}$ pelo emprego de fenol e p-clorofenol podem ser apreciadas nas figuras 5 e 6 . Os valores de Iv, obtidos pelas extrapolações das retascalculadas para ${ }^{\mathrm{OH}_{\mathrm{H}}} / \mathrm{n}_{\mathrm{CO}}=0$, acham-se na tabela 3 .

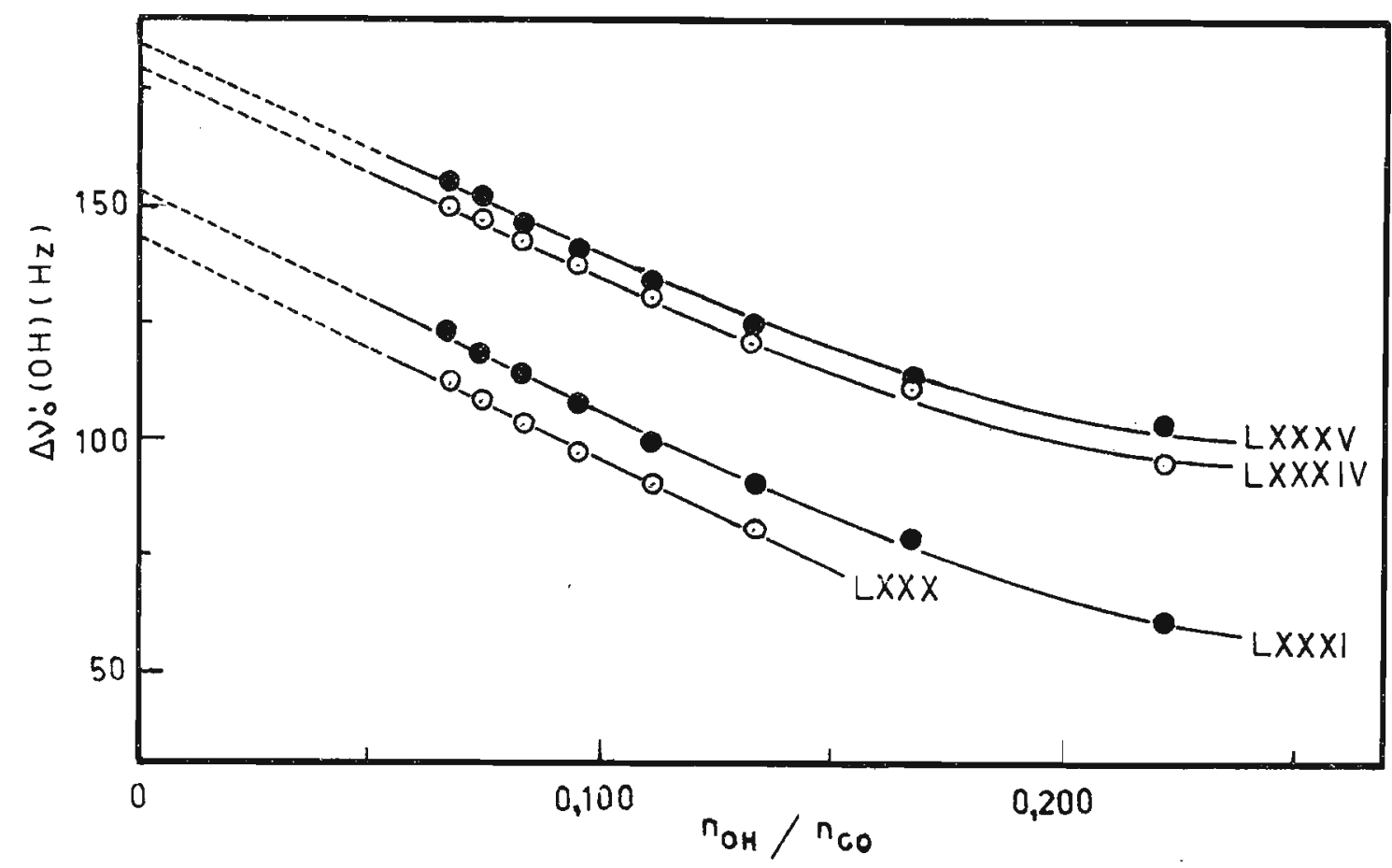

Figura 5 - Deslocamentos da ponte de hidrogēnio vs. quocien tes molares; sistema: fenol-aceptor de próton, em $\mathrm{CCl}_{4}$.

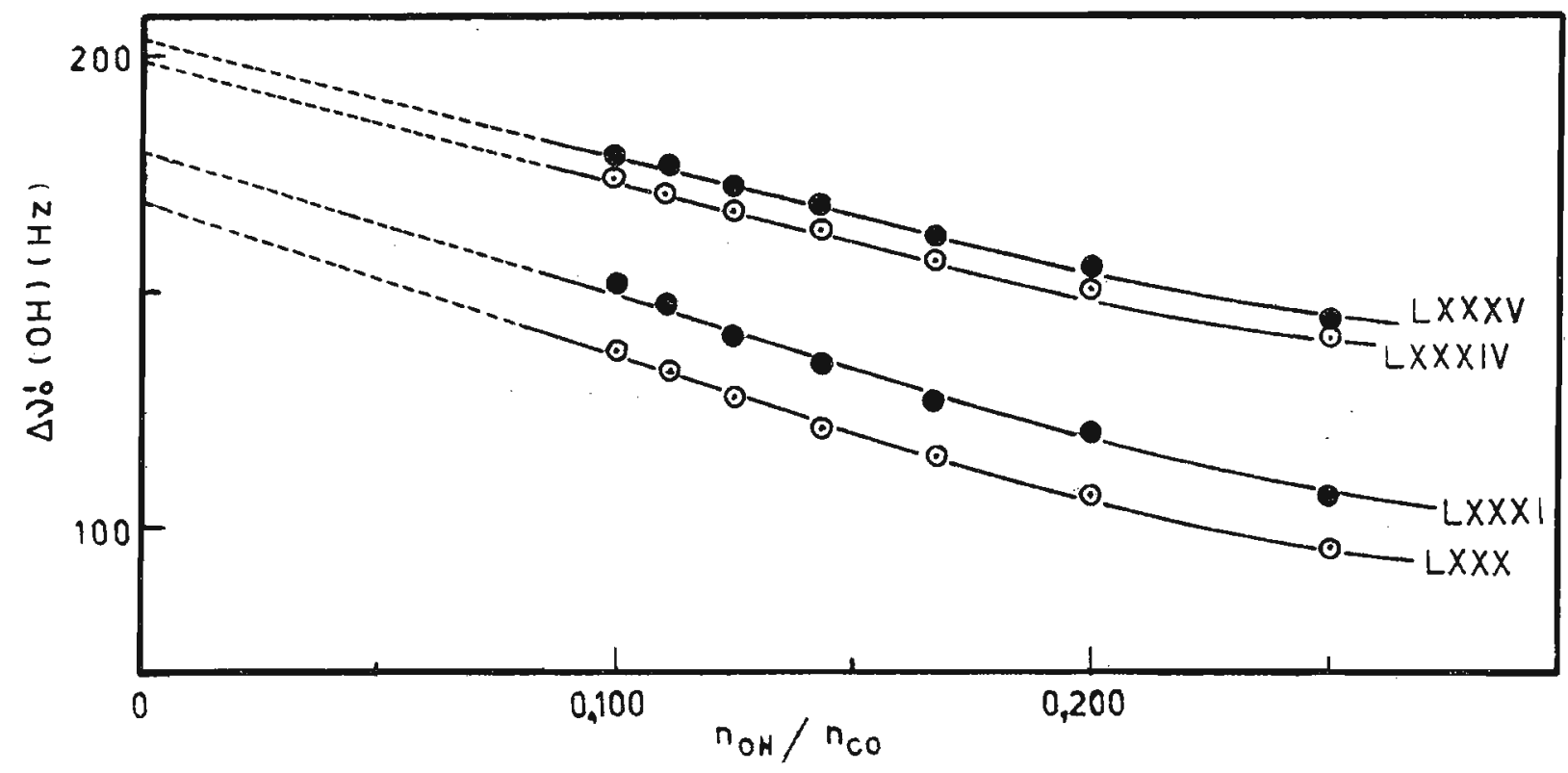

Figura 6 - Deslocamentos da ponte de hidrogēnio vs. quocien tes molares; sistema: p-clorofenol-aceptor de prōton, em $\mathrm{CCl}_{4}$. 


\section{TABELA 3}

Valores de $\Delta v$ para fenol e p-clorofenol associados com 4-tiaciclanonas e cetonas não substituidas correspondentes, em $\mathrm{CCl}_{4}$

\begin{tabular}{|c|c|c|c|}
\hline \multirow{2}{*}{ NO } & \multirow{2}{*}{ Composto } & \multicolumn{2}{|c|}{$\Delta v(H z)$} \\
\hline & & fenol & $p$-clorofenol \\
\hline LXXXIV & & 179 & 199 \\
\hline $\operatorname{LXXX}$ & & 143 & 172 \\
\hline$L X X X V$ & & 185 & 203 \\
\hline$L X X X I$ & & 153 & 179 \\
\hline
\end{tabular}

Procedeu-se tambēm neste caso ao cālculo das constantes de associação do sistema doador-aceptor de prōton, em tetracloreto de carbono, pelos mëtodos de Mathur e col. ${ }^{106}$ e de carper e col. ${ }^{33}$ os valores obtidos de $k$ ass encontram-se na tabela 4. 


\section{TABELA 4}

Valores de kass para fenol e p-clorofenol associados com 4-tia ciclanonas e cetonas não substituĩdas correspondentes, em $\mathrm{CCl}_{4}$

\begin{tabular}{|c|c|c|c|c|c|}
\hline \multirow[t]{2}{*}{ No } & \multirow[t]{2}{*}{ Composto } & Métod & de Mathur & Méto & o de Carper \\
\hline & & fenol & $p$-clorofenol & fenol & $p$-clorofenol \\
\hline LXXXIV & & 10,6 & 17,3 & 10,6 & 17,3 \\
\hline$L X X X$ & & 5,6 & 8,5 & 5,7 & 8,4 \\
\hline$L X X X V$ & & 10,7 & 17,4 & 11,1 & 17,7 \\
\hline$L X X X I$ & & 5,2 & 8,8 & 5,3 & 8,3 \\
\hline
\end{tabular}

Os resultados de $\Delta v$ (tabela 3) e de kass (tabela 4) demonstram que as tiaciclanonas contendo o ätomo de enxofre ligado ao carbono $B(L X X X, L X X X I)$ possuem as basicidades do grupo carbonila diminuídas quando comparadas com as de cetonas correspondentes não substituĩdas ( $X X X I V, L X X X V$ ). Surpreen centemente, estas diminuições de basicidade são quase da mesma ordem daquelas observadas em tiaciclanonas contendo o enxo fre 1 igado ao carbono a (tabelas 1 e 2 ).

Em vista disso, nos pareceu importante verificar se ainda haveria alguma alteração da basicidade do grupo carbonila numa tiaciclanona em que o ätomo de enxofre e o grupo carbonila fossem separados por trēs grupos metilênicos. A 5-tiaciclooctanona (LXXIII) seria um composto mais apropriado 
para este estudo, pois, conforme jä mencionado no capittulo an terior (pag. 35), Leonard e col.91,95 sugeriram nesta tiaciclanona (LXXIII) uma interação do tipo transanular, com trans ferência de carga do enxofre para o grupo carbonila. Tal inte ração deveria causar um aumento de sua basicidade em relação à anāloga não substituĩda, o que seria conträrio aos resultados verificados em tiaciclanonas contendo o ätomo de enxofre ligado ao carbono a ou ao $\beta$, por nös estudadas. Se realmente fossem confirmadas tais espectativas, não somente seria dada mais uma evidēncia para tal transferēncia de carga, como tambēm terĩamos uma indicação da ocorrência de uma interação diferente nas tiaciclanonas (LXXVII-LXXXI) por nōs estudadas.

Passou-se então, ao estudo das basicidades comparativas da ciclooctanona (LXXXVI) (exp. no 11, pag.111) e da 5-tiaciclooctanona (LXXIII) (exp. no 12, pag.112). As curvas de $\Delta v^{\prime} O$ em função de $n_{O H} / n_{C O}$ usando-se fenol e p-clorofenol, acham-se nas figuras 7 e 8 e os valores de $\Delta v$, na tabela 5.

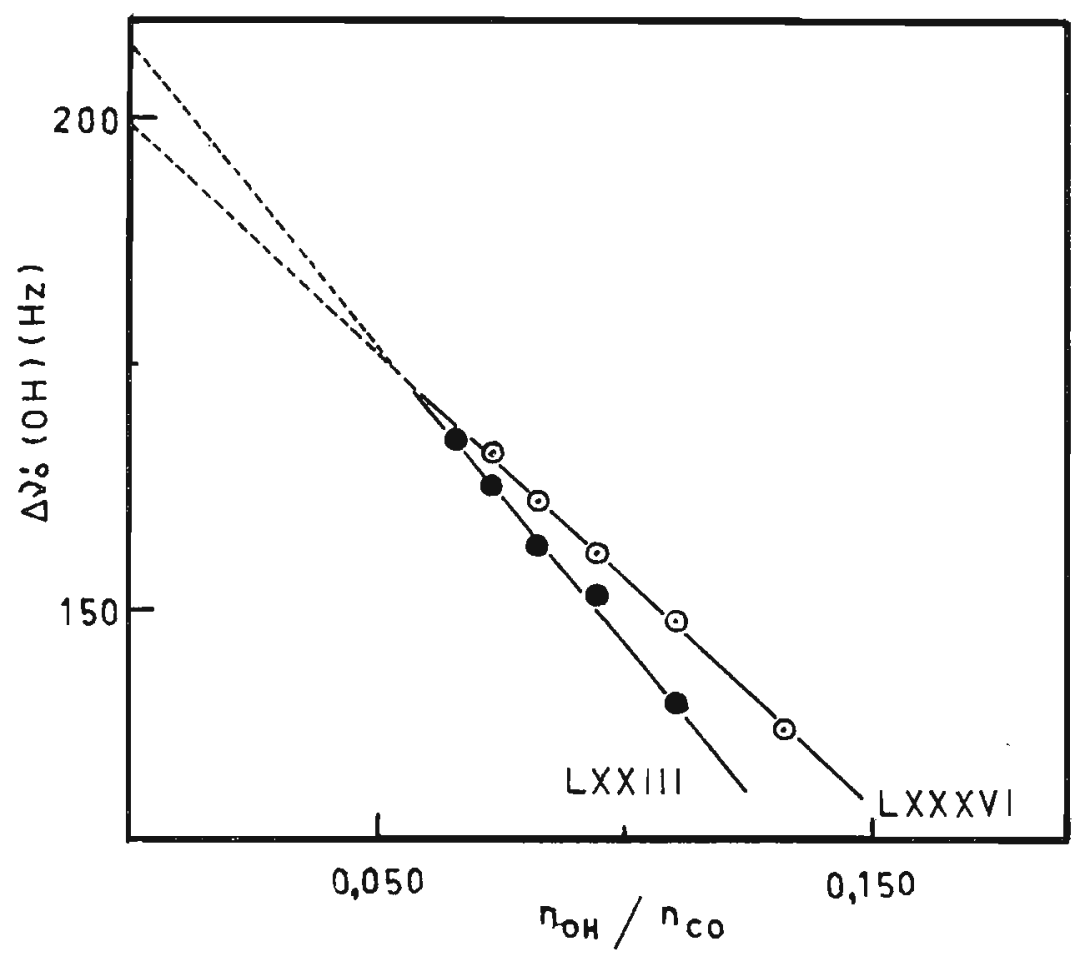

Figura 7 - Deslocamentos da ponte de hidrogēnio vs. quocientes molares: sistema: fenol-aceptor de prōton, em $\mathrm{CCl}_{4}$. 


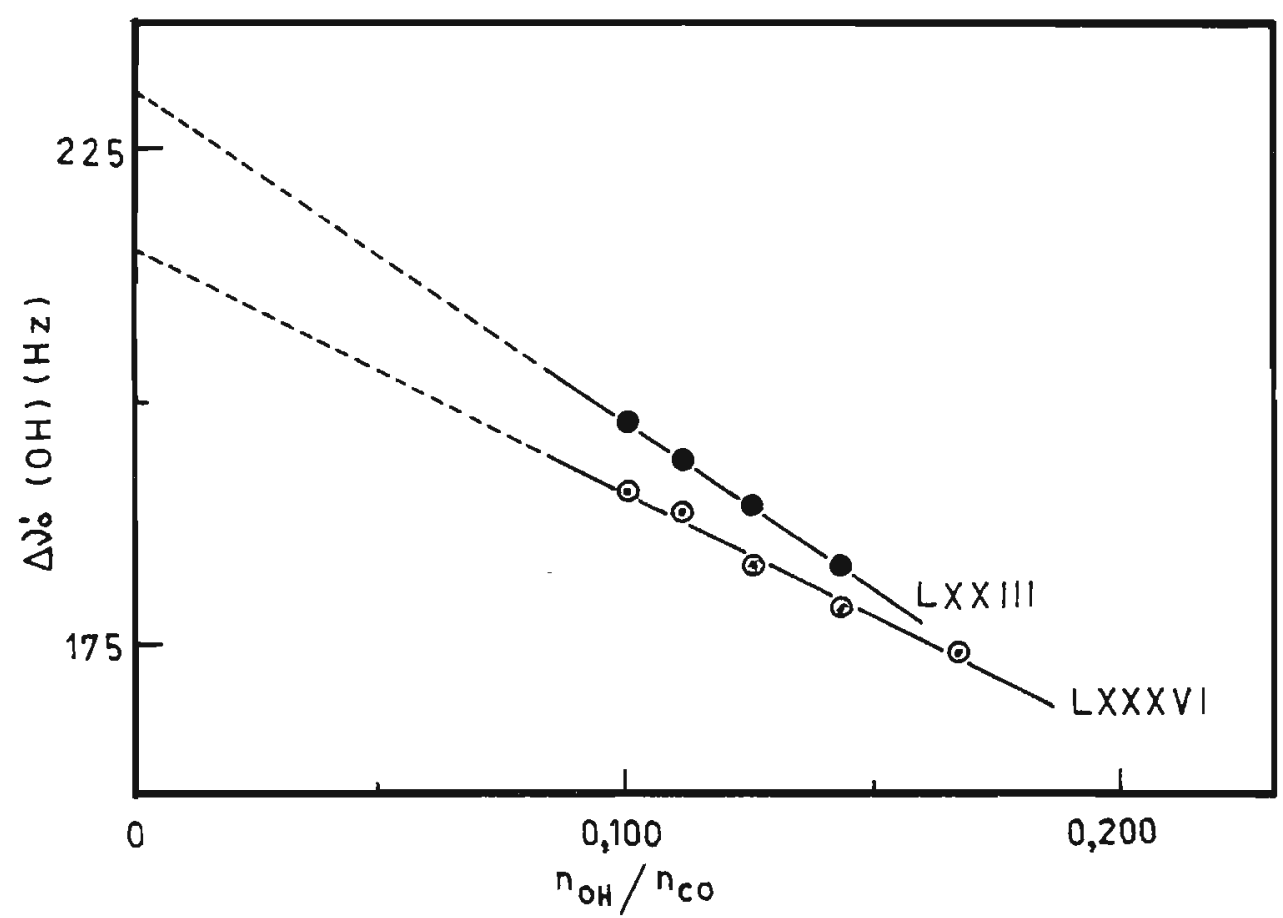

Figura 8 - Deslocamentos da ponte de hidrogênio vs. quocientes molares; sistema: p-clorofenol-aceptor de próton, em $\mathrm{CC}_{4}$.

\section{TABELA 5}

Valores de $\Delta v$ para fenol e p-clorofenol associados com ciclooctanona e 5-tiaciclooctanona, em $\mathrm{CCl}_{4}$

\begin{tabular}{lccc}
\hline & & \multicolumn{2}{c}{$\Delta v(\mathrm{~Hz})$} \\
\cline { 3 - 4 } & Composto & fenol & $\mathrm{p}$-clorofenol \\
LXXXVI & SXI & 198 & 215 \\
& Sor & 207 & 231 \\
\hline
\end{tabular}

os resultados realmente indicam um aumento de $\Delta v$ da 5-tiaciclooctanona (LXXIII) em relação ao da ciclooctanona ( LXXXVI). 
Para se poder avaliar as grandezas das diminuições de basicidade nos sistemas cíclicos e comparä-las com as dos aciclicos, tornou-se necessärio repetir as medidas em $\alpha-a 1-$ quiltiocetonas 165,168 nas condições experimentais por nös empregadas e efetuar as medidas com cetonas contendo o grupo a quiltio em posições mais afastadas do grupo carbonila. Procedeu-se então às medidas de basicidades comparativas de 2-pentanona (LXXXVII) (exp. nọ 13, pag. 113), 2-heptanona (LXXXVIII) (exp. nọ 14, pag. 114), 2-octanona (LXXXIX) (exp. no 15, pag.116), 2-undecanona (XC) (exp. nọ 16, pag.117), metiltioacetona (XCI) (exp. nọ 17, pag.119), etiltioacetona (LXXIV) (exp. nọ 18, pag.120), 4-etj1tio-2-butanona (XCII) (exp. no 19, pag.122), 5-eti1tio-2-pentanona (XCIII) (exp. no 20, pag.123) e 6-eti1tio-2-hexanona (XCIV) (exp. no 21, pag. 125). Pode-se observar as curvas de $\Delta \nu^{\prime} O$ em função de, $n_{O H} / n_{C O}$ nas figuras 9 e 10 .

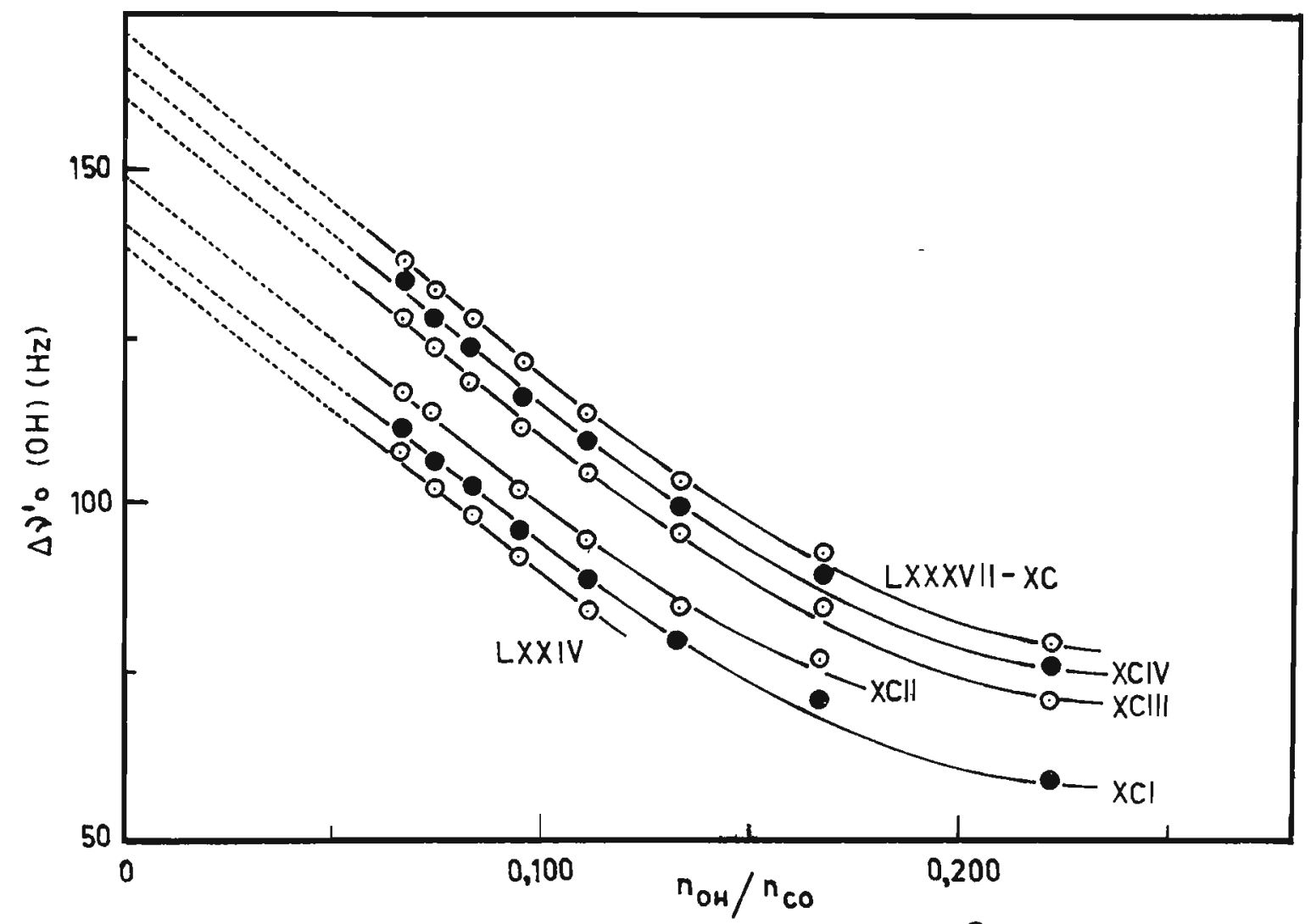

Figura 9 - Deslocamentos da ponte de hidrogēnio vs. quocientes molares; sistema: fenol-aceptor de próton, em $\mathrm{CCl}_{4}$. 


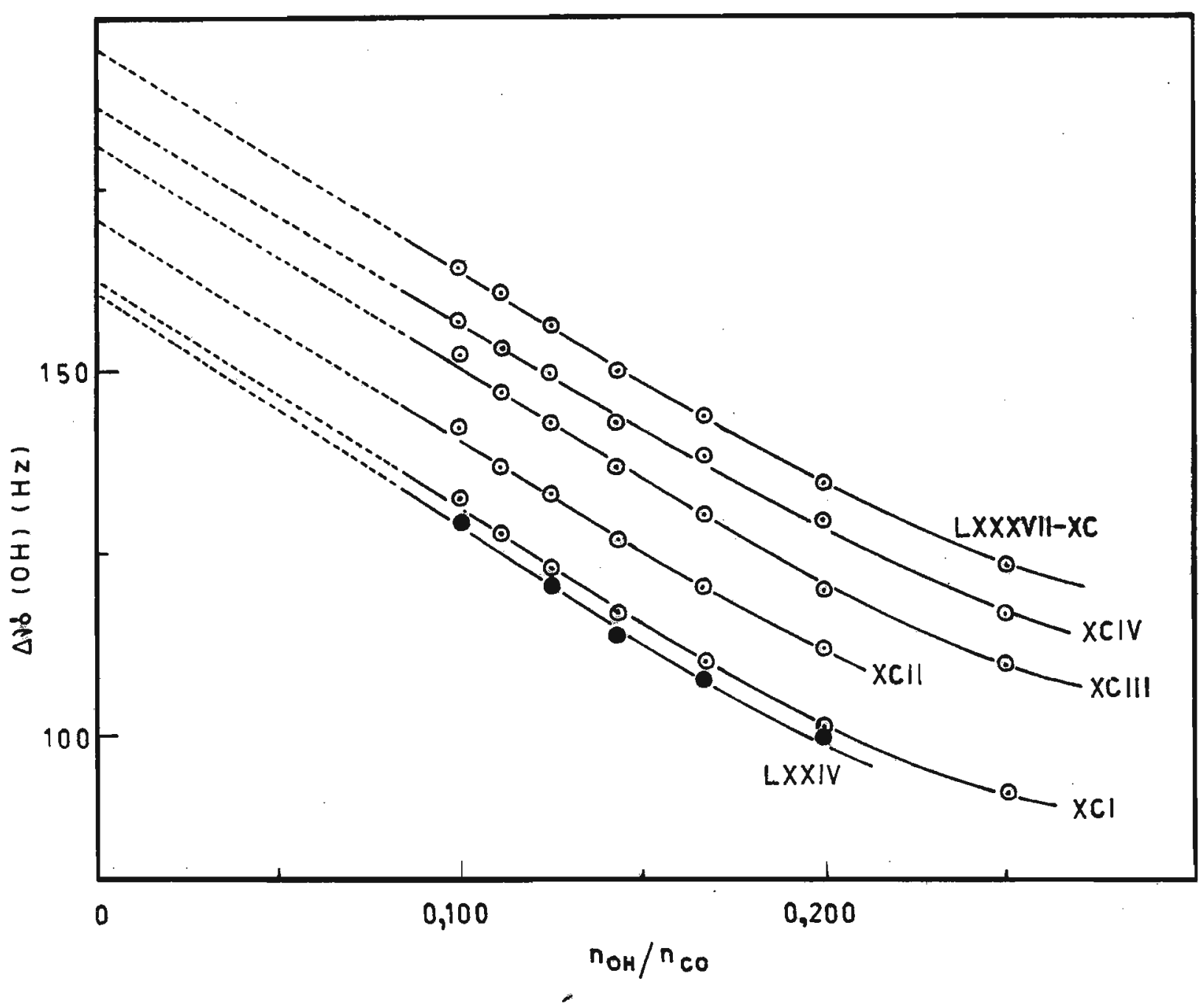

Figura 10 - Deslocamentos da ponte de hidrogénio vs. quocientes molares; sistema: p-clorofenol-aceptor de próton, em $\mathrm{CCl}_{4}$.

As extrapolações para $n_{O H} / n_{C O}=0$ das retas calculadas, forneceram os valores de $\Delta v$ agrupados na tabela 6 . A figura 11 indica que existe uma boa correlação entre os valores de $\Delta v$, pelo emprego de fenol e p-clorofenol. 
56.

TABELA 6

Valores de $\Delta u$ para fenol e p-clorofenol associados com alquiltio-cetonas e cetonas não substituĩdas, em $\mathrm{CCl}_{4}$

\begin{tabular}{|c|c|c|c|}
\hline \multirow{2}{*}{ No } & \multirow{2}{*}{ Composto } & \multicolumn{2}{|c|}{$\Delta v(H z)$} \\
\hline & & fenol & $p-c l o r o f e n o l$ \\
\hline$L X X X V I I$ & & 171 & 188 \\
\hline LXXXVI I I & & 173 & 192 \\
\hline LXXXIX & & 175 & 194 \\
\hline$x C$ & & 176 & 197 \\
\hline$X C I$ & & 141 & 162 \\
\hline LXXIV & & 139 & 161 \\
\hline XCI I & & 151 & 170 \\
\hline$X C I I I$ & & 163 & 181 \\
\hline$X C I V$ & & 164 & 184 \\
\hline
\end{tabular}


57 .

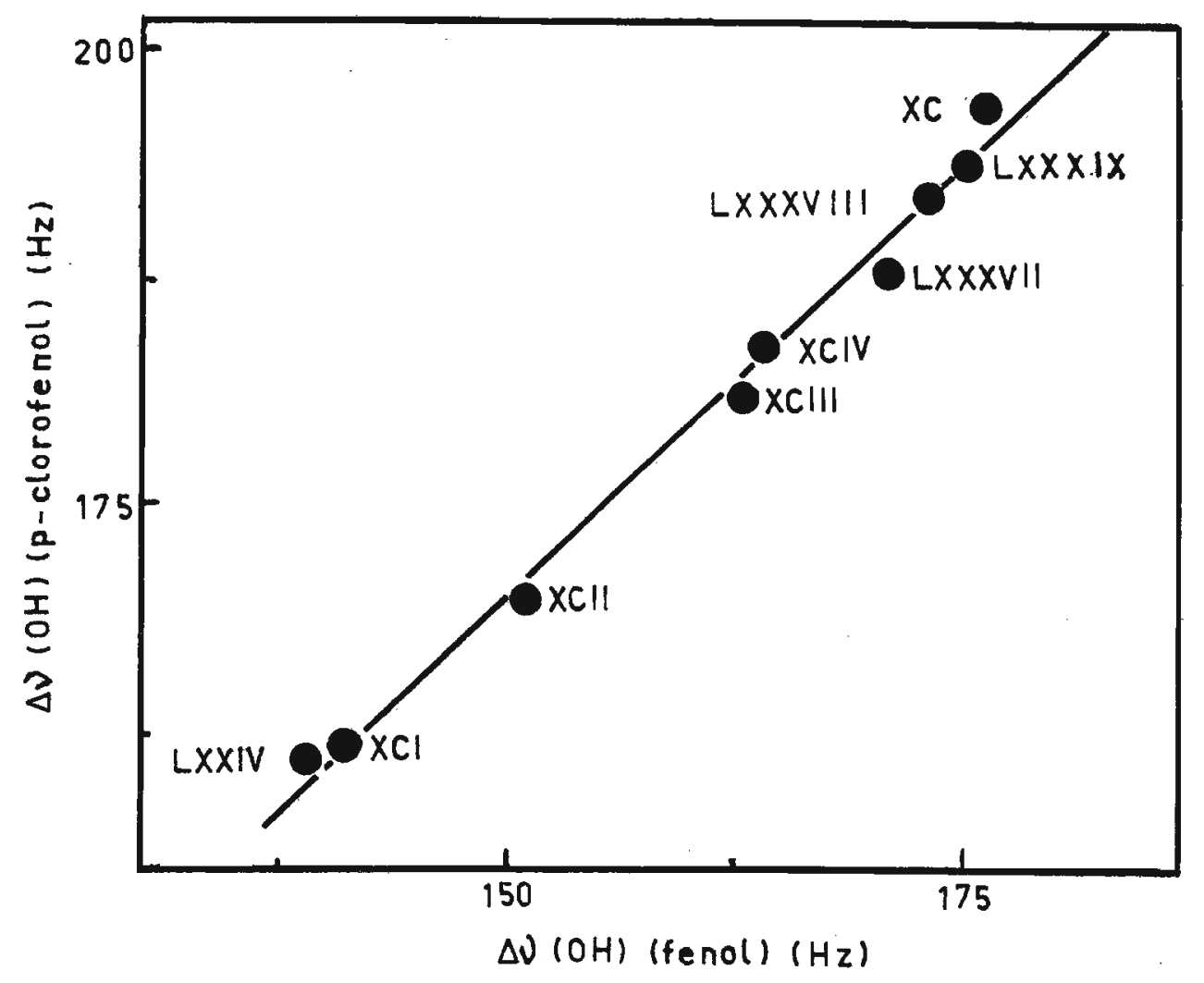

Figura 11 - Deslocamentos da ponte de hidrogēnio à dilui ção infinita do $p-c l o r o f e n o l$ vs. deslocamentos da ponte de hidrogênio à diluição infinita do fenol; sistema: doador-aceptor de próton, em $\mathrm{CCl}_{4}(r=0.993)$.

As constantes de associação ( $\left.K_{a s s}\right)$ dos sistemas fenol-e p-clorofenol-cetonas alifáticas acíclicas, em tetraclo reto de carbono, obtidas pelos mētodos de Mathur e col. ${ }^{106}$ e de Carper e col., 33 acham-se na tabela 7 e a correlação entre os valores de kass na figura 12 . 


\section{TABELA 7}

Valores de $k$ aśs parafenol e p-clorofenol associados com alquiltio-cetonas e cetonas não substituídas, em $\mathrm{CCl}_{4}$

$$
\mathrm{k}_{\text {ass }}\left(M^{-1}\right)
$$

Nọ

Composto Método de Mathur Mëtodo de Carper

fenol p-clorofenol fenol $p$-clorofenol

$L X X X V I I$

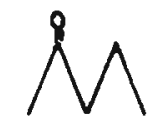

7,4 .

11,2

7,3

$11 ; 1$

LXXXVIII $\bigwedge$

7,4

11,4

7,4

11,4

LXXXIX

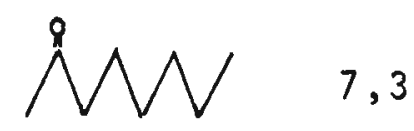

11,6

7,3

11,7

$x c$

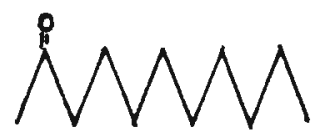

7,4

11,4

7,3

11,4

$X C I$

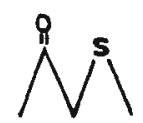

5,3

7,3

5,3

7,4

LXXIV

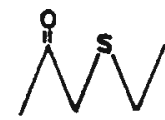

5,7

8,3

5,9

8,1

$X C I I$

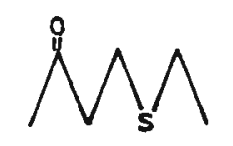

5,8

8,8

5,7

8,8

XCIII

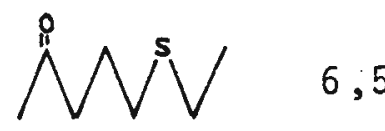

6,5

9,5

6,5

9,4

XCIV

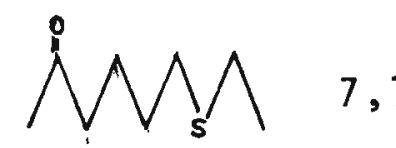

10,8

7,1

10,9 
59.

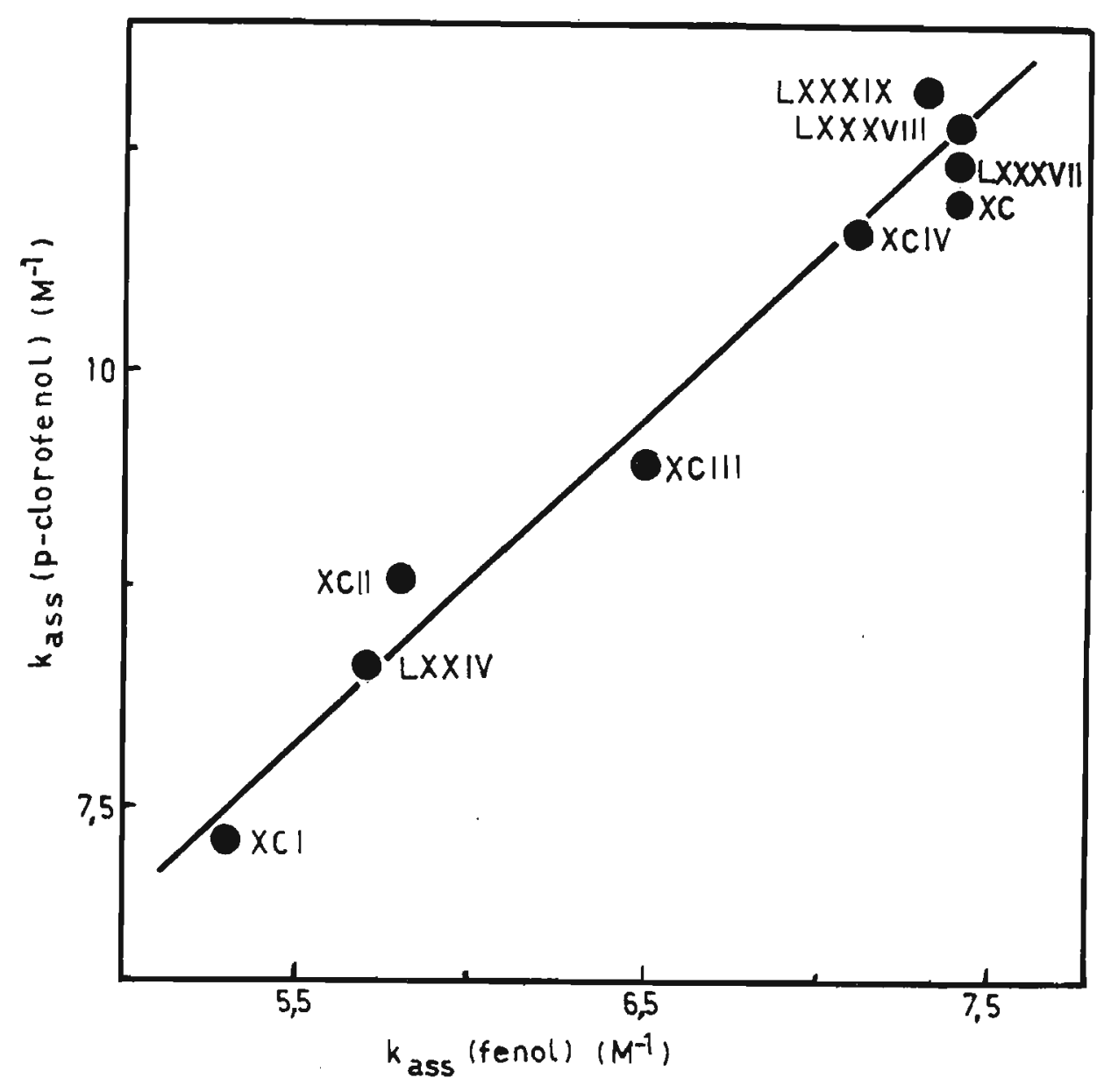

Figura 12 - kass de p-clorofenol-cetonas alifäticas vs. kass de fenol-cetonas alifäticas (mētodo de Mathur); solvente: $\mathrm{CCl}_{4}(r=0,990)$.

A inspeção dos resultados das tabelas 6 e 7 sugere que as cetonas alifáticas acíclicas contendo os grupos alquiltio ligados aos carbonos $\alpha, \beta$ e $\gamma$ são menos básicas do que as anālogas não substituĩdas.

A comparação entre os valores de $\Delta \nu$ e de kass dos sistemas doador de prōton-ciclanonas (tabelas 1-4) com os das cetonas aciclicas (tabelas 6 e 7 ) indica que as tiaciclanonas contendo os átomos de enxofre ligados aos carbonos $\alpha$ e $B$ demonstram maior diminuição de basicidade em relação às não subs 
60.

tituîdas do que as alifäticas acíclicas.

outro ponto importante a destacar é que enquanto a 5-tiaciclooctanona (LXXIII) que contēm o àtomo de enxofre $1 i$ gado ao carbono y possui o valor de $\Delta v$ major do que o da ciclooctanona (LXXXVI)(tabela 5), a anāloga acíclica (XCIII) apre senta diminuição do valor de $\Delta \nu$ em relação à não substituída $(L X X X I X)($ tabela 6$)$.

\subsection{DISCUSSAO DOS RESULTADOS DE MEDIDAS DE BASICIDADE}

Os resultados obtidos pelo emprego de dois doadores de prötons (fenol e p-clorofenol), indicaram que as cetonas contendo o ätomo de enxofre ligado ao carbono $\alpha$ ou $\beta$, possuem menor habilidade para a formação de ponte de hidrogênio do que as correspondentes não substituídas, tanto na série cî́clica (tabelas 1, pag. 45, 2, pag. 47, 3, pag.50 e 4, pag.51), como na sërie acíclica (tabelas 6, pag.56 e 7, pag. 58). Assim, os nossos resultados confirmam os anteriormente obtidos por Wladislaw e col., 165,168 em a-alquiltiocetonas, em sistemas binärios (fenol-cetona).

Os resultados experimentais não eliminavam, entretanto, a possibilidade de uma competição na complexação com o doador de prōton, entre o ātomo de enxofre e o grupo carboni1a. Esta hipōtese é, porēm, por nós agora rejeitada, devido aos seguintes fatos experimentais:

1 - A basicidade do tetrahidrotiofeno (XCV) (exp. no 22, pag. 126) nas condiçöes por nós empregadas, mostrou-se baixa e, aliās, bem menor do que a da ciclopentanona (LXXXIII)(figura 13 e tabela 8). Convēm ressaltar que numa tiacetona, a basicidade do enxofre deve ser ainda mais diminuida de- 
vido ao efeito indutivo da carbonila.

2 - A basicidade de uma mistura equimolar de tetrahidrotiofeno (XCV) e de ciclopentanona (LXXXIII) (exp. no 23, pag.127) mostrou-se semelhante à da ciclopentanona (LXXXIII)(figura 13 e tabela 8 ).

Pode-se, portanto, concluir que as basicidades observadas nas tiacetonas relacionam-se com o grupo carbonila, ou, mais precisamente, com os elētrons $n$ dooxigênio, 122 não havendo competição na complexação.

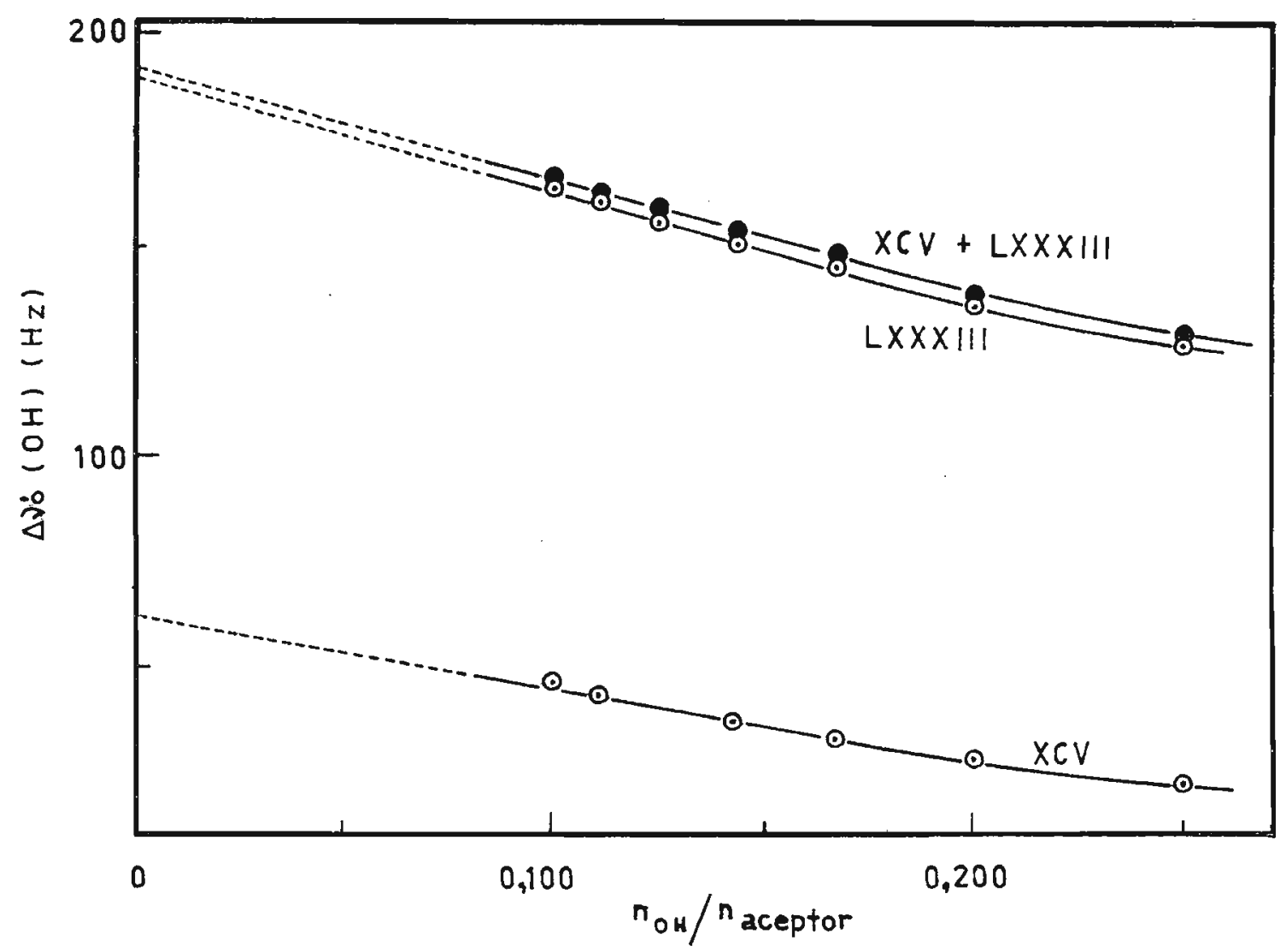

Figura 13 - Deslocamentos da ponte de hidrogēnio vs. quocien tes molares; sistema: p-clorofenol-aceptor de pröton, em $\mathrm{CCl}_{4}$. 


\section{TABELA 8}

Valores de $\Delta \nu$ e de $k_{\text {ass }}$ para $p-c l o r o f e n o l$ associado com tetrahidrotiofeno, ciclopentanona e mistura de ambos, em $\mathrm{CCl}_{4}$

\begin{tabular}{|c|c|c|c|c|}
\hline \multirow{2}{*}{ No } & \multirow{2}{*}{ Composto } & \multirow{2}{*}{$\Delta v(H z)$} & \multicolumn{2}{|c|}{$k_{\text {ass }}\left(M^{-1}\right)$} \\
\hline & & & Met.Mathur & Met.Carper \\
\hline$X C V$ & & 62 & 0,7 & 0,9 \\
\hline LXXXIII & & 190 & 14,4 & 14,3 \\
\hline$L X X X I I I+X C V$ & & 192 & 14,1 & 14,1 \\
\hline
\end{tabular}

Os nossos resultados de basicidade na sërie de ciclanonas não substituídas (tabelas 1 , pag.45 e 2, pag.47) in dicam uma ordem de basicidade anāloga à descrita na literatu$r a^{6,32}$ (ciclopentanona < ciclohexanona cicloheptanona). A di minuição de basicidade da ciclopentanona (LXXXIII) em relação à ciclohexanona ( $L X X X I V)$ e à cicloheptanona ( $L X X X V)$ foi atribuĩda por Arnett e col. ${ }^{6}$ à tensão existente no anel pentagona1. Embora a substituição de um grupo metilena por um ätomo de enxofre deva diminuir a tensão eclípsica entre hidrogénios adjacentes, 43,49 pensamos que a diminuição de basicidade das tiaciclanonas em relação às ciclanonas, talvez fosse devida $\bar{a}$ tensäo no ane 1 , resultante da modificação dos ângulos entre as ligações. A confirmaçăo ou exclusão de tal possibilidade pode ria ser fornecida pelas medidas das frequências de estiramento da carbonila destes compostos. Caso a introdução do átomo 
de enxofre causasse um aumento da tensão do anel, dever-se-ia esperar, nas tiaciclanonas, um aumento considerāvel da frequéncia de estiramento da carbonila. ${ }^{12}$ As medidas efetuadas por Buzzi 28,30 indicaram, entretanto, que enquanto as frequên cias da 3-tiaciclohexanona (LXXVIII) e a da 3-tiacicloheptano na (LXXIX) não mostraram alterações significativas em relação às ciclanonas correspondentes não substituīdas, a frequência de estiramento da carbonila da 3-tiaciclopentanona $(L X X V I I)$ mostrou-se menor do que a da ciclopentanona (LXXXIII). Estes resultados parecem indicar que, embora a existéncia da tensão não possa ser completamente eliminada, ela não pode ser o ünico fator responsāvel pela diminuição de basicidade em tiaciclanonas.

Comparando-se as propriedades doadoras de tiacetonas cíclicas (tabelas 1, pag.45 e 2, pag.47) com as acíclicas (tabelas 6 , pag.56 e 7 , pag.58), observa-se que as diminuições de basicidade sofridas pelas tiacetonas cíclicas, onde hä restrição da liberdade rotacional, são bem maiores do que nas acíclicas. Alēm disso, dentro da sërie cíclica, constatam-se diferenças de diminuição de basicidade, sendo a mais significativa a do anel pentagonal, onde a inspeção de modelos moleculares demonstra a menor liberdade rotacional. Estes resulta dos parecem indicar que tais diminuições de basicidade possuem dependēncia conformacional. Em vista disso, houve a necessidade do estudo em sistema de conformação rígida. Assim, nossa atenção recaiu sobre a 9 -tiabiciclo $(3,3,1)$-2-nonanona(C). A impossibilidade de hidrogenação da dupla olefínica de sua precursora, a 9-tiabiciclo(3,3,1)-6-nonen-2-ona (XCIX)(v.pag. 85), eliminou, entretanto, a viabilidade de tal estudo. 
Conforme jā foi mencionado (pag. 38), Wladislaw e co1. 165,168 aventaram a hipōtese da diminuição da basicidade em a-alquiltiocetona ser devida ao impedimentoestērico à apro ximação do doador de próton. Entretanto, os mesmos autores, 51,164 posteriormente, forneceram provas experimentais in dicativas da ausēncia de tal impedimento, ao verificarem que a introdução de um àtomo de enxofre no carbono $\alpha$, emnitrilas, também provocou a diminuição de basicidade. As diminuições das propriedades doadoras por nōs encontradas em compostos cÍ clicos, onde hā ausēncia de tal impedimento estērico, 78 elimi nam definitivamente essa hipōtese.

Outra causa da diminuição de basicidade poderia ser o efeito indutivo proveniente da substituição de um grupo metilénico por um ätomo de enxofre. Pareceu-nos que um argumento contra ou a favor desta suposição seria fornecido comoestudo de cetonas contendo o àtomo de oxigênio ligado ao carbono a. A comparação dos potenciais de ionização de um ditioēter e um diēter com os de um tioēter e um éter cíclicos, 146 (esquema 16) permite avaliar os efeitos indutivos de oxigênio e de enxofre. Pode-se ver que, enquanto o efeito indutivo do enxofre causa uma estabilização do nĩvel de energia médio dos orbitais $n_{s}$ interagentes ( $v$. pag. 13) de apenas $0,30 \mathrm{eV}, \quad 0$ efeito indutivo do oxigênio causa uma estabilização de 0,73 ev no nîvel de energia médio dos orbitais $n_{0}$. A substituição de um grupo meticênico por um ätomo de oxigênio na posição 3 de Lima cetona deveria, portanto, diminuir a basicidade do grupo carbonila em maior grau do que a substituição por enxofre. Os resultados de medida de basicidade da 3-oxaciclopentanona(XCVI) (exp. no 24, pag.128) e da metoxiacetona (XCVII) (exp. nọ 25, 
pag.130) (figura 14 e tabelas 9 e 10), comparadas com as de 3-tiaciclopentanona (LXXVII) e metiltioacetona (XCI) (tabelas 9 e 10), respectivamente, demonstram, entretanto, que os tiaderivados são menos bāsicos do que os oxa-anālogos. Esta ordem é conträria a do efeito indutivo.

\section{ESQUEMA 16}
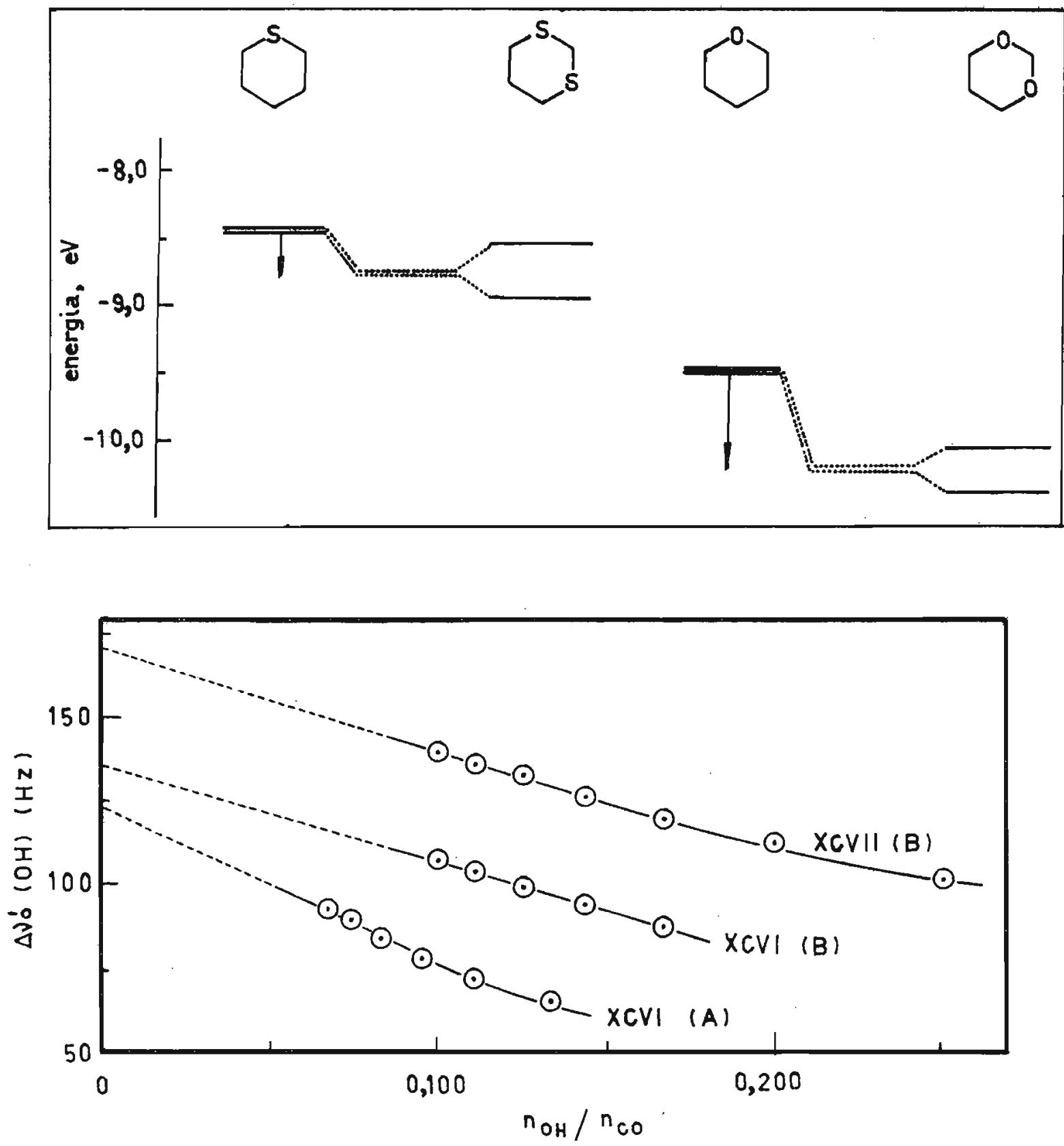

Figura 14 - Deslocamento da ponte de hidrogénio vs. quocien te molar; sistema: doador-aceptor de pröton, em $\mathrm{CCl}_{4} ; A=f e$ nol; $B=p-c$ lorofenol. 
TABELA 9

Valores de $\Delta v$ e de kass para fenol associado com oxa- e tiacetonas, em $\mathrm{CCl}_{4}$

No
XXVI

\section{TABELA 10}

Valores de $\Delta v$ e de kass para p-clorofenol associado com oxa- e tiacetonas, em $\mathrm{CCl}_{4}$

\begin{tabular}{|c|c|c|c|c|}
\hline \multirow{2}{*}{ NO } & \multirow{2}{*}{ Composto } & \multirow{2}{*}{$\Delta v(H z)$} & \multicolumn{2}{|c|}{$k_{\text {ass }}\left(M^{-1}\right)$} \\
\hline & & & Met. Mathur & Met. Carper \\
\hline$X C V I$ & & 135 & 6,7 & 6,6 \\
\hline$L X X V I I$ & & 12.6 & 4,6 & 5,0 \\
\hline$X C V I I$ & & 170 & 9,5 & 9,6 \\
\hline$X C I$ & & 162 & 7,3 & 7,4 \\
\hline
\end{tabular}

Para explicar esta discrepāncia, é necessārio exami nar os niveis energëticos dos orbitais $n$ do heteroätomo $\left(n_{x}\right)$ e $n$ do oxigēnio carbonillico $\left(n_{O(C O)}\right)$ em tia e oxacetonas, 
em comparação com os dos compostos anālogos não substituĩdos. os dados de potenciais de ionização indicam que, enquanto o nivel de energia do orbital $n_{s}$ de um tioéter ${ }^{146} \bar{e}$ mais elevado, o do orbital $n_{0}$ de um êter ${ }^{146}$ è mais baixo do que o do or bital $n_{O(C O)}$ de uma cetona não substituĩda. ${ }^{74} \mathrm{Em}$ vista disso, sugerem-se trēs possibilidades para explicar o fato de oxacetonas serem mais bāsicas do que as tia-anālogas.

1. $n_{0}(C O)$ de tiacetona seria estabilizado em relação à cetona não substituĩda por uma quantidade devida ao efeito induti vo do enxofre, acrescida de uma quantidade devida à intera ção no espaço entre $n_{0}(c 0)$ e $n_{s}$ (v. pag. 10). Em oxacetona, $n_{0(c o)}$ seria estabilizado somente pelo efeito indutivo do oxigênio (esquema 17).

\section{ESQUEMA 17}

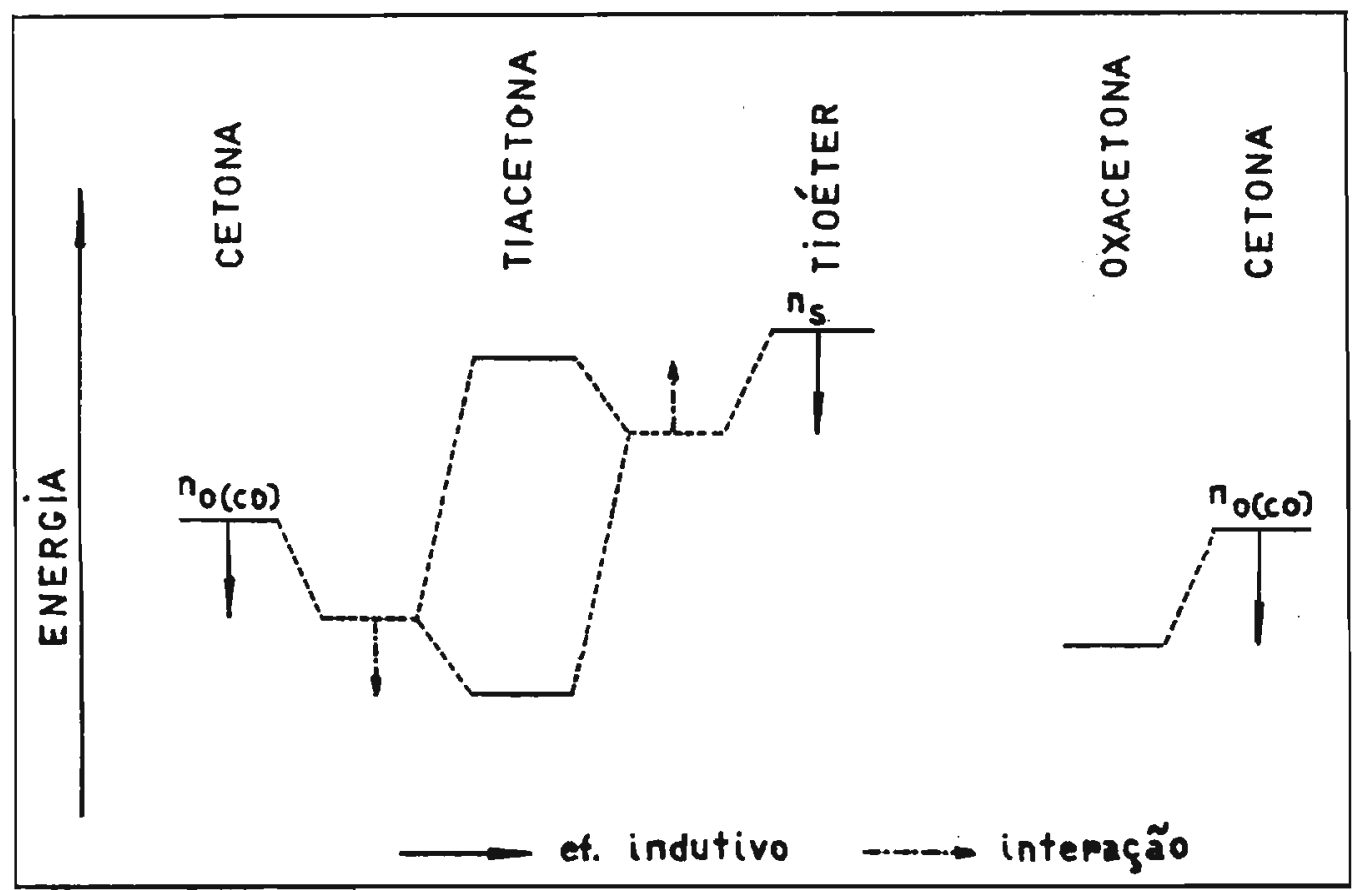

2. $n_{0}(C O)$ de oxacetona seria desestabilizado devido à interação no espaço entre os orbitais $n_{0} e n_{0}(c 0)$ e, porisso, a. estabilização de $n_{O}(C O)$ seria menor do que aquela devida apenas ao efeito indutivo do oxigênio. Em tiacetona, ${ }_{0}(\mathrm{CO})$ 
seria estabilizado apenas pelo efeito indutivo do enxofre (esquema 18).

ESQUEMA 18

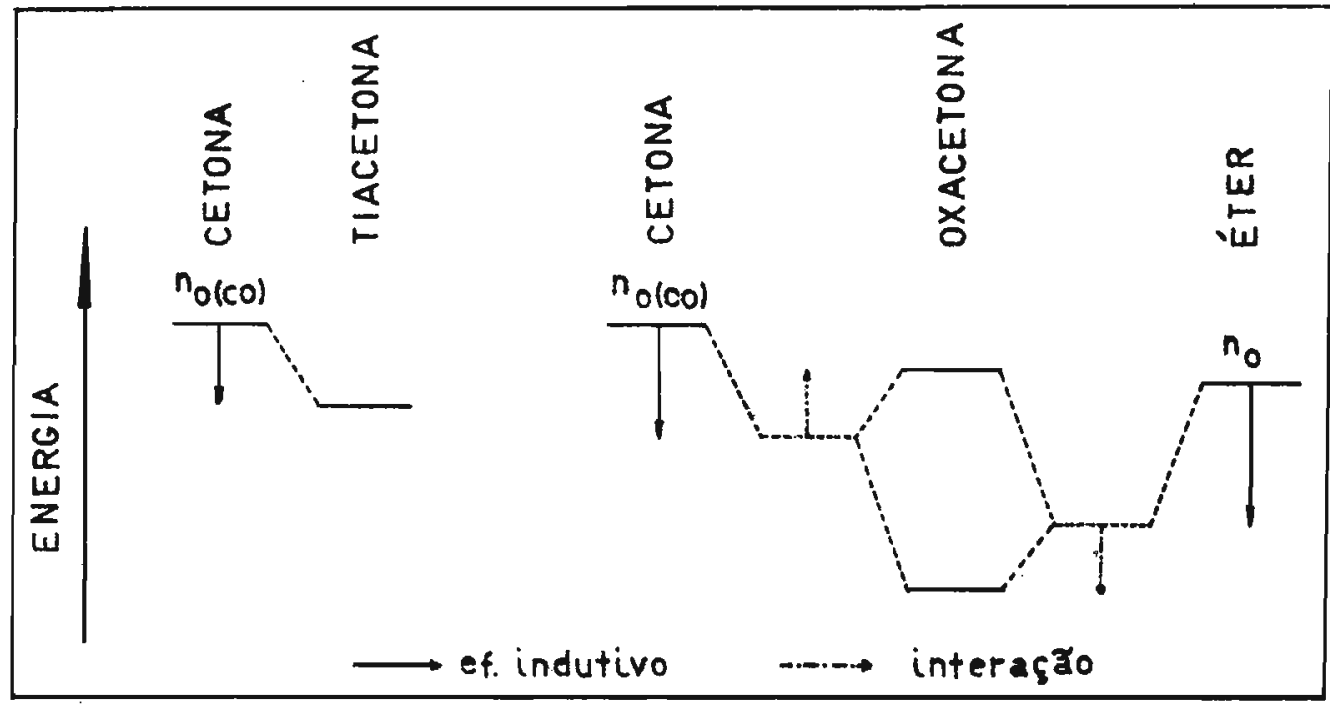

3. Ocorreria interação entre os orbitais $n_{s}$ e $n_{0}(c 0)$ em tiace tonas e entre $n_{0}$ e $n_{O(c 0)}$ em oxacetonas. No primeiro caso, a interação agiria no mesmo sentido do efeito indutivo do enxofre, estabilizando ainda mais $n_{0(c 0)}$. No segundo ca so, a interação desestabilizaria $n_{0(\mathrm{CO})}$, cancelando, em par te, o efeito indutivo do oxigênio e, portanto, resultando uma estabilização menor de $n_{0(c 0)}$ (esquema 19).

\section{ESQUEMA 19}

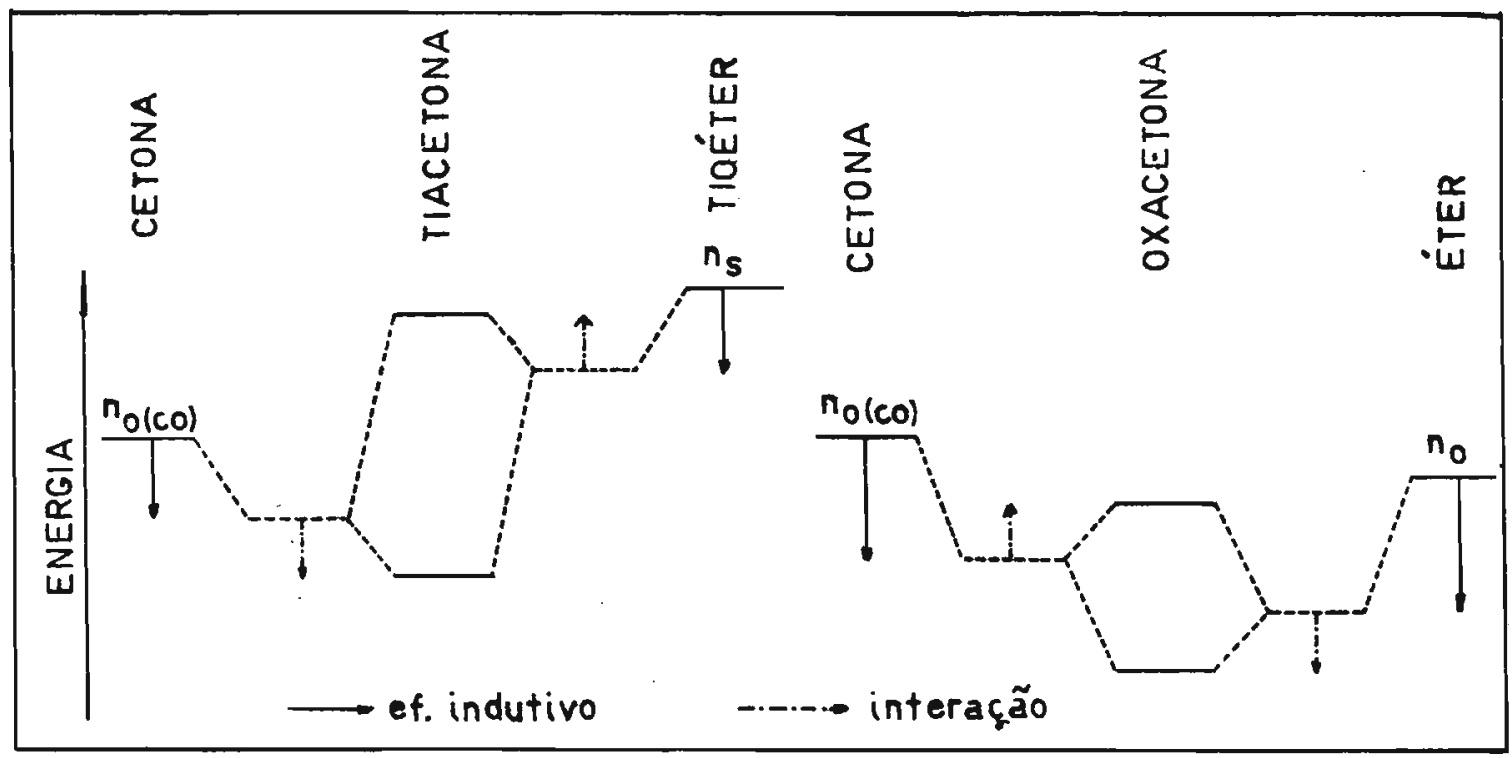


Embora a decisão final entre estas trēs hipōteses de penda de maiores estudos, principalmente através das medidas dos potenciais de ionização de oxa-e tiacetonas, existemevi dências experimentais que nos fazem optar pela terceira hipotese. Os estudos de correlação entre valores de basicidade de cetonas acíclicas, corrigidos para o impedimento estérico, e os valores correspondentes de $\sigma^{*}$ de Taft dos grupos substituintes, efetuados em nossos laboratörios, ** demonstraram que, enquanto todas as cetonas não substituĩdas encontravam-se numa linha reta, as oxa- e as tiacetonas apresentavam-se forada mesma. Estes resultados demonstram que as diminuiçōes de bas $\underline{j}$ cidade nas oxa- e tiacetonas não são determinadas somente pelos efeitos indutivos, sugerindo tambēm a ocorrēncia de interação no orbital em que estā se dando a protonação $\left(n_{0}(\operatorname{co})\right)$. E digno de nota que estes resultados confirmam a previsão de Cocksey e col.,$^{37}$ de acordo com a qual a existência de uma in teração direta entre um heteroätomo do grupo substituinte e oxigênio carbonīlico implicaria em falta de correlação entre potenciais de ionização deste ültimo e os valores de $\sigma^{*}$ de Taft dos respectivos grupos.

A comparação entre basicidades de ëteres, tioëteres e cetonas não substituídas e os respectivos potenciais de ionização permite ver que a ordem de basicidade nestes compostos não concorda com a de potenciais de ionização. Observa-se que as basicidades de tioëteres são bem menores do que as de

* Em estudo

* Comunicação pessoal da profa. B.Wladislaw 
cetonas e ēteres. Se a ordem de potenciais de ionização concordasse com a de basicidades, os potenciais de ionização de cetonas e ēteres deveriam ser menores do que o do tioēter. I so porém não ocorre, pois o enxofre do tioēter possui potencial de ionização menor do que o do oxigênio de ēter e de cetona. A explicação que pode ser fornecida para esta discordân cia é que basicidade mede associação do prōton e potencial de ionização mede nucleofilicidade, o que,especialmente no caso de enxofre,faz muita diferença. ${ }^{84}$ As basicidades e potenciais de ionização são comparảveis, porēm, numa mesma classe de com postos, como por exemplo, em cetonas.

Conforme jā relatado (pag.59), a substituição de um grupo metilena pelo ätomo de enxofre, na sērie acíclica (tabe las 6, pag.56 e 7, pag. 58), tanto na posição 4, como na 5 , em relação ao grupo carbonila de cetonas não substituridas, cau sa uma diminuição de basicidade, sendo a verificada na posição 4 a mais significativa. E dificil dizer se tais diminuições de basicidade devem-se apenas ao efeito indutivo do enxo fre, uma vez que o aumento da cadeia ligada ao grupo carbonila conduz a uma diminuição do potencial de ionização do orbital $n_{0(C O)^{37}}$ e, portanto, a um aumento de basicidade. O enxofre poderia estar destruindo este efeito de cadeia, causando assim, uma diminuição adicional de basicidade. A substituição de um grupo metilena pelo àtomo de enxofre na posição 4 de ci clanonas ( $L X X X$ e $L X X X I)$ ( $P a g .51$ ) conduz, surpreendentemente, a uma diminuição de basicidade do grupo carbonila quase da mes ma ordem daquela observada em 3-tiaciclanonas correspondentes. Esta diminuição de basicidade, em 4-tiaciclanonas, ë considerāvel e parece pouco provāvel que seja proveniente apenas do 
efeito indutivo do enxofre.

Era de interesse verificar se a introdução de enxofre na posição 5 de uma cetona cíclica provocaria ainda a diminuição de basicidade. Escolneu-se para este estudo a 5-tiaciclooctanona (LXXIII), procedendo-se assim, às medidas compa rativas de basicidade desta (LXXIII) e da ciclooctanona (LXXXVI). Pode-se observar nas figuras 7 e 8 (pags. 52 e 53 ) que, para os dois doadores de prötons (fenol e p-clorofenol), a Tinha correspondente à 5-tiaciclooctanona (LXXIII) sofre uma maior ascensão com o aumento da concentração da cetona do que a correspondente não substituĩda ( $L X X X V I)$. A explicação que se poderia fornecer para esta diferença de comportamento entre a tiaciclooctanona (LXXIII) e a cetona não substituĩda (LXXXVI) è que na primeira, à medida que se aumenta a polaridade do meio, deve se formar alguma estrutura mais polarizada. Esses fatos estão de acordo com a existência, proposta por Leonard e col., 91,95 de um equilíbrio entre duas conformações, a de não interação (menos polar) e a de interação (mais polar). As sim, a nossa experiência comprova a sugestão dos mesmos autores da ocorrēncia em 5-tiaciclooctanona (LXXIII) de transferência de carga do enxofre para o grupo carbonila. 0 aumento de $\Delta v$ na 5-tiaciclooctanona (LXXIII) em relação á ciclooctano na (LXXXVI) (tabela 5, pag. 53) indica, não um aumento da basicidade da cetona, mas sim, um aumento da concentração da con formação mais polar. No esquema 20, indicam-se as conformações extremas de não interação (a) e de interação (b) da 5-tia ciclooctanona (LXXIII). 


\section{ESQUEMA 20}

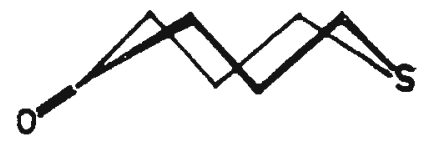

(a)

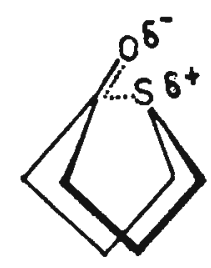

(b)

O nosso mëtodo de medida de basicidade pareceu ser de valor para a identificação de uma estrutura com transferên cia de carga num equilībrio conformacional. Achamos, porém, ne cessärio testā-10 em outro sistema a fim de comprovar a sua vạ lidade. Para esta finalidade, escolhemos um sistema cetōnico cíclico contendo uma dupla ligação situada em $\beta, \gamma$ em relação ao grupo carbonila. Conforme jämencionado (pag. 20), Klessin ger e col..$^{74}$ mediram os potenciais de ionização de tais siste mas, escolhendo värios representantes entre os quais 3-ciclohexenona (XV) e 5-norbornen-2-ona (VIII) (esquema 21). Na 3-ci clohexenona (XV) (esquema 21), os autores verificaram que os niveis de energia dos orbitais $n_{0(C O)}$ e $\pi_{C}=c$ eram estabilizados em relação aos da ciclohexanona (LXXXIV) e ciclohexeno (XCVIII), respectivamente. Enquanto que a estabilização do or bital $n_{0}(\mathrm{CO})$ correspondia ao valor esperado do efeito indutivo da dupla olefínica, a estabilização do orbital ${ }^{\pi} C=C$ era maior do que se esperaria do efeito indutivo do grupo carbon 1a. Esta estabilização de ${ }^{\pi} \mathrm{C}=\mathrm{C}$ foi considerada como provenien te do efeito indutivo acrescida de uma quantidade devida à in teração entre os orbitais $\pi_{C=C}$ e $\pi_{C=0}^{\star}$ (esquema 21 ) (v. pag. 20). Na 5-norbornen-2-ona (VIII) (esquema 21), onde 0 ane 1 nexagonal acha-se na conformação barco fixa, os autores obser varam uma grande estabilização do orbital ${ }^{\pi} C=C$, não somente 
maior do que se esperaria do efeito indutivo do grupo carbon $\underline{i}$ la, mas ainda maior do que a do orbital ${ }^{\pi} \mathrm{C}=\mathrm{C}$ em 3-ciclohexeno na $(X V)$. O nível de energia do orbital $n_{0(C O)}$ mostrou-se porëm, neste composto (VIII), desestabilizado em relação ao da 2-norbornanona (CI). Para explicar estes fatos, Klessinger e col. ${ }^{74}$ confirmaram sugestões anteriores de weiler e col. ${ }^{35}$ de que hä ocorrência de duas interações $\pi_{C=C} \operatorname{com} \pi_{C=0}^{*}$ e ${ }_{C} C=C$ com $\mathrm{n}_{0(\mathrm{CO})}$. Enquanto ambas interações, reforçando o efeito indut $\underline{j}$ vo da carbonila, seriam responsāveis pela estabilização de ${ }^{\pi} C=C$, a segunda delas desestabilizaria $n_{0}(C O)$ (v. pag. 12), agindo no sentido conträrio do efeito indutivo da dupla olefí nica, portanto, cancelando-o.

\section{ESQUEMA 21}

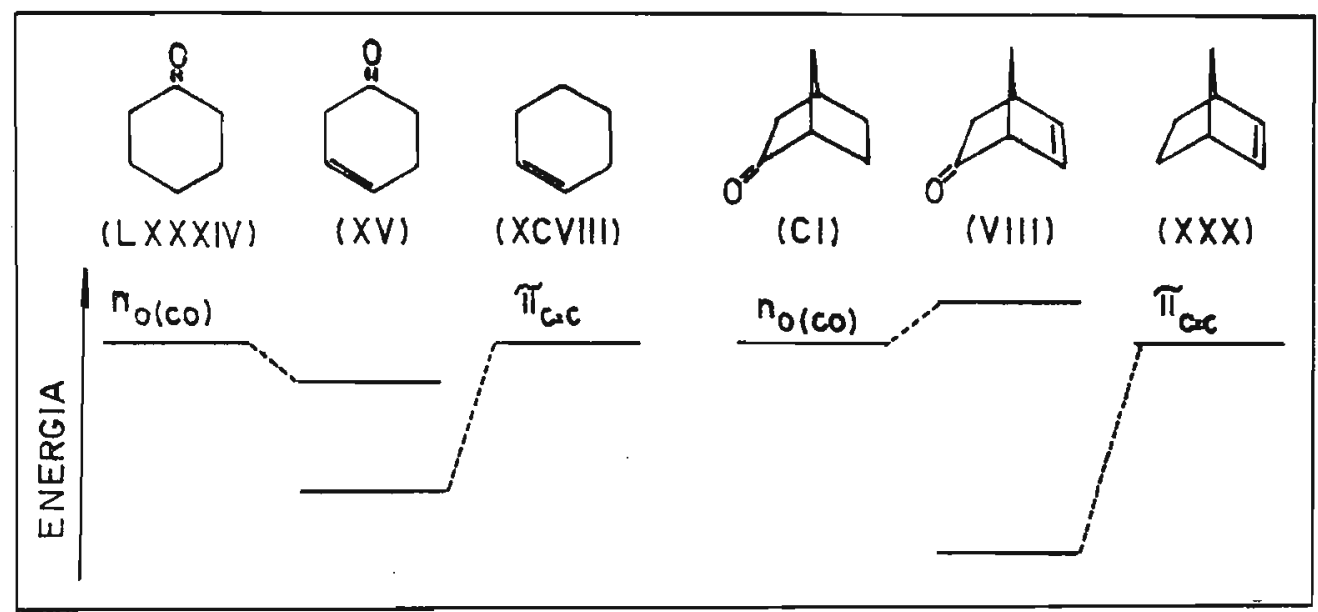

Pareceu-nos que na 5-norbonen-2-ona (VIII), em que a ponte metilênica fixa a conformação barco, aproximando os orbitais $\pi$ olefinico e carbon 3 lico, deveria ocorrer uma forte transferēncia de carga do orbital $\pi_{C=C}$ para $0 \pi_{C=0}^{\star} e$, ao nosso ver, a desestabilização de $n_{0}\left(C_{0}\right)$ seria causada, em grande par te, por tal tipo de interação. A inspeção do modelo molecular da 3-ciclohexenona (XV) permitiu ver que neste composto, seme 
Thantemente à 5-tiaciclooctanona (LXXIII), havia a possibilidade da existência de um equilíbrio entre dois isōmeros conformacionais, de cadeira (a) e de barco (b) (esquema 22), ambos distorcidos. Na conformação barco, os orbitais m olefinico e carbonilico pareciam estar suficientemente pröximos para a ocorrēncia de uma transferēncia de carga de ${ }^{\pi} \mathrm{C}=\mathrm{C}$ para ${ }^{*} \mathrm{C}=0$. Achamos provāvel que, com o aumento da polaridade do meio, hạ veria um aumento da população da conformação mais polarizada.

\section{ESQUEMA 22}

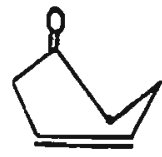

(a)

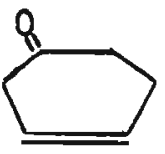

(b)

Para comprovar essa hipōtese, efetuamos as medidas de basicidade da 3-ciclohexenona (XV) (exp. nọ 26, pag.131) em comparação com as da ciclohexanona (LXXXIV). As figuras 15 e 16 demonstram claramente que as retas correspondentes à $3-c i-$ clohexenona (XV) sofrem maior ascensão ã medida que se a $\underline{u}$ menta a concentração de cetona, confirmando nossas previsões. Constata-se ainda, que a baixas concentrações de cetona os vạ 1ores de $\Delta v^{\prime} O$ da 3-ciclohexenona (XV) são menores do que os da ciclohexanona (LXXXIV). Tal fato deve-se à predominância da conformação de não interação (esquema 22a) onde 0 nível de energia de $n_{0}(c 0)$ é estabilizado devido ao efeito indutivo da dupla olefinica. E digno de nota que as medidas de potenciais de ionização deste composto (XV) na fase gasosa (esquema 21), concordam com este fato. Confirma-se assim, a importanncia do nosso método de medida de basicidade na identificação de estruturas com transferéncia de carga num equilíbrio conforma- 


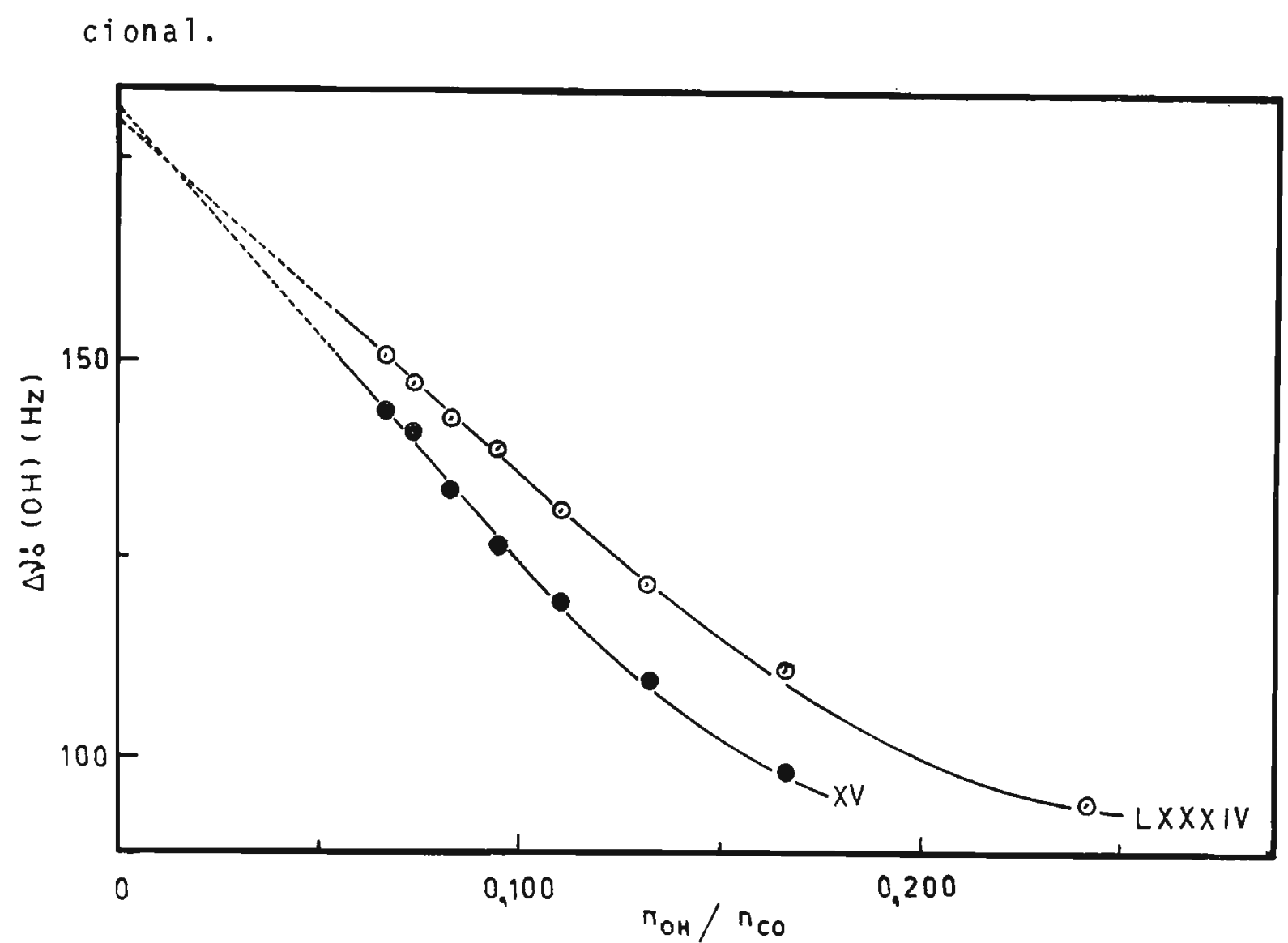

Figura 15 - Deslocamentos da ponte de hidrogēnio vs. quocientes molares; sistema: fenol-cetona cíclica, em $\mathrm{CCl}_{4}$.

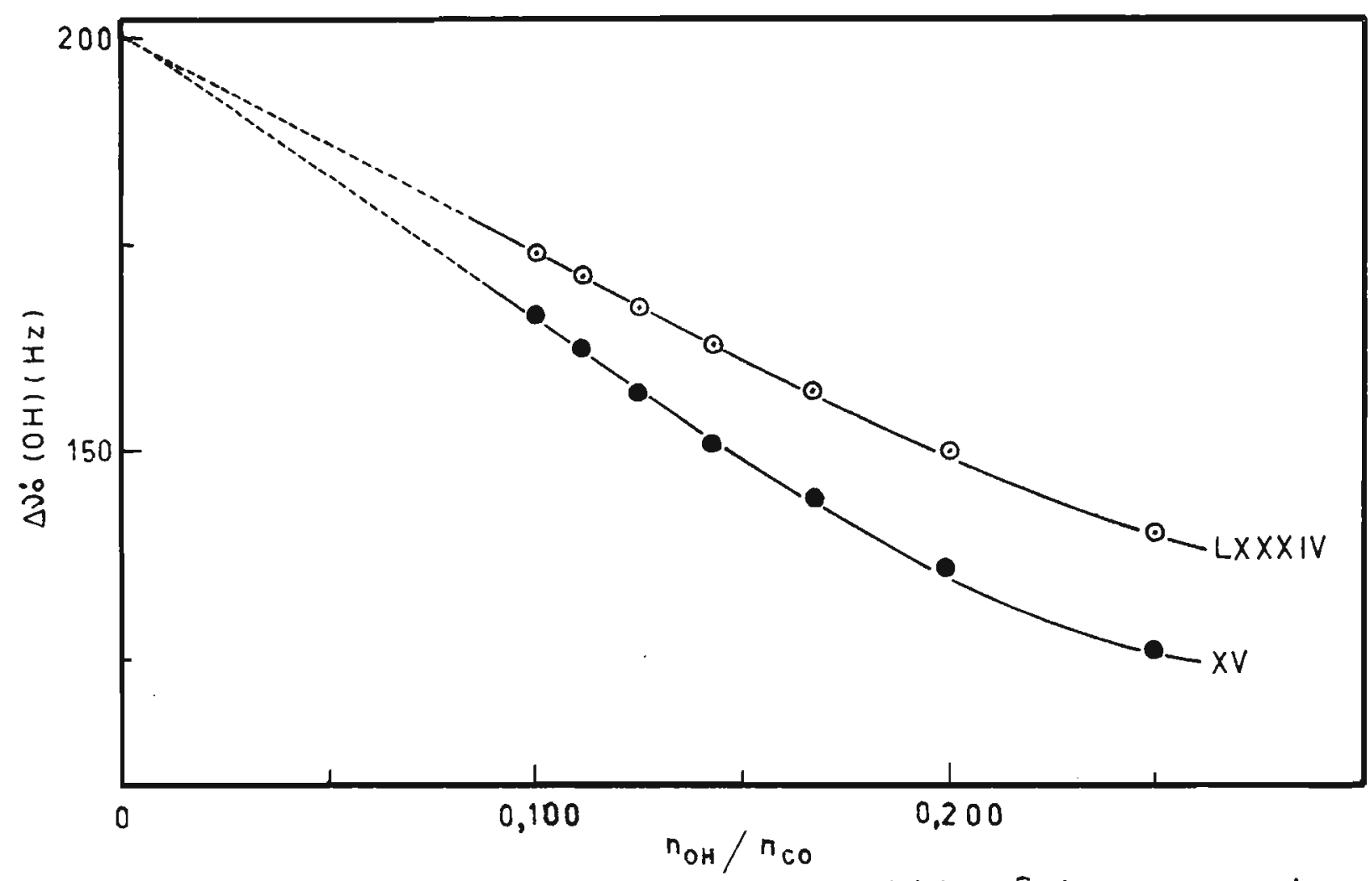

Figura 16 - Deslocamentos da ponte de hidrogênio vs. quocientes molares; sistema: p-clorofenol-cetona cíclica, em $\mathrm{CCl}_{4}$. 


\section{TABELA 11}

Valores de $\Delta$ para fenol e p-clorofenol associados com ciclohexanona e 3-ciclohexenona, em $\mathrm{CCl}_{4}$

\begin{tabular}{lccc}
\hline \multirow{2}{*}{ No Composto } & \multicolumn{2}{c}{$\Delta \nu(\mathrm{Hz})$} \\
\cline { 3 - 4 } & fenol & $p$-clorofenol \\
LXXXIV & 179 & 199 \\
& & & \\
& & & \\
\end{tabular}

As tiacetonas contendo o âtomo de enxofre ligado ao carbono $\alpha$ ou $\beta$, não demonstraram qualquer dependência conformacional com a variação da polaridade do meio, tendo portanto, comportamentos diferentes daqueles observados na 5-tiaciclooctanona (LXXIII) e na 3-ciclohexenona (XV). Nas tiacetonas assimétricas, alēm do efeito indutivo do enxofre, hā a possibilidade da interação no espaço entre os orbitais $n_{s}$ e $n_{0}(c 0)$ que estabilizam o nivel de energia do $n_{0}(c 0)$ (v.pag.67) diminuindo, consequentemente, suas basicidades. Na 4-tiaciclohe xanona $(L X X X)$, esta interação é proibida por simetria. Não se pode excluir, entretanto, a possibilidade que, juntamente com a interação no espaço entre os orbitais $n_{s}$ e $n_{O(C O)}$, existam outras interações (v.pag. 7 ) e que haja inclusive alguma par ticipação de orbitais "d" do enxofre. Maiores esclarecimentos poderão ser obtidos com medidas de potenciais de ionização,es tudo de sistemas de conformações mais rĩgidas e cālculos de orbitais. 


\subsection{APRESENTAÇÃO DE SINTESES}

Para as nossas medidas foram necessärias as sinteses dos seguintes compostos: cicloheptanona (LXXXV), ciclooctanona (LXXXVI), 4-tiacicloheptanona (LXXXI), 3-tiaciclohexanona (LXXVIII), 3-tiacicloheptanona (LXXIX), 5-tiacicloocta nona (LXXIII), 3-oxaciclopentanona (XCVI), 4-etiltio-2-butano na (XCII), 5-etiltio-2-pentanona (XCIII), 6-etiltio-2-hexanona (XCIV), 3-ciclohexenona (XV) e 9-tiabiciclo $(3,3,1)-2-$ nonanona $(C)$. Os demais compostos necessärios achavam-se disponiveis em nossos laboratórios.

Nestas sínteses, empregaram-se diversos mëtodos gerais. Assim, nas preparações de cicloheptanona (LXXXV), 87 ciclooctanona $(L X X X V I)^{87}$ e 4-tiacicloheptanona (LXXXI), 120 homo logaram-se as cadeias de ciclohexanona (LXXXIV) (3.3.4.1.,pag. 134), cicloheptanona ( LXXXV) (3.3.4.5., pag.139) e 4-tiaciciohexanona $(L X X X)(3.3 .4 .4$, pag.139), respectivamente. Em todos estes casos fez-se reagir a ciclanona com diazometano, ob tido no pröprio meio da reação pela decomposição da N-nitroso metiluretana (CIII), a qual foi facilmente preparada a partir de cloroformiato de etila e metilamina (esquema 23).

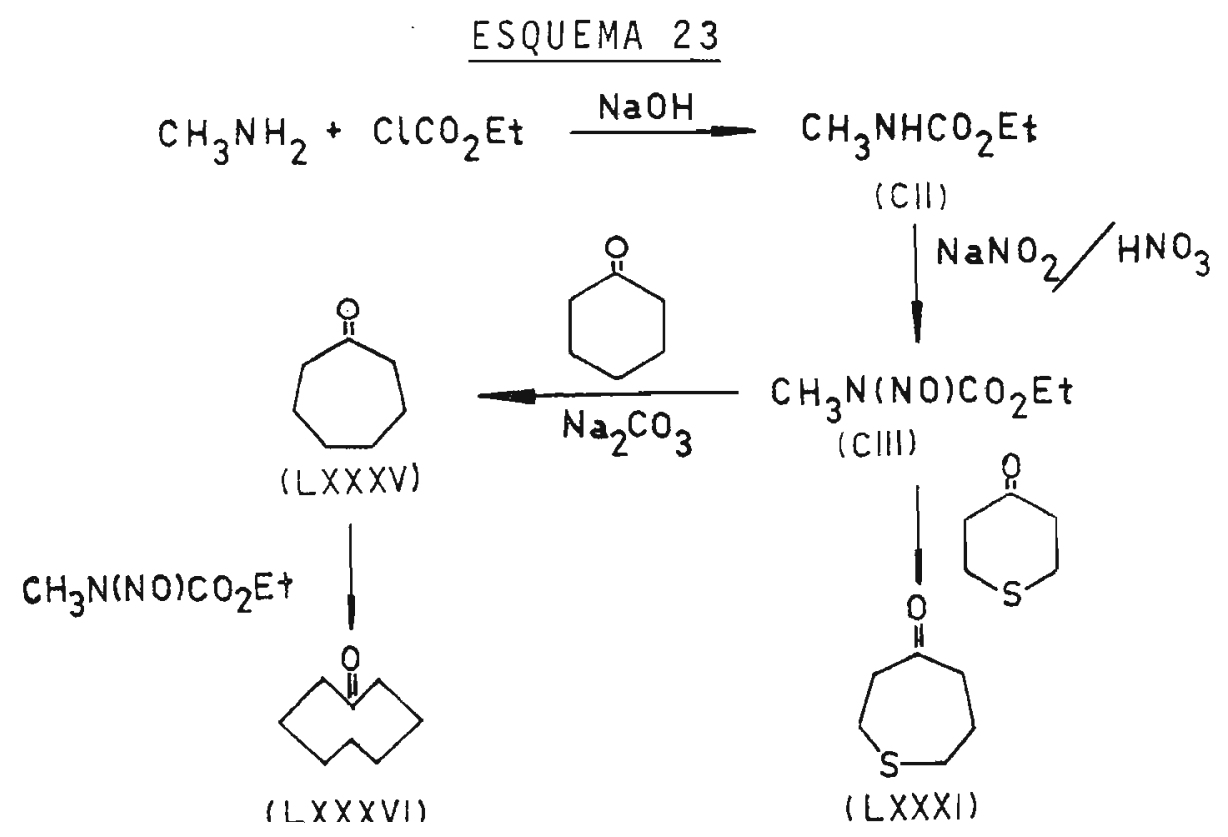


A 3-tiaciclohexanona (LXXVIII) ${ }^{92}$ (3.3.4.2., pag.135) a 3-tiacicloheptanona $(L X X I X)^{92}(3.3 .4 .3 .$, pag.137) e a 5-tia ciclooctanona (LXXIII) ${ }^{95}$ (3.3.4.6., pag.140) foram preparadas pelas condensações de Dieckmann dos diēsteres correspondentes (CVI, CXII e CXV), seguidas por hidrōlises e descarboxilações dos $\beta$-cetoēsteres formados (CVII, CXIII e CXVI) (esquema 24).

\section{ESQUEMA 24}

\section{$\left.\mathrm{E}+\mathrm{O}_{2} \mathrm{CCH}_{2} \mathrm{CCH}_{2}\right)_{x} \mathrm{SiCH}_{2} \mathrm{H}_{\mathrm{CH}} \mathrm{CH}_{2} \mathrm{CO}_{2} \mathrm{Et}$}

$x=0, y=2(C V I) ; \quad x=0, y=3(C X \| 1) ; \quad x=2, y=2(C X V)$

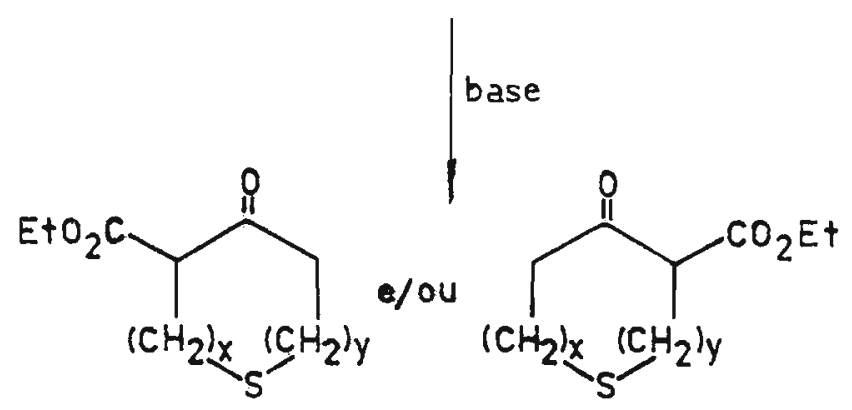

(a)

(b)

$x=0, y=2(C V \|) ; x=0, y=3(C X \| I) ; x=2, y=2(C X V I)$

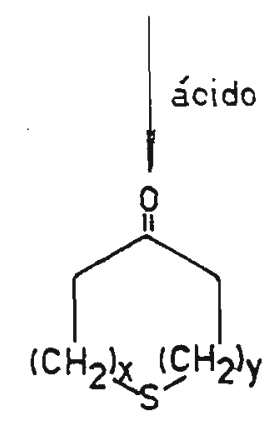

$x=0, y=2(L X X V \mid I) ; x=0, y=3(L X X \mid X) ; x=2, y=2(L X X \mid I))$

Nas obtenções dos diēsteres (CVI, CXII, CXV), os pro cedimentos variaram. Assim, o correspondente (CVI) à 3-tiaciclohexanona (LXXVIII) foi preparado a partir de r-butirolacto na e àcido tioglicólico, de acordo com a sequēncia de rea ções $10,92,117$ (esquema 25).

1. Esterificação do àcido tioglicōlico. 
2. Reação de $\gamma$-butirolactona com cloreto de hidrogênio e etanol conduzindo ao $\gamma$-clorobutirato de etila (CV).

3. Reação deste $\bar{u}$ timo (CV) com o sal sōdico do tioglicolato de etila, formando o sulfeto de carbetoximetil-y-carbetoxi propila (CVI).

\section{ESQUEMA 25}
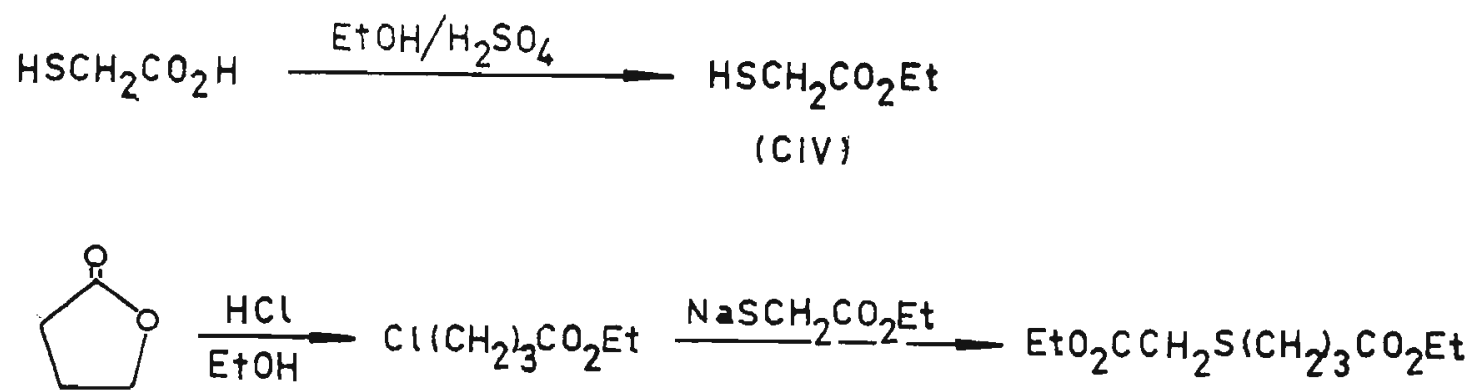

o diēster correspondente (CXII) à 3-tiacicloheptano na $(L X X I X)$, foi preparado a partir de tetrahidrofurano e tioglicolato de etila (CIV), de acordo com os seguintes passos consecutivos 92,145 (esquema 26).

1. Reação de tetrahidrofurano com cloreto de hidrogênio, fornecendo o 4-cloro-1-butanol (CVIII).

2. Reação do 4-cloro-1-butanol (CVIII) com tribrometo de fósforo, conduzindo a o clorobrometo de tetrametilena (CIX).

3. Cianetação do clorobrometo de tetrametilena (CIX).

4. Alcoólise da $\delta$-clorovaleronitrila (CX).

5. Reação do $\delta$-clorovalerato de etila (CXI) com o sal sódico do tioglicolato de etila, fornecendo o sulfeto de carbetoximeti $1-\delta-c a r b e t o x i b u t i l a$ (CXII). 
ESQUEMA 26

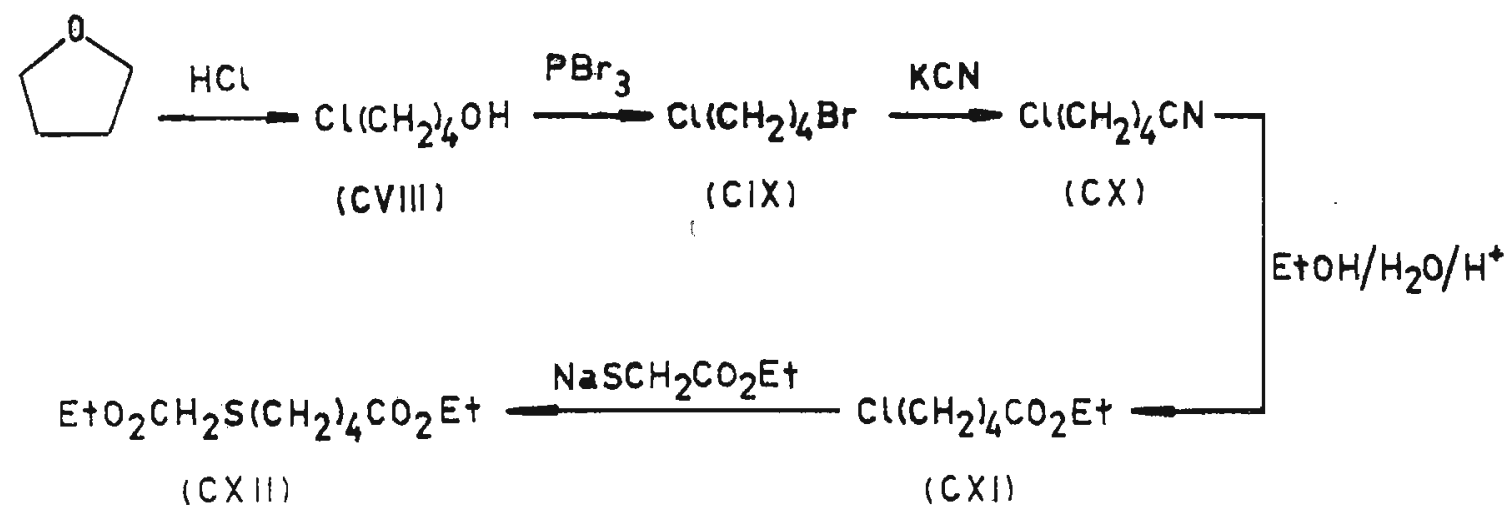

O diëster de partida (CXV) para a preparação da 5-tiaciclooctanona (LXXIII) foi por nós obtido a partir de y-butirolactona e sulfeto de hidrogēnio, por um processo que envolveu dois passos consecutivos 90,119 (esquema 27).

1. Obtenção do $\gamma$-bromobutirato de etila (CXIV) a partir de $\gamma$-b $\underline{u}$ tirolactona e brometo de hidrogênio.

2. Reação do $\gamma$-bromobutirato de etila (CXIV) com sulfeto de sō dio, preparado a partir de sulfeto de hidrogēnio e etōxido de sōdio, conduzindo ao sulfeto de $Y, \gamma^{\prime}$-bis-butirato de et $i$ la $(C \times V)$.

\section{ESQUEMA 27}

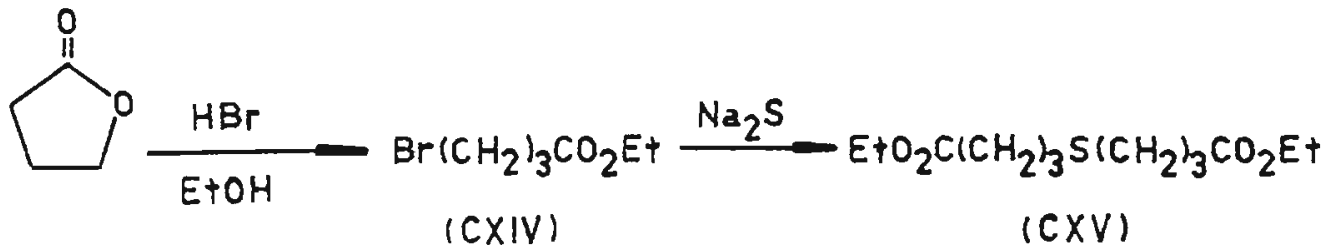

E digno de nota que as condensações dos diésteres (CXII, CXV) conduziram a produtos brutos escuros e viscosos, provavelmente provenientes de suas polimerizações lineares. A tentativa de destilação à pressão reduzida $(<0,5 \mathrm{mmHg})$ do 
B-cetoēster (CXIII), resultou em sua decomposição. Em vista disso, efetuaram-se as hidrólises e descarboxilações dos $\beta$-ce toésteres formados (CXIII, CXV), sem prēvia purificação. Os rendimentos baixos obtidos são justificados pela dificuldade de ciclização de anéis de mais de seis membros.

A 3-oxaciclopentanona (XCVI) (3.3.4.11.,pag. 147) foi obtida pela hidrōlise e descarboxilação da 2-carbometoxi-4-oxaciclopentanona (CXXVI). ${ }^{56}$ Este B-cetoêster (CXXVI) foi preparado pela reação de Michael entre acrilato de metila e sal södico do glicolato de metila, seguida pela condensação do enolato do diéster formado intermediariamente. 0 esquema 28 indica a sequēncia de reações envolvidas.

\section{ESQUEMA 28}

$$
\mathrm{HOCH}_{2} \mathrm{CO}_{2} \mathrm{H} \frac{\mathrm{CH}_{3} \mathrm{OH}}{\mathrm{HCl}} \longrightarrow \underset{(\mathrm{CXXV})}{\mathrm{HOCH}_{2} \mathrm{CO}_{2} \mathrm{CH}_{3}}
$$

$\mathrm{Na} / \mathrm{CH}_{2}: \mathrm{CHCO}_{2} \mathrm{CH}_{3}$<smiles>O=C1CCOC1</smiles>

(XCVI)

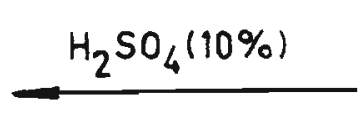

(CXXV)

A 4-eti1tio-2-butanona (XCII) foi preparada em apenas uma fase $(3.3 .4 .7 .$, pag.141) pela reação de Michael entre metilvinilcetona e etanotiol. Seguindo-se, inicialmente, opro cedimento de Fehnel e Carmack, ${ }^{54}$ fez-se reagir tais compostos na presença de sōdio metāilico como catalizador. Este conduziu, entretanto, a um produto de aspecto resinoso que, por desti1 ação, forneceu quantidade insuficiente da tiacetona (XCII), 
cromatograficamente impura. Em vista disso, seguiu-se o proce dimento de cain e cunneen, 31 que emprega piridina como catali zador, obtendo-se 4-etiltio-2-butanona (XCII), cromatografica mente pura (esquema 29).

\section{ESQUEMA 29}

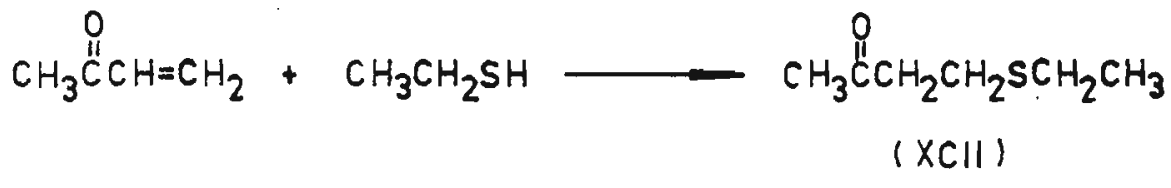

A 5-etiltio-2-pentanona (XCIII) (3.3.4.8., pag.142) e a 6-etiltio-2-hexanona (XCIV) (3.3.4.9., pag.143) foram pre paradas pelas reações de bromocetonas correspondentes (CXVII, CXIX) com etilmercapteto de sōdio ${ }^{31}$ (esquema 30 ).

\section{ESQUEMA 30}

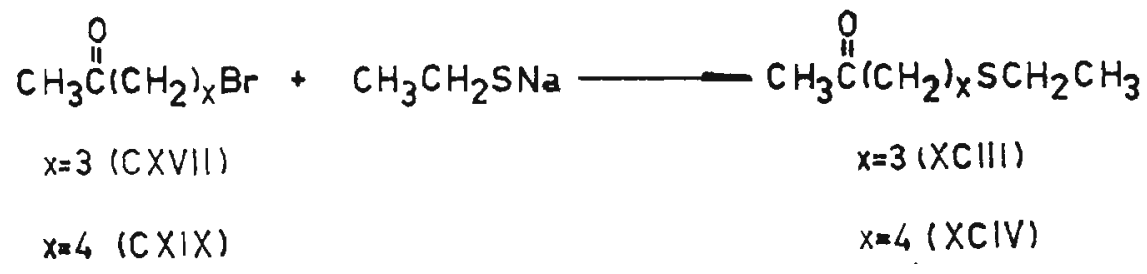

As bromocetonas (CXVII, CXIX) foram obtidas a partir de 2-aceti1-4-butirolactona ${ }^{8}$ (esquema 31 ) e a partir de acetilacetato de etila e brometo de trimetilenal,4 (esquema 32), respectivamente.

ESQUEMA 31

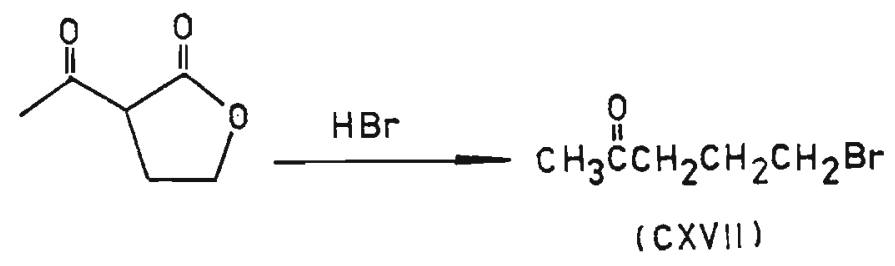




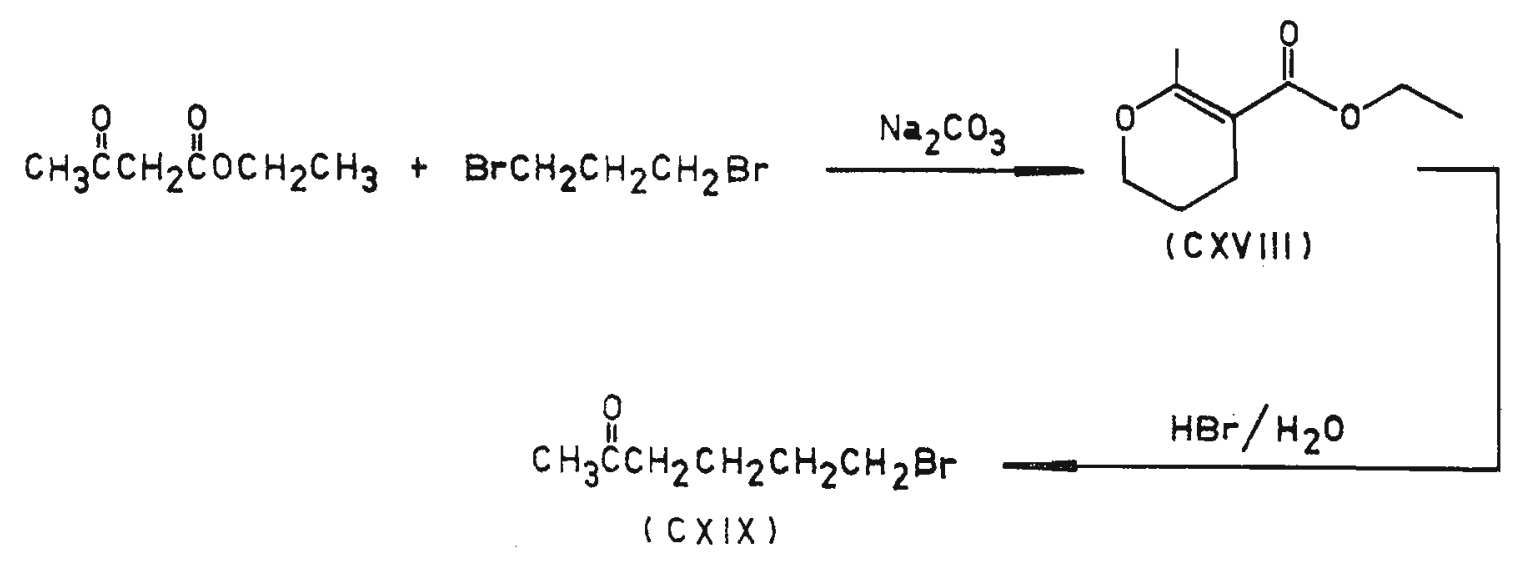

A 6-etiltio-2-hexanona (XCIV), ainda não descritana literatura, foi por nós identificada pela análise elementar e pelas anāifses de seus espectros de infravermelho e de ressonāncia magnética nuclear.

A 3-ciclohexenona (XV) (3.3.4.12, pag. 148) foi pre parada a partir de anisol, seguindo-se o procedimento descrito por Noyce e Evett ${ }^{118}$ (esquema 33 ).

ESQUEMA 33

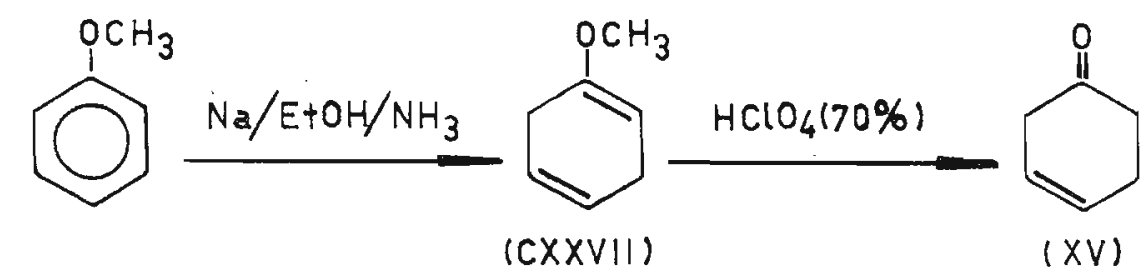

A sintese da. 9-tiabiciclo $(3,3,1)-2-n o n a n o n a$

(3.3.4.10., pag.144) foi por nōs planejada atravēs da sequência de reações abaixo indicada $25,40,121,160$ e formulada no esquema 34 .

1. Dicloreto de enxofre $(C X X)$ a partir de dicloreto de dienxo fre e cloro. 
2. Adição transanular do dicloreto de enxofre (CXX) ao 1,5-c clooctadieno, conduzindo ao 2,6 -dicloro-9-tiabiciclo $(3,3,1)-$ -non ano (CXXI).

3. Eliminação de cloreto de hidrogēnio do 2,6-dicloro-9-tiab $\underline{j}$ cic $10(3,3,1)$-nonano $(C X X I)$.

4. 9-tiabiciclo(3,3,1)-6-nonen-2-01 (CXXIII) a partir da reação de 6-cloro-9-tiabiciclo(3,3,1)-2-noneno (CXXII) com hi drōxido de sōdio.

5. Oxidação do ālcool (CXXIII) com triōxido de crōmio, conduzindo à 9-tiabiciclo(3,3,1)-6-nonen-2-ona (XCIX).

6. Hidrogenação da dupla olefínica da 9-tiabiciclo(3,3,1)-6-nonen-2-ona (XCIX).

ESQUEMA 34

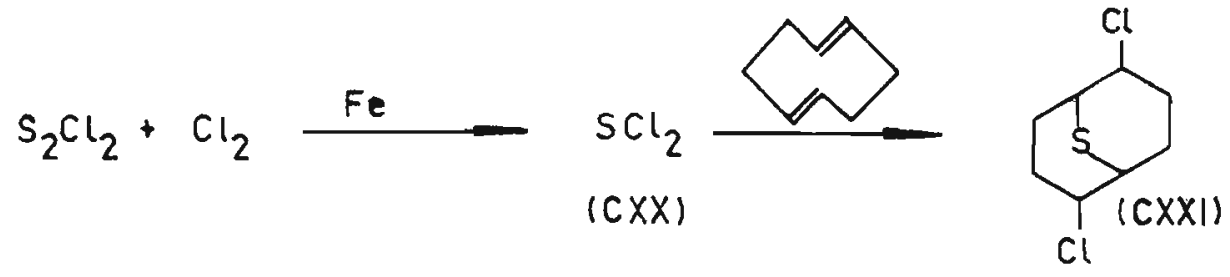<smiles>O=C1CCC2CCCC1S2</smiles>

(C)

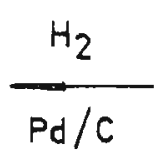<smiles>O=C1CCC2C=CCC1S2</smiles>

$(X C \mid X)$
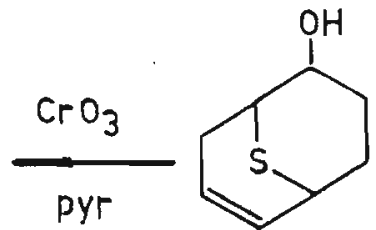

(CXXIII)<smiles>CC(C)O[C@H]1CC[C@@H]2C=CC[C@@H]1S2</smiles>

(CXXIV)
$\mathrm{NaOH}$<smiles>ClC1CCC2C=CCC1S2</smiles>

(CXXII) 
Os passos 1,2 e 3 não apresentaram dificuldades, permitindo obter 6-cloro-g-tiabiciclo(3,3,1)-2-noneno (CXXII) em bom rendimento. A hidrólise deste (CXXII) conduziu ao àlcool correspondente (CXXIII), cujo intervalo de fusão, apesar de duas recristalizações de ägua, era de $5^{\circ} \mathrm{C}$. Embora oseu cro matograma apresentasse apenas cerca de $0,5 \%$ de impurezas, acha mos conveniente identificar o composto (CXXIII) pela transfor mação em acetato de 9 -tiabiciclo $(3,3,1)-6-n o n e n-2-i 1 a$ (CXXIV). Verificamos que o ponto de fusão deste ūltimo mostrou-se idên tico ao descrito na literatura. o passo seguinte, oxidação do ālcool (CXXIII) a cetona (XCIX), tambẻm ocorreu normalmente.A reação final de hidrogenação da dupla olefínica da 9-tiabiciclo- $(3,3,1)-6-$ nonen-2-ona $(X C I X)$ apresentou, entretanto, difi culdades. Por trés vezes consecutivas seguimos as especificações de Pawda e Battisti ${ }^{121}$ recuperando, todavia, o composto de partida. Uma variação do mētodo originall21 foi testada. Assim, em vez de paládio, resolvemos utilizar cloreto de palädio suportado em carvão. Tal variação tambēm conduziu, infe lizmente, a resultados insatisfatōrios. 


\section{PARTE EXPERIMENTAL}

\subsection{INSTRUMENTOS}

ESPECTROMETRO DE RESSONANCIA MAGNETICA NUCLEAR - Foi empregado um espectrōmetro "Varian" modelo "T-60", que opera com uma fonte de radiofrequência de $60 \mathrm{MHz}$.

ESPECTROFOTOMETRO NO INFRAVERMELHO - Foi utilizado um espectrofotômetro "Perkin Elmer", modelo "457-A".

CROMATOGRAFO DE GAS - Com a finalidade de se testar a pureza dos compostos, empregou-se um cromatögrafo "Varian", equipado com um detector de ionizaçäo de chama, sērie "1.800". As col $\underline{u}$ nas empregadas foram: FFAP, Carbowax $20 \mathrm{M}$ e SE-30.

CALCULADORA ELETRÕNICA - Foi usada uma calculadora "Hewlett Packard", modelo"9.810A-10".

3.2. MEDIDAS COMPARATIVAS DE BASICIDADE DE TIACICLANONAS, AL: QUILTIOCETONAS E COMPOSTOS RELACIONADOS, POR RESSONÃNCIA MAGNETICA NUCLEAR

NOTAÇOES

No presente trabalho foram empregadas as seguintes notações:

$\Delta 1$ - Deslocamento químico total do hidrogénio ácido do doador de pröton (em $\mathrm{mm}$ ), em relação à referência interna, ciclohexano. 
4v' - Deslocamento químico total do hidrogênio ácido do doador de prōton (em $\mathrm{Hz}$ ), em relação ã referência interna, ciclohexano.

$\Delta v_{0}$ - Deslocamento químico do hidrogênio ácido do doador (em $H z)$ em um solvente inerte à diluição infinita, em rela ção à referência interna, ciclohexano.

$\Delta v^{\prime} 0$ - Deslocamento da ponte de hidrogênio (em $\mathrm{Hz}$ ).

$\Delta v$ - Deslocamento da ponte de hidrogênio (em $\mathrm{Hz}$ ) à diluição infinita do doador de próton.

$\Delta_{0} \quad$ - Deslocamento da ponte de hidrogênio (em $\mathrm{Hz}$ ) do doador de próton totalmente complexado com a base.

f - Fator de conversão $(\mathrm{Hz} / \mathrm{mm})$.

kass - Constante de associação do sistema doador-aceptor de prōton, em um solvente inerte, no caso, tetracloreto de carbono.

r - Coeficiente de correlação da reta.

No que se refere aós indices, "co" significa uma ba se carbonîlica e "OH", um doador de próton (fenol ou p-clorofenol).

Preparação de amostras do sistema ternärio: doador-aceptor de prōton-tetracloreto de carbono

Para o estudo deste sistema, eram preparadas soluções-mãe do doador $(0,040 \mathrm{M}$ para o fenol e 0,060M para o p-clo 
rofenol) e do aceptor de prōton $(0,60 \mathrm{M})$, ambos em tetracloreto de carbono. Antes de se completar o volume para $10 \mathrm{ml}$ da so lução-mãe do doador de prōton, adicionava-se cerca de $0,2 \mathrm{ml}$ de ciclohexano (referēncia interna). Destas soluções-mãe eram feitas as diluições necessārias para a medida (tabela 12).

\section{TABELA 12}

Diluiçōes necessārias para as preparações de amostras para medidas de basicidade, e respectivas concentraçōes

\begin{tabular}{|c|c|c|c|c|c|c|c|}
\hline \multirow{2}{*}{$\begin{array}{l}\text { volume do } \\
\text { doador, ml }\end{array}$} & \multirow{2}{*}{$\begin{array}{l}\text { Volume do } \\
\text { aceptor, ml }\end{array}$} & \multirow{2}{*}{$\begin{array}{l}\text { Volume de } \\
\mathrm{CCl}_{4}, \mathrm{ml}\end{array}$} & \multirow{2}{*}[\mathrm{co}]{} & \multicolumn{2}{|c|}{$p$-clorofenol } & \multicolumn{2}{|c|}{ fenol } \\
\hline & & & & $(\mathrm{OH})$ & ${ }^{n_{\mathrm{OH}}} /{ }^{n} \mathrm{CO}$ & $(\mathrm{OH})$ & ${ }^{n} \mathrm{OH} /{ }^{n} \mathrm{CO}$ \\
\hline $0,50 \ldots$ & 0,50 & 0 & 0,30 & 0,030 & 0,100 & 0,020 & 0,067 \\
\hline 0,50 & 0,45 & 0,05 & 0,27 & 0,030 & 0,111 & 0,020 & 0,074 \\
\hline 0,50 & 0,40 & 0,10 & 0,24 & 0,030 & 0,125 & 0,020 & 0,083 \\
\hline 0,50 & 0,35 & 0,15 & 0,21 & 0,030 & 0,143 & 0,020 & 0,095 \\
\hline 0,50 & 0,30 & 0,20 & 0,18 & 0,030 & 0,167 & 0,020 & 0,11 \\
\hline 0,50 & 0,25 & 0,25 & 0,15 & $0,0,30$ & 0,200 & 0,020 & 0,133 \\
\hline 0,50 & 0,20 & 0,30 & 0,12 & 0,030 & 0,250 & 0,020 & 0,167 \\
\hline 0,50 & 0,15 & 0,35 & $0,09$. & 0,030 & 0,333 & 0,020 & 0,222 \\
\hline
\end{tabular}

3.2.1. Descrição geral do mētodo empregado nas identificações e medidas dos deslocamentos químicos dos prótons hidro xilicos do fenol e do p-clorofenol

A identificação do sinal do próton hidroxilico, era feita por comparação com os sinais das substāncias puras. 0 único sinal que sofria uma mudança acentuada na sua posição, 
era o do hidrogênio ácido do doador (figura 17). Emalguns sis temas doador-aceptor de prōton esta identificação era, entretanto, dificultada devido à superposição do sinal do hidrogê nio ácido com os sinais dos prótons do anel aromätico do doador. Superava-se esta dificuldade variando-se a concentração do aceptor, o que provocava um deslocamento do sinal do hidro gênio äcido. Outras vezes, este sinal era totalmente obscurecido na presença da base. Apōs a verificação de que este fato devia-se principalmente à presença de traços de umidade, sana va-se o problema efetuando-se um tratamento prévio com peneiras moleculares $4 \mathrm{~A}$. Apös a localização inequĩvoca do sinal do prōton hidroxīico do àcido associado noespectro, efetuava-se a leitura de sua posição em relação ao dos hidrogênios do ciclohexano (referência interna). Assim, traçavam-se duas paralelas: uma na posição do māximo do sinal do hidrogēnio ācido do doador e a outra na dos hidrogênios de referência (figura 17D). Para se reduzir o erro de paralelismo das retas, procurava-se obter sinais de mesma intensidade (variando-se a sensibilidade do detector), medindo-se a distāncia entre elas, no máximo a $2 \mathrm{~cm}$ acima dos sinais. Lia-se, com a ajuda de um paquímetro, a distância entre estes dois sinais, em mm ( $\Delta T)$. Pa ra cada amostra obtinha-se um valor médio de $\Delta 1$, pelos registros e medidas de cerca de 6 espectros.

Empregava-se uma largura de varredura de $500 \mathrm{~Hz}$, efe tuando-se todas as medidas à temperatura constante de $35^{\circ} \mathrm{C}$. 

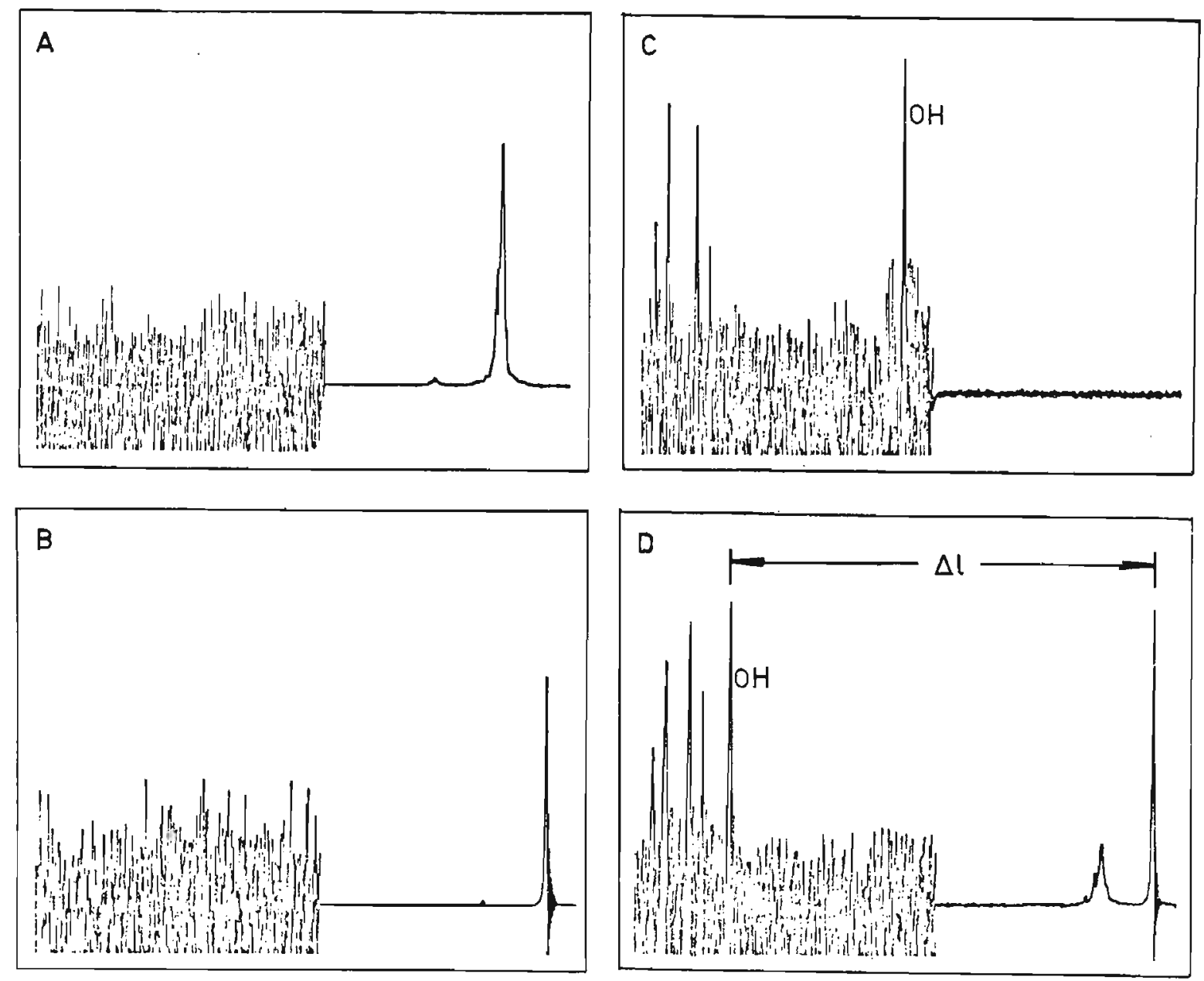

Figura 17 - Técnica de detecção e medida de deslocamento químico; $A=$ cetona; $B=c i c l o h e x a n o$ (referência); $C=p-c$ lorofenol; $D=$ sistema: $p$-clorofenol-cetona-ciclohexano; solvente: $\mathrm{CCl}_{4}$.

\subsubsection{Anälise estatística dos dados experimentais}

Rejeição dos valores discrepantes e avaliação do erro de medj $\underline{d a}$

Os dados experimentais sofriam um tratamento estatístico, cuja finalidade era a rejeição de valores discrepantes e a avaliação do erro de medida. Como critērio de erro, empregava-se a estimativa do desvio padrão (s) e, para a rejeição das medidas discrepantes, o teste "t" de student. 156 
Assim, analisavam-se as medidas de $\Delta l$ e, pela aplicação do teste "t", desprezavam-se as que ficavam fora da faixa $\overline{\Delta 1} \pm$ ts. $\sqrt{n}$, para um grau de confiança de $99 \% .45$

Verificou-se que a estimativa do desvio padrão

para $\overline{\Delta 1}$ foi, em mēdia, da ordem de $0,4 \mathrm{~mm}$.

Coeficiente de correlação e desvio padrão da reta

Em todos os grāficos, nos quais a relação entre as variāveis " $x "$ e " $y$ " parecia ser linear, era calculada a reta que melhor se ajustava ao conjunto de pontos apresentados. Pa ra esta finalidade, empregava-se o programa da calculadora Hew lett Packard.77 A equação da reta era expressa na forma $y=m x+b$, sendo os valores dos parâmetros "m" e "b", bem como o do coeficiente de correlação "r", fornecidos pelo progra ma .

o desvio padrão da reta era calculado utilizando-se - programa Stat-Pac IV-10.

3.2.3. Determinação do deslocamento químico do prōton hidroxí lico do doador em sistema ternärio: doador-aceptor de pröton-tetracloreto de carbono.

Determinação de $\Delta v_{0}$

Mediam-se, diretamente nos espectros, os valores de $\Delta 1$ (v. 3.2.1.). Transformava-se o valor mẻdio de $\Delta 1$ parà $\Delta v^{\prime}$ (em $H z$ ), utilizando-se de um fator "f", de acordo com a expressão (1). Correlacionavam-se os valores de $\Delta \nu^{\prime}$ com os de [doador] obtendo-se, por extrapolação, para [doador] $=0$ (diluição infinita), o valor de $\Delta \nu_{0}$. 


$$
\Delta v^{\prime}=f \cdot \overrightarrow{\Delta l}
$$

o valor de "f" utilizado era de $2,00 \mathrm{~Hz} / \mathrm{mm}$ para a largura de varredura empregada de $500 \mathrm{~Hz}$.

Determinação de $\Delta v^{\prime}{ }^{\prime}$

Mediam-se os valores de $\Delta 1$ (em $\mathrm{mm}$ ), como em 3.2 .1 . - valor mēdio de $\Delta l$ era transformado para $\Delta \nu^{\prime}$ através da expressão (1). 0 valor de $\Delta v^{\prime} \circ$ era obtido atravēs da expressão (2).

$$
\Delta v^{\prime} 0=\Delta v^{\prime}-\Delta v_{0}
$$

0 esquema 35 ilustra as relações existentes entre os deslocamentos químicos acima descritos.

\section{ESQUEMA 35}

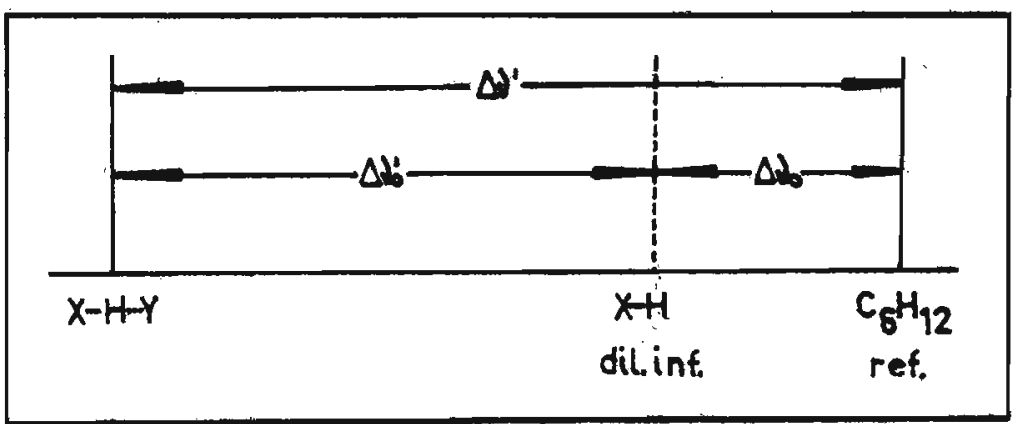

Determinação de $\Delta v$

Construia-se o gräfico de $\Delta v^{\prime} 0$ em função do quocien te molar $n_{\text {doador }} / n_{\text {aceptor }}$ Por extrapolação para $n_{\text {doador }} / n_{a c e p}$ tor $=0$ (diluição infinita do doador de prōton), obtinha-se 0 valor de $\Delta v$.

Verificou-se que o desvio padrão para $\Delta \nu$ foi, em mê dia, da ordem de $2 \mathrm{~Hz}$. 


\subsubsection{Determinação de constante de associação (kass)}

Mētodo de Mathur e col.106

Utilizando-se a expressão (3), efetuava-se o grāfico de $1 / \Delta \nu^{\prime} 0$ em função de $1 /$ [aceptor]. A divisão do coeficiente linear pelo coeficiente angular da reta obtida, fornecia o valor de kas.

$$
\frac{1}{\Delta \nu^{\prime} 0}=\frac{1}{\Delta_{0} \cdot k_{\text {ass }}} \cdot \frac{1}{\text { [aceptor] }}+\frac{1}{\Delta_{0}}
$$

Mētodo de Carper e col. ${ }^{33}$

Utilizando-se a expressão (4), efetuava-se o gräfico de $\Delta v^{\prime} o /$ [aceptor] em função de $\Delta v^{\prime} o$. Obtinha-se o valor de $k_{a s s}$, diretamente do coeficiente angular da reta obtida.

$$
\frac{\Delta v^{\prime} 0}{\text { [aceptor] }}=-k_{\text {ass }} \Delta v^{\prime} 0+k_{\text {ass }} \Delta_{0}
$$

Verificou-se que o desvio padrão para kass, em ambos os mētodos foi, em mëdia, da ordem de $0,3 \mathrm{M}^{-1}$.

\subsubsection{Experiências realizadas}

Experiência no 1

Determinação do deslocamento quĩmico do prōton hidroxīlico do fenol, à diluição infinita, em tetracloreto de carbono

Prepararam-se $10 \mathrm{ml}$ de uma solução de fenol em tetraćloreto de carbono, de concentração $0,060 \mathrm{M}$, contendo cerca de $0,2 \mathrm{ml}$ de ciclohexano (referência interna). Desta solução efetuaram-se as diluições necessärias obtendo-se as concentrações reunidas na tabela 13 . 
As medidas dos deslocamentos quimicos foram efetuadas segundo o procedimento descrito em 3.2 .1 . Os valores de $\Delta v^{\prime}(v .3 .2 .3$.$) , acham-se na tabe 1$ a 13 .

\section{TABELA 13}

Deslocamento químico do prōton hidroxīlico do fenol, em $\mathrm{CCl}_{4}$, a diferentes concentraçōes molares

\begin{tabular}{lc}
\hline [feno1] & $\Delta \nu^{\prime}(\mathrm{Hz})$ \\
\hline 0,00060 & 168,4 \\
0,015 & 172,0 \\
0,030 & 175,4 \\
0,045 & $178^{\prime}, 4$ \\
0,060 & 181,6 \\
\hline
\end{tabular}

Correlacionaram-se os valores de $\Delta v^{i}$ com os de [feno1.] (figura 18). Calculou-se a reta que melhor se ajustou ao conjunto de pontos apresentados (v. 3.2.2.). A extrapolação pa ra concentração zero do fenol, forneceu o valor:

$$
\Delta v_{0}=168,5 \mathrm{~Hz}
$$

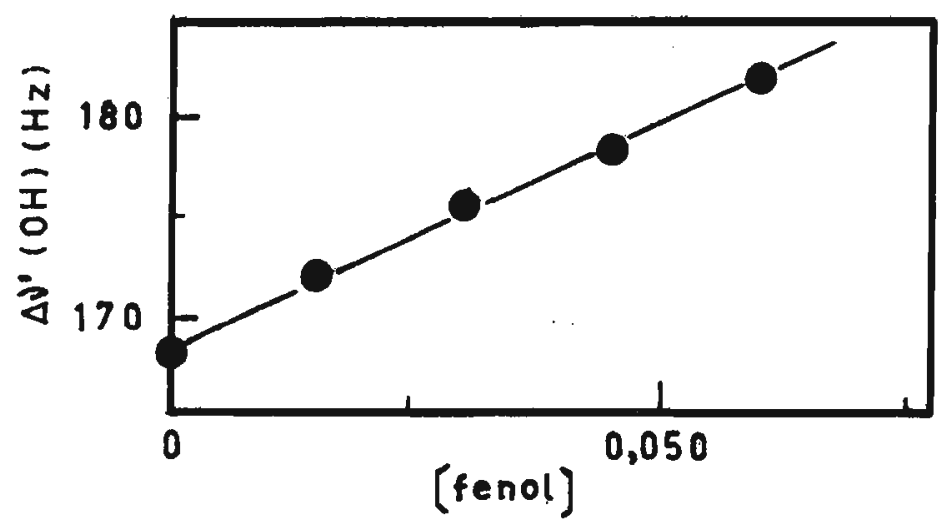

Figura 18 - Deslocamento químico do prōton hidroxîlico do fenol vs. concentraçäo molar, para soluções de fenol em $\mathrm{CCl}_{4}(r=0,999)$. 


\section{Experiēncia nọ 2}

Determinação do deslocamento químico do pröton hidroxīlico do p-clorofenol, à diluição infinita, em tetracloreto de carbono

Prepararam-se $10 \mathrm{ml}$ de uma solução de p-clorofenol, em tetracloreto de carbono de concentração $0,100 \mathrm{M}$, contendo cerca de $0,2 \mathrm{ml}$ de ciclohexano (referēncia interna). Desta so lução, efetuaram-se as diluições necessārias, obtendo-se as concentrações reunidas na tabe 1 a 14 .

As medidas dos deslocamentos quĩmicos foram efetuadas segundo o procedimento descrito em 3.2 .1 . Os valores de $\Delta v^{\prime}(v .3 .2 .3$.$) encontram-se na tabela 14$.

\section{TABELA 14}

Deslocamento químico do pröton hidroxîlico do p-clorofenol, em $\mathrm{CCl}_{4}$, a diferentes concentraçōes molares

\begin{tabular}{cc}
{$[\mathrm{p}-\mathrm{c}$ 10rofeno $]$} & $\Delta \nu^{\prime} \cdot(\mathrm{Hz})$ \\
\hline 0,0030 & 180,0 \\
0,010 & 181,6 \\
0,025 & 184,0 \\
0,050 & 188,4 \\
0,070 & 190,2
\end{tabular}

Correlacionaram-se os valores de $\Delta \nu^{\prime}$ com os de $[p-$ clorofenol) (figura 19). Calculou-se a reta que melhor se ajustou ao conjunto de pontos apresentados (v. 3.2.2.). A extrapolação para concentração zero do p-clorofenol, forneceu o valor: 


$$
\Delta \nu_{0}=180,0 \mathrm{~Hz}
$$

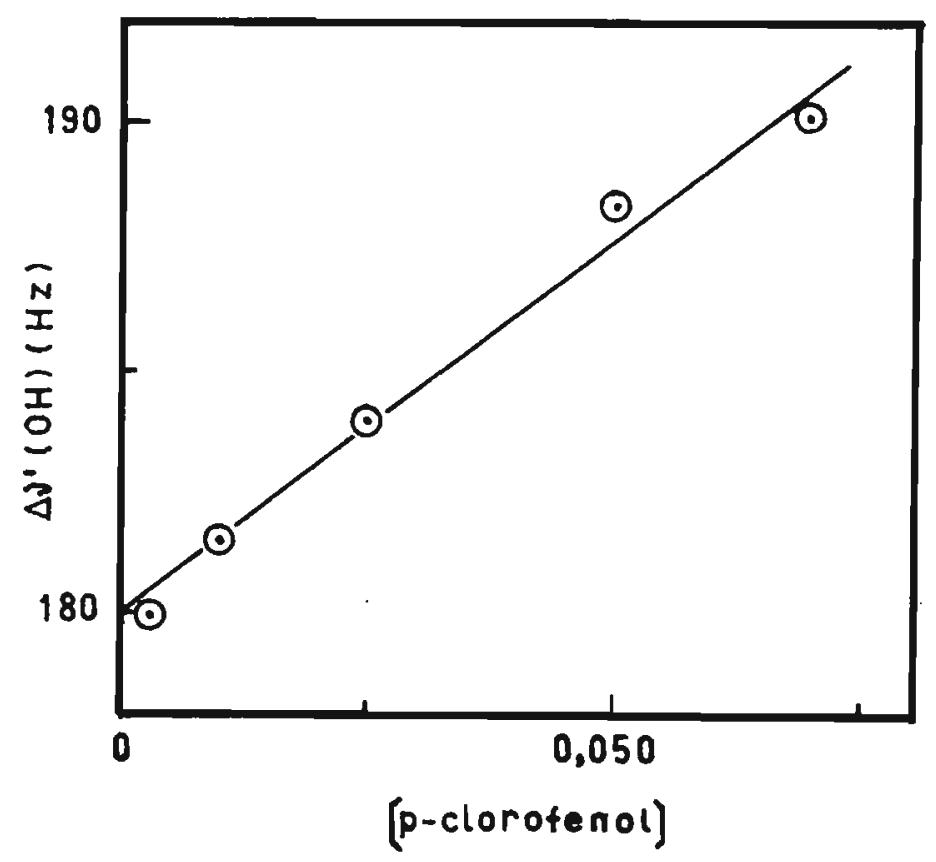

Figura 19 - Deslocamento químico do prōton hidroxîlico do p-clorofenol vs. concentração molar, pa ra soluções de p-clorofenol em $\mathrm{CCl}_{4}(r=0,993)$.

\section{Experiência no 3}

Deslocamento da ponte de hidrogênio e constante de associação do sistema: doador de prōton-ciclopentanona (LXXXIII), em tetracloreto de carbono

a) doador de pröton: fenol

As amostras foram preparadas como estä descrito na pag. 87 .

Efetuaram-se as medidas dos deslocamentos quỉmicos do prōton hidroxilico do fenol (v. 3.2.1.) e calcularam-se os valores de $\Delta \nu^{\prime}$ e de $\Delta \nu^{\prime}$ o segundo procedimentos descritos em 3.2.3. Os resultados obtidos acham-se na tabela 15 . 
TABELA 15

Deslocamentos quîmicos para o sistema fenol-ciclopentanona (LXXXIII), em $\mathrm{CCl}_{4}$, a diferentes relações molares

\begin{tabular}{llc}
$\mathrm{n}_{\mathrm{OH}} / \mathrm{n}_{\mathrm{CO}}$ & $\Delta \nu^{\prime}(\mathrm{Hz})$ & $\Delta \nu^{\prime} \mathrm{O}(\mathrm{Hz})$ \\
\hline 0,067 & 308,8 & 140,3 \\
0,074 & 307,8 & 139,3 \\
0,083 & 299,0 & 130,5 \\
0,095 & 293,0 & 124,5 \\
0,111 & 287,8 & 119,3 \\
0,133 & 279,2 & 110,7 \\
0,167 & 268,2 & 99,7 \\
0,222 & 253,2 & 84,5 \\
\hline
\end{tabular}

Correlacionaram-se os valores de deslocamento da pon te de hidrogênio $\left(\Delta \nu^{\prime} 0\right)$ com os de quocientes molares $\left(n_{\mathrm{OH}} / \mathrm{n}_{\mathrm{CO}}\right)$ (figura 1, pag. 43) e calculou-se a reta com os pontos em que a relação entre as variäveis pareceu ser linear (v. 3.2.2.). 0 valor de $\Delta v$, obtido por extrapolação para $n_{O H} / n_{C O}=0$, encon tra-se na tabela 1 (pag. 45).

Efetuaram-se os grāficos de $1 / \Delta v^{\prime} O$ em função de $1 /[c o]$ (figura 20) e de $\Delta v^{\prime} o /[c 0]$ en função de $\Delta v^{\prime}$ o(figura 21) (v. 3.2.4.). Calcularam-se as retas que meinor se ajustaram aos conjuntos de pontos apresentados ( $v$. 3.2.2.) obtendo-se os valores de $k_{\text {ass }}$ reunidos na tabela 2 (pag. 47). 
b) doador de pröton: p-clorofenol

As amostras foram preparadas como estä descrito na pag. 87 .

Efetuaram-se as medidas dos deslocamentos químicos do prōton hidroxīlico do p-clorofenol (v.3.2.1.) e calcularam-se os valores de $\Delta \nu^{\prime} e$ de $\Delta \nu^{\prime} o$ de acordo com procedimentos descritos em 3.2.3. Os resultados obtidos encontram-se na tabela 16 .

\section{TABELA 16}

Deslocamentos químicos para o sistema p-clorofenol-ciclopentanona ( $L X X X I I I$ ), em $\mathrm{CCl}_{4}$, a diferentes relações molares

\begin{tabular}{lll}
\hline $\mathrm{n}_{\mathrm{OH}} / \mathrm{n}_{\mathrm{CO}}$ & $\Delta \nu^{\prime}(\mathrm{Hz})$ & $\Delta \nu^{\prime} \mathrm{O}(\mathrm{Hz})$ \\
\hline 0,100 & 343,4 & 163,4 \\
0,111 & 340,6 & 160,6 \\
0,125 & 335,6 & 155,6 \\
0,143 & 331,6 & 151,6 \\
0,167 & 325,0 & 145,0 \\
0,200 & 316,6 & 136,6 \\
0,250 & 306,2 & 126,2 \\
0,333 & 291,4 & 111,4 \\
\hline
\end{tabular}

Correlacionaram-se os valores de deslocamento da pon te de hidrogênio $\left(\Delta \nu^{\prime} O\right)$ comos de quocientes molares $\left(n_{O H} / n_{C O}\right)$ (figura 2, pag. 44) e calculou-se a reta com os pontos em que a relação entre as variäveis pareceu ser linear (v.3.2.2.). 0 valor de $\Delta v$, obtido por extrapolação para $n_{O H} / n_{C O}=0$, encontra-se na tabela 1 (pag. 45). 
Efetuaram-se os gräficos de $1 / \Delta v^{\prime} o$ em função de $1 /[c o]$ (figura 20) e de $\Delta \nu^{\prime} 0 /[c o]$ em função de $\Delta \nu^{\prime} o$ (figura 21) (v. 3.2.4.). Calcularam-se as retas destas figuras, de acordo com procedimento descrito em 3.2.2., obtendo-se os valores de kass reunidos na tabela 2 (pag. 47).

A figura 22 (pag.149) mostra os espectros de r.m.n. do sistema ciclopentanona-p-clorofenol, em tetracloreto de car bono, a quocientes molares $\left(n_{\mathrm{OH}} / n_{\mathrm{CO}}\right) 0,125$ (A), 0,167 (B) e j, $250(C)$.

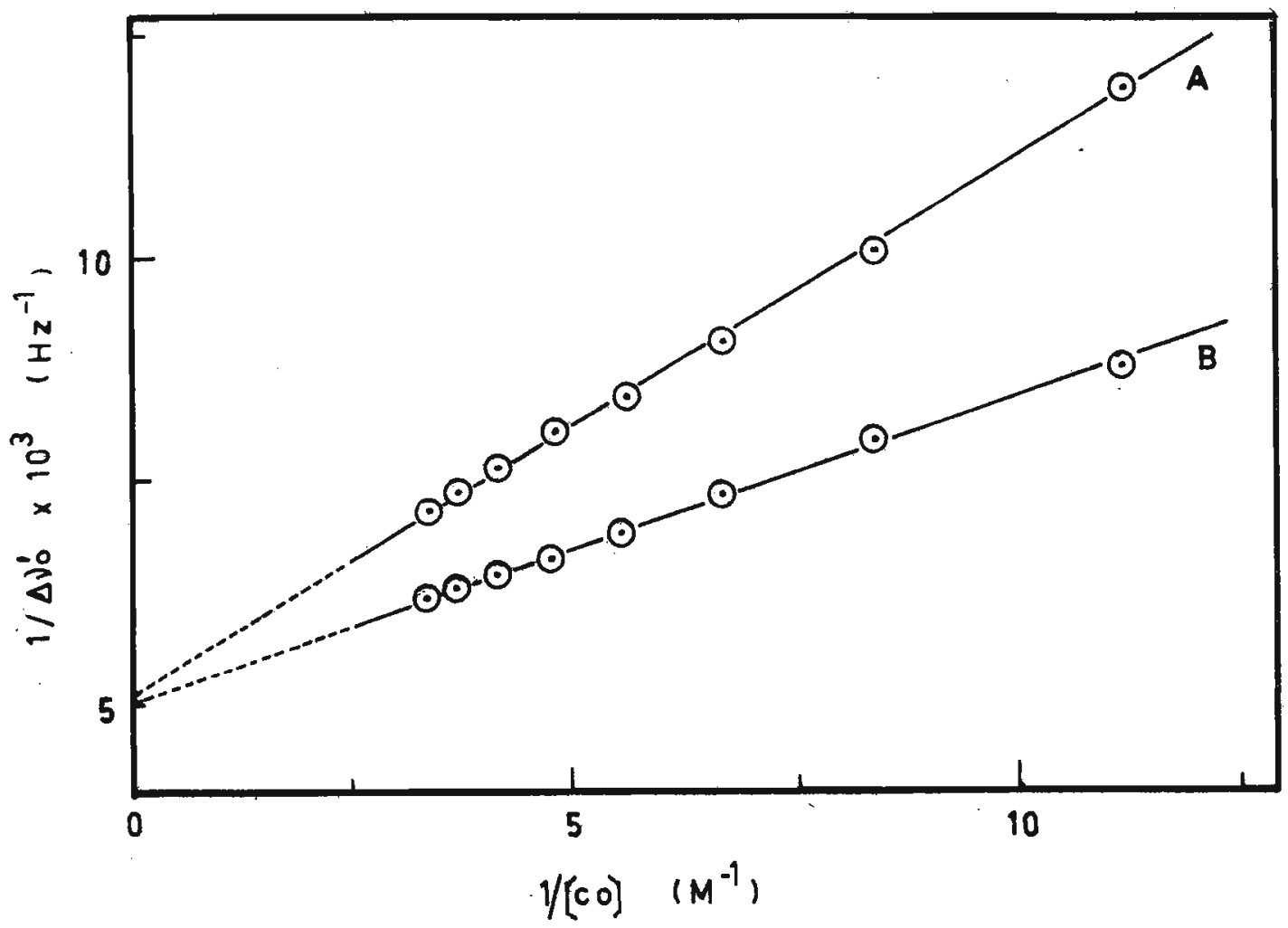

Figura 20 - $1 / \Delta v^{\prime} 0$ vs. $1 /[$ co]; sistema. doador de pröton-ciclopentanona, em. $\mathrm{CCl}_{4} ; A=$ fenol $(r=0,999)$; $B=p-c$ lorofenol $(r=0,999)$. 


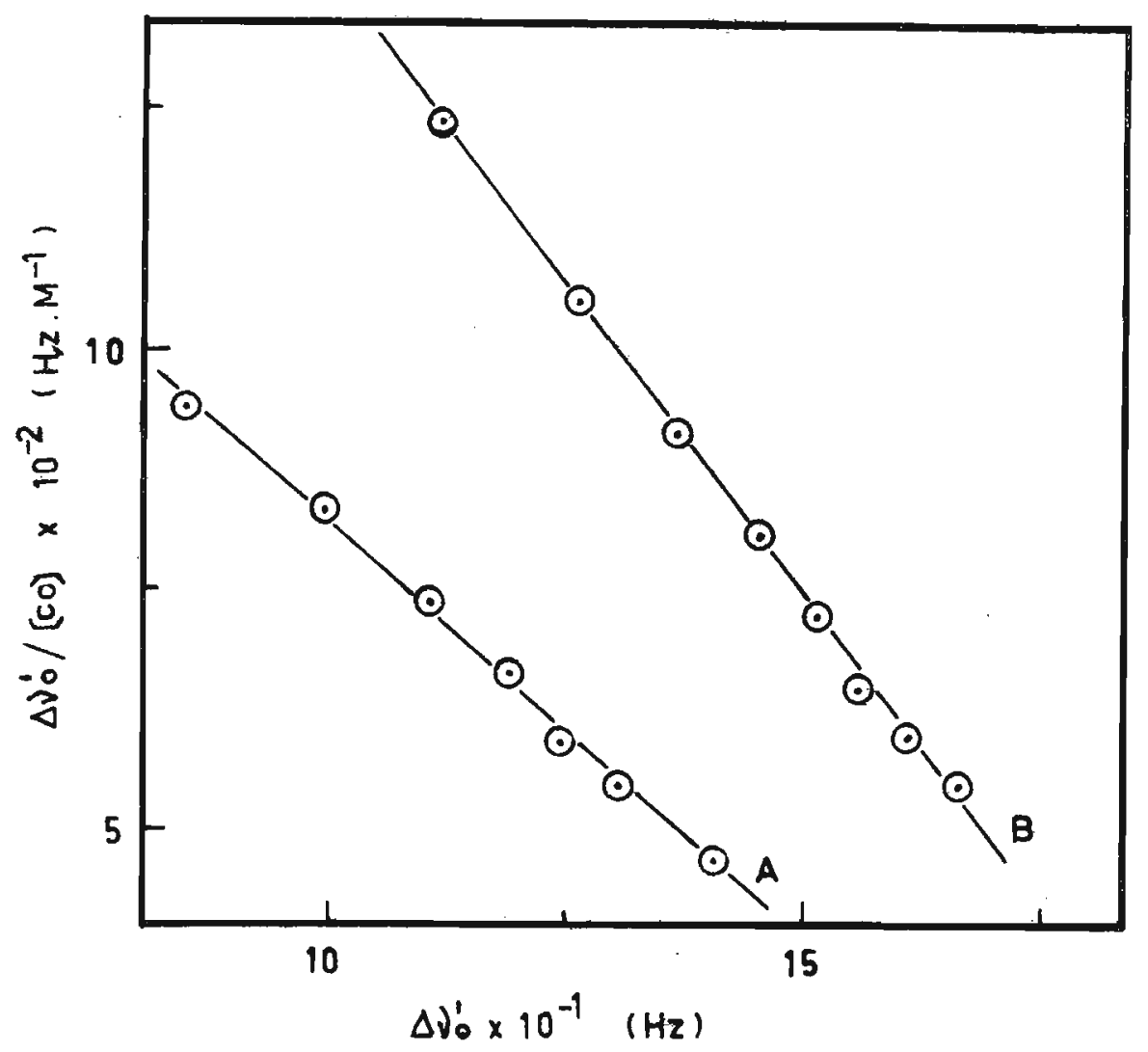

Figura $21-\Delta v^{\prime} o /[c o]$ vs. $\Delta v^{\prime} o$; sistema: doador de próton-ciclopentanona, em $\mathrm{CCl}_{4} ; A=$ fenol $(r=0,998)$; $B=p-c$ lorofenol $(r=0,999)$.

Experiência no 4

Des locamento da ponte de hidrogênio e constante de associação do sistema: doador de prōton-3-tiaciclopentanona (LXXVII), em tetracloreto de carbono

a) doador de pröton: fenol

Procedendo-se de acordo com a experiência nọ $3 a$, efetuaram-se as medidas e os cālculos dos deslocamentos quím cos, cujos resultados acham-se na tabela 17. A correlação entre $\Delta v^{\prime} O$ e quocientes molares $n_{\mathrm{OH}} / \mathrm{n}_{\mathrm{CO}}$ encontra-se na figura 1 (pag. 43) e o valor de deslocamento da ponte de hidrogênio à diluição infinita do doador de pröton $(\Delta \nu)$, na tabela 1 
$(p a g .45)$

Os valores de kass, obtidos segundo os procedimentos descritos em 3.2.4., encontram-se na tabela 2 (pag. 47).

b) doador de prōton: p-clorofenol

Procedendo-se de acordo com a experiência nọ $3 b$, efetuaram-se as medidas e os cālculos dos deslocamentos quími cos, cujos resultados acham-se na tabela 17. A correlação entre $\Delta v^{\prime} O$ e quocientes molares $n_{\mathrm{OH}} / n_{\mathrm{CO}}$ encontra-se na figura 2 (pag. 44) e o valor de deslocamento da ponte de hidrogênio à diluição infinita de p-clorofenol $(\Delta \nu)$, na tabela 1 (pag. 45).

Os valores de $k_{\text {ass }}$, obtidos segundo os procedimentos descritos em 3.2.4., acham-se na tabela 2 (pag. 47).

\section{TABELA 17}

Deslocamentos quîmicos para o sistema doador de próton-3-tiaciclopentanona ( $L X X V I I)$, em $\mathrm{CCl}_{4}$, a diferentes relações molares

\begin{tabular}{|c|c|c|c|c|c|}
\hline \multicolumn{3}{|c|}{ fenol } & \multicolumn{3}{|c|}{$p-c l o r o f e n o l$} \\
\hline${ }^{n_{\mathrm{OH}}} /{ }^{n} \mathrm{CO}$ & $\Delta v^{\prime}(H z)$ & $\Delta v^{\prime} \circ(\mathrm{Hz})$ & $\mathrm{n}_{\mathrm{OH}} / \mathrm{n}_{\mathrm{CO}}$ & $\Delta v^{\prime}(H z)$ & $\Delta v^{\prime} O(H z)$ \\
\hline 0,067 & 249,6 & 81,1 & 0,100 & 278,8 & 98,8 \\
\hline 0,074 & 246,0 & 77,5 & 0,111 & 275,8 & 95,8 \\
\hline 0,083 & 239,6 & 71,1 & 0,125 & 270,2 & 90,2 \\
\hline 0,095 & 233,2 & 64,7 & 0,143 & 265,0 & 85,0 \\
\hline 0,111 & 228,6 & 60,1 & 0,167 & 258,8 & 78,8 \\
\hline 0,133 & 222,0 & 53,5 & 0,200 & 250,8 & 70,8 \\
\hline 0,167 & 274,4 & 45,9 & 0,250 & 234,2 & 60,8 \\
\hline 0,222 & 207,4 & 38,9 & -- & -- & -- \\
\hline
\end{tabular}




\section{Experiēncia nọ 5}

Deslocamento da ponte de hidrogênio e constante de associação do sistema: doador de pröton-ciclohexanona ( $L X X X I V)$, em tetra cloreto de carbono

a) doador de prōton: fenol

Procedendo-se de acordo com a experiência no $3 a$, efetuaram-se as medidas e os cálculos dos deslocamentos quĩmi cos cujos resultados acham-se na tabela 18. A correlação entre $\Delta v^{\prime} \circ$ e quocientes molares $n_{\mathrm{OH}} / \mathrm{n}_{\mathrm{CO}}$ encontra-se na figura 1 (pag. 43) e o valor do deslocamento da ponte de hidrogénio à diluição infinita de fenol ( $\Delta \nu$ ), na tabela 1 (pag. 45).

os valores de $k_{a s s}$, obtidos segundo os procedimentos descritos em 3.2.4., encontram-se na tabela 2 (pag. 47).

b) doador de pröton: p-clorofenol

Procedendo-se de acordo com a experiência no $3 b$, efetuaram-se as medidas e os cālculos dos deslocamentos quĩmi cos cujos resultados encontram-se na tabela 18. A correlação entre $\Delta \nu^{\prime} O$ e quocientes molares $n_{\mathrm{OH}} /{ }^{n}{ }_{C O}$ acha-se na figura 2 (pag. 44) e o valor de deslocamento da ponte de hidrogênio à diluição infinita de $p$-clorofenol ( $\Delta \nu$ ), na tabela 1 (pag. 45).

os valores de $k_{\text {ass }}$, obtidos segundo os procedimentos descritos em 3.2.4., acham-se na tabela 2 (pag. 47).

A figura $23 \mathrm{~A}$ (pag. 150) mostra o espectro de r.m.n. do sistema: ciclohexanona-p-clorofenol, em $\mathrm{CCl}_{4}$, a quociente $\operatorname{molar}\left(n_{O H} / n_{C O}\right)=0,167$. 


\section{TABELA 18}

Deslocamentos químicos para o sistema: doador de pröton-ciclo hexanona (LXXXIV), em $\mathrm{CCl}_{4}$, a diferentes relações molares

\begin{tabular}{|c|c|c|c|c|c|}
\hline \multicolumn{3}{|c|}{ fenol } & \multicolumn{3}{|c|}{$p$-clorofenol } \\
\hline$n_{\mathrm{OH}} / n_{\mathrm{CO}}$ & $\Delta v^{\prime}(H z)$ & $\Delta v^{\prime} O(H z)$ & $n_{\mathrm{OH}} / \mathrm{n}_{\mathrm{CO}}$ & $\Delta v^{\prime}(H z)$ & $\Delta v^{\prime} O(H z)$ \\
\hline 0,067 & 318,4 & 149,9 & 0,100 & 354,2 & 174,2 \\
\hline 0,074 & 375,2 & 146,7 & 0,111 & 351,2 & 171,2 \\
\hline 0,083 & 310,8 & 142,3 & 0,125 & 347,6 & 167,6 \\
\hline 0,095 & 307,0 & 138,5 & 0,143 & 343,0 & 163,0 \\
\hline 0,111 & 298,8 & 130,3 & 0,167 & 337,2 & 157,2 \\
\hline 0,133 & 289,6 & 121,1 & 0,200 & 330,2 & 150,2 \\
\hline 0,167 & 279,4 & 110,9 & 0,250 & 380,2 & 140,2 \\
\hline 0,222 & 262,6 & 94,1 & 0,333 & 306,6 & 126,6 \\
\hline
\end{tabular}

Experiência no 6

Deslocamento da ponte de hidrogênio e constante de associação do sistema: doador de próton-3-tiaciclohexanona (LXXVIII), em tetracloreto de carbono

a) doador de próton: fenol

Procedendo-se de acordo com a experiência nọ $3 a$, efetuaram-se as medidas e os cālculos dos deslocamentos quỉmi cos, cujos resultados encontram-se na tabela 19. A correlação entre $\Delta \nu^{\prime} O$ e quocientes molares $n_{\mathrm{OH}} / n_{\mathrm{CO}}$ acha-se na figura 1 (pag. 43) e o valor de deslocamento da ponte de hidrogênio à diluição infinita de fenol ( $\Delta \nu$ ), na tabela 1 (pag. 45). 
os valores de kass, obtidos segundo os procedimentos descritos em 3.2.4., acham-se na tabela 2 (pag. 47).

b) doador de prōton: p-clorofenol

Procedendo-se de acordo com a experiēncia no $3 b$, efetuaram-se as medidas e os cälculos dos deslocamentos quími cos, cujos resultados encontram-se na tabela 19. A correlação entre $\Delta v^{\prime} O$ e quocientes molares $n_{\mathrm{OH}} / n_{\mathrm{CO}}$ acha-se na figura 2 (pag. 44) e o valor de deslocamento da ponte de hidrogēnio à diluição infinita de p-clorofenol ( $\Delta \nu$ ), na tabela 1 (pag. 45).

os valores de kass, obtidos segundo os procedimentos descritos em 3.2.4., acham-se na tabela 2 (pag. 47).

A figura 23B (pag.150) mostra o espectro de r.m.n. do sistema 3-tiaciclohexanona-p-clorofenol, em tetracloretode carbono, a quociente molar $\left(n_{\mathrm{OH}} / \mathrm{n}_{\mathrm{CO}}\right)=0,167$.

\section{TABELA 19}

Deslocamentos químicos para o sistema: doador de pröton-3-tiaci clohexanona (LXXVIII), em $\mathrm{CCl}_{4}$, a diferentes relaçōes molares

\begin{tabular}{|c|c|c|c|c|c|}
\hline \multicolumn{3}{|c|}{ fenot } & \multicolumn{3}{|c|}{$p-c l o r o f e n o l$} \\
\hline${ }^{n_{O H}} / n_{C O}$ & $\Delta v^{\prime}(H z)$ & $\Delta v^{\prime} O(H z)$ & ${ }^{n_{O H}} / n_{C O}$ & $\Delta v^{\prime}(H z)$ & $\Delta \nu^{\prime} O(H z)$ \\
\hline 0,067 & 279,4 & 110,9 & 0,100 & 319,0 & 139,0 \\
\hline 0,074 & 275,4 & 106,9 & 0,111 & 313,8 & 133,8 \\
\hline 0,083 & 270,0 & 101,5 & 0,125 & 307,0 & 127,0 \\
\hline 0,095 & 262,2 & 93,7 & 0,143 & 302,4 & 122,4 \\
\hline 0,111 & 258,0 & 89,5 & 0,167 & 293,6 & 113,6 \\
\hline 0,133 & 247,4 & 78,9 & 0,200 & 286,0 & 106,0 \\
\hline 0,167 & 238,6 & 70,1 & 0,250 & 274,0 & 94,0 \\
\hline 0,222 & 224,4 & 55,9 & 0,333 & 260,0 & 80,0 \\
\hline
\end{tabular}




\section{Experiēncia no 7}

Deslocamento da ponte de hidrogēnio e constante de associação do sistema: doador de prōton-cicloheptanona ( $L X X X V)$, em tetracloreto de carbono

\section{a) doador de prōton: fenol}

Procedendo-se de acordo com a experiéncia no $3 a$, efetuaram-se as medidas e os cālculos dos deslocamentos quími cos. Os resultados obtidos acham-se na tabela 20. O gráficode correlação entre $\Delta v^{\prime} O$ e $n_{O H} / n_{C O}$ encontra-se na figura 1 (pag. 43) e o valor de deslocamento da ponte de hidrogênio à diluição infinita de fenol ( $\Delta v)$, na tabela 1 (pag. 45).

os valores de ḱas, obtidos segundo os procedimentos descritos em 3.2.4., acham-se na tabela 2 (pag. 47).

b) doador de próton: p-clorofenol

Procedendo-se de acordo com a experiência nọ $3 b$, efetuaram-se as medidas e os cālculos dos deslocamentos quími cos. Os resultados obtidos encontram-se na tabela 20 . o gräf co de correlação entre $\Delta \nu^{\prime} O$ e $n_{O H} / n_{C O}$ encontra-se na figura 2 (pag. 44) e o valor do deslocamento da ponte de hidrogénio à diluição infinita de p-clorofenol ( $\Delta v)$, na tabela 1 (pag. 45). os valores de kass, obtidos de acordo com os métodos descritos em 3.2.4., acham-se na tabela 2 (pag. 47). 


\section{TABELA 20.}

Deslocamentos quĩmicos para o sistema: doador de pröton-ciclo neptanona ( $L X X X V$ ), em $\mathrm{CCl}_{4}$, a diferentes relações molares

\begin{tabular}{|c|c|c|c|c|c|}
\hline \multicolumn{3}{|c|}{ fenol } & \multicolumn{3}{|c|}{$p$-clorofenol } \\
\hline${ }^{n_{\mathrm{OH}}} / n_{\mathrm{CO}}$ & $\Delta v^{\prime}(H z)$ & $\Delta v^{\prime} O(H z)$ & $n_{\mathrm{OH}} / \mathrm{n}_{\mathrm{CO}}$ & $\Delta v^{\prime}(H z)$ & $\Delta v^{\prime} \circ\langle H z\}$ \\
\hline 0,067 & 324,4 & 155,9 & 0,100 & 359,6 & 179,6 \\
\hline 0,074 & 320,4 & 151,9 & 0,111 & 356,6 & 176,6 \\
\hline 0,083 & 314,6 & 146,1 & 0,125 & 352,0 & 172,0 \\
\hline 0,095 & 309,6 & 141,1 & 0,143 & 348,2 & 168,2 \\
\hline 0,111 & 301,4 & 132,9 & 0,167 & 340,6 & 160,6 \\
\hline 0,133 & 293,8 & 125,3 & 0,200 & 335,0 & 155,0 \\
\hline 0,167 & 280,6 & 112,1 & 0,250 & 322,6 & 142,6 \\
\hline 0,222 & 272,0 & 103,5 & 0,333 & 311,2 & 131,2 \\
\hline
\end{tabular}

\section{Experiēncia no 8}

Deslocamento da ponte de hidrogênio e constante de associação do sistema: doador de próton-3-tiacicloheptanona (LXXIX), em

\section{tetracloreto de carbono}

a) doador de pröton: fenol

Procedendo-se de acordo com a experiência no $3 a$, efetuaram-se as medidas e os cālculos dos deslocamentos quīmi cos. Os resultados obtidos acham-se na tabela 21. 0 gráfico de correlação entre $\Delta \nu^{\prime} \circ$ e ${ }^{n_{O H} / n_{C O}}$ encontra-se na figura 1 (pag. 43) e o valor de deslocamento da ponte de hidrogēnio à diluição infinita de fenol ( $\Delta \nu$ ), na tabela 1 (pag. 45).

os valores de $k_{a s s}$, obtidos segundo os procedimen- 
tos descritos em 3.2.4., acham-se na tabela 2 (pag. 47).

b) doador de pröton: p-clorofenol

Procedendo-se de acordo com a experiência no $3 b$, efetuaram-se as medidas e os cálculos dos deslocamentos quími cos.0s resultados obtidos acham-se na tabela 21 . 0 gräfico de correlação entre $\Delta \nu^{\prime} O$ e $n_{O H} /{ }^{n} C_{C O}$ encontra-se na figura 2 (pag. 44) e o valor de deslocamento da ponte de hidrogênio à diluição infinita de p-clorofenol ( $\Delta \nu$ ), na tabela 1 (pag. 45).

\section{TABELA 21}

Deslocamentos quîmicos para o sistema: doador de prōton-3-tia cicloheptanona ( $L X X I X)$, em $\mathrm{CCl}_{4}$, a diferentes relações molares

\begin{tabular}{ccccccc}
\hline & fenol & & & \multicolumn{3}{c}{$p$-clorofenol } \\
\cline { 1 - 4 } \cline { 5 - 7 } $\mathrm{n}_{\mathrm{OH}} /{ }^{n}{ }_{\mathrm{CO} O}$ & $\Delta \nu^{\prime}(\mathrm{Hz})$ & $\Delta \nu^{\prime} \mathrm{O}(\mathrm{Hz})$ & & $\mathrm{n}_{\mathrm{OH}} / \mathrm{n}_{\mathrm{CO}}$ & $\Delta \nu^{\prime}(\mathrm{Hz})$ & $\Delta \nu^{\prime} \mathrm{O}(\mathrm{Hz})$ \\
\hline 0,074 & 275,8 & 107,3 & & 0,125 & 311,0 & 131,0 \\
0,083 & 271,0 & 102,5 & & 0,143 & 305,6 & 125,6 \\
0,095 & 265,8 & 97,3 & & 0,200 & 289,0 & 109,0 \\
0,111 & 258,6 & 90,1 & & 0,250 & 276,0 & 96,0 \\
0,133 & 250,4 & 81,9 & & -- & -- & -- \\
0,167 & 240,6 & 72,1 & & -- & -- & -- \\
0,222 & 228,2 & 59,3 & -- & -- & -- \\
\hline
\end{tabular}




\section{Experiência nọ 9}

Deslocamento da ponte de hidrogēnio e constante de associação do sistema: doador de prōton-4-tiaciclohexanona ( $L X X X)$, em te tracloreto de carbono

\section{a) doador de pröton: fenol}

Procedendo-se de acordo com a experiência nọ $3 a$, efetuaram-se as medidas e os cālculos dos deslocamentos quími cos. Os resultados acham-se na tabela 22 . O gräfico de $\Delta v^{\prime} 0$ em função de $n_{O H} / n_{C O}$ encontra-se na figura 5 (pag. 49) e o valor de $\Delta v$, na tabela 3 (pag. 50).

Os valores de $k_{\text {ass }}$, obtidos segundo os procedimentos descritos em 3.2.4., acham-se na tabela 4 (pag. 51).

b) doador de pröton: p-clorofenol

Procedendo-se de acordo com a experiēncia no $3 b$, efetuaram-se as medidas e os cālculos dos deslocamentos quĩmi cos. Os resultados acham-se na tabela 22. O grāfico de correTação entre $\Delta \nu^{\prime} O$ e $n_{O H} / n_{C O}$ encontra-se na figura 6 (pag. 49) e o valor de $\Delta v$ na tabela 3 (pag. 50).

Os valores de kass, obtidos de acordo com os procedimentos descritos em 3.2.4., acham-se na tabela. 4 (pag. 51). A figura $23 \mathrm{C}$ (pag.150) mostra o espectro de r.m.n. do sistema 4-tiaciclohexanona-p-clorofenol, em tetracloreto de carbono a quociente molar $\left(n_{\mathrm{OH}} / n_{\mathrm{CO}}\right)=0,167$. 
Deslocamentos quîmicos para o sistema: doador de próton-4-tia ciclohexanona ( $L X X X)$, em $\mathrm{CCl}_{4}$, a diferentes relaçöes molares

\begin{tabular}{lcccccc}
\hline & fenol & & & \multicolumn{3}{c}{$p$-clorofenol } \\
\cline { 6 - 8 }$n_{\mathrm{OH}} / \mathrm{n}_{\mathrm{CO}}$ & $\Delta \nu^{\prime}(\mathrm{Hz})$ & $\Delta \nu^{\prime} \mathrm{O}(\mathrm{Hz})$ & & $\mathrm{n}_{\mathrm{OH}} / \mathrm{n}_{\mathrm{CO}}$ & $\Delta \nu^{\prime}(\mathrm{Hz})$ & $\Delta \nu^{\prime} \mathrm{O}(\mathrm{Hz})$ \\
\hline 0,067 & 280,2 & 111,7 & & 0,100 & 316,8 & 136,8 \\
0,074 & 276,6 & 108,1 & & 0,111 & 312,6 & 132,6 \\
0,083 & 271,6 & 103,1 & & 0,125 & 307,2 & 127,2 \\
0,095 & 264,6 & 96,1 & & 0,143 & 301,6 & 121,6 \\
0,111 & 258,6 & 90,1 & & 0,167 & 294,6 & 114,6 \\
0,133 & 248,6 & 80,1 & & 0,200 & 287,6 & 107,6 \\
0,167 & 240,6 & 72,1 & & 0,250 & 274,8 & 94,8 \\
0,222 & 228,6 & 60,1 & & 0,333 & 262,6 & 82,6 \\
\hline
\end{tabular}

Experiência n? 10

Deslocamento da ponte de hidrogênio e constante de associação do sistema: doador de próton-4-tiacicloheptanona (LXXXI), em tetracloreto de carbono

a) doador de pröton: fenol

Procedendo-se de acordo com a experiēncia no $3 a$, efetuaram-se as medidas e os cālculos dos deslocamentos quĩmi cos. Os resultados obtidos acham-se na tabela 23. 0 gräfico de correlação de $\Delta v^{\prime} O$ e $n_{O H} / n_{C O}$ encontra-se na figura 5 (pag. 49) e o valor de $\Delta v$, na tabela 3 (pag. 50).

os valores de $k_{a s s}$, obtidos segundo os procedimentos descritos em 3.2.4., acham-se na tabela 4 (pag. 51). 
b) doador de próton: p-clorofenol

Procedendo-se de acordo com a experiēncia no $3 b$, efetuaram-se as medidas e os cālculos dos deslocamentos quimi cos. Os resultados obtidos acham-se na tabela 23. O grāfico de correlação de $\Delta \nu^{\prime} O$ e $n_{O H} / n_{C O}$ encontra-se na figura 6 (pag. 49) e o valor de $\Delta v$ na tabela 3 (pag. 50).

os valores de $k_{\text {ass }}$ obtidos segundo os procedimentos descritos em 3.2.4., acham-se na tabela 4 (pag. 51).

\section{TABELA 23}

Deslocamentos químicos para o sistema: doador de prōton-4-tia cicloheptanona ( $L X X X I)$, em $\mathrm{CC}_{4}$, a diferentes relações molares

\begin{tabular}{|c|c|c|c|c|c|}
\hline \multicolumn{3}{|c|}{ fenol } & \multicolumn{3}{|c|}{ p-clorofenol } \\
\hline$n_{\mathrm{OH}} / n_{\mathrm{CO}}$ & $\Delta v^{\prime}(H z)$ & $\Delta v^{\prime} O(H z)$ & ${ }^{n_{\mathrm{OH}}} / n_{\mathrm{CO}}$ & $\Delta v^{\prime}(H z)$ & $\Delta v^{\prime} O(H z)$ \\
\hline 0,067 & 292,0 & 123,5 & 0,100 & 332,0 & 152,0 \\
\hline 0,074 & 286,8 & 118,3 & 0,111 & 326,8 & 146,8 \\
\hline 0,083 & 281,6 & 113,1 & 0,125 & 320,2 & 140,2 \\
\hline 0,095 & 275,8 & 107,3 & 0,143 & 314,4 & 134,4 \\
\hline 0,111 & 267,8 & 99,3 & 0,167 & 307,2 & 127,2 \\
\hline 0,133 & 258,2 & 89,7 & 0,200 & 301,0 & 121,0 \\
\hline 0,167 & 246,4 & 77,9 & 0,250 & 286,0 & 106,0 \\
\hline
\end{tabular}


Experiência nọ 11

Deslocamento da ponte de hidrogênio; sistema: doador de próton-ciclooctanona ( $L X X X V I$ ), em tetracloreto de carbono

a) doador de pröton: fenol

Procedendo-se de acordo com a experiência no $3 a$, efetuaram-se as medidas e os cālculos dos deslocamentos quími cos. Os resultados encontram-se na tabela 24. 0 gräfico de correlação entre $\Delta \nu^{\prime} O$ e $n_{O H} / n_{C O}$ acha-se na figura 7 (pag. 52) e o valor de $\Delta v$, na tabela 5 (pag. 53).

b) doador de próton: p-clorofenol

Procedendo-se de acordo com a experiência nọ $3 b$, efetuaram-se as medidas e os cálculos dos deslocamentos quími cos. Os resultados obtidos acham-se na tabela 24. Ogräfico de correlação entre $\Delta \nu^{\prime} O$ e $n_{O H} / n_{C O}$ encontra-se na figura 8 (pag. 53) e o valor de $\Delta v$, na tabela 5 (pag. 53).

\section{TABELA 24}

Deslocamentos quĩmicos para o sistema: doador de pröton-ciclo octanona ( $L X X X V I$ ), em $\mathrm{CCl}_{4}$, a diferentes relações molares

\begin{tabular}{|c|c|c|c|c|c|}
\hline \multicolumn{3}{|c|}{ fenol } & \multicolumn{3}{|c|}{$p-c$ lorofenol } \\
\hline${ }^{n_{\mathrm{OH}} / n_{\mathrm{CO}}}$ & $\Delta v^{\prime}(H z)$ & $\Delta v^{\prime} O(H z)$ & ${ }^{n_{O H}} / n_{C O}$ & $\Delta v^{\prime}(H z)$ & $\Delta v^{\prime} O(H z)$ \\
\hline 0,067 & 338,4 & 169,9 & 0,100 & 370,6 & 190,6 \\
\hline 0,074 & 334,2 & 165,7 & 0,111 & 368,2 & 188,2 \\
\hline 0,083 & 329,0 & 160,5 & 0,125 & 363,0 & 183,0 \\
\hline 0,095 & 323,6 & 155,1 & 0,143 & 359,8 & 179,8 \\
\hline 0,111 & 316,8 & 148,3 & 0,167 & 354,0 & 174,0 \\
\hline 0,133 & 306,4 & 137,9 & -- & -- & -- \\
\hline 0,167 & 296,4 & 127,9 & -- & -- & -- \\
\hline
\end{tabular}


Experiência no 12

Deslocamento da ponte de hidrogênio; sistema: doador de prôton-5-tiaciclooctanona (LXXIII), em tetracloreto de carbono

a) doador de prōton: fenol

Procedendo-se de acordo com a experiēncia no $3 a$, efetuaram-se as medidas e os cālculos dos deslocamentos quīmi cos. Os resultados obtidos acham-se na tabela 25. 0 gräfico de correlação entre $\Delta v^{\prime} O$ e ${ }{ }_{O H} / n_{C O}$ encontra-se na figura 7 (pag. 52) e o valor de $\Delta v$, na tabela 5 (pag. 53).

b) doador de pröton: p-clorofenol

Procedendo-se de acordo com a experiēncia no $3 b$, efetuaram-se as medidas e os cálculos dos deslocamentos quími cos. Os resultados obtidos acham-se na tabela 25. O gráfico de correlação entre $\Delta v^{\prime} O$ e $n_{O H} / n_{C O}$ encontra-se na figura 8 (pag. 53) e o valor de $\Delta v$, na tabela 5 (pag. 53).

\section{TABELA 25}

Deslocamentos químicos para o sistema: doador de próton-5-tia ciclooctanona (LXXII), em $\mathrm{CCl}_{4}$, a diferentes quocientes molares

\begin{tabular}{|c|c|c|c|c|c|}
\hline \multicolumn{3}{|c|}{ fenol } & \multicolumn{3}{|c|}{$p-c l o r o f e n o l$} \\
\hline $\mathrm{n}_{\mathrm{OH}} / \mathrm{n}_{\mathrm{CO}}$ & $\Delta \nu^{\prime}(H z)$ & $\Delta v^{\prime} O(H z)$ & $\mathrm{n}_{\mathrm{OH}} / \mathrm{n}_{\mathrm{CO}}$ & $\Delta \nu^{\prime}(H z)$ & $\Delta v^{\prime} O(H z)$ \\
\hline 0,067 & 335,6 & 167,1 & 0,100 & 377,6 & 197,6 \\
\hline 0,074 & 330,8 & 162,3 & 0,111 & 373,2 & 193,2 \\
\hline 0,083 & 324,8 & 156,3 & 0,125 & 368,6 & 188,6 \\
\hline 0,095 & 319,6 & 151,1 & 0,143 & 362,8 & 182,8 \\
\hline 0,111 & 308,8 & 140,3 & 0,200 & 350,2 & 170,2 \\
\hline
\end{tabular}


Experiēncia nọ 13

Deslocamento da ponte de hidrogênio e constante de associação do sistema: doador de pröton-2-pentanona(LXXXVII), em tetracloreto de carbono

a) doador de prōton: fenol

Procedendo-se de acordo com a experiência nọ $3 a$, efetuaram-se as medidas e os cālculos dos deslocamentos quími cos. Os resultados obtidos acham-se na tabela 26. 0 gräfico de correlação entre $\Delta \nu^{\prime} O$ e $n_{O H} / n_{C O}$ encontra-se na figura 9 (pag. 54) e o valor de $\Delta v$, na tabela 6 (pag. 56).

Os valores de kass, obtidos segundo os procedimentos descritos em 3.2.4., acham-se na tabela 7 (pag. 58).

A figura $24 \mathrm{~A}$ (pag.151) mostra o espectro de r.m.n. do sistema fenol-2-pentanona, em tetracloreto de carbono, a quociente molar $\left(n_{\mathrm{OH}} / n_{\mathrm{CO}}\right)=0,111$.

\section{b) doador de pröton: p-clorofenol}

Procedendo-se de acordo com a experiência n! $3 b$, efetuaram-se as medidas e os cālculos dos deslocamentos quími cos. Os resultados obtidos acham-se na tabela 26. 0 gräfico de correlação entre $\Delta \nu^{\prime} O$ e $n_{O H} / n_{C O}$ encontra-se na figura 10 (pag. 55) e o valor de $\Delta v$, na tabela 6 (pag. 56).

os valores de kass, obtidos segundo os procedimentos descritos em 3.2.4., acham-se na tabela 7 (pag. 58). 


\section{TABELA 26}

Deslocamentos quĩmicos para o sistema: doador de próton-2-pen tanona (LXXXVII), em $\mathrm{CCl}_{4}$, a diferentes quocientes molares

\begin{tabular}{|c|c|c|c|c|c|}
\hline \multicolumn{3}{|c|}{ fenol } & \multicolumn{3}{|c|}{$p-c l$ orofenol } \\
\hline$n_{\mathrm{OH}} / n_{\mathrm{CO}}$ & $\Delta v^{\prime}(H z)$ & $\Delta v^{\prime} O(H z)$ & $\mathrm{n}_{\mathrm{OH}} / \mathrm{n}_{\mathrm{CO}}$ & $\Delta v^{\prime}(H z)$ & $\Delta \nu^{\prime} O(H z)$ \\
\hline 0,067 & 305,6 & 137,1 & 0,100 & 344,4 & 164,4 \\
\hline 0,074 & 299,8 & 131,3 & 0,111 & 342,2 & 162,2 \\
\hline 0,083 & 295,2 & 126,7 & 0,125 & 335,6 & 155,6 \\
\hline 0,095 & 287,4 & 118,9 & 0,143 & 328,2 & 148,2 \\
\hline 0,111 & 281,8 & 113,3 & 0,167 & 321,6 & 141,6 \\
\hline 0,133 & 271,4 & 102,9 & 0,200 & 314,0 & 134,0 \\
\hline 0,167 & 261,2 & 92,7 & 0,250 & 302,8 & 122,8 \\
\hline 0,222 & 247,6 & 79,1 & 0,333 & 287,2 & 107,2 \\
\hline
\end{tabular}

Experiēncia nọ 14

Deslocamento da ponte de hidrogênio e constante de associação do sistema: doador de prōton-2-heptanona (LXXXVIII), em tetra cloreto de carbono
a) doador de pröton: fenol

Procedendo-se de acordo com a experiência no $3 a$, efetuaram-se as medidas e os câlculos dos deslocamentos quīmi cos. Os resultados obtidos acham-se na tabela 27. 0 gräfico de correlação entre $\Delta \nu^{\prime} O$ e $n_{O H} / n_{C O}$ encontra-se na figura 9 (pag. 54) e o valor de $\Delta v$, na tabela 6 (pag. 56).

os valores de $k_{a s s}$, obtidos segundo os procedimentos descritos em 3.2.4., acham-se na tabela 7 (pag. 58). 
b) doador de pröton: $p$-clorofenol

Procedendo-se de acordo com a experiência no $3 b$, efetuaram-se as medidas e os cálculos dos deslocamentos quĩmi cos. Os resultados obtidos acham-se na tabela 27 . 0 grāfico de correlação entre $\Delta v^{\prime} O$ e $n_{O H} / n_{C O}$ encontra-se na figura 10 (pag. 55) e o valor de $\Delta v$, na tabela 6 (pag. 56).

os valores de $k_{a s s}$, obtidos segundo os procedimentos descritos em 3.2.4., acham-se na tabela 7 (pag. 58).

\section{TABELA 27}

Deslocamentos químicos para o sistema: doador de próton-2-hep tanona (LXXXVIII) em $\mathrm{CCl}_{4}$, a diferentes quocientes molares

\begin{tabular}{|c|c|c|c|c|c|}
\hline \multicolumn{3}{|c|}{ fenol } & \multicolumn{3}{|c|}{$p-c l o r o f e n o l$} \\
\hline$n_{O H} / n_{C O}$ & $\Delta v^{\prime}(H z)$ & $\Delta v^{\prime} O(H z)$ & $\mathrm{n}_{\mathrm{OH}} / \mathrm{n}_{\mathrm{CO}}$ & $\Delta v^{\prime}(H z)$ & $\Delta v^{\prime} \circ(H z)$ \\
\hline 0,067 & 306,2 & 137,7 & 0,100 & 343,8 & 163,8 \\
\hline 0,074 & 301,8 & 133,3 & 0,111 & 339,8 & 159,8 \\
\hline 0,083 & 296,6 & 128,1 & 0,125 & 335,6 & 155,6 \\
\hline 0,095 & 289,0 & 120,5 & 0,143 & 329,4 & 149,4 \\
\hline 0,111 & 282,8 & 114,3 & 0,167 & 324,0 & 144,0 \\
\hline 0,133 & 274,2 & 105,7 & 0,200 & 314,4 & 134,4 \\
\hline 0,167 & 261,8 & 93,3 & 0,250 & 302,0 & 122,0 \\
\hline 0,222 & 248,6 & 80,1 & -- & -- & -- \\
\hline
\end{tabular}


Experiēncia no 15

Deslocamento da ponte de hidrogēnio e constante de associação do sistema: doador de prōton-2-octanona ( $L X X X I X)$, em tetraclo reto de carbono

a) doador de próton: fenol

Procedendo-se de acordo com a experiência nọ $3 a$, efetuaram-se as medidas e os cālculos dos deslocamentos quími cos. Os resultados obtidos acham-se na tabela 28 . 0 grāfico de correlação entre $\Delta \nu^{\prime} O$ e $n_{O H} / n_{C O}$ encontra-se na figura 9 (pag. 54) e o valor de $\Delta v$, na tabela 6 (pag. 56).

os valores de $k_{a s s}$, obtidos segundo os procedimentos descritos em 3.2.4., acham-se na tabela 7 (pag. 58).

b) doador de pröton: p-clorofenol

Procedendo-se de acordo com a experiência no $3 b$, efetuaram-se as medidas e os cálculos dos deslocamentos quími cos. Os resultados obtidos acham-se na tabela 28 . O grāfico de correlação entre $\Delta v^{\prime} O$ e $n_{O H} / n_{C O}$ encontra-se na figura 10 (pag. 55) e o valor de $\Delta v$, na tabela 6 (pag. 56).

os valores de $k_{a s s}$, obtidos segundo os procedimentos descritos em 3.2.4., acham-se na tabela 7 (pag. 58). 


\section{$\underline{T A B E L A \quad 28}$}

Des locamentos químicos para o sistema: doador de prōton-2-octanona ( $L X X X I X)$, em $\mathrm{CCl}_{4}$, a diferentes quocientes molares

\begin{tabular}{|c|c|c|c|c|c|}
\hline \multicolumn{3}{|c|}{ fenol } & \multicolumn{3}{|c|}{$p-c 1$ orofenol } \\
\hline $\mathrm{n}_{\mathrm{OH}} / \mathrm{n}_{\mathrm{CO}}$ & $\Delta v^{\prime}(H z)$ & $\Delta v^{\prime} O(H z)$ & $\mathrm{n}_{\mathrm{OH}} / \mathrm{n}_{\mathrm{CO}}$ & $\Delta v^{\prime}(H z)$ & $\Delta v^{\prime} \circ(H z)$ \\
\hline 0,067 & 307,0 & 138,5 & 0,100 & 344,0 & 164,0 \\
\hline 0,074 & 302,3 & 133,8 & 0,111 & 340,4 & 160,4 \\
\hline 0,083 & 297,7 & 129,2 & 0,125 & 335,8 & 155,8 \\
\hline 0,095 & 292,8 & 124,3 & 0,143 & 326,8 & 146,8 \\
\hline 0,111 & 281,2 & 112,7 & 0,167 & 323,6 & 143,6 \\
\hline 0,133 & 275,0 & 106,5 & 0,250 & 303,0 & 123,0 \\
\hline 0,167 & 262,6 & 94,1 & 0,333 & 288,0 & 108,0 \\
\hline 0,222 & 248,8 & 80,3 & - & -- & -- \\
\hline
\end{tabular}

\section{Experiência nọ 16}

Deslocamento da ponte de hidrogēnio e constante de associação do sistema: doador de prōton-2-undecanona $(X C)$, em tetraclore to de carbono

a) doador de prōton: fenol

Procedendo-se de acordo com a experiência nọ $3 a$, efetuaram-se as medidas e os cālculos dos deslocamentos quími cos. Os resultados obtidos acham-se na tabela 29. o gräfico de correlação entre $\Delta \nu^{\prime} O$ e $n_{0 H} / n_{C O}$ encontra-se na figura 9 (pag. 54) e o valor de $\Delta v$, na tabela 6 (pag. 56).

Os valores de kass, obtidos segundo os procedimentos descritos em 3.2.4., acham-se na tabela 7 (pag. 58). 
b) doador de prōton: p-clorofenol

Procedendo-se de acordo com a experiēncia no $3 b$, efetuaram-se as medidas e os câlculos dos deslocamentos quĩmi cos. Os resultados obtidos acham-se na tabela 29. 0 gráfico de correlação entre $\Delta \nu^{\prime} O$ e $n_{0 H} / n_{C O}$ encontra -se na figura 10 (pag. 55) e o valor de $\Delta v$, na tabela 6 (pag. 56).

os valores de $k_{a s s}$, obtidos segundo os procedimentos descritos em 3.2.4., acham-se na tabela 7 (pag. 58).

\section{TABELA 29}

Deslocamentos químicos para o sistema: doador de próton-2-undecanona $(X C)$, em $\mathrm{CCl}_{4}$, a diferentes quocientes molares

\begin{tabular}{|c|c|c|c|c|c|}
\hline \multicolumn{3}{|c|}{ fenol } & \multicolumn{3}{|c|}{ p-clorofenol } \\
\hline$n_{\mathrm{OH}} / n_{\mathrm{CO}}$ & $\Delta v^{\prime}(H z)$ & $\Delta \nu^{\prime} \circ(H z)$ & $\mathrm{n}_{\mathrm{OH}} / \mathrm{n}_{\mathrm{CO}}$ & $\Delta \nu^{\prime}(H z)$ & $\Delta v^{\prime} O(H z)$ \\
\hline 0,067 & 306,8 & 138,3 & 0,100 & 345,0 & 165,0 \\
\hline 0,074 & 302,0 & 133,5 & 0,111 & 341,6 & 161,6 \\
\hline 0,083 & 297,4 & 128,9 & 0,725 & 337,6 & 157,6 \\
\hline 0,095 & 292,8 & 124,3 & 0,143 & 330,0 & 150,0 \\
\hline 0,111 & 280,8 & 112,3 & 0,167 & 324,0 & 144,0 \\
\hline 0,133 & 274,8 & 106,3 & 0,200 & 314,6 & 134,6 \\
\hline 0,167 & 263,0 & 94,5 & 0,250 & 303,8 & 123,8 \\
\hline 0,222 & 248,8 & 80,3 & - & -- & -- \\
\hline
\end{tabular}


Experiēncia nọ 17

Deslocamento da ponte de hidrogênio e constante de associação do sistema: doador de pröton-metiltioacetona (XCI), em tetracloreto de carbono

a) doador de prōton: fenol

Procedendo-se de acordo com a experiéncia no $3 a$, efetuaram-se as medidas e os cālculos dos deslocamentos quimi cos. Os resultados obtidos acham-se na tabela 30. 0 gräfico de correlação entre $\Delta \nu^{\prime} O$ e $n_{O H} / n_{C O}$ encontra-se na figura 9 (pag. 54) e o valor de $\Delta v$, na tabela 6 (pag. 56).

os valores de $k_{a s s}$, obtidos segundo os procedimentos descritos em 3.2.4., acham-se na tabela 7 (pag. 58).

b) doador de pröton: $p-c l o r o f e n o l$

Procedendo-se de acordo com a experiência no $3 b$, efetuaram-se as medidas e os cälculos dos deslocamentos quími cos. Os resultados obtidos acham-se na tabela 30. 0 gräfico de correlação entre $\Delta \nu^{\prime} O$ e $n_{O H} / n_{C O}$ encontra-se na figura 10 (pag. 55) e o valor de $\Delta v$, na tabela 6 (pag. 56).

os valores de $k_{a s s}$, obtidos segundo os procedimentos descritos em 3.2.4., acham-se na tabela 7 (pag. 58). 


\section{TABELA 30}

Deslocamentos químicos para o sistema: doador de pröton-metil tioacetona (XCI), em $\mathrm{CCl}_{4}$, a diferentes quocientes molares

\begin{tabular}{|c|c|c|c|c|c|}
\hline \multicolumn{3}{|c|}{ fenol } & \multicolumn{3}{|c|}{$p$-clorofenol } \\
\hline$n_{\mathrm{OH}} / n_{\mathrm{CO}}$ & $\Delta v^{\prime}(H z)$ & $\Delta v^{\prime} O(H z)$ & $n_{\mathrm{OH}} / n_{\mathrm{CO}}$ & $\Delta v^{\prime}(H z)$ & $\Delta v^{\prime} o(H z)$ \\
\hline 0,067 & 280,0 & 111,5 & 0,100 & 312,4 & 132,4 \\
\hline 0,074 & 274,4 & 105,9 & 0,11 & 307,2 & 127,2 \\
\hline 0,083 & 270,8 & 102,3 & 0,125 & 302,6 & 122,6 \\
\hline 0,095 & 263,8 & 95,3 & 0,143 & 296,2 & 116,2 \\
\hline 0,111 & 257,2 & 88,7 & 0,167 & 289,8 & 109,8 \\
\hline 0,133 & 248,4 & 79,9 & 0,200 & 280,4 & 100,4 \\
\hline 0,167 & 239,0 & 70,5 & 0,250 & 271,2 & 91,2 \\
\hline 0,222 & 227,2 & 58,7 & 0,333 & 256,0 & 76,0 \\
\hline
\end{tabular}

Experiēncia nọ 18

Deslocamento da ponte de hidrogênio e constante de associação do sistema: doador de próton-etiltioacetona (LXXIV), em tetra cloreto de carbono

a) doador de prōton: fenol

Procedendo-se de acordo com a experiēncia nọ $3 a$, efetuaram-se as medidas e os cälculos dos deslocamentos quĩmi cos. Os resultados obtidos acham-se na tabela 31 . 0 gráfico de correlação entre $\Delta \nu^{\prime} O$ e $n_{O H} / n_{C O}$ encontra-se na figura 9 (pag. 54) e o valor de $\Delta v$, na tabela 6 (pag. 56).

Os valores de $\mathrm{k}_{\text {ass }}$, obtidos segundo os procedimentos descritos em 3.2.4., acham-se na tabela 7 (pag. 58). 
A figura 24B (pag.151) mostra o espectro de r.m.n. do sistema etiltioacetona-fenol, em tetracloreto de carbono,a quociente molar $\left(n_{O H} / n_{C O}\right)=0,111$.

b) doador de pröton: p-clorofenol

Procedendo-se de acordo com a experiência nọ $3 b$, efetuaram-se as medidas e os cālculos dos deslocamentos quimi cos. Os resultados obtidos acham-se na tabela 31 . O gráfico de correlação entre $\Delta \nu^{\prime} O$ e $n_{O H} / n_{C O}$ encontra-se na figura 10 (pag. 55) e o valor de $\Delta v$, na tabela 6 (pag. 56).

Os valores de kass, obtidos segundo os procedimentos descritos em 3.2.4., acham-se na tabela 7 (pag. 58).

\section{TABELA 31}

Deslocamentos quimicos para o sistema: doador de próton-etil tioacetona ( LXXIV), em $\mathrm{CCl}_{4}$, a diferentes quocientes molares

\begin{tabular}{|c|c|c|c|c|c|}
\hline \multicolumn{3}{|c|}{ fenol } & \multicolumn{3}{|c|}{$p$-clorofenol } \\
\hline $\mathrm{n}_{\mathrm{OH}} / \mathrm{n}_{\mathrm{CO}}$ & $\Delta v^{\prime}(H z)$ & $\Delta \nu^{\prime} O(H z)$ & $\mathrm{n}_{\mathrm{OH}} / \mathrm{n}_{\mathrm{CO}}$ & $\Delta \nu^{\prime}(H z)$ & $\Delta v^{\prime} O(H z)$ \\
\hline 0,067 & 276,6 & 108,1 & 0,100 & 309,0 & 129,0 \\
\hline 0,074 & 270,0 & 101,5 & 0,125 & 300,0 & 120,0 \\
\hline 0,083 & 266,8 & 98,3 & 0,143 & 293,2 & 113,2 \\
\hline 0,095 & 259,8 & 91,3 & 0,167 & 287,8 & 107,8 \\
\hline 0,111 & 251,8 & 83,3 & 0,200 & 280,0 & 100,0 \\
\hline
\end{tabular}


Experiéncia nọ 19

Deslocamento da ponte de hidrogênio e constante de associação do sistema: doador de próton-4-eti1tio-2-butanona (XCII), em tetracloreto de carbono

a) doador de próton: fenol

Procedendo-se de acordo com a experiēncia no $3 a$, efetuaram-se as medidas e os cālculos dos deslocamentos quĩm cos. Os resultados obtidos acham-se na tabela 32 . o gräfico de correlação entre $\Delta \nu^{\prime} O$ e $n_{O H} / n_{C O}$ encontra-se na figura 9 (pag. 54) e o valor de $\Delta v$, na tabela 6 (pag. 56).

os valores de kass, obtidos segundo os procedimentos descritos em 3.2.4., acham-se na tabela 7 (pag. 58).

A figura $24 \mathrm{C}$ (pag.151) mostra o espectrodosistema: feno1-4-etiltio-2-butanona, em tetracloreto de carbono, a quociente molar $\left(\mathrm{n}_{\mathrm{OH}} / \mathrm{n}_{\mathrm{CO}}\right)=0,111$.

b) doador de prōton: p-clarofenol

Procedendo-se de acordo com a experiēncia nọ $3 b$, efetuaram-se as medidas e os cálculos dos deslocamentos quími cos. Os resultados obtidos acham-se na tabela 32. 0 grä́fico de correlação entre $\Delta \nu^{\prime} O$ e $n_{O H} / n_{C O}$ encontra-se na figura 10 (pag. 55) e o valor de $\Delta \nu$, na tabela 6 (pag. 56).

os valores de kass, obtidos segundo os procedimentos descritos em 3.2.4. acham-se na tabela 7 (pag. 58). 


\section{TABELA 32}

Deslocamentos químicos para o sistema: doador de prōton-4-etiltio-2-butanona (XCII), em $\mathrm{CCl}_{4}$, a diferentes quocientes molares

\begin{tabular}{|c|c|c|c|c|c|}
\hline \multicolumn{3}{|c|}{ fenol } & \multicolumn{3}{|c|}{$p-c l o r o f e n o l$} \\
\hline$n_{\mathrm{OH}} / n_{\mathrm{CO}}$ & $\Delta \nu^{\prime}(H z)$ & $\Delta v^{\prime} O(H z)$ & $n_{\mathrm{OH}} / \mathrm{n}_{\mathrm{CO}}$ & $\Delta v^{\prime}(H z)$ & $\Delta v^{\prime} O(H z)$ \\
\hline 0,067 & 285,4 & 116,9 & 0,100 & 322,0 & 142,0 \\
\hline 0,074 & 281,8 & 113,3 & 0,111 & 316,6 & 136,6 \\
\hline-- & -- & -- & 0,125 & 312,8 & 132,8 \\
\hline 0,095 & 269,8 & 101,3 & 0,143 & 306,2 & 126,2 \\
\hline 0,111 & 263,0 & 94,5 & 0,167 & 300,0 & 120,0 \\
\hline 0,133 & 253,4 & 84,9 & 0,200 & 291,0 & 111,0 \\
\hline 0,767 & 244,4 & 75,9 & -- & -- & -- \\
\hline-- & -- & -- & 0,333 & 266,2 & 86,2 \\
\hline
\end{tabular}

Experiência nọ 20

Deslocamento da ponte de hidrogênio e constante de associação do sistema: doador de prōton-5-etiltio-2-pentanona (XCIII), em tetracloreto de carbono

a) doador de pröton: fenol

Procedendo-se de acordo com a experiência nọ $3 a$, efetuaram-se as medidas e os cālcuios dos deslocamentos quími cos. Os resultados obtidos acham-se na tabela 33. 0 gráfico de correlação entre $\Delta \nu^{\prime} O$ e $n_{0 H} / n_{C O}$ encontra-se na figura 9 (pag. 54) e o valor de $\Delta v$, na tabela 6 (pag. 56).

os valores de kass, obtidos segundo os procedimentos descritos em 3.2.4., acham-se na tabela 7 (pag. 58). 
b) doador de pröton: p-clorofenol

Procedendo-se de acordo com a experiēncia nọ $3 b$, efetuaram-se as medidas e os cālculos dos deslocamentos quím i cos. Os resultados obtidos acham-se na tabela 33. 0 gräfico de correlação entre $\Delta \nu^{\prime} \circ$ e $n_{O H} / n_{C O}$ encontra-se na figura 10 (pag. 55) e o valor de $\Delta v$, na tabela 6 (pag. 56).

os valores de $k_{a s s}$, obtidos segundo os procedimentos descritos em 3.2.4., acham-se na tabela 7 (pag. 58).

\section{TABELA 33}

Deslocamentos químicos para o sistema: doador de prōton-5-eti1tio-2-pentanona (XCII), em $\mathrm{CCl}_{4}$, a diferentes quocientes molares

\begin{tabular}{|c|c|c|c|c|c|}
\hline \multicolumn{3}{|c|}{ fenol } & \multicolumn{3}{|c|}{$p-c l o r o f e n o l$} \\
\hline$n_{\mathrm{OH}} / n_{\mathrm{CO}}$ & $\Delta v^{\prime}(H z)$ & $\Delta \nu^{\prime} O(H z)$ & $\mathrm{n}_{\mathrm{OH}} / \mathrm{n}_{\mathrm{CO}}$ & $\Delta v^{\prime}(H z)$ & $\Delta \nu^{\prime} O(H z)$ \\
\hline 0,067 & 296,4 & 127,9 & 0,100 & 332,6 & 152,6 \\
\hline 0,074 & 292,0 & 123,5 & 0,111 & 326,8 & 146,8 \\
\hline 0,083 & 286,2 & 117,7 & 0,125 & 322,4 & 142,4 \\
\hline 0,095 & 279,6 & 111,1 & 0,143 & 316,2 & 136,2 \\
\hline 0,111 & 273,0 & 104,5 & 0,167 & 309,8 & 129,8 \\
\hline 0,133 & 263,6 & 95,1 & 0,200 & 299,2 & 119,2 \\
\hline 0,167 & 253,4 & 84,9 & 0,250 & 289,6 & 109,6 \\
\hline 0,222 & 239,8 & 71,3 & 0,333 & 274,4 & 94,4 \\
\hline
\end{tabular}




\section{Experiēncia nọ 21}

Deslocamento da ponte de hidrogênio e constante de associação do sistema: doador de pröton-6-etiltio-2-hexanona (XCIV), em tetracloreto de carbono

a) doador de prōton: fenol

Procedendo-se de acordo com a experiência no $3 a$, efetuaram-se as medidas e os cálculos dos deslocamentos quími cos. Os resultados obtidos acham-se na tabela 34 . O gráfico de correlação entre $\Delta v^{\prime} O$ e $n_{O H} / n_{C O}$ encontra-se na figura 9 (pag. 54) e o valor de $\Delta v$, na tabela 6 (pag. 56).

os valores de kass, obtidos segundo os procedimentos descritos em 3.2.4., acham-se na tabela 7 (pag. 58).

b) doador de prōton: p-clorofenol

Procedendo-se de acordo com a experiência no $3 b$, efetuaram-se as medidas e os câlculos dos deslocamentos quími cos. Os resultados obtidos acham-se na tabela 34 . 0 gräfico de correlação entre $\Delta v^{\prime} \circ$ e $n_{O H} / n_{C O}$ encontra-se na figura 10 (pag. 55) e o valor de $\Delta v$, na tabela 6 (pag. 56).

os valores de $k_{a s s}$, obtidos segundo os procedimentos descritos em 3.2.4., acham-se na tabela 7 (pag. 58). 


\section{TABELA 34}

Des locamentos quīmicos para o sistema: doador de prōton-6-etiltio-2-hexanona (XCIV), em $\mathrm{CCl}_{4}$, a diferentes quocientes molares

\begin{tabular}{lcccccc}
\hline & fenol & & \multicolumn{3}{c}{$p$-clorofenol } \\
\cline { 5 - 7 }$n_{O H} / n_{C O}$ & $\Delta \nu^{\prime}(H z)$ & $\Delta \nu^{\prime} O(H z)$ & & $n_{O H} / n_{C O}$ & $\Delta \nu^{\prime}(H z)$ & $\Delta \nu^{\prime} O(H z)$ \\
\hline 0,067 & 301,6 & 133,1 & & 0,100 & 336,2 & 156,2 \\
0,074 & 296,0 & 127,5 & & 0,111 & 332,4 & 152,4 \\
0,083 & 291,8 & 123,3 & & 0,125 & 329,2 & 149,2 \\
0,095 & 284,8 & 116,3 & & 0,143 & 321,8 & 141,8 \\
0,111 & 277,8 & 109,3 & 0,167 & 317,8 & 137,8 \\
0,133 & 268,0 & 99,5 & 0,200 & 309,0 & 129,0 \\
0,167 & 258,4 & 89,9 & 0,250 & 296,0 & 116,0 \\
0,222 & 244,6 & 76,1 & 0,333 & 281,0 & 101,0 \\
\hline
\end{tabular}

Experiēncia n! 22

Deslocamento da ponte de hidrogênio e constante de associação do sistema: $p$-clorofenol-tetrahidrotiofeno (XCV), em tetraclo reto de carbono

Procedendo-se de acordo com a experiēncia no $3 b$, efetuaram-se as medidas e os cālculos dos deslocamentos quími cos. Os resultados obtidos acham-se na tabela 35 . O gräfico de correlação entre $\Delta \nu^{\prime} O$ e $n_{O H} / n_{-s}$ encontra-se na figura 13 (pag. 61) e o valor de $\Delta \nu$, na tabela 8 (pag. 62).

os valores de $k_{a s s}$, obtidos segundo os procedimentos descritos em 3.2.4., acham-se na tabela 8 (pag. 62). 


\section{TABELA 35}

Deslocamentos químicos para o sistema: p-clorofenol-tetrahidro tiofeno (XCV), em $\mathrm{CCl}_{4}$, a diferentes quocientes molares

\begin{tabular}{llc}
\hline $\mathrm{n}_{\mathrm{OH}} / \mathrm{n}_{-S}$ & $\Delta \nu^{\prime}(\mathrm{Hz})$ & $\Delta \nu^{\prime} \mathrm{O}(\mathrm{Hz})$ \\
\hline 0,100 & 225,8 & 45,8 \\
0,111 & 222,8 & 42,8 \\
0,143 & 216,2 & 36,2 \\
0,167 & 212,2 & 32,2 \\
0,200 & 207,0 & 27,0 \\
0,250 & 201,6 & 21,6 \\
0,333 & 196,2 & 16,2 \\
\hline
\end{tabular}

Experiência nọ 23

Deslocamento da ponte de hidrogênio e constante de associação do sistema: p-clorofenol-tetrahidrotiofeno (XCV) + ciclopenta nona (LXXXIII), em tetracloreto de carbono

Prepararam-se $10 \mathrm{ml}$ de solução do aceptor de prōton contendo concentrações $0,60 \mathrm{M}$ de ciclopentanona e $0,60 \mathrm{M}$ de tetrahidrotiofeno, em $\mathrm{CCl}_{4}$. Desta solução foram feitas as diluições necessärias (v. pag. 88).

Procedendo-se de acordo com a experiência no $3 b$, efetuaram-se as medidas e os cālculos dos deslocamentos quími cos. Os resultados obtidos acham-se na tabela 36 . 0 gräfico de correlação entre $\Delta \nu^{\prime} O$ e $n_{O H} / n_{C O}$ encontra-se na figura 13 (pag. 61) e o valor de $\Delta v$, na tabela 8 (pag. 62).

Os valores de kass, obtidos segundo os procedimentos descritos em 3.2.4., acham-se na tabela 8 (pag. 62). 


\section{TABELA 36}

Deslocamentos químicos para o sistema: p-clorofenol-tetrahi drotiofeno (XCV) + ciclopentanona (LXXXIII), em $\mathrm{CCl}_{4}$, a diferentes quocientes molares

\begin{tabular}{lll}
\hline$n_{\mathrm{OH}} / n_{\mathrm{CO}}$ & $\Delta \nu^{\prime}(\mathrm{Hz})$ & $\Delta \nu^{\prime} \mathrm{O}(\mathrm{Hz})$ \\
\hline 0,100 & 344,8 & 164,8 \\
0,111 & 341,8 & 161,8 \\
0,125 & 338,2 & 158,2 \\
0,143 & 333,2 & 153,2 \\
0,167 & 327,0 & 147,0 \\
0,200 & 317,8 & 137,8 \\
0,250 & 308,0 & 128,0 \\
0,333 & 294,6 & 114,6 \\
\hline
\end{tabular}

Experiência nọ 24

Des locamento da ponte de hidrogênio e constante de associação do sistema: doador de pröton-3-oxaciclopentanona (XCVI), em tetracloreto de carbono

a) doador de prōton: fenol

Procedendo-se de acordo com a experiência no $3 a$, efetuaram-se as medidas e os cālculos dos deslocamentos quími cos. Os resultados obtidos acham-se na tabela 37 . 0 grāfico de correlação entre $\Delta \nu^{\prime} \circ$ e $n_{O H} / n_{C O}$ encontra-se na figura 14 (pag. 65) e o valor de $\Delta v$, na tabela 9 (pag. 66).

Os valores de $k_{\text {ass }}$, obtidos segundo os procedimentos descritos em 3.2.4., acham-se na tabela 9 (pag. 66). 
b) doador de pröton: p-clorofenol

Procedendo-se de acordo com a experiência nọ $3 b$, efetuaram-se as medidas e os cālculos dos deslocamentos quîmi cos. Os resultados obtidos acham-se na tabela 37. O gráfico de correlação entre $\Delta \nu^{\prime} \circ$ e $n_{0 H} / n_{C O}$ encontra-se na figura 14 (pag. 65) e o valor de $\Delta \nu$, na tabela 10 (pag. 66).

os valores de $k_{a s s}$, obtidos segundo os procedimentos descritos em 3.2.4., acham-se na tabela 10 (pag. 66).

\section{TABELA 37}

Desiocamentos químicos para o sistema: doador de próton-3-oxạ ciclopentanona (XCVI), em $\mathrm{CCl}_{4}$, a diferentes quocientes molares

\begin{tabular}{|c|c|c|c|c|c|}
\hline \multicolumn{3}{|c|}{ fenol } & \multicolumn{3}{|c|}{$p-c l o r o f e n o l$} \\
\hline $\mathrm{n}_{\mathrm{OH}} / \mathrm{n}_{\mathrm{CO}}$ & $\Delta \nu^{\prime}(\mathrm{OH})$ & $\Delta \nu^{\prime} O(O H)$ & $n_{\mathrm{OH}} / n_{\mathrm{CO}}$ & $\Delta \nu^{\prime}(\mathrm{OH})$ & $\Delta v^{\prime} \mathrm{O}(\mathrm{OH})$ \\
\hline 0,067 & 260,4 & 91,9 & 0,100 & 286,2 & 106,2 \\
\hline 0,074 & 257,0 & 88,5 & 0,111 & 283,4 & 103,4 \\
\hline 0,083 & 251,8 & 83,3 & 0,125 & 278,0 & 98,0 \\
\hline 0,095 & 245,8 & 77,3 & 0,143 & 273,2 & 93,2 \\
\hline 0,111 & 240,2 & 71,7 & 0,167 & 267,2 & 87,2 \\
\hline 0,133 & 233,2 & 64,7 & 0,250 & 248,8 & 68,8 \\
\hline 0,167 & 230,6 & 62,1 & -- & -- & -- \\
\hline
\end{tabular}


Experiēncia nọ 25

Deslocamento da ponte de hidrogênio e constante de associação do sistema: $p$-clorofenol-metoxiacetona (XCVII), em tetraclore to de carbono

Procedendo-se de acordo com a experiência no $3 b$, efetuaram-se as medidas e os cālculos dos deslocamentos quími cos. Os resultados obtidos acham-se na tabela 38. 0 gräfico de correlação entre $\Delta v^{\prime} O$ e ${ }^{n_{O H}} / n_{C O}$ encontra-se na figura 14 (pag. 65) e o valor de $\Delta v$, na tabela 10 (pag. 66).

os valores de $k_{a s s}$, obtidos segundo os procedimentos descritos em 3.2.4., acham-se na tabela 10 (pag. 66).

\section{$\underline{\text { TABELA } 38}$}

Desiocamentos químicos para o sistema: p-clorofenol-metoxiacetona (XCVII), em $\mathrm{CCl}_{4}$, a diferentes quocientes molares

\begin{tabular}{lcc}
\hline $\mathrm{n}_{\mathrm{OH}} / \mathrm{n}_{\mathrm{CO}}$ & $\Delta \nu^{\prime}(\mathrm{Hz})$ & $\Delta \nu^{\prime} \mathrm{O}(\mathrm{Hz})$ \\
\hline 0,100 & 319,6 & 139,6 \\
0,111 & 315,8 & 135,8 \\
0,125 & 312,2 & 132,2 \\
0,143 & 305,4 & 125,4 \\
0,167 & 299,4 & 119,4 \\
0,200 & 292,2 & 112,2 \\
0,250 & 281,0 & 101,0 \\
0,333 & 267,0 & 87,0 \\
\hline
\end{tabular}




\section{Experiência nọ 26}

Deslocamento da ponte de hidrogênio;sistema: doador de prōton-3-ciclohexenona (XV), em tetracloreto de carbono

a) doador de pröton: fenol

Procedendo-se de acordo com a experiência no $3 a$, efetuaram-se as medidas e os cālculos dos deslocamentos quími cos. Os resultados obtidos acham-se na tabela 39. O gräfico de correlação entre $\Delta v^{\prime} \circ$ e $n_{O H} / n_{C O}$ encontra-se na figura 15 (pag. 75) e o valor de $\Delta v$, na tabela 11 (pag. 76).

b) doador de prōton: p-clorofenol

Procedendo-se de acordo com a experiência no $3 b$, efetuaram-se as medidas e os cālculos dos deslocamentos quími cos. Os resultados obtidos acham-se na tabela 39. 0 grä́ico de correlação entre $\Delta \nu^{\prime} O$ e $n_{O H} / n_{C O}$ encontra-se na figura 16 (pag. 75) e o valor de $\Delta \nu$, na tabela 11 (pag. 76).

\section{$\underline{\text { TABELA } 39}$}

Deslocamentos quïmicos para o sistema: doador de próton-3-ciclohexenona (XV), em $\mathrm{CCl}_{4}$, a diferentes quocientes molares

\begin{tabular}{lcccccc}
\hline & fenol & & & \multicolumn{3}{c}{$p$-clorofenol } \\
\cline { 5 - 7 } $\mathrm{n}_{\mathrm{OH}}{ }^{/ n} \mathrm{n}_{\mathrm{CO}}$ & $\Delta \nu^{\prime}(\mathrm{Hz})$ & $\Delta \nu^{\prime} \mathrm{O}(\mathrm{Hz})$ & & $\mathrm{n}_{\mathrm{OH}} / \mathrm{n}_{\mathrm{CO}}$ & $\Delta \nu^{\prime}(\mathrm{Hz})$ & $\Delta \nu^{\prime} \mathrm{O}(\mathrm{Hz})$ \\
\hline 0,067 & 311,5 & 143,0 & & 0,100 & 346,5 & 166,5 \\
0,074 & 309,0 & 140,5 & & 0,111 & 342,5 & 162,5 \\
0,083 & 301,5 & 133,0 & & 0,125 & 337,0 & 157,0 \\
0,095 & 294,5 & 126,0 & & 0,143 & 331,0 & 151,0 \\
0,111 & 287,4 & 118,9 & & 0,167 & 324,0 & 144,0 \\
0,133 & 278,0 & 109,5 & 0,200 & 315,5 & 135,5 \\
0,167 & 266,5 & 98,0 & 0,250 & 306,0 & 126,0 \\
\hline
\end{tabular}




\subsection{COMPOSTOS}

\subsubsection{Reagentes não purificados}

Ciclohexano (Merck, uvasol)

Tetracloreto de carbono (Merck, uvasol)

\subsubsection{Reagentes comerciais por nós purificados}

Fenol (Merck) - Secou-se em dissecador à pressão reduzida, so bre pentōxido de fósforo, durante 3 dias. Destilou-se, recoThendo-se a fração de PE $91,0-91,5^{\circ} \mathrm{C} / 25 \mathrm{mmHg}\left(1 \mathrm{it} .{ }^{48} \mathrm{PE} 91,4^{\circ} \mathrm{C} /\right.$ $25 \mathrm{~mm} H \mathrm{Hg}$ ).

p-Clorofenol (Carlo Erba) - Secou-se em dissecador a pressão reduzida, sobre pentōxido de fósforo, durante uma noite. Destilou-se, recolhendo-se a fração de $\mathrm{PE} 216^{\circ} \mathrm{C}$ (1it. ${ }^{116} \mathrm{PE} 216-$ $\left.7^{\circ} \mathrm{C}\right)$.

Ciclopentanona (LXXXIII) (BDH) - Secou-se com sulfato de s $\vec{o}-$ dio anidro e submeteu-se à destil ação fracionada, recolhendo-se a fração de PE $131^{\circ} \mathrm{C}\left(1 \mathrm{it.} .^{149} \mathrm{PE} 131^{\circ} \mathrm{C}\right)$.

Ciclohexanona (LXXXIV) (B\&A) - Secou-se com sulfato de södio anidro. Destilou-se, recolhendo-se a fração de $P E 47^{\circ} \mathrm{C} / 15 \mathrm{mmHg}$ (1it. ${ }^{67 \mathrm{a}} \mathrm{PE} 47^{\circ} \mathrm{C} / 15 \mathrm{mmHg}$ ).

2-Pentanona (LXXXVII) (Eastman Kodak) - Secou-se com carbonato de sōdio anidro e submeteu-se à destilação fracionada, recolhendo-se a fração de $\mathrm{PE} 102^{\circ} \mathrm{C}$ (1it. ${ }^{142} \mathrm{PE} 102^{\circ} \mathrm{C}$ ).

2-Heptanona (LXXXVIII) (BDH) - Secou-se com sulfato de södio anidro. Destilou-se, recolhendo-se a fração de $P E 147^{\circ} \mathrm{C}$ (1it. ${ }^{142}$ PE $151^{\circ} \mathrm{C}$ ). 
2-0ctanona ( $L X X X I X)(B D H)$ - Secou-se com sulfato de sōdio anị dro e submeteu-se à destilação fracionada, recolhendo-se a frạ ção de PE $177^{\circ} \mathrm{C}$. Redestilação PE $44^{\circ} \mathrm{C} / 3 \mathrm{mmHg}$ (1it. ${ }^{142} \mathrm{PE}$ $\left.173^{\circ} \mathrm{C}\right)$.

2-Undecanona $(X C)$ (Eastman Kodak) - Secou-se com sulfato de sō dio anidro. Destilou-se, recolhendo-se a fração de $P E 112^{\circ} \mathrm{C} /$ $11 \mathrm{mmHg}$ (1 it. ${ }^{142} \mathrm{PE} 108^{\circ} \mathrm{C} / 9 \mathrm{mmHg}$ ).

Tetrahidrotiofeno (XCV) (Aldrich) - Secou-se com sulfato de sọ dio anidro e submeteu-se à destillação fracionada, recolhendo-se a fração de PE $120^{\circ} \mathrm{C}\left(1\right.$ it. $\left.{ }^{150} \mathrm{PE} 119-120^{\circ} \mathrm{C}\right)$.

3.3.3. Compostos disponíveis em nossos laboratörios e por nös purificados

3-Tiaciclopentanona (LXXVII) - PE $65,5-66,0^{\circ} \mathrm{C} / 7 \mathrm{mmHg}$. Redes tilação PE $65,5-66,0^{\circ} \mathrm{C} / 7 \mathrm{mmHg}$ (1it. ${ }^{169} \mathrm{PE} 60,5^{\circ} \mathrm{C} / 8 \mathrm{mmHg}$ ). R.M.N. ( $\tau): 6,90(\mathrm{~s}, 2 \mathrm{H}) ; 7,00(t, 2 \mathrm{H}) ; 7,51(t, 2 \mathrm{H})$. I.V.: $v_{\mathrm{CO}}\left(\mathrm{CC}_{4}\right): 1.742 \mathrm{~cm}^{-1}$.

4-Tiaciclohexanona $(L X X X)-P F 64-6^{\circ} \mathrm{C}\left(1 i t .{ }^{14} \mathrm{PF} 65-6^{\circ} \mathrm{C}\right)$. R.M.N. $(\tau): 6,93-7,27(\mathrm{~m}, 4 \mathrm{H}) ; 7,27-7,60(\mathrm{~m}, 4 \mathrm{H})$. I.V.: $v_{\mathrm{CO}}\left(\mathrm{CCl}_{4}\right): 1.717 \mathrm{~cm}^{-1}$.

Metiltioacetona $(X C I)-P E 53-5{ }^{\circ} \mathrm{C} / 11 \mathrm{mmHg}$. Redestilação PE $53^{\circ} \mathrm{C} / 11 \mathrm{mmHg}\left(1 \mathrm{it} .{ }^{9} \mathrm{PE} 152,5-153,0^{\circ} \mathrm{C}\right)$.

R.M.N. $(\tau): 6,95(\mathrm{~s}, 2 \mathrm{H}) ; 7,75(\mathrm{~s}, 3 \mathrm{H}) ; 7,95(\mathrm{~s}, 3 \mathrm{H})$.

I.V.: $v_{\mathrm{CO}}\left(\mathrm{CC}_{4}\right): 1.710 \mathrm{~cm}^{-1}$.

Etiltioacetona (LXXIV) - PE $63,5^{\circ} \mathrm{C} / 13 \mathrm{mmHg}$. Redestilação PE $64^{\circ} \mathrm{C} / 13 \mathrm{mmHg}\left(1 \mathrm{it} .{ }^{132 \mathrm{a}} \mathrm{PE} 63,5^{\circ} \mathrm{C} / 13 \mathrm{mmHg}\right)$. 
R.M.N. $(\tau): 6,93(\mathrm{~s}, 2 \mathrm{H}) ; 7,42(\mathrm{q}, 2 \mathrm{H}) ; 7,76(\mathrm{~s}, 3 \mathrm{H}) ; 8,76(\mathrm{t}, 3 \mathrm{H})$.

I.V.: $v_{\mathrm{CO}}\left(\mathrm{CCl}_{4}\right): 1.713 \mathrm{~cm}^{-1}$.

Metoxiacetona $(X C V I I)-P E 112^{\circ} \mathrm{C}$. Redestilação PE $112^{\circ} \mathrm{C}$ (1it. $131 \mathrm{PE} 114-6^{\circ} \mathrm{C}$ ).

R.M.N. $(\tau): 6,22(\mathrm{~s}, 2 \mathrm{H}) ; 6,62(\mathrm{~s}, 3 \mathrm{H}) ; 7,90(\mathrm{~s}, 3 \mathrm{H})$.

As purezas de todos estes compostos foram testadas cromatograficamente.

\subsubsection{Sinteses}

\subsubsection{Cicloheptanona (LXXXV)}

a) N-Metilcarbamato de etila (CII) ${ }^{68}$ - Numa mistura de $225 \mathrm{ml}$ de éter etîlico e $137 \mathrm{~g}$ de solução aquosa de metilamina a $33 \%$, gelada, adicionaram-se $80 \mathrm{~g}(0,74 \mathrm{~mol})$ de cloroformiato de etila e a seguir mais $80 \mathrm{~g}(0,74 \mathrm{~mol})$ deste, simultaneamente com $148 \mathrm{~g}$ de $\mathrm{NaOH}$ a $40 \%$. Deixou-se em repouso durante 15 minu tos. Destilou-se o produto bruto, à pressão reduzida, obtendo-se $114 \mathrm{~g}(63 \%)$ de $\mathrm{N}$-metilcarbamato de etila (CII), PE 59 $62^{\circ} \mathrm{C} / 12 \mathrm{mmHg}\left(1 \mathrm{it} .68 \mathrm{PE} 55-60^{\circ} \mathrm{C} / 12 \mathrm{mmHg}\right)$.

b) $\mathrm{N}$-Nitrosometiluretana (CIII) 69 - A $114 \mathrm{~g}(0,93 \mathrm{~mol})$ de $\mathrm{N}$-me tilcarbamato de etila (CII) em $340 \mathrm{ml}$ de ēter etīlico, foram adicionados $360 \mathrm{~g}$ de nitrito de sōdio dissolvidos em $550 \mathrm{ml}$ de ägua gelada. A seguir, jogaram-se cautelosamente, $664 \mathrm{~g}$ de āci do nitrico a 35\%, gelado. Manteve-se a temperatura abaixo de $15^{\circ} \mathrm{C}$, atē que a camada etérea tornou-se verde. Após a destila ção à pressão reduzida, obteve-se $119 \mathrm{~g}$ (97\%) da N-nitrosometiluretana (CIII), PE $60,5-62,0^{\circ} \mathrm{C} / 10 \mathrm{mmHg}$ (1it. ${ }^{69}$ PE $59-$ $\left.61^{\circ} \mathrm{C} / 10 \mathrm{mmHg}\right)$. 
c) Ciclaheptanona (LXXXV) 87 - Numa mistura de $39 \mathrm{~g} \quad(0,40 \mathrm{~mol})$ de ciclohexanona (LXXXIV), $40 \mathrm{~m} 7$ de metanol e $0,2 \mathrm{~g}$ de carbonato de sôdio, adicionaram-se $49 \mathrm{~g}(0,37 \mathrm{~mol})$ de $N$-nitrosometiluretana (CIII), mantendo-se a temperatura na faxia de 20 a $25^{\circ} \mathrm{C}$. Evaporou-se o metanol e submeteu-se o resíduo à desti $\underline{a}$ ção a pressão reduzida, obtendo-se $15 \mathrm{~g}$ (35\%) da cicloheptano na $(L X X X V)$, de PE $64-5^{\circ} \mathrm{C} / 15 \mathrm{mmHg}$ ( 1 it. ${ }^{154} \mathrm{PE} 65-6^{\circ} \mathrm{C} / 15 \mathrm{mmHg}$ ). Esta cetona mostrou-se cromatograficamente pura. R.M.N. ( $\mathrm{\tau}): 7,40-7,83(\mathrm{~m}, 4 \mathrm{H}) ; 7,83-8,57(\mathrm{~m}, 8 \mathrm{H})$. I.V.: $v_{\mathrm{CO}}\left(\mathrm{CCl}_{4}\right): 1.705 \mathrm{~cm}^{-1}$.

\subsubsection{3-Tiaciclohexanona (LXXVIII)}

a) Tioglicolato de etila (CIV) ${ }^{10}$ - A $86 \mathrm{~g}(0,93 \mathrm{~mol})$ de äcido tioglicōlico, juntaram-se $115 \mathrm{ml}$ de álcool etîlico absoluto, $173 \mathrm{ml}$ de benzeno seco e $12 \mathrm{ml}$ de ácido sulfürico concentrado. Refluxou-se por 16 horas, extraindo-se a āgua formada atravēs de um "Soxlet" munido de um cartucho contendo sulfato de magnésio anidro. Submeteu-se o produto bruto à destitação, obten do-se $84 \mathrm{~g}(75 \%)$ de tioglicolato de etila (CIV), PE $63-4{ }^{\circ} \mathrm{C} / 20$ $\mathrm{mmHg}\left(1 \mathrm{it} .{ }^{10} \mathrm{PE} 63^{\circ} \mathrm{C} / 20 \mathrm{mmHg}\right)$.

b) $\gamma$-Clorobutirato de etila (CV $)^{117}-\mathrm{A} 37 \mathrm{~g}(0,43 \mathrm{~mol})$ de $\gamma$-butirolactona, foram adicionados $250 \mathrm{ml}$ de $\vec{a} 1$ cool et $\vec{i} l i c o$ ab soluto. Saturou-se a mistura com cloreto de hidrogénio e deixou-se em repouso por 48 horas. Jogou-se a mistura em gelo e água e separou-se a camada orgânica. Submeteu-se oprodutobru to à destilação a pressão reduzida, obtendo-se $55 \mathrm{~g}(84 \%)$ de $\gamma$-clorobutirato de etila (CV), PE $95-6^{\circ} \mathrm{C} / 37 \mathrm{mmHg}(1 \mathrm{it} .117 \mathrm{PE}$ $94-5^{\circ} \mathrm{C} / 37 \mathrm{mmHg}$ ). 
c) Sulfeto de carbetoximetil-r-carbetoxipropila $(\text { CVI })^{92}-A$ $310 \mathrm{ml}$ de etanol absoluto, adicionaram-se $8,4 \mathrm{~g}$ de sōdio e apōs a reação, $43 \mathrm{~g}(0,36$ mol) de tioglicolato de etila, traços de iodeto de potässio e $54 \mathrm{~g}(0,36$ mol) de $\gamma$-clorobutirato de etila (CV). Refluxou-se por duas horas. Removeu-se osal por filtração e submeteu-se o produto bruto à destilação, obtendo-se $53 \mathrm{~g}(63 \%)$ do sulfeto de carbetoximetil-y-carbetoxipropila (CVI), PE $141-2^{\circ} \mathrm{C} / 4 \mathrm{mmHg}$ (1it. ${ }^{52} \mathrm{PE} 139-142^{\circ} \mathrm{C} / 4 \mathrm{mmHg}$ ). d) 2-(CVIIa) e/ou 6-Carbetoxi-3-tiaciclohexanona (CVIIb) 92 A $80 \mathrm{ml}$ de etanol absoluto, adicionaram-se $530 \mathrm{ml}$ de tolueno seco e $5,2 \mathrm{~g}(0,23 \mathrm{~mol})$ de sōdio. Apōs a reação, destilou-se - azeotrōpico tolueno-etanol até que a temperatura atingiu $105^{\circ} \mathrm{C}$. Adicionaram-se às gotas, na mistura, $53 \mathrm{~g}(0,23$ mo 1$) \mathrm{de}$ sulfeto de carbetoximetil-r-carbetoxipropila (CVI), dissolvidos em $200 \mathrm{ml}$ de tolueno seco. Destilou-se o azeotrópico tolueno-etanol até que a temperatura atingiu $106^{\circ} \mathrm{C}$. Esfriou-se e jogou-se a mistura em $265 \mathrm{~g}$ de gelo e $40 \mathrm{ml}$ de ācido clorídrico 12N. Extraiu-se com ēter etīlico. Secou-se o extrato etēreo com sulfato de sōdio anidro e evaporou-se o solvente. Submeteu-se o resịduo à destilação a pressão reduzida, obtendo-se $27 \mathrm{~g}(65 \%)$ do 2-(CVIIa) e/ou 6-carbetoxi-3-tiaciclohexanona (CVIIb) PE $119-121^{\circ} \mathrm{C} / 4 \mathrm{mmHg}\left(1 \mathrm{it.}{ }^{52} \mathrm{PE} 117-120^{\circ} \mathrm{C} / 4\right.$ $\mathrm{mmHg}$.

e) 3-Tiaciclohexanona $(L X X V I I I)^{92}-A 27 \mathrm{~g}(0,14$ mol) de 2(CVIIa) e/ou 6-carbetoxi-3-tiaciclohexanona (CVIIb), adiciona ram-se $90 \mathrm{~m} 1$ de äcido sulfürico $2 \mathrm{~N}$. Refluxou-se por 9 horas. Extraiu-se com cloreto de metilena, secou-se com sulfato de magnësio anidro, evaporou-se o solvente e submeteu-se o resí- 
duo à destilação, obtendo-se $11 \mathrm{~g}$ (66\%) da 3-tiaciclohexanona (LXXVIII), PE $78-9^{\circ} \mathrm{C} / 4 \mathrm{mmHg}\left(1 \mathrm{it} .{ }^{92} \mathrm{PE} 80^{\circ} \mathrm{C} / 4 \mathrm{mmHg}\right)$. Esta ce tona mostrou-se cromatograficamente pura.

R.M.N. ( $\tau): 6,88(\mathrm{~s}, 2 \mathrm{H}) ; 7,10-7,40(\mathrm{~m}, 2 \mathrm{H}) ; 7,47-7,70(\mathrm{~m}, 4 \mathrm{H})$.

I.V.: $v_{\mathrm{CO}}\left(\mathrm{CCl}_{4}\right): 1.723 \mathrm{~cm}^{-1}$.

3.3.4.3. 3-Tiacicloheptanona ( LXXIX)

a) 4-C1oro-1-butanol (CVIII) ${ }^{145}$ - Aqueceram-se $720 \mathrm{~g}$ (10 mōis) de tetrahidrofurano atē a ebulição. Passou-se uma corrente de cloreto de hidrogēnio sob refluxo até que a temperatura atingiu $106^{\circ} \mathrm{C}$. Submeteu-se o produto bruto à destilação, obtendo-se $545 \mathrm{~g}(50 \%)$ de 4-cloro-1-butanol (CVIII), PE 82,0-82, ${ }^{\circ} \mathrm{C} /$ $14 \mathrm{mmHg}$ ) ( 1 it. ${ }^{145}$ PE $81-2^{\circ} \mathrm{C} / 14 \mathrm{mmHg}$ ).

b) Clorobrometo de tetrametilena (CIX) ${ }^{145}$ - A $681 \mathrm{~g}$ de tribro meto de fósforo frio, adicionaram-se, às gotas, $545 \mathrm{~g}(5,0 \mathrm{mō}$ is) de 4-cloro-1-butanol (CVIII). Aqueceu-se a mistura por 10 horas. 0 produto bruto foi submetido à destilação, fornecendo $669 \mathrm{~g}(78 \%)$ de clorobrometo de tetrametilena (CIX), PE 171$3^{\circ} \mathrm{C}\left(1 \mathrm{it.}{ }^{145} \mathrm{PE} 175-6^{\circ} \mathrm{C}\right)$.

c) $\delta$-clorovaleronitrila $(C X)^{145}$ - Numa soluçäo de $320 \mathrm{~g}$ de cia neto de potāssio em $400 \mathrm{ml}$ de āgua, foram adicionados $1.350 \mathrm{ml}$ de āicool etîlico a $95 \%$ e $669 \mathrm{~g}$ (3,90 móis) de clorobrometo de tetrametilena (CIX). Refluxou-se por 15 horas. 0 produto bruto foi submetido à destilação a pressão reduzida, fornecendo $236 \mathrm{~g}(51 \%)$ de $\delta$-clorovaleronitrila $(\mathrm{CX}), \mathrm{PE} 110-2^{\circ} \mathrm{C} / 16 \mathrm{mmHg}$ (1it. $145 \mathrm{PE} 100-110^{\circ} \mathrm{C} / 16 \mathrm{mmHg}$ ).

d) $\delta$-Clorovalerato de etila (CXI) - Efetuou-se uma adaptação de um mëtodo descrito na literatura, ${ }^{153 b}$ para a preparação do 
valerato de etila. Assim, numa mistura de $500 \mathrm{ml}$ de etanol a $95 \%$ e $218 \mathrm{~m} 1$ de ācido sulfúrico concentrado, adicionaram-se $236 \mathrm{~g}$ (2,0 mōis) de $\delta$-clorovaleronitrila (CX). Refluxou-se por 10 horas. Submeteu-se o produto bruto à destilação,obtendo-se $268 \mathrm{~g}(82 \%)$ do $\delta$-clorovalerato de etila (CXI), PE $84-5^{\circ} \mathrm{C} / 8$ $\mathrm{mmHg}\left(1 \mathrm{it.}{ }^{36} \mathrm{PE} 83,5-85,0^{\circ} \mathrm{C} / 8 \mathrm{mmHg}\right)$.

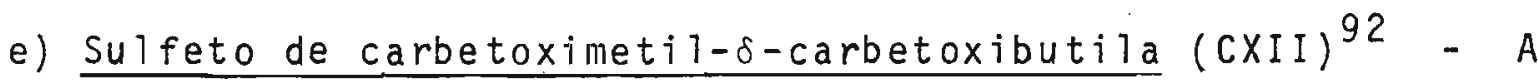
$1.400 \mathrm{ml}$ de etanol absoluto, adicionaram-se $37 \mathrm{~g}(1,6 \mathrm{mōis}) \mathrm{de}$ sōdio e após a reação, $196 \mathrm{~g}(1,62$ mōis) de tioglicolato de etila (CIV), contendo traços de iodeto de sōdio e $268 \mathrm{~g}(1,62$ móis) de $\delta$-clorovalerato de etila (CXI). Refluxou-se por 2 ho ras. o produto bruto foi destilado, fornecendo $290 \mathrm{~g}(72 \%)$ do

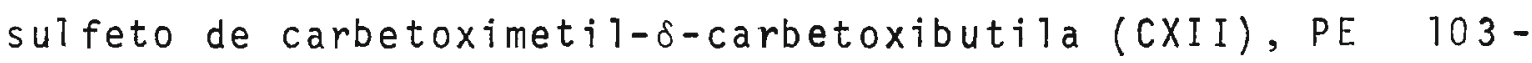
$4^{\circ} \mathrm{C} / 0,2 \mathrm{mmHg}\left(1 \mathrm{it} .{ }^{92} \mathrm{PE} 106^{\circ} \mathrm{C} / 0,2 \mathrm{mmHg}\right)$.

f) 3-Tiacicloheptanona $(L X X I X)$ - Seguiu-se o mētodo descrito por Leonard e col..$^{92}$ introduzindo-se pequenas modificações. As sim, numa suspensão de $27 \mathrm{~g}(1,2$ mōis $)$ de sōdio em $2.700 \mathrm{ml}$ de tolueno seco, adicionaram-se cautelosamente, $340 \mathrm{ml}$ de etanol absoluto. O excesso de ā lcool foi destilado como azeotrōpico etanol-tolueno, atē que a temperatura atingiu $105^{\circ} \mathrm{C}$. Adiciona

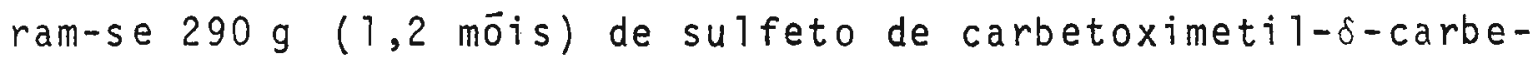
toxibutila (CXII), vagarosamente. A seguir, destilou-se o azeo trōpico etanol-tolueno, atē que a temperatura atingiu $106^{\circ} \mathrm{C}$. Jogou-se a mistura em $1.350 \mathrm{~g}$ de gelo e $204 \mathrm{ml}$ de ācido clorí drico 12N. Extraiu-se com éter etílico, lavou-se com ägua, se cou-se com sulfato de sódio anidro e evaporou-se o solvente. Ao resíduo, adicionaram-se $600 \mathrm{ml}$ de àcido sulfürico $2 \mathrm{~N}$. Refluxou-se por 9 horas, esfriou-se e extraiu-se com cloreto de 
metilena. Lavou-se com āgua, secou-se com sulfato de sōdio aṇ dro e evaporou-se o solvente. Submeteu-se o resíduo à destila ção, a pressão reduzida, obtendo-se $12 \mathrm{~g}(7,2 \%)$ de 3-tiaciclo heptanona (LXXIX), PE $56^{\circ} \mathrm{C} / 0,4 \mathrm{mmHg}$ (1it. $92 \mathrm{PE} 54^{\circ} \mathrm{C} / 0,55 \mathrm{mmHg}$ ). Purificou-se esta cetona pela tēcnica da cromatografia de coluna, usando-se como fase mōvel o ēter de petróleo e como fase estacionāria, sîlicagel.

R.M.N. $(\tau): 6,71(\mathrm{~s}, 2 \mathrm{H}) ; 7,23(\mathrm{t}, 4 \mathrm{H}) ; 7,60-8,63(\mathrm{~m}, 4 \mathrm{H})$.

I.V.: $v_{\mathrm{CO}}\left(\mathrm{CCl}_{4}\right): 1.706 \mathrm{~cm}^{-1}$.

\subsubsection{4-Tiacicloheptanona (LXXXI)}

Seguindo-se o procedimento indicado por overberger e Katchman, ${ }^{120}$ alcalinizou-se uma mistura de $24 \mathrm{~g}(0,21$ mol) de 4-tiaciclohexanona $(L X X X)$ e $50 \mathrm{ml}$ de metanol, com ōxido de bārio. Adicionaram-se cautelosamente $28 \mathrm{~g}(0,21 \mathrm{~mol})$ da $\mathrm{N}-\mathrm{ni}-$ trosometiluretana. (CIII) (v. 3.2.4.1.a,b). Agitou-se durante uma hora. Filtrou-se e evaporou-se o metanol. Adicionou-se éter etílico e secou-se com sulfato de sódio anidro. Evaporou-se o ēter e submeteu-se o produto bruto à destilação a pressão reduzida, obtendo-se $7,1 \mathrm{~g}(26 \%)$ da 4-tiacicloheptano na $\left(\right.$ LXXXI), PE $73-5^{\circ} \mathrm{C} / 2 \mathrm{mmHg}\left(1 \mathrm{it} .120 \mathrm{PE} 72,5^{\circ} \mathrm{C} / 2 \mathrm{mmHg}\right)$. Es ta cetona mostrou-se cromatograficamente pura.

R.M.N. ( $\tau): 6,83-7,76(\mathrm{~m}, 8 \mathrm{H}) ; 7,76-8,67(\mathrm{~m}, 2 \mathrm{H})$.

I.V.: $v_{\mathrm{CO}}\left(\mathrm{CCl}_{4}\right): 1.712 \mathrm{~cm}^{-1}$.

\subsubsection{Ciclooctanona (LXXXVI)}

Seguindo-se o procedimento indicado por Kohler e co1. 87 numa mistura de $35 \mathrm{~g}(0,31$ mo1) de cicloheptanona ( $X X X X V)$, $31 \mathrm{ml}$ de metanol e $0,5 \mathrm{~g}$ de carbonato de sódio,adicionaram-se 
$63 \mathrm{~g}$ de $\mathrm{N}$-nitrosometiluretana (CIII) ( $v .3 .2 .4 .1 . \mathrm{a}, \mathrm{b})$, mantendo-se a temperatura em torno de $30^{\circ} \mathrm{C}$. Agitou-se por 4 horas. Evaporou-se o metanol e submeteu-se o produto bruto à destil a ção a pressão reduzida, obtendo-se $19 \mathrm{~g}(47 \%)$ de ciclooctanona $(L X X X V I), P E 72-3^{\circ} \mathrm{C} / 12 \mathrm{mmHg}$ (1it. $\left.67 \mathrm{~b} P E 74^{\circ} \mathrm{C} / 12 \mathrm{mmHg}\right)$. Es ta cetona mostrou-se cromatograficamente pura.

R.M.N. ( $\tau): 7,43-7,87(\mathrm{~m}, 4 \mathrm{H}) ; 7,97-8,80(\mathrm{~m}, 10 \mathrm{H})$.

I.V.: $v_{\mathrm{CO}}\left(\mathrm{CCl}_{4}\right): 1.704 \mathrm{~cm}^{-1}$.

3.3.4.6. 5-Tiaciclooctanona (LXXIII)

a) Y-Bromobutirato de etila (CXIV) ${ }^{90}$ - Uma solução de $250 \mathrm{~g}$ $(2,9$ mōis) de $\gamma$-butirolactona em $470 \mathrm{ml}$ de etanol foi saturada com brometo de hidrogênio obtido a partir da reação de tetralina com bromo. $153 a$ Deixou-se em repouso por 24 horas. Ad $\underline{i}$ cionaram-se gelo e ägua na mistura e extraiu-se combrometo de etila. Submeteu-se o produto à destilação, obtendo-se $459 \mathrm{~g}$ ( $81 \%)$ de $\gamma$-bromobutirato de etila (CXIV), PE $98-9^{\circ} \mathrm{C} / 25 \mathrm{mmHg}$ (1it. $\left.{ }^{90} \mathrm{PE} 97-9^{\circ} \mathrm{C} / 25 \mathrm{mmHg}\right)$.

b) Sulfeto de $Y, Y^{1}$-bis-butirato de etila (CXV) 119 - A $425 \mathrm{~m} 1$ de etanol absoluto, foram adicionados $24 \mathrm{~g}(1,03$ móis $)$ de sódio e após a reação, passou-se uma corrente de sulfeto de hidrogēnio por um período de 10 horas. Jogou-se, nesta mistura, uma solução de etōxido de sōdio preparada atravēs da reação de $24 \mathrm{~g}(1,03$ móis) de sódio com etanol absoluto (425 ml). Refl $\underline{u}$ xou-se por 2 horas. A seguir, adicionaram-se $400 \mathrm{~g}$ (2,05 mōis) de $\gamma$-bromobutirato de tila (CXIV). Refluxou-se por 5 horas. 0 produto bruto foi submetido à destilaçäo, fornecendo $158 \mathrm{~g}$ (58\%) de sulfeto de $\gamma, \gamma^{\prime}-b i s-b u t i r a t o$ de etila (CXV), PE $186-7^{\circ} \mathrm{C} / 11 \mathrm{mmHg}\left(1 \mathrm{it} .119 \mathrm{PE} 185^{\circ} \mathrm{C} / 11 \mathrm{mmHg}\right)$. 
c) 5-Tiaciclooctanona $(L X X I I I)^{95}-$ A $3.200 \mathrm{ml}$ de xileno e $400 \mathrm{ml}$ de terc-butanol, adicionaram-se $38 \mathrm{~g}(0,96 \mathrm{~mol})$ de potāssio, sob atmosfera de nitrogēnio e em seguida, outra porção de $1.600 \mathrm{ml}$ de xileno. O excesso de terc-butanol foi destilado como azeotrōpico xileno-álcool. Ajustou-se o volume pa ra 4,8 litros com xileno e jogaram-se $138 \mathrm{~g}(0,53 \mathrm{~mol})$ de su? feto de $\gamma, \gamma^{\prime}-b i s-b u t i r a t o$ de etila (CXV), dissolvidos em $7.600 \mathrm{~m}$ ? de xileno, por um periodo de 110 horas. Lavou-se a mistura sucessivamente com ācido clorídrico aquoso $2,5 \mathrm{~N}$, solução aquo sa de bicarbonato de sōdio a $5 \%$ e finalmente com àgua. Removeu-se o xileno por destilação a pressão reduzida. No resĩduo, adicionaram-se $760 \mathrm{ml}$ de ácido clorídrico $6 \mathrm{~N}$. Refluxou-se a mistura por trēs horas. Neutralizou-se com hidrōxido de potās sio, numa temperatura inferior a $15^{\circ} \mathrm{C}$. Extraiu-se com ëter etīlico, lavou-se com àgua,secou-se com sulfato de magnésio anidro e evaporou-se o solvente. A destilação do produto bruto forneceu $2,5 \mathrm{~g}(3,2 \%)$ da 5-tiaciclooctanona (LXXIII), PE $120-1^{\circ} \mathrm{C} / 20 \mathrm{mmHg}$ e PF $53-4^{\circ} \mathrm{C}$ (1it. ${ }^{119} \mathrm{PE} 120-3^{\circ} \mathrm{C} / 19 \mathrm{mmHg} e$ lit. $\left.{ }^{95} \mathrm{PF} 53,2-54,2^{\circ} \mathrm{C}\right)$.

R.M.N. ( $\tau): 7,20-7,50(\mathrm{~m}, 4 \mathrm{H}) ; 7,50-8,00(\mathrm{~m}, 8 \mathrm{H})$.

I.V.: $v_{\mathrm{CO}}\left(\mathrm{CCl}_{4}\right): 1.705 \mathrm{~cm}^{-1}$.

\subsubsection{4-Etiltio-2-butanona (XCII)}

Procedendo-se de acordo com as indicaçöes de cain e Cunneen, ${ }^{31}$ a $19,6 \mathrm{~g}(0,19 \mathrm{~mol})$ de metilvinilcetona em $17,4 \mathrm{~g}$ de etanotiol, adicionaram-se 4 gotas de piridina. Aqueceu-se a $60^{\circ} \mathrm{C}$, mantendo-se esta temperatura por 40 minutos. Esfriou-se, lavou-se com solução aquosa de ācido sulfürico a $0,5 \%$ e a seguir com água. Secou-se com sulfato de magnésio anidro 
e submeteu-se o produto bruto à destilação, obtendo-se $6,0 \mathrm{~g}$ de 4-eti1tio-2-butanona (XCII) de PE $77-8^{\circ} \mathrm{C} / 10 \mathrm{mmHg}$. Purificou-se esta cetona pelo emprego do metodo de cromatografia de coluna, utilizando-se como fase estacionāria sīlicagel e como fase mövel, acetato de etila a $15 \%$ em tetracloreto de carbono. obteve-se $3,0 \mathrm{~g}(12 \%)$ da 4 -eti1tio-2-butanona (XCII), PE $80^{\circ} \mathrm{C} /$ $10 \mathrm{mmHg}\left(1 \mathrm{it} .31 \mathrm{PE} 78-9^{\circ} \mathrm{C} / 10 \mathrm{mmHg}\right)$.

R.M.N. ( $\tau): 7,35(s, 4 H) ; 7,50(q, 2 H) ; 7,88(s, 2 H) ; 8,75(t, 3 H)$. I.V.: $v_{\mathrm{CO}}\left(\mathrm{CCl}_{4}\right): 1.724 \mathrm{~cm}^{-1}$.

\subsubsection{5-Etiltio-2-pentanona (XCIII)}

a) 5-Bromo-2-pentanona $(C X V I I)^{8}$ - Aqueceu-se atë à ebulição, ácido bromīdrico diluído ( $36 \mathrm{ml}$ de äcido bromîdrico de densidade 1,48 com $29 \mathrm{ml}$ de àgua). Adicionaram-se, às gotas, $30 \mathrm{~g}$ $(0,23 \mathrm{~mol})$ da 2-aceti1-4-butirolactona, removendo-se a bromocetona, à medida que se formava, pela destilação com vapor. A destilação do produto forneceu $22 \mathrm{~g}(57 \%)$ de 5-bromo-2-pentanona (CXVII), PE $80-1{ }^{\circ} \mathrm{C} / 20 \mathrm{mmHg}$ ( 1 it. ${ }^{8} \mathrm{PE} 78-9^{\circ} \mathrm{C} / 20 \mathrm{mmHg}$ ).

b) 5-Eti1tio-2-pentanona (XCIII) - Procedendo-se de acordo com as sugestões de Cain e Cunneen, 31 adicionaram-se $8,7 \mathrm{~g}(0,14$ mol) de etanotiol ao etōxido de sōdio obtido pela reação de $2,9 \mathrm{~g}(0,13 \mathrm{~mol})$ de sōdio e 98 ml de etanol absoluto. Refluxou-se por 20 minutos. Juntaram-se às gotas e a frio, $21 \mathrm{~g}$ $(0,13$ mol) de 5-bromo-2-pentanona (CXVII) e refluxou-se por mais 20 minutos. Esfriou-se e jogou-se em āgua. A solução aquo sa foi saturada com cloreto de södio e extraīda com ëter etí1ico. Lavou-se a solução etērea com àgua, secou-se com sulfato de magnésio anidro e evaporou-se o solvente. Submeteu-se o resīduo à destilação a pressão reduzida,obtendo-se $9,0 \mathrm{~g}(48 \%)$ da 5-eti1tio-2-pentanona (XCIII), PE $\left.108-9{ }^{\circ} \mathrm{C} / 20 \mathrm{mmHg}\right)(1 \mathrm{it} .148$ 
PE $107-110^{\circ} \mathrm{C} / 20 \mathrm{mmHg}$ ). Esta cetona mostrou-se cromatografica mente pura.

R.M.N. ( $\tau): 7,30-7,77(\mathrm{~m}, 6 \mathrm{H}) ; 7,93(\mathrm{~s}, 3 \mathrm{H}) ; 8,23(q, 2 \mathrm{H}) ; \quad 8,78$ $(t, 3 H)$.

I. V.: $v_{\mathrm{CO}}\left(\mathrm{CC}_{4}\right): 1.722 \mathrm{~cm}^{-1}$.

\subsubsection{6-Etiltio-2-hexanona (XCIV)}

a) 2-Meti1-3-carbetoxi-5,6-dihidropirano (CXVIII) ${ }^{1}-\mathrm{A} 265 \mathrm{ml}$ de etanol, $212 \mathrm{~g}$ de carbonato de potāssio e $98 \mathrm{~g}(0,75$ mol) de acetilacetato de etila, adicionaram-se $152 \mathrm{~g}(0,75$ moll) de bro meto de trimetilena e aqueceu-se a $60^{\circ} \mathrm{C}$. Refluxou-se por 5 ho ras. A destillação do produto bruto forneceu $90 \mathrm{~g} \mathrm{(71 \% )} \mathrm{do} \mathrm{2-}$ meti1-3-carbetoxi-5,6-dihidropirano (CXVIII), PE $105-6{ }^{\circ} \mathrm{C} / 14$ $\mathrm{mmHg}$ ( $1 \mathrm{it.}$. $\mathrm{PE} 105-8^{\circ} \mathrm{C} / 14 \mathrm{mmHg}$ ).

b) 6-Bromo-2-hexanona $(\text { CXIX) })^{4}$ - A $270 \mathrm{~g}$ de ácido bromīdrico a $48 \%$, recentemente destilados, adicionaram-se, às gotas, $90 \mathrm{~g}$ $(0,53$ mol) de 2-meti1-3-carbetoxi-5,6-dihidropirano (CXVIII). Agitou-se por 4 horas à temperatura ambiente e refluxou-se a seguir por 3 horas. Submeteu-se o produto bruto à destilação a pressão reduzida, obtendo-se $51 \mathrm{~g}(53 \%)$ de 6-bromo-2-hexano $\mathrm{na}(\mathrm{CXIX}), \mathrm{PE} 107-9^{\circ} \mathrm{C} / 17 \mathrm{mmHg}\left(1 \mathrm{it} .{ }^{4} \mathrm{PE} 104-5^{\circ} \mathrm{C} / 15 \mathrm{mmHg}\right)$.

c) 6-Etiltio-2-hexanona (XCIV) - Seguindo-se as sugestões de Cain e Cunneen, 31 preparou-se etōxido de sōdio a partir de $6,7 \mathrm{~g}(0,25 \mathrm{~mol})$ de sōdio e $230 \mathrm{ml}$ de etanol absoluto. Nesta mistura foram adicionados $19 \mathrm{~g}(0,31$ mol) de etanotiol. Refl $\underline{\underline{y}}$ xou-se por 20 minutos. Jogaram-se às gotas, e a frio $51 \mathrm{~g}$ $(0,29$ mol) de 6-bromo-2-hexanona (CXIX) e refluxou-se por mais 20 minutos. Esfriou-se, jogou-se em āgua, saturou-se com clo- 
reto de sódio e extraiu-se com ëter etīlico. Lavou-se comägua, secou-se com sulfato de magnēsio anidro e evaporou-se o solvente. Submeteu-se o resĩduo à destilação a pressão reduzida, obtendo-se $34 \mathrm{~g}(68 \%)$ da 6-eti1tio-2-hexanona (XCIV), PE $111^{\circ} \mathrm{C} /$ $9 \mathrm{mmHg}$ e $93^{\circ} \mathrm{C} / 3 \mathrm{mmHg}$. Esta cetona mostrou-se cromatograficamente pura.

R.M.N. $(\tau): 7,27(\mathrm{~m}, 6 \mathrm{H}) ; 7,93(\mathrm{~s}, 3 \mathrm{H}) ; 8,20-8,57(\mathrm{~m}, 4 \mathrm{H}) ; \quad 8,80$ $(t, 3 H)$.

I.V.: $v_{\mathrm{CO}}\left(\mathrm{CCl}_{4}\right): 1.723 \mathrm{~cm}^{-1}$.

\section{Anālise elementar}
Calculado para $\mathrm{C}_{8} \mathrm{H}_{16}$ OS:
C: $59,94 \%$
$H: 10,06 \%$
Encontrado
C: $59,94 \% \quad H: 10,45 \%$

\subsubsection{9-Tiabiciclo(3,3,1)-2-nonanona (C)}

a) Dicloreto de enxofre $(C X X)^{25}$ - Saturou-se com cloro, sob at mosfera de nitrogēnio, uma mistura de $250 \mathrm{~g}(1,85$ mōis $)$ de dí cloreto de dienxofre de $0,1 \mathrm{~g}$ de ferro. Deixou-se em repouso por 1 hora. A destilação do produto bruto forneceu $339 \mathrm{~g}(89 \%)$ de dicloreto de enxofre $(C X X), P E 57-8^{\circ} \mathrm{C}$ (1it. ${ }^{25}$ PE $60^{\circ} \mathrm{C}$ ).

b) 2,6-Dicloro-9-tiabiciclo $(3,3,1)$-nonano $(C X X I)^{40}$ - Numa mis tura de $139 \mathrm{~g}(1,28$ möis $)$ de 1,5 -ciclooctadieno em 1,25 litros de cloreto de metilena, a $-50^{\circ} \mathrm{C}$ e sob atmosfera de nitro gēnio, adicionaram-se $134 \mathrm{~g}(1,30$ mōis $)$ de dicloreto de enxofre $(C X X)$, dissolvidos em $600 \mathrm{ml}$ de cloreto de metilena. Deixou-se em repouso por 30 minutos. Obteve-se uma massa de $250 \mathrm{~g}$ $(92 \%)$ do 2,6 -dicloro-9-tiabiciclo $(3,3,1)$-nonano (CXXI), PF $98-100^{\circ} \mathrm{C}\left(1 \mathrm{it} .{ }^{40}\right.$ PF $\left.98,1-99,6^{\circ} \mathrm{C}\right)$. 
c) 6-C1oro-9-tiabiciclo(3,3,1)-2-noneno $($ CXXII) $160-250 \mathrm{~g}$ $(1,18$ möis) de 2,6-dicloro-9-tiabiciclo $(3,3,1)$-nonano (CXXI) foram aquecidos a $166-184^{\circ} \mathrm{C}$, sob atmosfera de nitrogênio. Assim que findou a liberação de cloreto de hidrogēnio (20 horas), o 1 íquido residual foi destilado à pressão reduzida, for necendo $190 \mathrm{~g}(92 \%)$ do 6-cloro-9-tiabiciclo $(3,3,1)-2$-noneno (CXXII), PE $96-7^{\circ} \mathrm{C} / 2 \mathrm{mmHg}$ ( 1 it. $160 \mathrm{PE} 64-9^{\circ} \mathrm{C} / 0,3 \mathrm{mmHg}$ ).

d) 9-Tiabiciclo(3,3,1)-6-nonen-2-01 (CXXIII) $160-A 190 \mathrm{~g}(1,09$ móis) de 6-c1oro-9-tiabiciclo $(3,3,1)-2$-noneno (CXXII), dissol vidos em $360 \mathrm{ml}$ de 1,2-dimetoxietano, adicionaram-se $430 \mathrm{ml}$ de solução aquosa de hidrōxido de sōdio a 10\%. Refluxou-se por 24 horas. Evaporou-se o solvente e recristalizou-se o sōlido de àgua quente, obtendo-se $90 \mathrm{~g}(53 \%)$ de 9 -tiabiciclo( $3,3,1)-6-$ nonen-2-01 (CXXIII). Identificou-se este älcool na forma de acetato de 9-tiabiciclo(3,3,1)-6-nonen-2-ila (CXXIV). Efetuou-se uma adaptação de um mëtodo descrito na literatura ${ }^{152}$ pa ra a sua preparação. Assim, $5 \mathrm{~g}$ do 9-tiabiciclo(3,3,1)-6-nonen-2-01 (CXXIII), $10 \mathrm{~g}$ de anidrido acētico e $10 \mathrm{~g}$ de piridina foram deixados em repouso por 19 horas. Adicionou-se ägua fria para decompor o excesso de anidrido e extraiu-se com ben zeno. Lavou-se sucessivamente com solução diluida de äcido sul fūrico, solução de bicarbonato de sōdio e āgua. Secou-se com sulfato de sōdio anidro e evaporou-se o benzeno. o sōlido obtido foi recristalizado de àcido acético. 0 acetato de 9-tiabiciclo(3,3,1)-6-nonen-2-ila (CXXIV) tinha PF $52-3^{\circ} \mathrm{C}$ (1it. 160 PF $52-3^{\circ} \mathrm{C}$ ).

e) 9-Tiabiciclo(3,3,1)-6-nonen-2-ona $(X C I X)^{121}$ - Numa mistura de $107 \mathrm{~g}$ de triōxido de crōmio e $1550 \mathrm{ml}$ de piridina, à $0^{\circ} \mathrm{C}$, 
adicionaram-se, às gotas, uma solução de $54 \mathrm{~g}(0,35 \mathrm{~mol})$ de 9-tiabiciclo(3,3,1)-6-nonen-2-01 (CXXIII) em $170 \mathrm{ml}$ de piridi na. Agitou-se por 20 horas. Jogaram-se $3.500 \mathrm{ml}$ de ēter etīi co. Filtrou-se a mistura, lavou-se a camada com solução aquosa de ācido clorídrico a $5 \%$ e depois com água. Secou-se com sulfato de magnésio anidro, evaporou-se o solvente e submeteu-se o produto bruto à destilação a pressão reduzida, obten do-se $16,3 \mathrm{~g}$ de 9-tiabiciclo(3,3,1)-6-nonen-2-ona (XCIX) de $P E 90-2^{\circ} \mathrm{C} / 1 \mathrm{mmHg}$. Verificou-se, entretanto, que esta cetona não se mostrou cromatograficamente pura. Procedeu-se à sua pu rificação, pelo método da cromatografia em coluna, utilizando-se como fase estacionāria, sîlicagel e como fase mōvel clo roförmio. Obteve-se $13 \mathrm{~g}(24 \%)$ da cetona pura de PF $78-9^{\circ} \mathrm{C}$ (it. ${ }^{121}$ PF $79-87^{\circ} \mathrm{C}$ ).

f) 9-Tiabiciclo(3,3,1)-2-nonanona (C) 121 - Partiu-se de 1,0 g de paládio sobre carvão a $5 \%$. Adicionou-se $500 \mathrm{mg}$ de 9 -tiabiciclo $(3,3,1)-6$-nonen-2-ona (XCIX) em $200 \mathrm{mt}$ de metanol absol $\underline{u}$ to. Ambos foram agitados sob atmosfera de hidrogênio a 50 p.s.i. num "Shaker de Paar" por 24 horas. Removeu-se o catalizador usando-se um funil de vidro sinterizado, à pressão reduzida. Evaporou-se o solvente e analisou-se o produto. Este era o de partida. Efetuou-se, por mais duas vezes, tal tentativa de hi drogenação variando-se as ordens de adição dos reagentes. Em ambas as tentativas recuperou-se o produto de partida. Numa va riaçäo do método original ${ }^{121}$ resolvemos utilizar cloreto de pa lädio suportado em carvão como catalizador. Tal variação também conduziu, infelizmente, a resultados insatisfatörios. 


\subsubsection{3-0xaciclopentanona (XCVI)}

a) Glicolato de metila (CXXV) - Efetuou-se uma adaptação de um mëtodo descrito na 1 iteratura. 143 Assim, a $50 \mathrm{~g}(0,66$ mol) de àcido glicōlico, adicionaram-se $150 \mathrm{ml}$ de solução de cloreto de hidrogênio a $4,6 \%$ em metanol. Refluxou-se por 7 horas. Sub meteu-se o produto bruto à destilação, obtendo-se $41 \mathrm{~g}$ (70\%) do glicolato de metila $(\mathrm{CXXV}), \mathrm{PE} 80-1^{\circ} \mathrm{C} / 61 \mathrm{mmHg}$ (1it. ${ }^{143} \mathrm{PE}$ $\left.76-80^{\circ} \mathrm{C} / 60-5 \mathrm{mmHg}\right)$.

b) 2-Carbometoxi-4-oxaciclopentanona (CXXVI) 56 - Numa suspensão de $16 \mathrm{~g}(0,71 \mathrm{~mol})$ de sōdio, em $500 \mathrm{ml}$ de ēter absoluto, foram adicionados $64 \mathrm{~g}(0,70 \mathrm{~mol})$ de glicolato de metila (CXXV) e a seguir $74 \mathrm{~g}(0,86 \mathrm{~mol})$ de acrilato de metila dissolvidos em $350 \mathrm{ml}$ de dimetilsulfóxido, a frio. Agitou-se durante $45 \mathrm{mi}$ nutos, acidulou-se com ācido clorídrico diluido e extraiu-se com ēter etīilco. o resĩduo da solução etērea foi destilado à pressão reduzida, fornecendo. $43 \mathrm{~g}(42 \%)$ da 2-carbometoxi-4oxaciclopentanona (CXXVI), PE $60-1^{\circ} \mathrm{C} / 0,3 \mathrm{mmHg}$ (1it. ${ }^{56}$ PE $\left.57-8{ }^{\circ} \mathrm{C} / 0,15 \mathrm{mmHg}\right)$.

c) 3-0xaciclopentanona $(X C V I)^{56}-A 43 \mathrm{~g}(0,30$ mol) da 2-carbometoxi-4-oxaciclopentanona (CXXVI), adicionaram-se $200 \mathrm{~m} 1 \mathrm{de}$ ácido sulfürico a 10\%. Refluxou-se por 1 hora, esfriou-se, ex traiu-se com éter etîlico, lavou-se com solução aquosa de car bonato de sōdio e depois com ägua. Secou-se com sulfato de sō dio anidro e evaporou-se o solvente. A destilação do produto bruto forneceu $4,5 \mathrm{~g}(17 \%)$ da 3 -oxaciclopentanona (XCVI), PE $139-140^{\circ} \mathrm{C}\left(1 \mathrm{it} .^{56} \mathrm{PE} 139-140^{\circ} \mathrm{C}\right)$. Esta cetona mostrou-se cro matograficamente pura.

R.M.N. ( $\tau): 5,83(t, 2 H) ; 6,28(s, 2 H) ; 7,61(t, 2 H)$. 
I.V.: $v_{\mathrm{CO}}\left(\mathrm{CCl}_{4}\right): 1.766 \mathrm{~cm}^{-1}$.

\subsubsection{3-Ciclohexenona (XV)}

a) 1-Metoxi-1,4-ciclohexadieno $\left(\right.$ CXXVII) ${ }^{20}$ - A $520 \mathrm{ml}$ de amônea líquida, adicionaram-se $28 \mathrm{~g}(0,26 \mathrm{~mol})$ de anisol, $60 \mathrm{~g}$ de etanol e $28 \mathrm{~g}$ de sōdio. Apōs o tërmino da reação, jogou-se água e extraiu-se com éter etîlico. Submeteu-se o produto bruto à destilação a pressão reduzida, obtendo-se $21 \mathrm{~g}(73 \%)$ do 1 -metoxi-1,4-ciclohexadieno (CXXVII), PE $45-7^{\circ} \mathrm{C} / 15 \mathrm{mmHg}$ (1it. ${ }^{20}$ PE $\left.45-6^{\circ} \mathrm{C} / 15 \mathrm{mmHg}\right)$.

b) 3-Ciclohexenona $(X V)^{118}$ - A $20 \mathrm{~g}(0,18 \mathrm{~mol})$ de 1 -metoxi1,4-ciclohexadieno (CXXVII), foram adicionados $50 \mathrm{ml}$ de tetra cloreto de carbono, $125 \mathrm{ml}$ de àgua e 10 gotas de àcido perclō rico a $70 \%$. Agitou-se vigorosamente esta mistura, seguindo-se a reação atravēs do desaparecimento do sinal do próton metîli co de $\tau=6,55 \mathrm{ppm}$, por ressonāncia magnētica nuclear. Separou-se a fase orgânica e extraiu-se a fase aquosa com tetracloreto de carbono. As fases orgānicas combinadas foram lavadas com āgua e secas com.sulfato de magnésio anidro. Evaporou-se o solvente e submeteu-se o produto bruto à destilação, obtendo-se $8,0 \mathrm{~g}(46 \%)$ da 3 -ciclohexenona (XV), PE $45-6{ }^{\circ} \mathrm{C} / 4$ $\mathrm{mmHg}$ (1it. ${ }^{107} \mathrm{PE} 43,5^{\circ} \mathrm{C} / 3,5 \mathrm{mmHg}$ ). Esta cetona mostrou-se cro matograficamente pura.

R.M.N. $(\tau): 4,18(d, 2 H) ; 7,20(d, 2 H) ; 7,58(d, 4 H)$.

I. V.: $v_{\mathrm{CO}}\left(\mathrm{CCl}_{4}\right): 1.726 \mathrm{~cm}^{-1}$. 


\subsection{ESPECTROS}
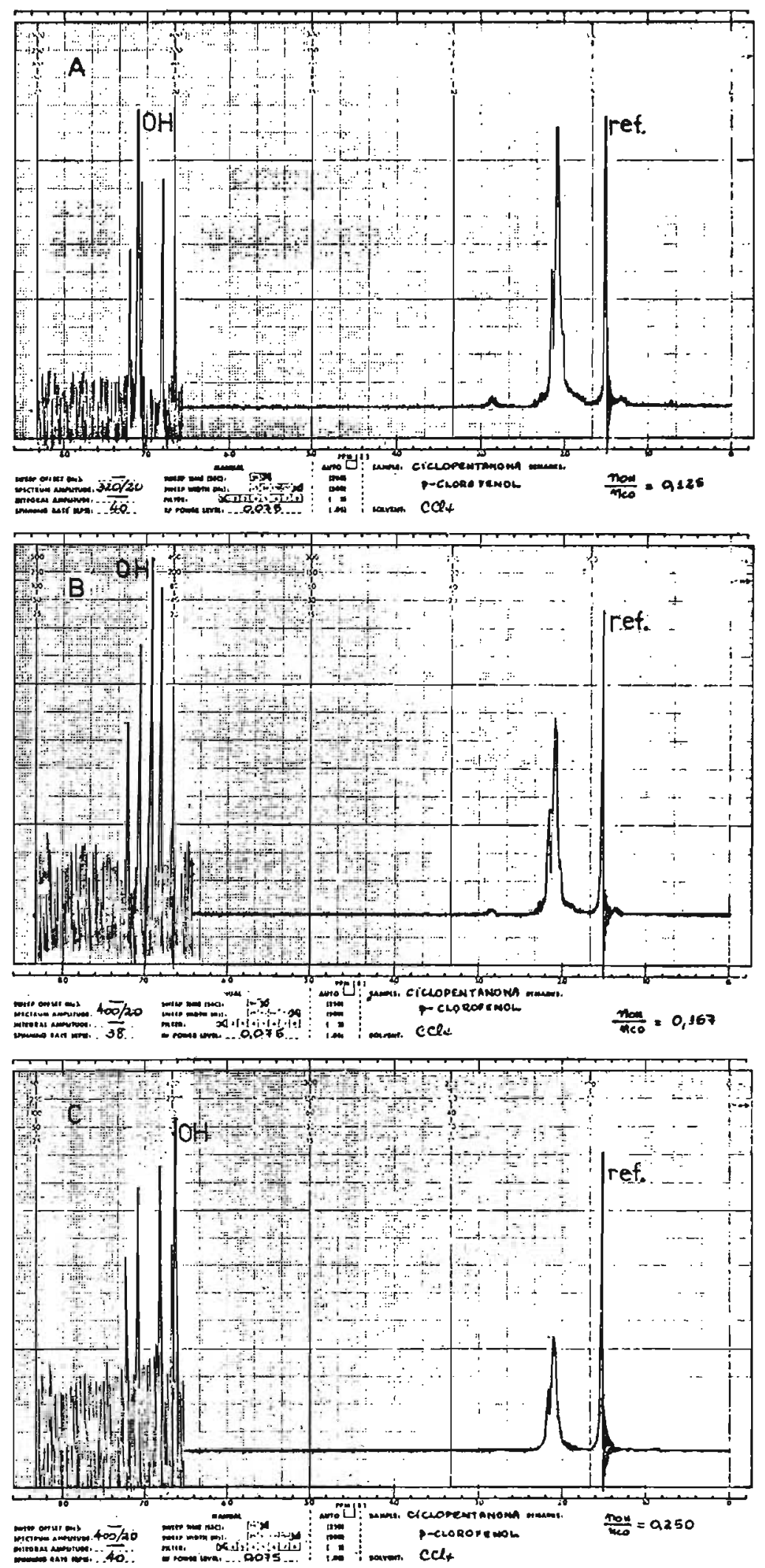

Figura 22 - Espectros de r.m.n. do sistema: ciclopentanona-p-clorofenol- $\mathrm{CCl}_{4} ; \mathrm{n}_{\mathrm{OH}} / \mathrm{n}_{\mathrm{CO}}=$ $0,125(A) ; n_{O H} / n_{C O}=0,167(B) ; n_{O H} / n_{C O}=0,250(C)$. 

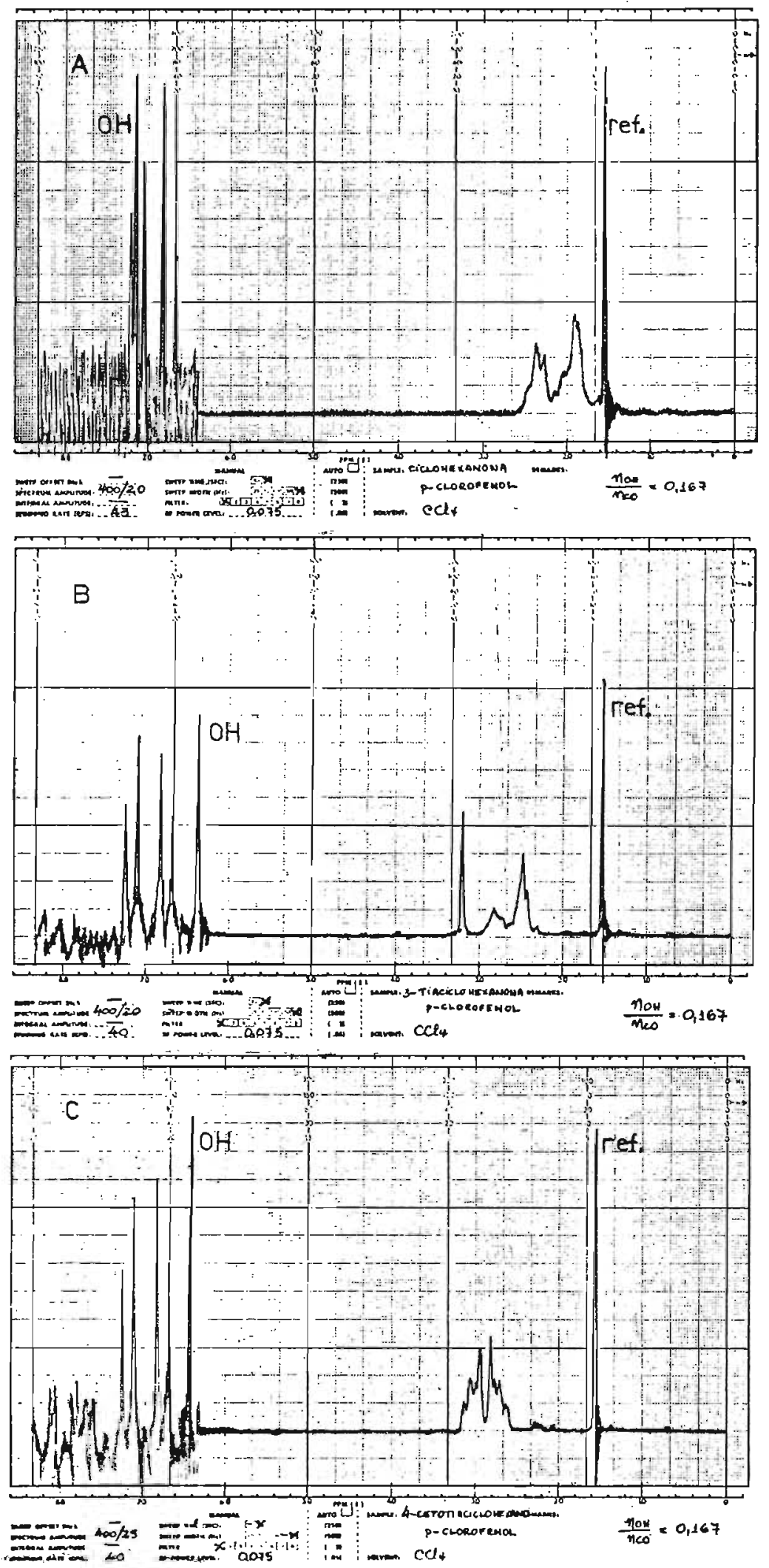

Figura 23 - Espectros de r.m.n. do sistema: p-clorofenol-ciclanona, em $\mathrm{CCl}_{4}\left(\mathrm{n}_{\mathrm{OH}} / \mathrm{n}_{\mathrm{CO}}=\right.$ $0,167) ; A=c i c l o h e x a n o n a ; B=3-t i a c i c l o h e x \underline{a}$ nona; $C=4-t i a c i c l o h e x a n o n a$. 
151.
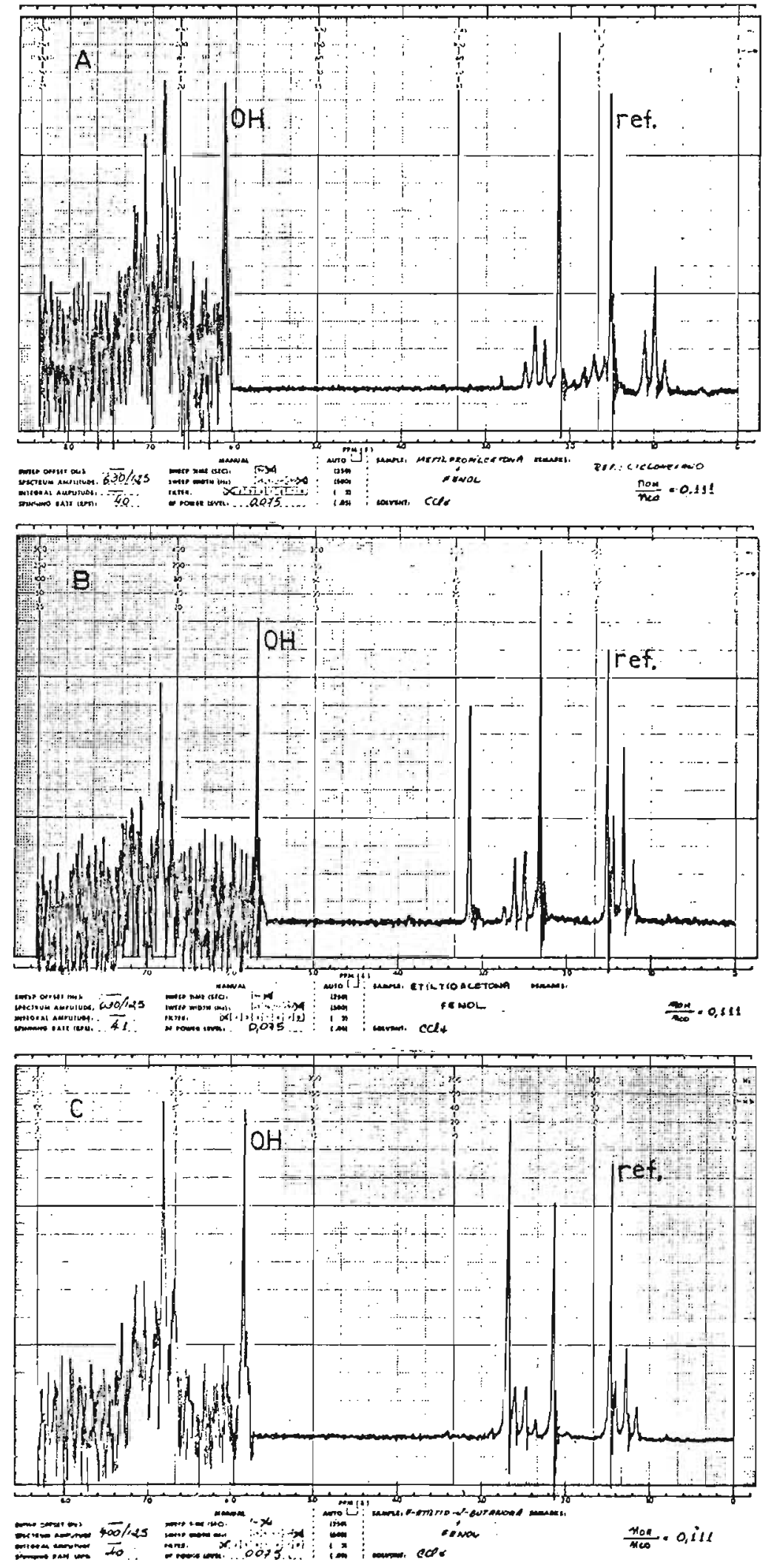

Figura 24 - Espectros de r.m.n. do sistema:

feno1-cetona, em $\mathrm{CCl}_{4}\left(\mathrm{n}_{\mathrm{OH}} / \mathrm{n}_{\mathrm{CO}}=0,111\right)$;

$A=2-$ pentanona; $B=$ etiltioacetona; $\quad C=4-$

eti1tio-2-butanona. 


\section{RESUMO}

Este trabalho investiga as interações entre o ātomo de enxofre e o grupo carbonila nos seguintes compostos: 3-tia ciclopentanona (II), 3-tiaciclohexanona (IV), 4-tiaciclohexanona (V), 3-tiacicloheptanona (VII), 4-tiacicloheptanona (VIII), 5-tiaciclooctanona $(X)$, metiltioacetona $(X V)$, etiltioacetona (XVI), 4-etiltio-2-butanona (XVII), 5-etiltio-2-pentanona(XVIII) e 6-etitio-2-hexanona (XIX).

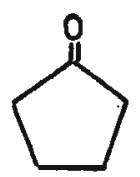

(1)<smiles>O=C1CCSC1</smiles>

(II)<smiles>O=C1CCCCC1</smiles>

(III)<smiles>O=C1CCCSC1</smiles>

(IV)<smiles>O=C1CCSCC1</smiles>

(V)<smiles>O=C1CCCCCC1</smiles>

(VI)<smiles>O=C1CCCCSC1</smiles>

(VII)<smiles>O=C1CCCSCC1</smiles>

(VIII)<smiles>O=C1CCCCCCCC1</smiles>

(IX)<smiles>O=C1CCCSCCC1</smiles>

(X)<smiles>CCCC(C)=O</smiles>

(XI)

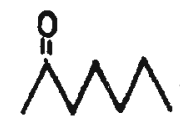

(XII)
$\Lambda^{\circ} \wedge \Lambda^{\prime} \wedge \wedge \wedge$

(XIII)

(XIV)

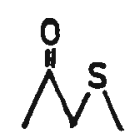

(XV)<smiles>CCSCC(C)=O</smiles>

(XVI)<smiles>[AlH2]</smiles>

(XVII)

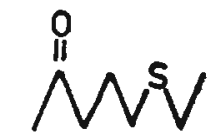

(XVIII)<smiles>CCSCCCC(C)=O</smiles>

(xIX)<smiles>O=C1CCOC1</smiles>

$(x x)$<smiles>COCC(C)=O</smiles>

(XXI)<smiles>O=C1CC=CCC1</smiles>

(XXI)<smiles>O=C1CCC2CCCC1S2</smiles>

(XXIII)<smiles>C1CCSC1</smiles>

(XXIV) 
São apresentados:

Revisão bibliogrāfica sobre interações eletrōnicas intramoleculares.

As sinteses dos seguintes compostos: 3 -tiaciclohexa nona (IV), cicloheptanona (VI), 3-tiacicloheptanona(VII), 4tiacicloheptanona (VIII), ciclooctanona (IX), 5-tiaciclooctanona $(X)$, 4-etiltio-2-butanona (XVII), 5-etiltio-2-pentanona (XVIII), 6-etiltio-2-hexanona (XIX), 3-oxaciclopentanona (XX), 3-ciclohexenona (XXII) e 9-tiabiciclo(3,3,1)-2-nonanona(XXIII), A 6-etiltio-2-hexanona $(X I X)$, composto ainda não descrito na literatura, foi por nös caracterizado.

Os dados de basicidades relativas $(\Delta \nu)$ de cetonas cîclicas e acíclicas (I-XXII), pelo emprego do método de ressonância magnëtica nuclear. Estes dados foram obtidos atravēs de medidas dos deslocamentos das posições dos sinais dos prötons ácidos de fenol e de p-clorofenol associados, em complexo 1:1, com aceptores de prōtons, em tetracloreto de carbono.

As constantes de equilibrio ( $k_{\text {ass }}$ ) dos complexos doador-aceptor de prōton, associados por pontes de hidrogēnio, em tetracloreto de carbono.

A presente tese permite apresentar as seguintes sugestões e conclusões:

A comparação das basicidades da ciclopentanona (I), e tetrahidrotiofeno (XXIV), isoladamente e em mistura, com a basicidade da 3-tiaciclopentanona (II), indica que os valores de $\Delta \nu$ e de $k_{a s s}$ para tiacetonas são medidas de basicidade do oxigēnio carbonilico e não do enxofre.

As tiacetonas contendo o átomo de enxofre ligado ao 
carbono a ou $\beta$ são menos bäsicas do que as cetonas anālogas não substituĩdas, tanto na sērie cíclica, como na acíclica.

As diminuições de basicidade das tiacetonas cíclicas não são devidas nem ao impedimento estërico para a aproxi mação do doador de prōton e nem, pelo menos exclusivamente, a uma tensão que poderia ser causada pela introdução do ātomo de enxofre no anel.

As oxacetonas contendo o àtomo de oxigênio ligado ao carbono $\alpha(X X)$ e (XXI) são mais bàsicas do que as tia-anālogas (II) e (XV), entretanto, menos bāsicas do que as cetonas correspondentes não substituĩdas (I) e (XI). Esta ordem ē con trāria à esperada dos efeitos indutivos dos dois heteroātomos.

Eliminados o impedimento estérico, a tensão do anel e os efeitos indutivos, apresenta-se a possibilidade de uma interação no espaço entre os orbitais $n$ do oxigênio carbonílico e $n$ do enxofre como responsāvel pela diminuição de bas cidade do grupo carbonila, atravēs de considerações de potenciais de ionização e de resultado de correlação entre kass $e$ de $\sigma^{*}$ de Taft de grupos substituintes.

A 5-tiaciclooctanona (X) e a 3-ciclohexenona (XXII) apresentam, em solução de tetracloreto de carbono, aumentos anômalos de basicidade com o aumento da concentração de cetona, quando comparados com as outras cetonas estudadas. A explicação que se poderia fornecer para este comportamento é que ambas as cetonas (X, XXII) existem, em solução, como misturas de conformações, de não interação (menos polar) e de interação (mais polar), sendo que a concentração desta ūltima aumen ta com o aumento da concentração de cetona. Os nossos resulta dos apoiam a hipótese sugerida na literatura da existência,na 
5-tiaciclooctanona $(X)$, de uma transferência de carga do enxo fre para o grupo carbonila. Semelhantemente, uma transferēncia de carga da dupla olefinica para o grupo carbonila é por nós proposta para a 3-ciclohexenona (XXII).

0 nosso método de medida de basicidade relativa mos trou-se útil para a identificação de estruturas com transferência de carga em equilibrios conformacionais. 


\section{ABSTRACT}

This thesis investigates the interactions between the sulphur atom and the carbonyl group in the following compounds: 3-thiacyclopentanone (II), 3-thiacyclohexanone (IV) 4-thiacyclohexanone (V), 3-thiacycloheptanone (VII), 4-thiacycloheptanone (VIII), 5-thiacyclooctanone (X), 4-thiapentan-2one (XV), 4-thiahexan-2-one (XVI), 5-thiaheptan-2-one (XVII), 6-thiaoctan-2-one (XVIII) and 7-thianonan-2-one (XIX).

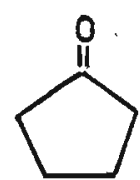

(1)<smiles>O=C1CCSC1</smiles>

(II)<smiles>O=C1CCCCC1</smiles>

(III)<smiles>O=C1CCCSC1</smiles>

(IV)<smiles>O=C1CCSCC1</smiles>

(V)<smiles>O=C1CCCCCC1</smiles>

(VI)<smiles>O=C1CCCCSC1</smiles>

(VII)<smiles>O=C1CCCSCC1</smiles>

(VIII)

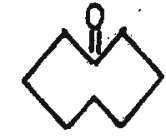

(IX)<smiles>O=C1SC2CCC[SH]1(=O)CC2</smiles>

(X)<smiles>CCC1(C)CCC1=O</smiles>

(XI)<smiles>CCCCC(CC)CCC(C)=O</smiles>

(XII)<smiles>CCCC1CCCCC1CCC</smiles>

(XIII)<smiles>CCC(C)=O</smiles>
(XIV)<smiles>CC1(C)CCS1</smiles>

(XV)

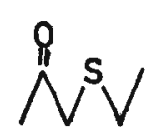

(XVI)<smiles>CCCCC(CC)SCCC(C)=O</smiles>

(XVII)

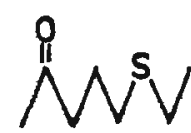

(XVIII)<smiles>CCC(C)SCCCCCC(C)=O</smiles>

$(x \mid x)$<smiles>O=C1CCOC1</smiles>

$(x x)$

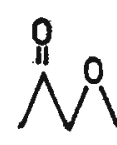

(xxI)<smiles>O=C1CC=CCC1</smiles>

(XXII)<smiles>O=C1CCC2CCCC1S2</smiles>

(XXIII)<smiles>C1CCSC1</smiles>

(XXIV) 
It contains :

A review on the intramolecular electronic interaction described in the literature.

The syntheses of the following compounds: 3-thiacyclohexanone (IV), cycloheptanone (VI), 3-thiacycloheptanone (VII), 4-thiacycloheptanone (VIII), cyclooctanone (IX), 5thiacyclooctanone $(X)$, 5-thiaheptan-2-one (XVII), 6-thiaoctan2-one (XVIII), 7-thianonan-2-one (XIX), 3-oxacyclopentanone $(X X)$, cyclohex-3-enone (XXII) and 9-thiabicyclo $(3,3,1)$ nonan2-one (XXIII). The thianonan-2-one (XIX), not yet reported in the literature, was characterized.

The data of relative basicities ( $\Delta v)$ for cyclic and open-chain ketones (I-XXII), obtained from the measurements of chemical shifts of hydroxylic proton of phenol and p-chlorophenol associated to the ketones $(1: 1)$, in carbon tetrachloride.

The equilibrium constants $\left(k_{a s}\right)$ for the same complexes.

The following conclusions and suggestions are presented:

The $\Delta v$ and $k$ as values for thiaketones express the basicity of carbonyt oxygen and not that of the sulphur, as indicated by the comparative basicities measurements for cyclopentanone (I), tetrahydrothiophene (XXIV) and 3-thiacyclopentanone (II).

Thiaketones, wich sulphur atom and carbony 1 group apart by one or two methylene groups, in cyclic as well as in the open-chain series, show a decrease of basicity in comparison to the corresponding unsubstituted ketones.

The decrease of basicity of the cyclic thiaketones 
cannot be attributed either to the steric hindrance to hydrogen bonding with phenol and p-chlorophenol or to some strain due to the introduction of sulphur atom into the ring.

The oxaketones $(X X)$ and $(X X I)$, in which the oxygen atom is separated from the carbony 1 group by one methylene group, though of lower basicity than the corresponding unsubstituted ketones, show an increased basicity when compared to the thia-analogues (II) and (XV). The basicity order $-\mathrm{CH}_{2}-\mathrm{CH}_{2}-\mathrm{CO}->-0-\mathrm{CH}_{2}-\mathrm{CO}->-\mathrm{S}-\mathrm{CH}_{2}-\mathrm{CO}-$ is contrary to that expected from the inductive effect of the heteroatoms envolved. Therefore, the inductive effect of sulphur cannot be responsible for the decrease in basicity of the thiaketones.

The data of the ionization potentials and the result of the correlation between $k_{a s}$ and $\sigma^{*}$ Taft for the substituents suggest through-space interaction as responsible for the decrease of the carbonyl-group basicity.

The 5-thiacyclooctanone (X) and cyclohex-3-enone (XXII) show an abnormal raise of basicity with increased concentration in carbon tetrachloride solution, when compared to the otherketones studied. The existence of a mixture of conformations, the non-interacted (less polar) and interacted (more polar), is proposed to be responsible for these data, as the increase of concentration would lead to an increase of the more polar conformation. Our results give a support to the existence of charge-transfer from sulphur to the carbony 1 group in the 5 -thiacyclooctanone $(X)$ suggested in the literature. Similarly, a charge-transfer from the $\pi_{C=C}$ to the ${ }^{\pi} \mathrm{C}=0$ sistem is now proposed for the cyclohex-3-enone (XXII). our method of relative basicity measurements show to 
be useful for the identification of the structures, in which a charge-transfer occurs. 


\section{REFERENCIAS BIBLIOGRAFICAS}

1. Albert, W., Neth.App1.6.511.581, Chem.Abstr., 1966, 65, $20.151 d$.

2. Allinger, N.L., Tai, J.C. e Miller, M.A., J.Amer.Chem.Soc., $1966,88,4495$.

3. Alpen, E.L., Kumler, W.D. e Strait, L.A., J.Amer.Chem.Soc., $1950, \underline{72}, 4558$.

4. Anderson, E.P., Crawford, J.V. e Sherrill, M.L., J.Amer. Chem.Soc., 1946, 68, 1294.

5. Anet, F.A.L., Bailey, A.S. e Robinson, R., Chem.Ind., 1953, 944.

6. Arnett, E.D., Quirk, R.P. e Larsen, J.W., J.Amer.Chem.Soc., $1970,92,3977$.

7. Asmus, P. e Klessinger, M., Tetrahedron, 1974, 30, 2447.

8. Bacchetti, T. e Fiechi, A., Gazz.Chim.Ital., 1953, 83, 1037 .

9. Badsher, C.K., Brown, F.C. e Granthan, R.J., J.Amer.Chem. Soc., $1954, \underline{76}, 114$.

10. Baker, B.R., Querry, M.V., Safir, S.R. e Bernstein, S., J. Org.Chem., $1947,12,138$.

11. Batich, C. e Adam, W., Tetrahedron Letters, 1974, 1467.

12. Bellamy, L.D. e Pace, R.J., Spectrochim.Acta, 1963, 19, 1831 .

13. Bennet, W.B. e Burger, A., J.Amer.Chem.Soc., 1953, $75,84$.

14. Bennett, G.M. e Scorah, L.V.D., J.Chem.Soc., 1927, 194. 
15. Bergson, G. e Delin, A.L., Arkiv Kemi, 1962, 18, 489.

16. Betteridge, D. e Thompson, M., J.Mol.Structure, 1974, 21, 341 .

17. Bishof, P., Hashmall, J.A., Heilbronner, E. e Hornung, V., Helv.Chim.Acta, $1969, \underline{52}, 1745$.

18. Bishof, P., Hashmall, J.A., Heilbronner, E. e Hornung, V., Tetrahedron Letters, $1969,4.025$.

19. Bishof, P., Hashmall, J.A., Heilbronner, E. e Hornung, V., Tetrahedron Letters, $1970,1033$.

20. Birch, A.J., J.Chem.Soc., 1946, 593.

21. Bock, H. e Mollere, P.D., J.Chem.Educ., 1974, 51, 506.

22. Bock, H. e Ramsey, B.G., Angew.Chem.Internat.Edn., 1973, 12, 734 .

23. Bock, H. e Wagner, G., Angew.Chem.Internat.Edn., 1972, 11, 150 .

24. Bock, H., Wagner, G., Wittel, K., Sauer, J. e Seebach, D., Chem.Ber., $1974,107,1869$.

25. Brauer, G., "Handbook of Preparative Inorganic Chemistry", Acad.Press., N.Y.-London, 1963, pag. 370.

26. Brogli, F., Heilbronner, E. e Kobayashi, T., Helv.Chim. Acta, $1972, \underline{55}, 274$.

27. Brogli, F., Heilbronner, E. e Ipaktschi, J., Helv.Chim. Acta, $1972, \underline{55}, 2447$.

28. Buzzi, B.T., "Tese de Doutoramento" a ser apresentada ao Instituto de Química da Universidade de São Paulo. 
29. Buzzi, B.T., Fabi, M.T., Marzorati, L., Olivato, P.R., Rittner, R., Trufem, C., Viertler, H. e Wladislaw, B., Rev.Latinoamer.Quim., no prelo.

30. Buzzi, B.T., Olivato, P.R., Rittner, R., Trufem, C., Vier tler, H. e Wladislaw, B., J.C.S. Perkin II, $1975,1294$.

31. Cain, M.E. e Cunneen, J.1., J.Chem.Soc., 1962, 2959.

32. Campbe11, H.J. e Edward, J.T., Can.J.Chem., 1960, 38, 2109.

33. Carper, W.R., Buess, C.M. e Hipp, G.R., J.Phys.Chem.,1970, 74, 4229 .

34. Chadwick, D., Frost, D.C. e Weiler, L., J.Amer.Chem.Soc., $1971, \underline{93}, 4320$.

35. Chadwick, D., Frost, D.C. e Weiler, L., J.Amer.Chem.Soc., $1971,93,4962$.

36. Cheney, L.C. e Piening, J.R., J.Amer.Chem.Soc., 1945, 67, 731 .

37. Cocksey, B.J., Elland, J.H.D. e Danby, C.J., J.Chem.Soc.(B), 1971,790 .

38. Cookson, R.C., Henstock, J. e Hudec, J., J.Amer.Chem.Soc., $1966, \underline{88}, 1060$.

39. Cookson, R.C. e Wariyar, N.S., J.Chem.SoC., 1956, 2302.

40. Corey, E.J. e Block, E., J.0rg.Chem., 1966, 31, 1663.

41. Cowan, D.0., Gleiter, R., Hashmall, J.A., Heilbronner, E. e Hornung, V., Angew.Chem.Internat.Edn., 1971, 10, 401.

42. Cowling, S.A., Johnstone, R.A.W., Gorman, A.A. e Smith, P.G., J.C.S. Chem.Comm., 1973, 627.

43. Cox, J.D., Tetrahedron, 1963, 19, 1175. 
44. Dale, A.J. e Gramstad, T., Spectrochim.Acta, 1972, 28A, 639 .

45. Davies, O.L., "Statistical Methods in Research and Production", 01iver and Boyd, London, 1961, pag. 53.

46. Davis, J.C. e Deb, K.K., Advan.Magn.Resonance, 1970, 4. 201.

47. Dekkers, A.W.J.D., Verhoeven, J.W. e Speckamp, W.N., Tetrahedron, 1973, 29, 1691 .

48. Einsenlohr, F., Chem.Ber., $1911, \underline{44}, 3188$.

49. Elie1, E.L., "Stereochemistry of Carbon Compounds", Mc Graw Hill, 1962, pag. 248.

50. Ensslin, W., Bock, H. e Becker, G., J.Amer.Chem.Soc., 1974, $\underline{96}, 2757$.

51. Fabi, M.T., Marzorati, L., Olivato, P.R., Rittner, R., viertler, H. e wladislaw, B., J.C.S. Perkin II, 1976, 16.

52. Fehne1, E.A., J.Amer.Chem.Soc., 1952, 74, 1569.

53. Fehne1, E.A. e Carmack, M., J.Amer.Chem.Soc., 1948, 70, 1813.

54. Fehne1, E.A. e Carmack, M., J.Amer.Chem.Soc., 1949, 71, 84 .

55. Fergus on, L.N. e Nnadi, J.C., J.Chem.EduC., 1965, 42, 529.

56. Gianturco, M.A., Friede1, P. e Giammarino, A.S., Tetrahedron, $1964, \underline{20}, 1763$.

57. Gleiter, R., Angew.Chem.Internat.Edn., 1974, 13, 696.

58. Gleiter, R., Heilbronner, E. e Hornung, V., Angew.Chem. Internat.Edn., $1970,9,901$.

59. Gleiter, R., Heilbronner, E. e Hornung, V., Helv.Chim. Acta, $1972, \underline{55}, 255$. 
60. Gleiter, R., Heilbronner, E., Kekman, M. e Martin, H.D., Chem.Ber., 1973, 106, 28.

61. Goldstein, M.G., Natowsky, S., Heilbronner, E. e Hornung, v., Helv.Chim.Acta, $1973, \underline{56}, 294$.

62. Gramstad, T. e Becker, E.D., J.Mol.Structure, 1970, $\underline{5}, 253$.

63. Guimon, C., Guimon, M.F. e Guillouzo, G.P, Tetrahedron Letters, $1975,1413$.

64. Guimon, M.F., Guimon, C. e Guil10uzo, G.P., Tetrahedron Letters, $1975,441$.

65. Gurutada e Stothers, J.B., Can.J.Chem., 1969, 47, 3601.

66. Hamada, Y., Hirakawa, A.Y., Tsuboi, M. e Ogata, H., Bull. Chem.Soc.uapan, 1973, 46, 2244.

67. "Handbook of Chemistry and Physics", The Chemical Rubber Co., 1973-4, pag. C-258(a), pag. C-260(b).

68. Hatmann, W.W. e Brethen, M.R., Org.Synth., 1943, Coll. vol. II, 278.

69. Hartman, W.W. e Phillips, R., Org.Synth., 1943, Coll.vol. II, 464 .

70. Heilbronner, E., Israel J.Chem., 1972, 10, 143.

71. Heilbronner, E. e Martin, H.D., Helv.Chim.Acta, 1972, $\underline{55}$, 1490 .

72. Heilbronner, E. e Muszkat, K.A., J.Amer.Chem.Soc., 1970, 92, 3818 .

73. Heilbronner, E. e Schmelzer, A., Helv.Chim.Acta, 1975, 58, 936. 
74. Hentrich, G., Gunke1, E. e Klessinger, M., J.Mol.Structure, $1974, \underline{21}, 231$.

75. Herzschuh, R. e Borsdorf, R., J.Electroanalyt.Chem.Interfacial Electrochem., $1969,23,55$.

76. Herzschuh, R., Hoa, L.C., Borsdorf, R., Remane, H. e Muhlstadt, M., J.Electroanalyt.Chem.Interfacial Electrochem., $1972, \underline{39}, 195$.

77. "Hewlett Packard Calculator", 9.810A, Mode1 10, "Operating Manúal", pag. 4-4.

78. Hoeke, M. e Koevoet, A.L., Rec.Trav.chim., 1962, 82, 7.

79. Hoffmann, R., Accounts Chem.Res., 1971, 4, 1.

80. Hoffmann, R., Heilbronner, E. e Gleiter, R., J.Amer.Chem. Soc., $1970, \underline{92}, 706$.

81. Hoffmann, R., Imamura, A. e Hehre, W.J., J.Amer.Chem.Soc., $1968, \underline{90}, 1499$.

82. Hoffmainn, R.W., Schuttler, R., Schafer, W. e Schweig, A., Angew.Chem.Internat.Edn., 1972, 11, 512.

83. Hudec, J., J.C.S.Chem.Comm., 1970, 829.

84. Jansen, M.J., em "The Chemistry of Carboxylic Acid and Esters", Ed. Patai, S., Interscience Pub1., 1969, pag. 711.

85. Katrib, A. e Rabalais, J.W., J.Phys.Chem., 1973, 77, 2358.

86. Kelder, J., Cerfontain, H., Higginson, B.R. e Lloyd, D.R., Tetrahedron Letters, 1974,739 .

87. Kohler, E.P., Tishler, M., Potter, H. e Thompson, H.T., J.Amer.Chem.Soc., $1939, \underline{61}, 1059$. 
88. Kosower, E.M., Closson, W.D., Goering, H.L. e Gross, J.C., J.Amer.Chem.Soc., 1961, 83, 2013.

89. Labhart, H. e Wagniere, G., Helv.Chim.Acta, 1959, 42, 2219.

90. Lavety, J. e Proctor, R.R., Org.Synth., 1965, 45, 42.

91. Leonard, N.J., Brown, T.L. e Milligan, T.W., J.Amer.Chem. Soc., $1959,81,504$.

92. Leonard, N.J. e Figueras Jr., J., J.Amer.Chem.Soc., 1952, 74, 917 .

93. Leonard, N.J., Fox, R.C., Oki, M. e Chiavarelli, S., J. Amer.Chem.Soc., $1954, \underline{76}, 630$.

94. Leonard, N.J., Fox, R.C. e Oki, M., J.Amer.Chem.Soc., $1954,76,5708$.

95. Leonard, N.J., Milligan, T.W. e Brown, T.L., J.Amer.Chem. Soc., $1960, \underline{82}, 4075$.

96. Leonard, N.J., Morrow, D. F. e Rogers, M.T., J.Amer.Chem. Soc., $1957, \underline{79}, 5476$.

97. Leonard, N.J. e Oki, M., J.Amer.Chem.Soc., 1954, 76, 3463.

98. Leonard, N.J. e Oki, M., J.Amer.Chem.Soc., 1955, 77, 6239.

99. Leonard, N.J. e Oki, M., J.Amer.Chem.Soc., 1955, 77,6241.

100. Leonard, N.J. e Oki, M., J.Amer.Chem.Soc, 1955, 77, 6245.

101. Leonard, N.J., Oki, M., Brader, J. e Boaz, H., J.Amer.Chem. Soc., $1955,77,6237$.

102. Leonard, N.J., Oki, M. e Chiavarel1i, S., J.Amer.Chem.Soc., $1955,77,6234$.

103. Leonard, N.J. e Owens, F.H., J.Amer.Chem.Soc., 1958, 80, 6039 . 
104. Levin, C.C., Hoffmann, R., Hehre, W.J. e Hudec, J., J.C.S. Perkiń II, $1973,210$.

105. Maksimovic, Z.B., Miksa-Spiric, A. e Ribnikav, S. V., J.Inorg. Nuclear Chem., 1973, 35, 1239.

106. Mathur, R., Becker, E.D., Bradley, P.B. e Li, N.C., J.Phys.Chem., 1963, 67, 2190.

107. Millward, B.B., J.Chem.Soc., 1960, 26.

108. Mollēre, P.D., Bock, H., Becker, G. e Fritz, G., J.Organometallic Chem., 1972, 46, 89.

109. Mottus, E.H., Schwarz, H. e Marion, L., Can.J.Chem., 1953, 31, 1144 .

110. Muller, C., Schweig, A., Anastassiou, A.G. e Wetzel, J.C., Tetrahedron, 1974, 30, 4089.

111. Murre11, J.N., "The Theory of the Electronic Spectra of Organic Molecules", John Willey \& Sons Inc., N. York, 1963, pag. 165 .

112. Neijzen, B.J.M., Schmitz, R.F., Klumpp, G.W.'e Lange, C. A., Tetrahedron, $1975,31,873$.

113. Nelsen, S.F. e Buschek, J.M., J.Amer.Chem.Soc., 1973, 95, 2011 .

114. Nelsen, S.F., Buschek, J.M. e Hintz, P.J., J.Amer.Chem. Soc., $1973, \underline{95}, 2073$.

115. Nesmeyanov, A.N., Blinova, V.A., Fedin, E.I., Kritskaya, I.I. e Fedorov, L.A., Dok1.Akad.Nauk, SSSR, 1975, 220, 1336 .

116. Neu, R., Chem.Ber., 1939, 72B, 1505. 
117. Noyce, D.S. e Canfield, J.H., J.Amer.Chem.Soc., 1954, 76, 3630 .

118. Noyce, D.S. e Evett, M., J.0rg.Chem., 1972, 37, 394.

119. Overberger, C.G., Barkan, P., Lusi, A. e Ringsdorf, H., J.Amer.Chem.Soc., 1962, 84, 2814.

120. Overberger, C.G. e Katchman, A., J.Amer.Chem.Soc., 1956, 78, 1965.

121. Padwa, A. e Battisti, A., J.Amer.Chem.Soc., 1972, 94, 521.

122. Palm, V.A., Haldna, V.L. e Talvik, A.J., em "The Chemistry of the Carbonyl group",Ed. Patai, S., Interscience Publ., 1966, pag. 421 .

123. Paquette, L.A., Meehan, G.V. e Wise, L.D., J.Amer.Chem. Soc., $1969, \underline{91}, 3231$.

124. Paquette, L.A. e Wise, L.D., J.Amer.Chem.Soc., 1967, 89 , 6659 .

125. Pople, J.A., Schneider, W.G. e Bernstein, H.J., "High Resolution Nuclear Magnetic Resonance", Mc Graw Hill, N.Y., 1959, pag. 400.

126. Rademacher, P., Angew.Chem.Internat.Edn., 1973, 12, 408.

127. Rademacher, P., Chem.Ber., $1975,108,1548$.

128. Rademacher, P., Tetrahedron Letters, $1974,83$.

129. Rademacher, P. e Koopmann, H., Chem.Ber., 1975, 108, 1557.

130. Ramsey, B.G., Brook, A., Bassindale, A.R. e Bock, H., J. Organometallic Chem., 1974, 74, C41.

131. Reppe, W., Ann., 1955, 596, 62. 
132. Rittner, R., "Tese de Doutoramento", Instituto de Quïmica da Universidade de São Paulo, São Paulo, 1972, pag. 128(a), pag. 35(b).

133. Sasaki, T., Eguchi, S., Kiriyama, T., Sakito, Y. e Kato, H., J.C.S.Chem.Comm., 1974,725 .

134. Schafer, W., Schmidt, H. e Schweig, A., Tetrahedron Letters, $1974,1953$.

135. Schafer, W. e Schweig, A., J.C.S.Chem.Comm., 1972, 824.

136. Schafer, W. e Schweig, A., Tetrahedron Letters, 1972, 5205.

137. Schmidt, H. e Schweig, A., Angew.Chem.Internat.Edn., 1973, 12,307 .

138. Schmidt, H. e Schweig, A., J.C.S.Chem.Comm., 1974, 218.

139. Schmidt, H., Schweig, A. e Manuel, G., J.Organometallic Chem., $1973, \underline{55}, \mathrm{Cl}$.

140. Schmidt, H., Schweig, A., Mathey, F. e Muller, G., Tetrahedron, $1975, \underline{31}, 1287$.

141. Schweig, A., Weidner, U. e Manue1, G., J.Organometallic Chem., $1973, \underline{54}, 145$.

142. Shenton, T. e Smith, J.C., Chem.Ind., 1958, 1510.

143. Sporzinski, A., Kokay, W. e Briscoe, H.V.A., Rec.Trav. chim., $1949,68,613$.

144. Stafast, H. e Bock, H., Chem.Ber., 1974, 107, 1882.

145. Starr, D. e Hixon, R.M., J.Amer.Chem.Soc., 1934, 56, 1596.

146. Sweigart, D.A. e Turner, D.W., J.Amer.Chem.Soc., 1972, $\underline{94}, 5599$.

147. Swenson, J.R. e Hoffmann, R., He lV.Chim.Acta, 1970, 53, 2331. 
148. Thompson, R.B., Chenicek, J.A. e Symon, T., Ind.Eng.Chem., $1952, \underline{44}, 1659$.

149. Thorpe, J.F. e Kon, G.A.R., Org.Synth., 1941, Coll.vol.I, 192.

150. Torbe11, D.S. e Weaver, C., J.Amer.Chem.Soc., 1941, 63, 2939.

151. Turner, D.W., Baker, C., Baker, A.D. e Brundle, C.R., "Molecular Protoelectron Spectroscopy", Wiley-Interscience, London, 1970.

152. Turner, R.B., Mattox, V.R., Enge 1, L.L., Mckenzie, B.F. e Kenda11, E.C., J.Biol.Chem., 1946, 162, 571.

153. Voge1, A.I., "Textbook of Practical Organic Chemistry", Longman, London, 1967, pag. 182(a), pag. 389(b).

154. Voge 1, I., J.Chem.Soc., 1928, 2033.

155. Wagner, G. e Bock, H., Chem.Ber., 1974, 107, 68.

156. Walker, H.M. e Lev, J., "Elementary Statistical Methods", Holt, Rinehart e Winston, N.Y., 1958, pag. 221.

157. Worre11, C., Verhoeven, J.W. e Speckamp, W.N., Tetrahedron, $1974, \underline{30}, 3525$.

158. Weidner, U. e Schweig, A., Angew.Chem.Internat.Edn., 1972 11, 146 .

159. Weidner, U. e Schweig, A., J.Organometallic Chem., 1972 , $\underline{39}, 261$.

160. Wei1, E.D., Smith, K.J. e Gruber, R.J., J.Org.Chem., 1966, 31, 1669 . 
161. Wladislaw, B., Giora, A. e Viertler, H., Anais Acad. brasil.Ciênc., $1971, \underline{43}, 381$.

162. Wladislaw, B., Olivato, P.R., Rittner, R., Trufem, C. e Buzzi, B.T., Anais Acad.brasil.Ciēnc., 1972, 44, 599.

163. Wladislaw, B., 0livato, P.R., Trufem, C. e Buzzi, B.T., "VI International Symposium on Organic Sulphur Chemistry", Bangor, Inglaterra, 1974 .

164. Wladislaw, B., Rittner, R., Olivato, P.R. e Sancho, C.C., J.C.S.Chem.Comm., $1972,236$.

165. Wladislaw, B., Rittner, R. e Viertler, H., J.Chem.Soc.(B), 1971,1859 .

166. Wladislaw, B., Viertler, H., Andrade, F.A.C. e Demant, E.B., Int.J.Sulfur Chem."A", 1972, 2, 161.

167. Wladislaw, B., Viertler, H. e Demant, E.B., J.Chem.Soc. (B), 1971,565 .

168. Wladislaw, B., Viertler, H., Rittner, R. e Berthold, E., Quart.Reports Sulphur Chem., 1970, $\underline{5}, 242$.

169. Woodward, R.B. e Eastman, R.H., J.Amer.Chem.Soc., 1946, 68, 2229 . 